\title{
FNREL
}

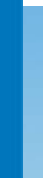

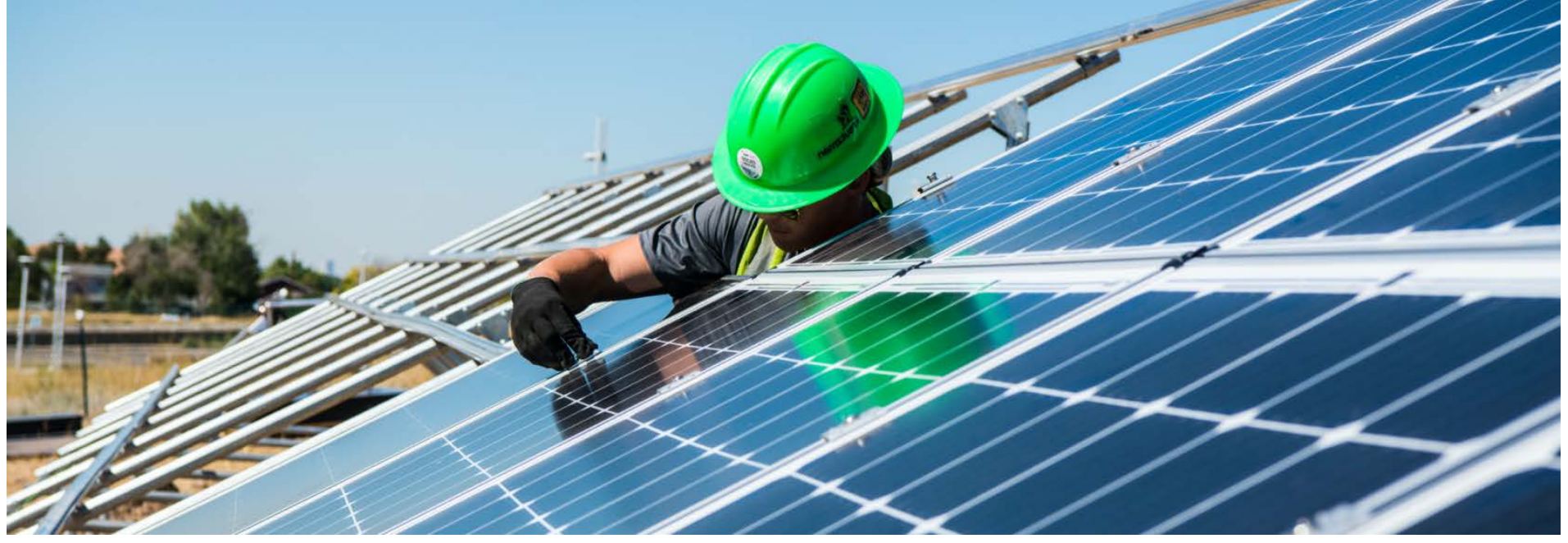

\section{Environmental and Circular Economy Implications of Solar Energy in a Decarbonized U.S. Grid}

Garvin Heath, ${ }^{1}$ Dwarakanath Ravikumar, ${ }^{1}$ Silvana Ovaitt, ${ }^{1}$ Leroy Walston, ${ }^{2}$ Taylor Curtis, ${ }^{1}$ Dev Millstein, ${ }^{3}$ Heather Mirletz, ${ }^{1}$ Heidi Hartmann, ${ }^{2}$ and James McCall ${ }^{1}$

1 National Renewable Energy Laboratory

2 Argonne National Laboratory

3 Lawrence Berkeley National Laboratory

NREL is a national laboratory of the U.S. Department of Energy Office of Energy Efficiency \& Renewable Energy

Operated by the Alliance for Sustainable Energy, LLC

This report is available at no cost from the National Renewable Energy Laboratory (NREL) at www.nrel.gov/publications.
Technical Report

NREL/TP-6A20-80818

February 2022 


\section{ENREL}

\section{Environmental and Circular Economy Implications of Solar Energy in a Decarbonized U.S. Grid}

Garvin Heath, ${ }^{1}$ Dwarakanath Ravikumar, ${ }^{1}$ Silvana Ovaitt, ${ }^{1}$ Leroy Walston, ${ }^{2}$ Taylor Curtis, ${ }^{1}$ Dev Millstein, ${ }^{3}$ Heather Mirletz, ${ }^{1}$ Heidi Hartmann, ${ }^{2}$ and James McCall ${ }^{1}$

1 National Renewable Energy Laboratory

2 Argonne National Laboratory

3 Lawrence Berkeley National Laboratory

\section{Suggested Citation}

Heath, Garvin, Dwarakanath Ravikumar, Silvana Ovaitt, Leroy Walston, Taylor Curtis, Dev Millstein, Heather Mirletz, Heidi Hartmann, and James McCall. 2022. Environmental and Circular Economy Implications of Solar Energy in a Decarbonized U.S. Grid. Golden, CO: National Renewable Energy Laboratory. NREL/TP-6A20-80818.

https://www.nrel.gov/docs/fy22osti/80818.pdf.

NREL is a national laboratory of the U.S. Department of Energy Office of Energy Efficiency \& Renewable Energy Operated by the Alliance for Sustainable Energy, LLC

This report is available at no cost from the National Renewable Energy Laboratory (NREL) at www.nrel.gov/publications.

Contract No. DE-AC36-08GO28308
Technical Report NREL/TP-6A20-80818 February 2022

National Renewable Energy Laboratory 15013 Denver West Parkway Golden, CO 80401 303-275-3000 • www.nrel.gov 


\section{NOTICE}

This work was authored in part by the National Renewable Energy Laboratory, operated by Alliance for Sustainable Energy, LLC, for the U.S. Department of Energy (DOE) under Contract No. DE-AC36-08GO28308. Funding provided by the U.S. Department of Energy Office of Energy Efficiency and Renewable Energy Solar Energy Technologies Office. The views expressed herein do not necessarily represent the views of the DOE or the U.S. Government.

This report is available at no cost from the National Renewable Energy Laboratory (NREL) at www.nrel.gov/publications.

U.S. Department of Energy (DOE) reports produced after 1991 and a growing number of pre-1991 documents are available free via www.OSTI.gov.

Cover Photo by Dennis Schroeder: NREL 40820.

NREL prints on paper that contains recycled content. 


\section{The Solar Futures Study and Supporting Reports}

The Solar Futures Study, initiated by the U.S. Department of Energy (DOE) Solar Energy Technologies Office and led by the National Renewable Energy Laboratory (NREL), envisions how, over the next few decades, solar could come to power $40 \%$ or more of U.S. electricity demand, dramatically accelerating the decarbonization of buildings, transportation, and industry.

Through state-of-the-art modeling, the Solar Futures Study is the most comprehensive review to date of the potential role of solar in decarbonizing the U.S. electric grid and broader energy system. However, not all the detailed analysis that informed the Solar Futures Study could be included within its pages. This further analysis is collected in additional NREL reports, each dedicated to a different technology or socioeconomic concern.

This report, Environmental and Circular Economy Implications of Solar Energy in a Decarbonized U.S. Grid, focuses on a particular set of environmental, economic, and social considerations related to the decarbonization of the U.S. energy system.

\section{The Solar Futures Study Reports}

- $\quad$ Solar Futures Study (main report published by DOE)

- Research and Development Priorities to Advance Solar Photovoltaic Lifecycle Costs and Performance

- $\quad$ The Role of Concentrating Solar-Thermal Technologies in a Decarbonized U.S. Grid

- $\quad$ The Demand-Side Opportunity: The Roles of Distributed Solar and Building Energy Systems in a Decarbonized Grid

- Maximizing Solar and Transportation Synergies

- The Potential for Electrons to Molecules Using Solar Energy

- Affordable and Accessible Solar for All: Barriers, Solutions, and On-Site Adoption Potential

- Environmental and Circular Economy Implications of Solar Energy in a Decarbonized U.S. Grid

You can learn more about the project and reports on the NREL website at https://www.nrel.gov/analysis/solar-futures.html. 


\section{Acknowledgments}

The authors would like to thank members of a technical review panel that provided review and guidance on the content of this report in support of the Solar Futures Study:

Fulvio Ardente Joint Research Centre, Ispra

Tom Rommens $\quad$ VITO

Suvi Sharma Solaria

Stephanie Shaw The Electric Power Research Institute

Parikhit Sinha First Solar, Inc.

Aarohi Vijh SunPower

Ryan Wiser $\quad$ Lawrence Berkeley National Laboratory

Finally, several of the graphics from this report have been previously published as part of the Solar Futures Study, for which we thank Eric O’Shaughnessy (Clean Kilowatts). 


\section{List of Acronyms and Abbreviations}

$\mathrm{ac}$

AI

ANSI

bgal

$\mathrm{BC}$

$\mathrm{BoS}$

Btu

CdTe

$\mathrm{CE}$

$\mathrm{CO}_{2}$

$\mathrm{c}-\mathrm{Si}$

CSP

DOE

DUPV

EOL

EPA

EVA

GHG

$\mathrm{GW}_{\mathrm{AC}}$

$\mathrm{GW}_{\mathrm{DC}}$

ha

IEA

IEEE

IRENA

ITRPV

$\mathrm{kg}$

LCA

ML

MOVES

$M W_{D C}$

$\mathrm{NO}_{\mathrm{x}}$

NREL

PM

$\mathrm{PM}_{2.5}$

PSS

PV

PViCE

QA

R\&D

ReEDS

$\mathrm{reV}$

RFID

$\mathrm{SO}_{2}$

TCLP

TES acres

artificial intelligence

American National Standards Institute

billion gallons

black carbon

balance of system

British thermal unit

cadmium telluride

circular economy

carbon dioxide

crystalline silicon

concentrating solar power

U.S. Department of Energy

distributed utility-scale photovoltaic

end of life

U.S. Environmental Protection Agency

ethylene vinyl acetate

greenhouse gas

gigawatts alternating current

gigawatts direct current

hectares

International Energy Agency

Institute of Electrical and Electronics Engineers

International Renewable Energy Agency

International Technology Roadmap for Photovoltaic

kilograms

life cycle assessment

machine learning

MOtor Vehicle Emission Simulator

megawatts direct current

nitrogen oxides

National Renewable Energy Laboratory

particulate matter

fine particulate matter

product service system

photovoltaic(s)

$\mathrm{PV}$ in the Circular Economy model

quality assurance

research and development

Regional Energy Deployment System

Renewable Energy Potential

radio frequency identification

sulfur dioxide

toxicity characteristic leaching procedure

thermal energy storage 
TW

TW

UPV

USGS

USDA

VOC

$\mathrm{W}_{\mathrm{DC}}$ terawatts

terawatts direct current utility-scale photovoltaic

U.S. Geological Survey

U.S. Department of Agriculture volatile organic compound

watts direct current 


\section{Executive Summary}

The U.S. Department of Energy's (DOE's) Solar Futures Study projects deployment of solar technologies — including photovoltaics (PV) and concentrating solar power (CSP) — of up to nearly 1.6 terawatts by 2050. These technologies account for far lower levels of greenhouse gas (GHG) emissions than conventional power generation technologies based on fossil fuels, both during their operation and across their full life cycles. They also reduce emissions of non-GHG air pollutants. However, expanded PV and CSP deployment has spurred environmental and resource concerns related to issues including material requirements, land use, water use (primarily for CSP), and plans for managing system components that reach end of life (EOL).

This report addresses environmental and circular economy (CE) considerations related to solar technologies via novel analysis of the three Solar Futures core scenarios as well as synthesis of published research. We organize these issues into the three basic life cycle phases of a solar technology: manufacturing, operation (including site selection and construction), and EOL. Related environmental justice issues are also explored. Finally, we recommend research and development (R\&D) activities that could help clarify challenges and identify solutions. Because PV deployment is projected to be much larger than CSP deployment, we offer a more detailed analysis of PV-related issues.

\section{Manufacturing}

We use the PV in the Circular Economy (PViCE) tool to calculate material demands for PV module manufacturing during 2010-2050 based on deployment in the Solar Futures scenarios, assuming a completely linear economy (no recycling, repair, etc.). ${ }^{i}$ Our estimates are gross material demands and may overestimate material requirements if some manufacturers use secondary materials, although this does not appear to be a prevalent practice today. We only examine crystalline silicon (c-Si) modules, which are assumed to represent a constant $85 \%$ of new capacity in the Solar Futures scenarios.

Figure ES-1 compares cumulative virgin material demands for c-Si PV during 2020-2050 by scenario. Glass accounts for most of the mass in each scenario, which corresponds to typical PV module design. The Decarb $+\mathrm{E}$ scenario has the greatest cumulative material demand through 2050. Although silver is barely visible within the scale of the chart, it is the material demanded at the highest fraction of global supply. While U.S. demand for silver is less than 5\% of global supply in the Decarb+E scenario, when considered on a global scale in a global decarbonization scenario, silver demand from PV could reach almost $40 \%$ of 2020 global production. Overall, our analysis of U.S. solar material demands under the Solar Futures scenarios suggests material supplies likely will not limit solar deployment growth, especially if EOL materials are recovered and used to offset virgin material demand.

A broad range of CE methods can be incorporated in the PV manufacturing stage to improve the economic and environmental performance of PV systems. These include reducing the material intensity of manufacturing, using EOL PV materials in PV manufacturing (closed-loop recycling), using materials recovered from non-PV systems in PV manufacturing (open-loop

\footnotetext{
${ }^{i}$ See the introduction for descriptions of the Solar Futures scenarios.
} 
recycling), powering PV manufacturing processes with renewable electricity, and using novel PV module designs and materials in the manufacturing stage to enhance recyclability, transition away from supply-constrained materials to abundant materials, and decrease risks to human health and the environment over the PV life cycle (design for circularity).

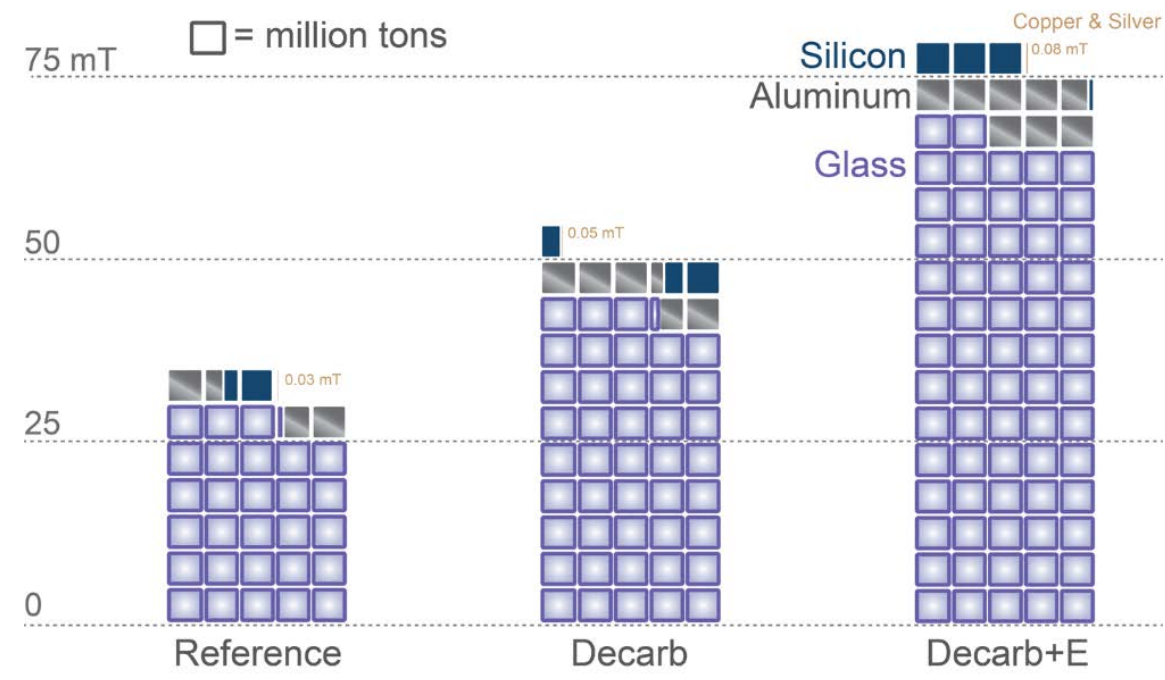

Figure ES-1. Comparison of virgin material demands for each silicon-based PV material cumulatively (2020-2050) across the three Solar Futures scenarios

\section{Site Selection, Construction, and Operation}

We evaluate solar land requirements under the Solar Futures scenarios from 2010 to 2050. In the scenario with the largest land requirement $($ Decarb $+E)$, the total aggregated solar deployment area across the contiguous United States is approximately 10.3 million ac $\left(41,683 \mathrm{~km}^{2}\right)$ by 2050 - roughly equivalent to the combined surface area of Connecticut, Massachusetts, and Rhode Island. The maximum amount of land required among the three scenarios is equivalent to just $6.4 \%$ of the area of potentially suitable lands that have been previously disturbed. Deploying solar on such lands can avoid conflict with current, productive land uses and high-value ecological systems. Contaminated lands - a subset of disturbed lands - are not currently suitable for any productive use but could be cleaned and made suitable for solar. Using contaminated lands helps local communities by removing blight, and these lands are often located near infrastructure that facilitates solar development. However, contaminated lands suitable for solar are not plentiful enough to meet the maximum estimated land use area under the Solar Futures scenarios, and they would require site-specific assessment to evaluate economic feasibility. In a larger context, maximum total land requirements across all technology types for ground-based solar in 2030, 2040, and 2050 are approximately $0.2 \%, 0.3 \%$, and $0.5 \%$, respectively, of the total contiguous U.S. surface area. Figure ES-2 compares the maximum modeled land requirement $(0.5 \%)$ with solar-suitable disturbed and contaminated land areas and examples of other areas in the United States. The maximum total solar land requirements are not expected to exceed 5\% of any state's land area by 2050, with the exception of Rhode Island (6.5\%).

Opportunities exist to deploy solar in ways that promote rural economic development and social justice while avoiding conflict with other land uses. In addition to siting solar on disturbed or formerly contaminated lands as described above, strategies include avoiding lands important for biodiversity conservation or farming, managing vegetation to provide ecosystem services, co- 
locating solar systems with agriculture, and deploying water-based (floating) PV systems as an alternative to land-based PV systems.

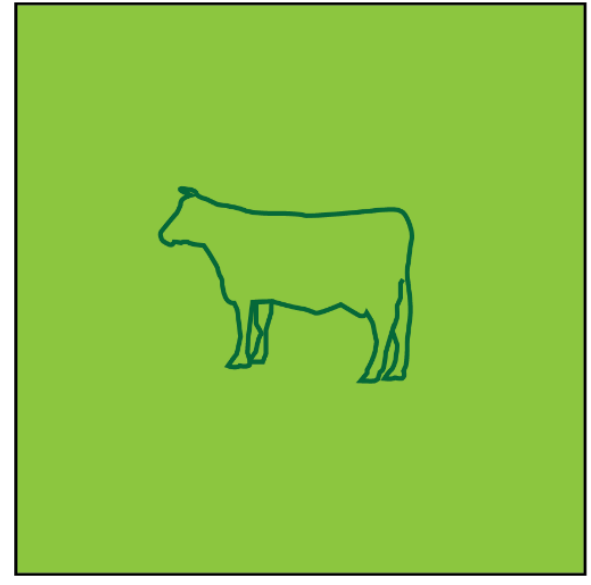

Agriculture

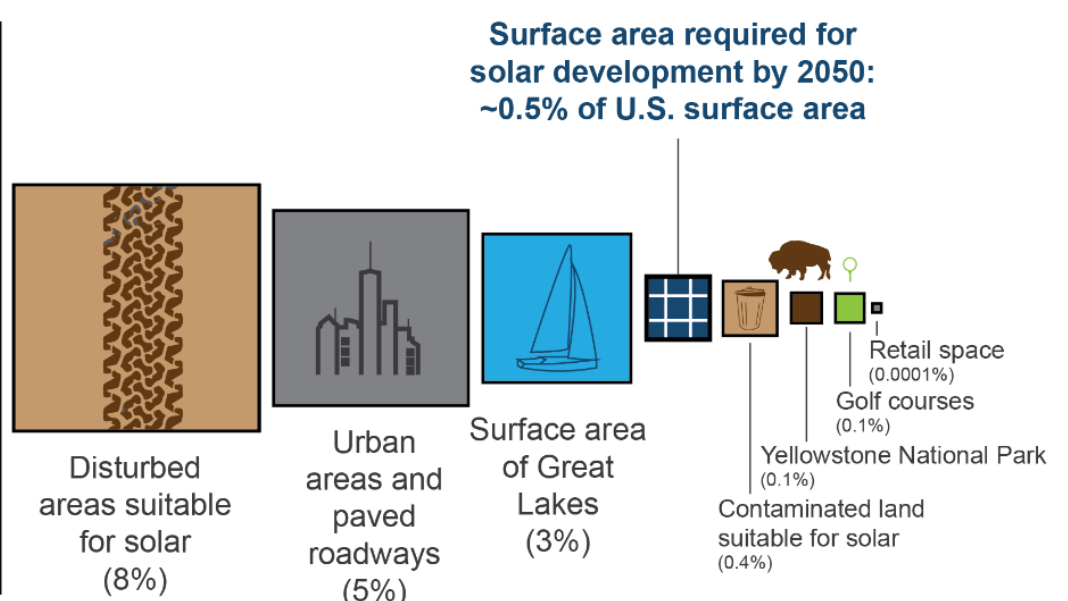

(43\% of contiguous U.S. surface area)

Figure ES-2. Maximum land use required for solar in 2050 in the Solar Futures scenarios compared with solar-suitable disturbed and contaminated areas and examples of other U.S. land uses

We analyze water use in the Solar Futures scenarios with a model that includes water constraints. Results show that water withdrawals decline over time, mainly from retirements of coal, nuclear, and natural gas combined-cycle plants. The Decarb+E scenario achieves the lowest yearly U.S. water withdrawals, declining from 48,500 billion gals/yr (bgal/yr) in 2010 to 6,040 bgal/yr in 2050. Although CSP never contributes more than $1 \%$ of total power-system withdrawals over the 2010-2050 timeframe, it can account for a large portion of state-level power-sector water withdrawals even when dry cooling technologies are used, ${ }^{\text {ii }}$ rising to almost $100 \%$ of power-sector withdrawals in Colorado and New Mexico starting in 2040 for the Decarb scenario. These values are still less than current power-sector water withdrawals in both states, given the current reliance on fossil (thermal) power plants in those states.

We also present order-of-magnitude monetary estimates of the air-quality benefits of the Solar Futures scenarios. In the Decarb scenario, reducing air pollution from electricity generation results in air-quality and health benefits worth roughly $\$ 300$ billion, based on the discounted value of all emission reductions (compared with the Reference scenario) between 2021 and 2050. Approximately $\$ 100$ billion of additional health benefits could be realized from the Decarb $+\mathrm{E}$ scenario owing to the replacement of a larger number of gasoline and diesel vehicles by electric vehicles and the associated reduction in pollutant emissions. These air-quality benefits alone offset the incremental costs of decarbonization in the Solar Futures scenarios, even before

\footnotetext{
ii Dry cooling technologies cool the working fluid by ejecting heat into the air, whereas wet cooling (which is not allowed in some states owing to water consumption concerns) cools the working fluid by evaporating water.
} 
accounting for the much larger GHG-reduction benefits in the scenarios; together, the air-quality and GHG benefits yield net benefits of more than $\$ 1$ trillion over the 2020-2050 period. ${ }^{\text {iii }}$

Various CE strategies can be applied during the PV use phase. Product service system approaches (known in the U.S. as third-party ownership) can delink ownership of PV modules from the generation of PV electricity, lower cost barriers for individual customers to consume PV electricity, transfer the economic and operational burdens of PV system purchase and maintenance to third-party owners, and help address social and energy justice issues by widening access to PV electricity. Repowering in-service PV systems can help increase renewable electricity generation over the lifetime of the PV project by installing newer, more efficient modules, and it can extend the lifetime of other system components - both of which can reduce environmental burdens normalized over the lifetime generation of the system. In-field repair of PV system components is another option for lifetime extension, although questions remain about inspection and regulatory requirements, safety, reliability, and legal liability related to in-field repairs.

\section{End of Life}

Using the PViCE model, we project the mass of EOL materials from c-Si PV modules considering the known degradation and failure rates that affect lifetime. Because of long module lifetimes, most modules deployed in the Solar Futures scenarios do not reach EOL until after 2050. The Decarb and Decarb+E scenarios result in nearly identical 2050 cumulative EOL material, at around 6.5 million metric tons, consisting mostly of glass. The PViCE model also calculates the mass of manufacturing scrap, which is estimated to be approximately half of the mass of materials in EOL modules. Compared with the availability of materials recovered at EOL, the availability of manufacturing scrap is better aligned in time with virgin material demands, emphasizing the importance of efficient manufacturing and closed-loop manufacturing scrap recycling to reduce virgin material needs. Geospatial analysis provided in this report can enable stakeholders to plan proactively for EOL materials on a regional basis, which can lead to more efficient deployment of capital for recycling and other EOL management infrastructure.

Substituting EOL materials for virgin materials could mitigate material demands in a growing PV sector, improve supply chain resilience, reduce the environmental and social justice burdens of mining, provide markets for recycling facilities, and reduce critical material demands. Our modeling suggests that EOL material, on a technical potential basis, could supply around $25 \%$ $30 \%$ of demand for silver, aluminum, and silicon in the Decarb+E scenario after 2040.

Recycling is the most widely applied and analyzed PV CE strategy. However, R\&D has focused more on recovery of bulk materials (glass, aluminum, silicon) and less on recovery of trace materials (tin, lead, copper, and silver). Other key recycling challenges include delamination to eliminate the ethylene vinyl acetate (EVA) and separate the glass and silicon wafer, lack of robust and publicly available assessments of the economic viability of commercial-scale PV recycling, and variability across legacy and current-generation PV modules.

\footnotetext{
iii See the Solar Futures Study (www.energy.gov/eere/solar/solar-futures-study) for a detailed discussion of scenario costs and benefits.
} 
Another option for EOL PV components is repair and reuse, which can extend component lifetime and avoid the economic and environmental burdens associated with disassembly, separation, and recycling of individual material constituents. Data are needed on reliability, failure mechanisms, and standards to ensure quality and performance of repaired and reused modules. There is also a need to robustly assess and compare the economic and environmental trade-offs between module repair/reuse and alternative CE strategies (e.g., recycling). $\mathrm{CE}$ strategies at PV EOL could provide environmental justice and social benefits including employment opportunities and safer management of hazardous materials.

The report concludes with a summary of key recommendations for applying CE strategies to improve the environmental, social, and environmental justice outcomes associated with solar deployment at the Solar Futures scale. 


\section{Table of Contents}

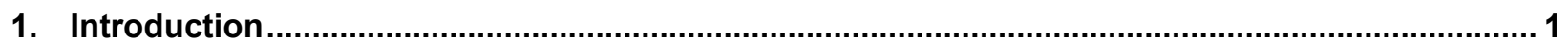

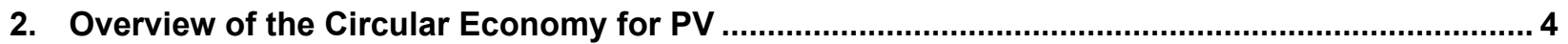

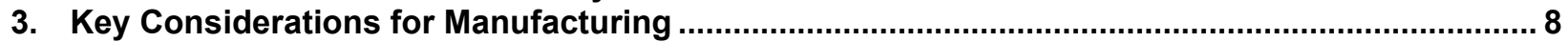

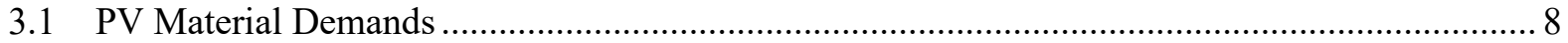

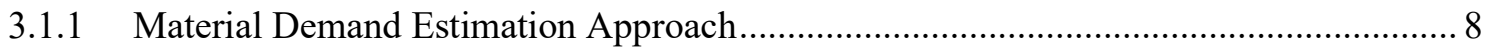

3.1.2 Results: Manufacturing Material Demands............................................................... 9

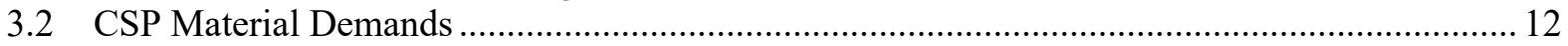

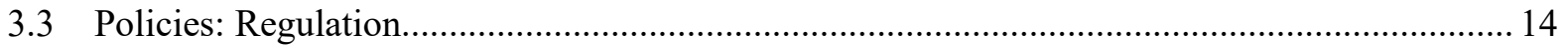

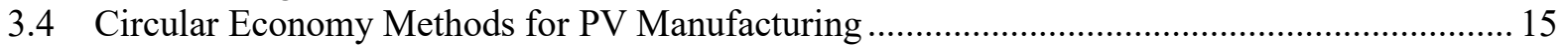

3.4.1 Reduced Material Intensity and Closed-Loop Recycling ............................................. 16

3.4.2 Open-Loop Recycling to Reuse Materials from Allied, Non-PV Industries.................. 16

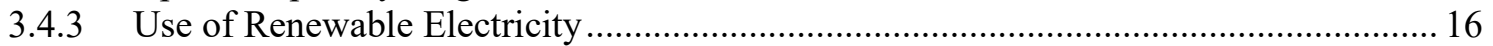

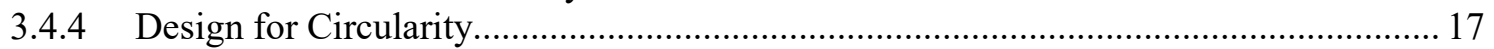

3.5 Potential for Sustainability Factors to Be Preferentially Identified for Purchase....................... 18

3.5.1 Potential for Low-Carbon Solar to Reduce Life Cycle GHG Emissions ....................... 18

3.5.2 Fluorine- and Lead-Free Modules ....................................................................... 18

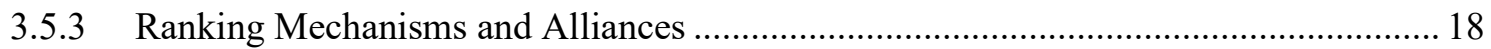

3.6 Environmental Justice and Social Benefit Through Circular Economy During PV

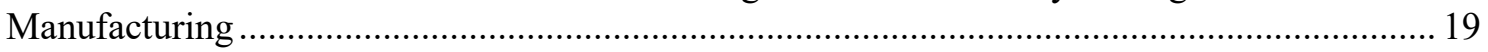

4. Key Considerations for Site Selection, Construction, and Operation ......................................... 20

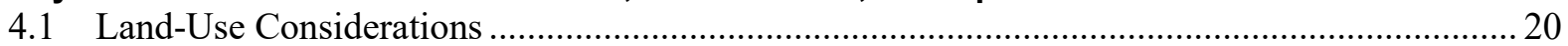

4.1.1 Solar Futures Study Land Requirements............................................................. 20

4.1.2 Opportunities to Improve Solar-Environmental Synergies with Regard to Land and

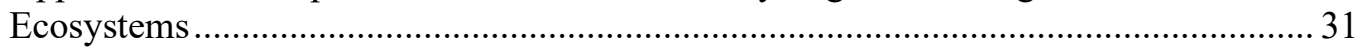

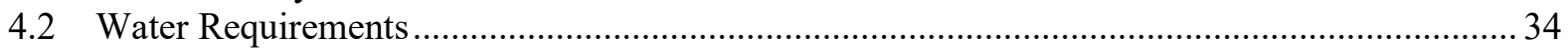

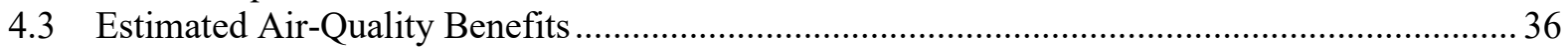

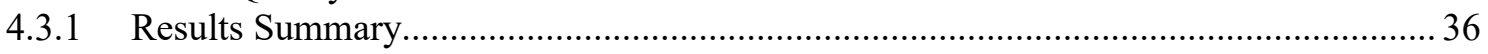

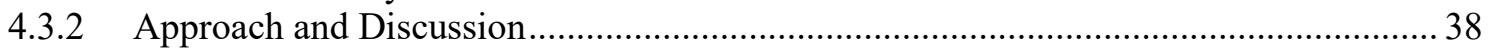

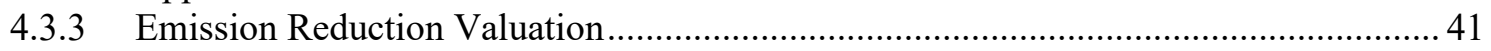

4.4 Circular Economy Approaches During the PV Use Phase.................................................... 42

4.5 Environmental Justice and Social Benefit Through Circular Economy During the PV Use Stage

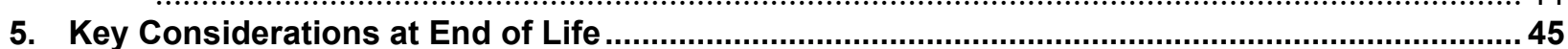

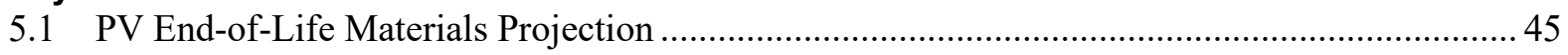

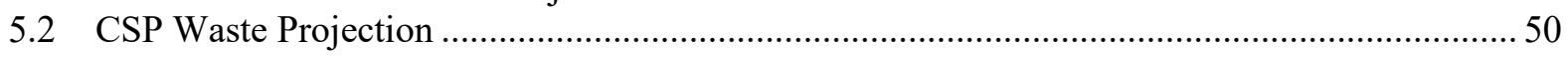

5.3 Policy, Market, and Regulatory Considerations for Recycling, Reuse, and Repair................... 51

5.4 Circular Economy as an Approach to Addressing EOL Issues .............................................. 52

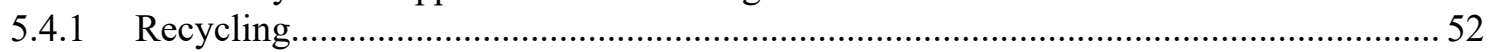

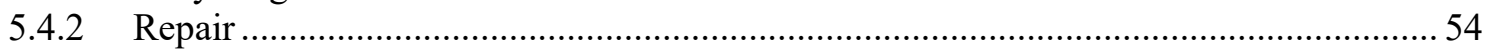

5.5 Environmental Justice and Social Benefit Through Circular Economy at PV End of Life ........ 55

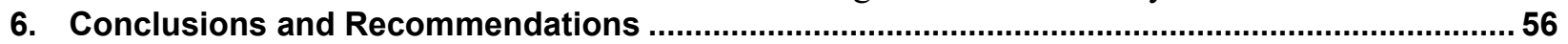

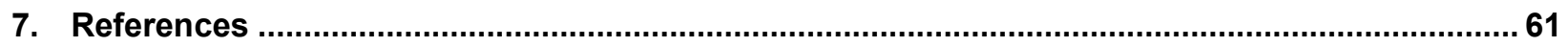

Appendix A. Supplemental Information Regarding Land Requirements .......................................81

Appendix B. PViCE Material Demand and EOL Material Projections ............................................. 97

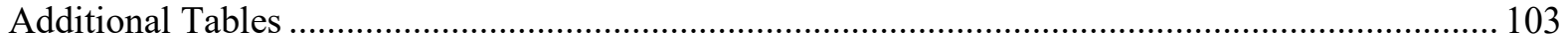

Appendix C. Order-of-Magnitude Estimates of Air-Quality Benefits of the Solar Futures Study

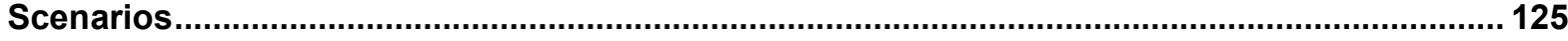

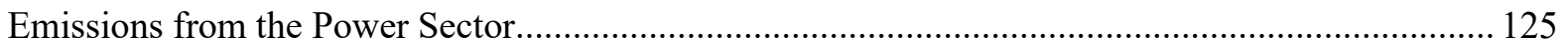

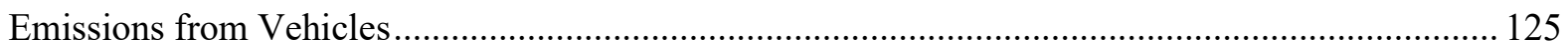

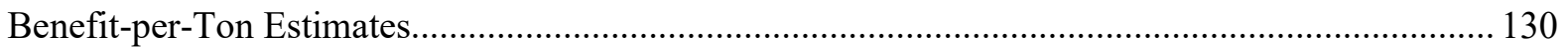




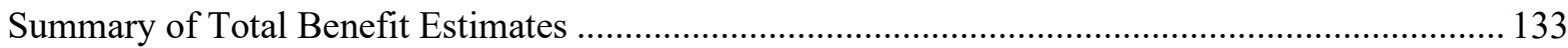

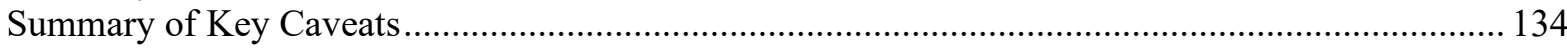

Appendix D. CSP Tower Systems: Material Requirements and Retirements by Scenario ............. 137 


\section{List of Figures}

Figure 1. Grid emissions and abated grid emissions by Solar Futures scenario in 2035 and 2050, relative to 2005 grid emissions ${ }^{1}$.

Figure 2. Cumulative deployed capacity of PV and CSP in 2020, 2030, and 2050 in the three core Solar

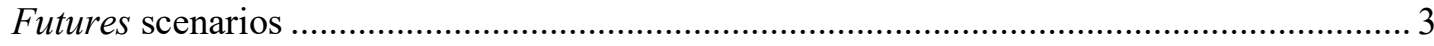

Figure 3. Systems framework to assess the current state-of-the-art and identify opportunities to advance

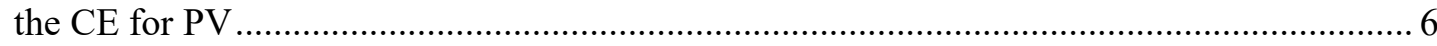

Figure 4. PV CE strategies by number of data sets found in the literature, alone and in combination........ 7

Figure 5. Comparison of virgin material demands for each silicon-based PV material cumulatively (2020

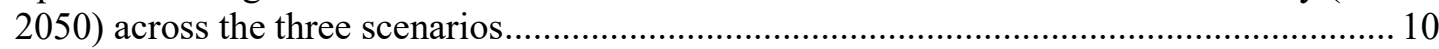

Figure 6. Annual demand of selected materials for PV manufacturing across the three core Solar Futures

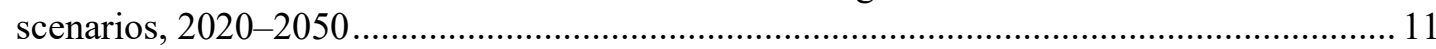

Figure 7. Percentage of 2020 global production of various materials needed to supply average annual virgin materials demand for c-Si PV in the two decarbonization-based Solar Futures Study scenarios

Figure 8. Five most-used materials in the manufacturing and construction of power tower CSP plants in

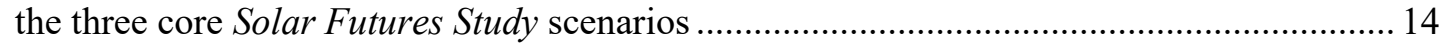

Figure 9. National solar land-use projections for the three core scenarios, 2010-2050 ........................ 24

Figure 10. Maximum land use required for solar in 2050 in the Solar Futures Study scenarios compared with solar-suitable disturbed and contaminated areas and examples of other U.S. areas ...... 25

Figure 11. Total U.S. power-sector water withdrawals under the Solar Futures Study core scenarios (top) and withdrawals for key states in the Decarb scenario (bottom), assuming water constraints

Figure 12. CSP water withdrawals as percentage of total power-sector water withdrawals in key states in

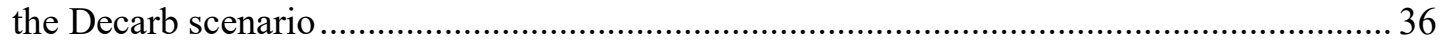

Figure 13. Net present value of health damages from electric-sector and vehicle emissions, 2021-2050.37

Figure 14. Net present value of the benefits from the Decarb and Decarb+E scenarios .......................... 37

Figure 15. Total $\mathrm{NO}_{\mathrm{x}}$ emissions from the power sector in the Solar Futures Study core scenarios ........... 39

Figure 16. Fleet-average $\mathrm{NO}_{\mathrm{x}}$ emission rates of U.S. light-duty gasoline vehicles and heavy-duty diesel

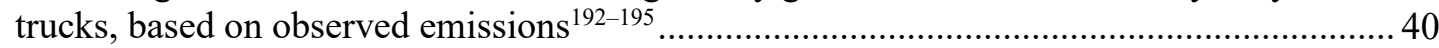

Figure 17. Future fleet-average $\mathrm{NO}_{\mathrm{x}}$ emission rates for U.S. light-duty gasoline vehicles and heavy-duty

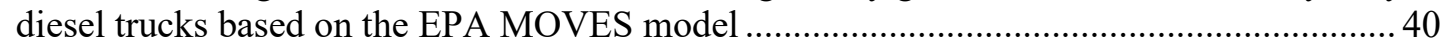

Figure 18. Total vehicle $\mathrm{NO}_{\mathrm{x}}$ emissions in the Reference and Decarb+E scenarios.................................. 41

Figure 19. Annual and cumulative PV EOL material mass by Solar Futures Study scenario through 2050

Figure 20. Annual and cumulative mass of c-Si PV manufacturing scrap by Solar Futures Study scenario

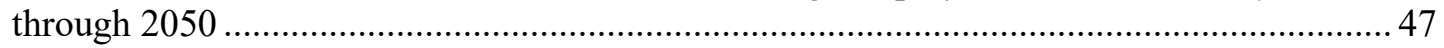

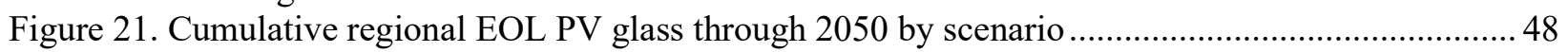

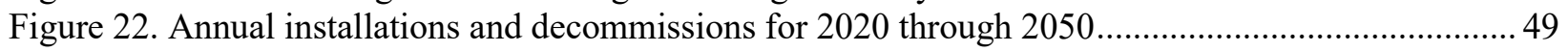

Figure 23. Yearly virgin material demands and EOL silver, aluminum, and silicon, with right axis showing the fraction of Decarb+E scenario demand that could be supplied by the EOL material.

Figure 24. Five materials that contribute most to projected waste from power tower CSP plants between

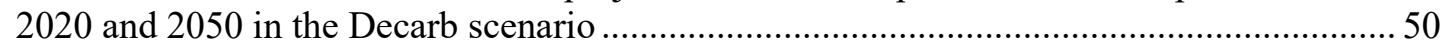

Figure 25. Literature on material recovery from recycling c-Si PV modules............................................ 53

Figure A-1. Estimated cumulative solar land requirement by state for the three core scenarios projected by

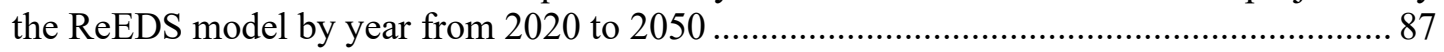

Figure B-1. Market share of c-Si technologies from various literature sources and PViCE averaged market share (black)..... 
Figure B-2. All materials on a mass per meter squared of module basis over time (a) and the

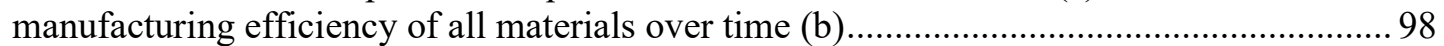

Figure $\mathrm{C}-1$. Total $\mathrm{NO}_{\mathrm{x}}$ and $\mathrm{SO}_{2}$ emissions from the power sector................................................... 125

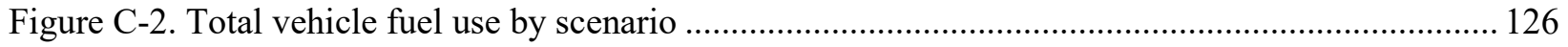

Figure C-3. Fleet-average $\mathrm{NO}_{\mathrm{x}}$ and $\mathrm{PM}_{2.5}$ emission rates of light-duty cars and heavy-duty diesel trucks,

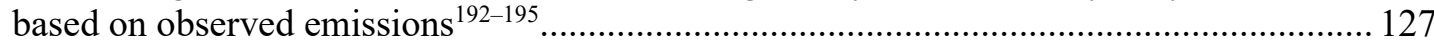

Figure C-4. Future vehicle $\mathrm{NO}_{\mathrm{x}}$ and $\mathrm{PM}_{2.5}$ emission rates based on EPA MOVES model .................... 128

Figure C-5. Total annual (top) and cumulative (middle) $\mathrm{NO}_{\mathrm{x}}$ and $\mathrm{PM}_{2.5}$ emissions from vehicles and (bottom) split of emissions by diesel or gasoline vehicles within the Reference scenario .. 130

Figure C-6. Power-sector benefits per metric ton of avoided emissions ............................................ 131

Figure C-7. Vehicle-sector benefit per metric ton of avoided emissions ............................................. 133

Figure C-8. Discounted annual damages by sector, pollutant, and scenario.......................................... 134

\section{List of Tables}

Table 1. Data and Filtering Criteria to Determine Suitability of Disturbed and Contaminated Lands for

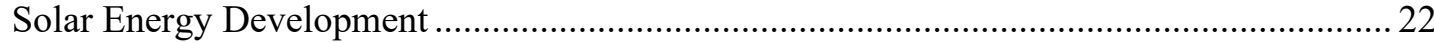

Table 2. Summary of Solar Energy Development Land Needs in 2030, 2040, and 2050 Aggregated Across the Contiguous United States ................................................................................ 24

Table 3. Availability of Disturbed and Contaminated Lands to Meet Maximum Net ${ }^{1}$ Solar Deployment in 2030, 2040, and 2050, by State and Solar Technology ........................................................ 29

Table A-1. Total Land Area Required for All Ground-Mounted Solar Technologies by Balancing Area. 81

Table A-2. Comparison of Disturbed Land Availability for Ground-Mounted PV with and without a

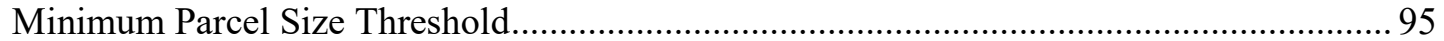

Table B-1. Baseline Material Circularity and Yield Settings for PViCE Calculations.............................98 Table B-2. Comparison of 2030 Installed PV Mass, with Material Breakdown, Between CSA Group's Recent 2030 Material Demands Projection and PViCE + ReEDS Projections ..................... 99

Table B-3. Comparison of U.S. Installed Capacity (GW) up to 2030 and 2050 .................................. 100

Table B-4. Comparison of Cumulative U.S. EOL Materials for Various Years Based on Different

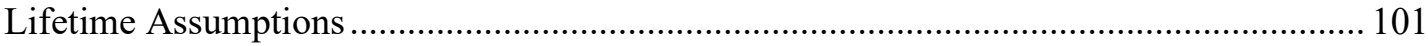

Table B-5. U.S. Annual Demand by Material for Select Years (metric tons) ....................................... 103

Table B-6. U.S. Cumulative Demand by Material for Select Years (metric tons)................................... 103

Table B-7. Yearly Material Requirements (tons) for Scenario 1: Reference.......................................... 104

Table B-8. Yearly Material Requirements (tons) for Scenario 2: Decarb ............................................... 105

Table B-9. Yearly Material Requirements (tons) forScenario 3: Decarb+E.......................................... 106

Table B-10. Cumulative Material Requirements (tons) forScenario 1: Reference ................................... 107

Table B-11. Cumulative Material Requirements (tons) for Scenario 2: Decarb...................................... 108

Table B-12. Cumulative Material Requirements (tons) forScenario 3: Decarb+E................................. 109

Table B-13. Yearly EOL Materials by Material, by State (tons) for Scenario 1: Reference .................... 110

Table B-14. Yearly EOL Materials by Material, by State (tons) forScenario 2: Decarb .......................... 113

Table B-15. Yearly EOL Materials by Material, by State (tons) forScenario 3: Decarb+E .................... 116

Table B-16. Cumulative EOL Materials by Material, by State (tons )for Scenario 1: Reference ............ 119

Table B-17. Cumulative EOL Materials by Material, by State (tons) forScenario 2: Decarb .................. 121

Table B-18. Cumulative EOL Materials by Material, by State (tons) for Scenario 3: Decarb+E ............ 123

Table C-1. Conversion Factors Used to Estimate Kilograms of Fuel Use from Quads of Energy ........... 126

Table C-2. Summary of Observed Fleet-Average Emission ( $\mathrm{g} / \mathrm{kg}$ fuel) Factors from the Literature....... 128

Table D-1. Material Requirements for CSP Tower Systems (from Whitaker et al. ${ }^{26}$ )........................... 137

Table D-2. CSP Retirements by Scenario (from ReEDS)...................................................................... 139 


\section{Introduction}

The U.S. Department of Energy's (DOE's) Solar Futures Study projects deployment of solar technologies - including photovoltaics (PV) and concentrating solar power (CSP) — of up to nearly 1.6 terawatts (TW) by 2050 (see Text Box 1, page 2). ${ }^{1}$ This report supports the larger Solar Futures Study of which it is part by focusing on certain opportunities and challenges with regard to large-scale solar deployment and the circular economy (CE) for materials as well as effects on the environment.

PV and CSP are rapidly evolving technologies. They account for far lower levels of greenhouse gas (GHG) emissions than conventional power generation technologies based on fossil fuels, both during their operation and across their full life cycles. ${ }^{4}$ Text Box 1 depicts U.S. electricsector carbon dioxide $\left(\mathrm{CO}_{2}\right)$ emissions resulting from the Solar Futures Study scenarios, demonstrating the decarbonization potential from solar and other zero-carbon technologies, especially wind. In the past, however, PV and CSP have confronted environmental sustainability challenges related to design and deployment. For instance, some first-generation CSP systems increased electricity generation using supplemental natural gas combustion, resulting in a much higher carbon footprint than solar-only mode. Overall, the chief concern for both technologies has been high material requirements (per unit of generation) and, for PV, the need for materials that are scarce, valuable, or potentially hazardous to human health and the environment if uncontrolled (see, e.g. ${ }^{2,3}$ ). Another concern for PV and CSP is the quantity and location of land required. CSP requires high direct normal irradiation and large tracts for favorable economics, which generally limits U.S. siting to the Southwest, where ecosystems are fragile and water availability is low. PV can be sited anywhere, including rooftops, but even historical deployment has raised concerns about the quantity of land used for utility-scale, ground-mounted systems and their impacts on ecosystems and rural character.

Industry, government, nongovernmental organizations, and academia have attempted to address these issues, yet continued exponential growth in deployment scales highlights the need to clarify the challenges and continue to work on solutions. The benefits of increased solar deployment, such as reduced pollutant emissions, should also be considered, as should new challenges that are arising. For instance, significant PV deployment has been occurring for a decade or more, which is raising questions about the fate of system components that have reached end of life (EOL) early (e.g., from damage by extreme weather events, vandalism, or component failures) or are still functional but have been retired early, for instance to repower a site with newer, betterperforming products, including use of CE approaches. ${ }^{5}$

\footnotetext{
${ }^{4}$ See "Life Cycle Assessment Harmonization," NREL, https:/www.nrel.gov/analysis/life-cycle-assessment.html and references therein.

${ }^{5}$ EOL, as used in this report, can include what might be called "end of first use," or a first owner's use- - whereby the technology could be directly reused or repaired and then reused — in addition to its more precise meaning whereby the technology cannot be used further and must be recycled or discarded. To date, the literature has not established broadly adopted terminology to succinctly differentiate these two lifetimes. Thus, in this report, EOL is a shorthand phrase that can include products still functional (or repairable to be functional) for their original purpose, whether or not ownership changes.
} 
This report addresses environmental and CE considerations related to solar technologies via novel analysis of the three Solar Futures core scenarios as well as synthesis of published research. We organize these issues into the three basic life cycle phases of a solar technology: manufacturing, operation (including site selection and construction), and EOL. Related environmental justice issues are also explored. Finally, we recommend research and development (R\&D) activities that could help clarify challenges and identify solutions. Because PV deployment is projected to be much larger than CSP deployment, we focus on PV-related issues.

\section{Text Box 1. Solar Futures Study Scenarios and $\mathrm{CO}_{2}$ Emissions}

The Solar Futures Study explores pathways for solar energy to drive deep decarbonization of the U.S. electric grid and considers how further electrification could decarbonize the broader energy system; for more information, see "Solar Futures Study," NREL, https://www.nrel.gov/analysis/solar-futures.html). The study focuses on three core scenarios.

The Reference scenario outlines a business-as-usual future that includes existing state and federal clean energy policies and assumes ongoing, moderate technology cost reductions but lacks a comprehensive effort to decarbonize the grid.

The Decarbonization (Decarb) scenario assumes policies drive a 95\% reduction (from 2005 levels) in the grid's $\mathrm{CO}_{2}$ emissions by 2035 and a $100 \%$ reduction by 2050 . This scenario assumes more-aggressive cost-reduction projections than the Reference scenario for solar as well as other renewable and energy storage technologies, but it uses standard future projections for electricity demand.

The Decarbonization with Electrification (Decarb+E) scenario goes further by including large-scale electrification of buildings and transportation, meaning a significant increase in electricity demand and an expanded role for the grid in decarbonizing the broader U.S. energy system. Under this scenario, solar grows from $3 \%$ of the U.S. electricity supply in 2020 to $42 \%$ by 2035 and $45 \%$ by 2050 . Figure 1 summarizes the $\mathrm{CO}_{2}$ emissions reductions in the core scenarios.

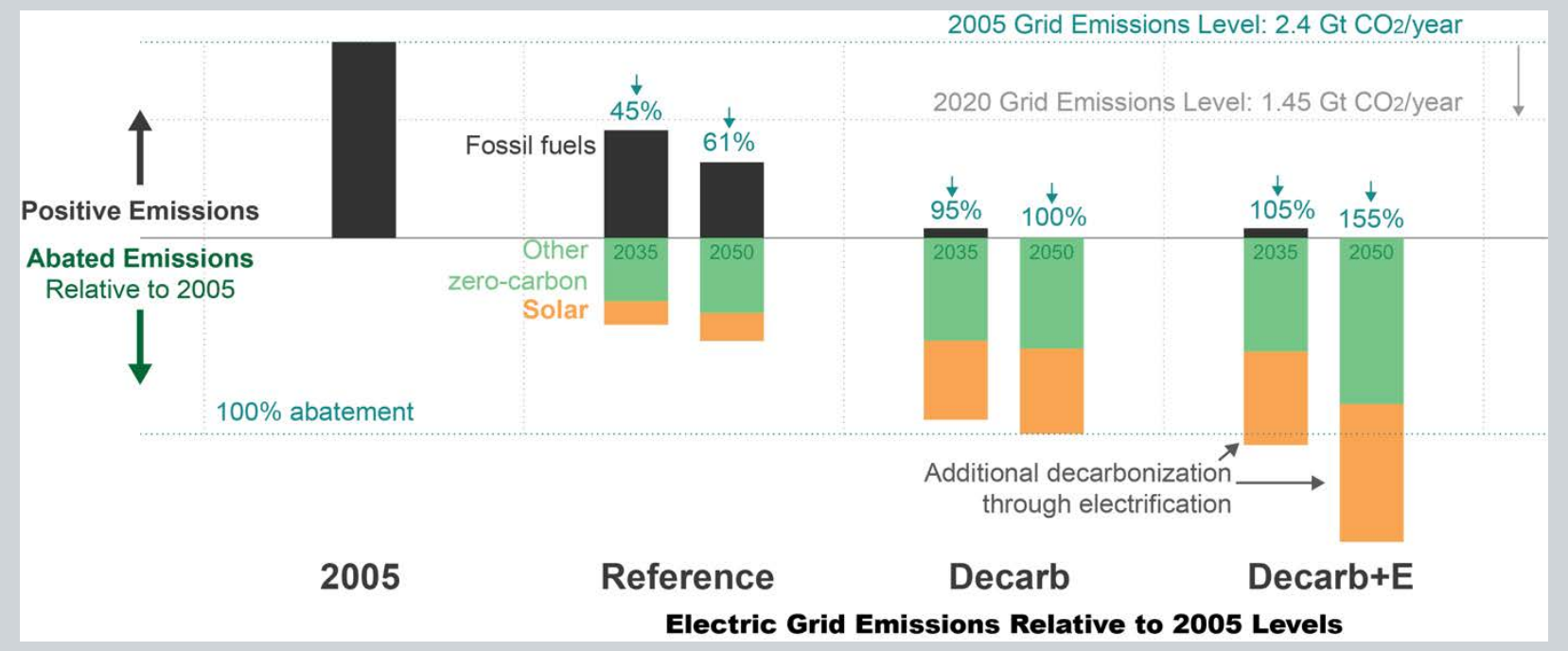

Figure 1. Grid emissions and abated grid emissions by Solar Futures scenario in 2035 and 2050, relative to 2005 grid emissions ${ }^{1}$ 
Most analyses in this report-for materials, land and water use, and waste generation-relate to the scale of solar capacity deployed. Figure 2 summarizes cumulative solar deployment in each core Solar Futures scenario. The United States installed about 15 GW alternating current (GWAC) of PV capacity in 2020. In the Decarb scenario, the average annual deployment rate increases to $28 \mathrm{GW}$ AC from 2021 to 2025,48 $\mathrm{GW}_{\mathrm{AC}}$ from 2026 to 2030, and $46 \mathrm{GW}_{\mathrm{AC}}$ from 2031 to 2035. In the Decarb+E scenario, average annual deployment rates reach 66 GWAC in 2026-2030 and 72 GWAC in 2031-2035.

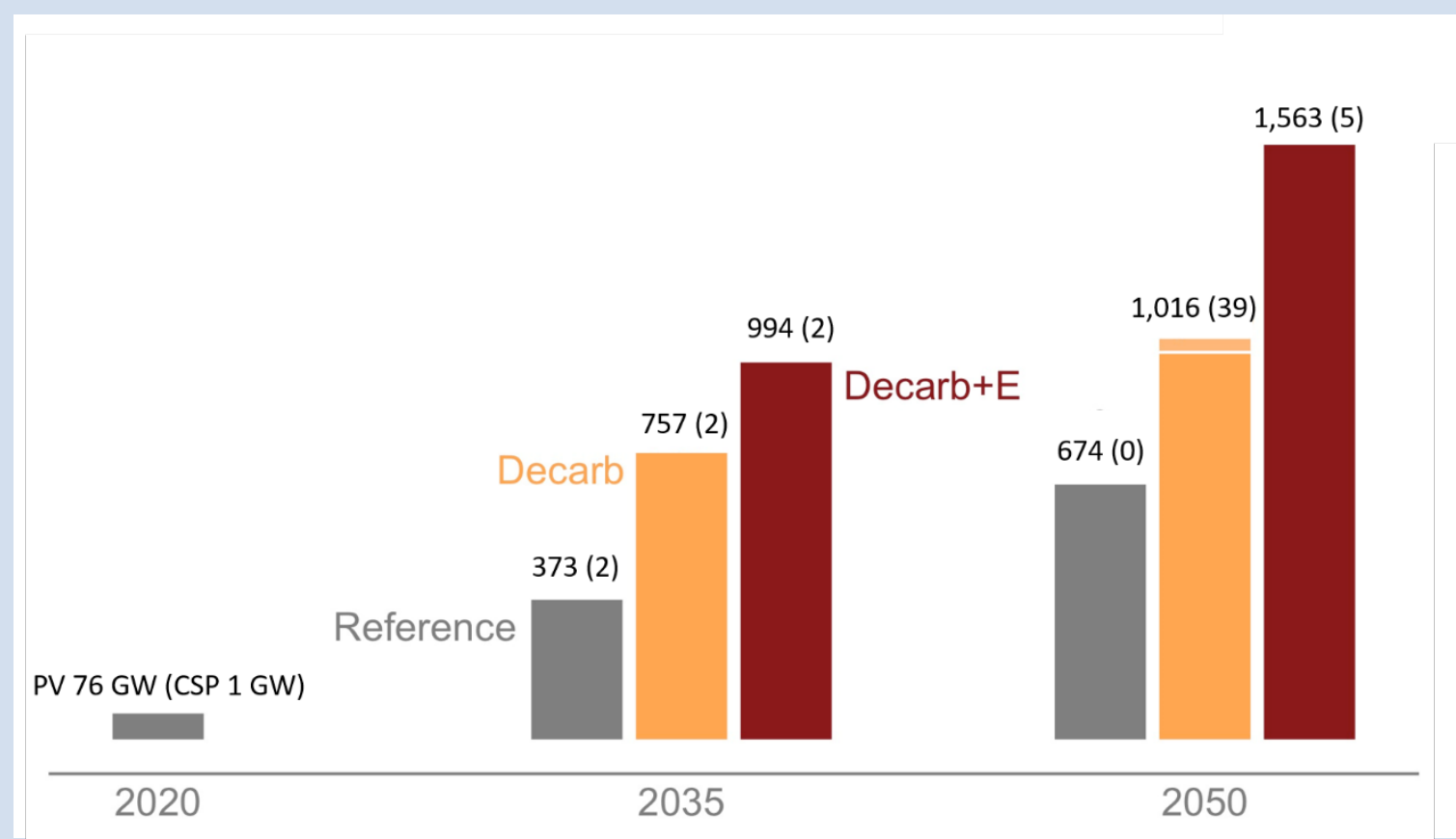

Figure 2. Cumulative deployed capacity of PV and CSP in 2020, 2030, and 2050 in the three core Solar Futures scenarios 


\section{Overview of the Circular Economy for PV}

The CE is relevant for all three solar life cycle phases. Many definitions of the CE have been proposed. ${ }^{4}$ Leveraging the pioneering work of the Ellen MacArthur Foundation, the World Economic Forum defines it as follows:

A circular economy is an industrial system that is restorative or regenerative by intention and design. It replaces the end-of-life concept with restoration, shifts towards the use of renewable energy, eliminates the use of toxic chemicals, which impair reuse and return to the biosphere, and aims for the elimination of waste through the superior design of materials, products, systems and business models. ${ }^{5}$

In addition to synthesizing literature on CE strategies for PV, we employ a novel open-source tool - developed by the National Renewable Energy Laboratory (NREL) — called PV in the Circular Economy (PViCE) to estimate material demands for future generations of PV modules and EOL materials, both of which are based on the deployment projections (and historical deployment in the case of EOL materials) from the Solar Futures scenarios. This first-of-its-kind analysis uses a stock-vintage approach to track annual changes to the amount of five specific materials used in PV modules and, by market share, of several prominent designs. CSP material demands and EOL materials are also estimated. We also review private-sector and policy options in the manufacturing phase to improve the sustainability of solar.

In the operation phase, we review key considerations for site selection, construction, and operation pertaining to land, ecosystems, water, and air pollutant emissions. Environmental justice and CE are also discussed, although the latter is less prominent in this phase.

$\mathrm{CE}$ is well recognized as an EOL material management strategy; our comprehensive consideration of CE strategies in the other life cycle phases is a notable addition to typical prior treatment. Policies and other legal issues (such as waste characterization) are important considerations for CE at EOL. CE presents opportunities to address historical environmental justice in terms of locations of waste management facilities by diverting waste to more productive uses and creating jobs in the sustainability sector.

The framework in Figure 3 comprehensively depicts the extant literature in terms of strategies that can be implemented across the three main life cycle stages to enable the transition to a CE for PV — outlining physical material and energy flows (right side) and information flows (left side). During manufacturing, the material flows account for the raw materials required for the production of a PV system. After completion of manufacturing, the material flows account for potential operational CE pathways such as repowering, ${ }^{6}$ repair, and reuse. For PV systems that require recycling after collection at EOL, the material flows account for the individual materials that can be recovered from the PV system and recipient industries.

\footnotetext{
${ }^{6}$ Repowering replaces certain components of a system for better performance without replacing the whole system, for instance replacing inverters or modules in a PV power plant but retaining racking, tracking, and other balance of system components. In Europe, repowering is often called "revamping."
} 
Information flows are required to operationalize or enhance the $\mathrm{CE}$ across the different life cycle stages. For example, digital service providers can facilitate the coordination of supply and demand in the secondary market for PV modules and facilitate the repair and reuse of PV modules after the collection stage. ${ }^{6,7}$

Stakeholders can influence the CE by leveraging the mechanisms and tools categorized as the "Decision Enablers." For example, government could incentivize the transition to a CE through policies, ${ }^{8,9}$ and analytical tools such as life cycle assessment (LCA) and techno-economic assessment can help industry commercialize the most environmentally and economically preferable technologies to realize sustainable CE outcomes for PV systems.

By impacting the material, energy, and waste flowing in and out of natural systems, the CE strategies in each of the PV life cycle stages (denoted $\mathrm{M}$ for manufacturing, $\mathrm{U}$ for use, and EOL for end of life) impact ecological services. For example, reuse and recycling of materials offset virgin material use and thereby prevent the environmental impact associated with upstream mining and material extraction processes.

Figure 3 identifies two broad pathways of recycling: open loop and closed loop. In closed-loop recycling, the materials recovered from PV modules are reused in PV modules. By contrast, open-loop recycling involves the sourcing or supply of recycled materials between PV and non$\mathrm{PV}$ industries. 


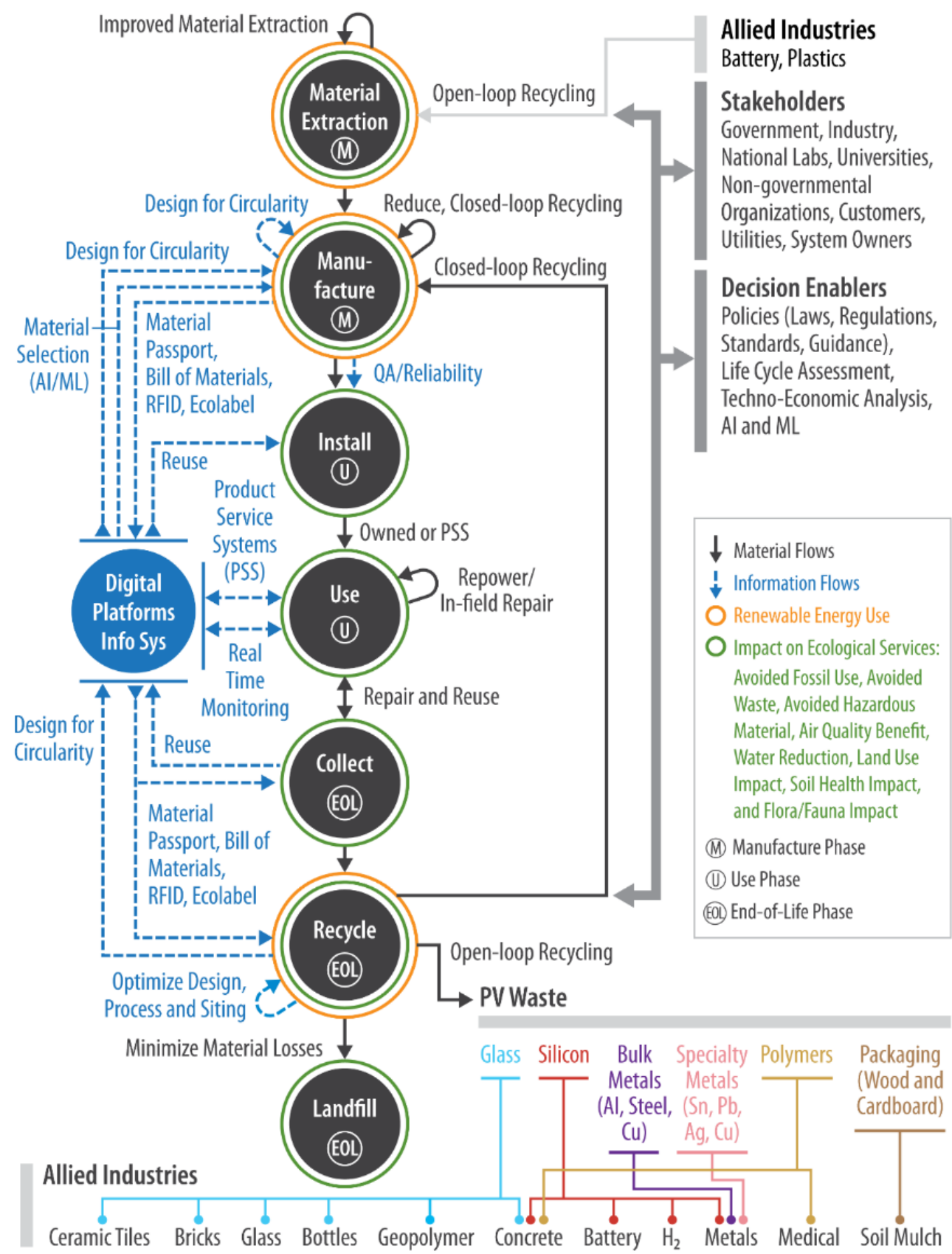

\section{Figure 3. Systems framework to assess the current state-of-the-art and identify opportunities to advance the CE for PV}

Material flows are in solid black arrows, and information flows are in dashed blue arrows, both of which flow through different stages within the three main life cycle phases denoted "M", " $U$," and "EOL" in circles representing the manufacturing, use, and EOL stages of PV systems respectively. Renewable energy can be used to lower the $\mathrm{CO}_{2}$ footprint of the stages within orange circles. The stages within green circles have an impact on ecological services. The framework includes stakeholders and decision enablers who affect the transition to a CE for PV. Allied industries are the downstream, non-PV CE pathways to reuse materials recovered from a PV system and non-PV sources for secondary materials that can be reused in the manufacture of PV systems. Product service systems (PSS) entail the consumption of PV electricity without ownership of the PV system (e.g., leasing a residential PV system). (QA = quality assurance; $\mathrm{Al}=$ artificial intelligence; $\mathrm{ML}$ = machine learning; RFID = radio frequency identification; Info Sys = information system) 
The systems framework in Figure 3 is based on a detailed literature review conducted to identify key historical trends and recent advances in research and development (R\&D) of a CE for PV systems. The review identified 358 data sets consisting of scientific articles, conference proceedings, technical reports, and trade articles focusing on technology development as well as environmental, economic, and social assessment of CE approaches and strategies to facilitate a transition to a PV CE. Figure 4 categorizes the CE strategies that can be applied across PV life cycle stages and the degree to which the strategies have been analyzed in extant literature.

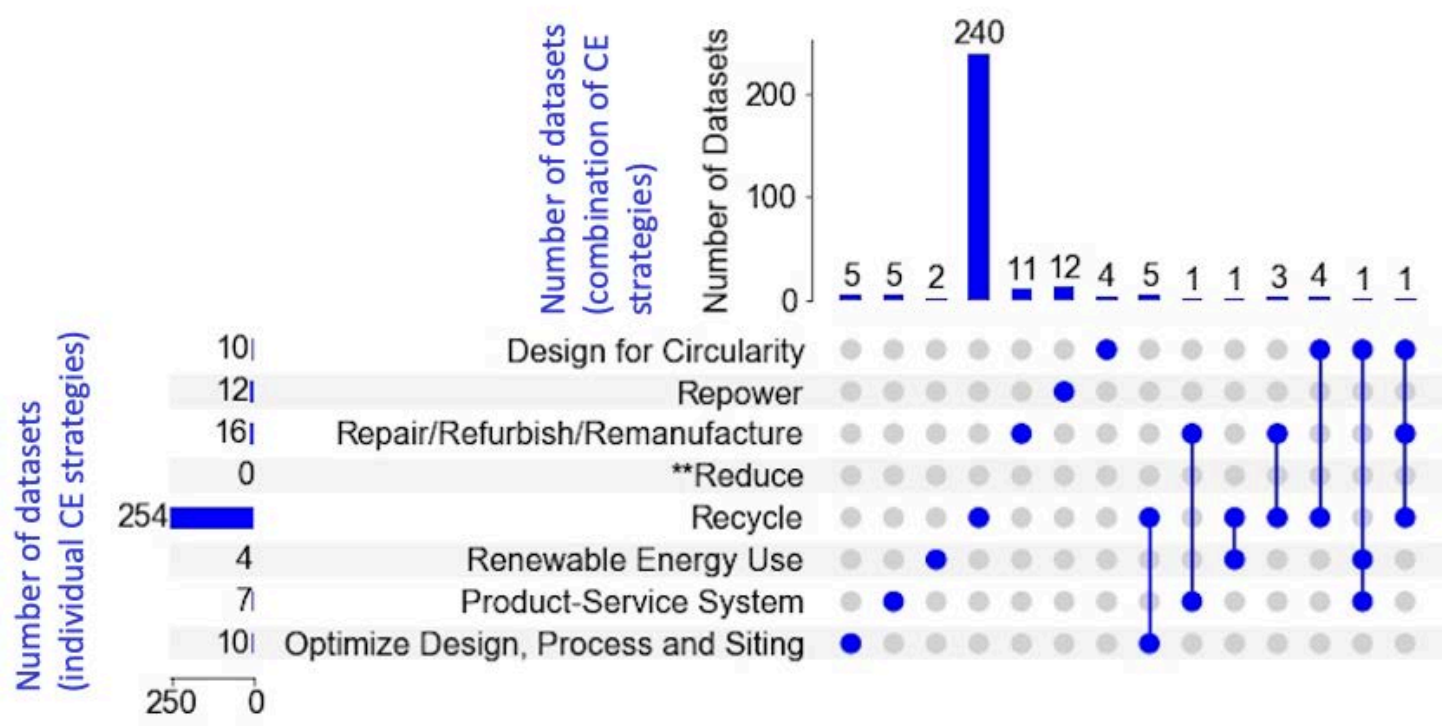

Figure 4. PV CE strategies by number of data sets found in the literature, alone and in combination

The horizontal bars represent the number of data sets focusing on an individual CE strategy (rows). For example, the fifth row from the top shows 254 data sets focusing on recycling of PV modules out of a total of 358 identified in the literature. The vertical bars represent the number of data sets focusing on a combination of CE strategies, which are identified by the solid blue circles in the column corresponding to the bar. (Linking of blue circles with blue lines is done solely for visual convenience; it does not indicate inclusion of all intervening CE strategies.) For example, the last column on the right indicates one study discusses three CE strategies: design for circularity, repair/refurbish/remanufacture, and recycling. ${ }^{* *}$ This literature review did not focus on the reduction of material use (e.g., reduced silicon and silver use in crystalline silicon [c-Si] panels), which has been pursued to decrease the costs of manufacturing of PV modules, although such dematerialization does in fact decrease material intensity. 


\section{Key Considerations for Manufacturing}

U.S. solar manufacturing has not kept up with domestic demand, and worldwide the United States lost $80 \%$ of its market share for solar-grade polysilicon, PV cells, and PV modules in the last decade. ${ }^{10}$ The United States is reliant on imports of raw materials for domestic solar manufacturing as well as imports of PV cells, modules, and balance of system (BoS) equipment needed to meet domestic demand. ${ }^{10-12}$ In 2017, the United States imported $60 \%$ of the domestic market demand for c-Si cells and $92 \%$ of the domestic market demand for c-Si and thin-film modules. ${ }^{10}$ The U.S. solar market also depends on imports of BoS equipment, such as junction boxes, connectors, aluminum frames, and inverters. ${ }^{10-12}$ In terms of raw materials, despite ample polysilicon production, the United States relied on imported wafers in 2017 owing to the relative lack of solar silicon manufacturers. ${ }^{10}$ Moreover, in 2019, U.S. manufacturers indicated that they relied entirely on glass imports to meet c-Si module demand. ${ }^{10}$

The recent impacts of COVID-19 on the solar market demonstrate vulnerabilities in the PV supply chain and a need for domestic manufacturing and improved resource recovery in the United States. In addition to impacting customer demand, the pandemic has disrupted supply chains and distribution channels along the entire solar value chain from raw material extraction through construction. ${ }^{10-13}$ One study found that the BoS supply shortages alone, due to COVID19 impacts, could result in 300-700 MW direct current (MWDC of utility-scale project delays in the United States in 2020. ${ }^{11}$ The study also found that supply chain delays and supply shortages, in conjunction with U.S. construction disruptions, may result in $2 \mathrm{GW}$ direct current $\left(\mathrm{GW}_{\mathrm{DC}}\right)$ to 5 $\mathrm{GW}_{\mathrm{DC}}$ of utility-scale project development delays in the United States in $2020 .{ }^{11}$

\subsection{PV Material Demands}

\subsubsection{Material Demand Estimation Approach}

To estimate the environmental and resource impacts of rapid solar growth, the manufacturing material demands associated with various quantities and types of solar technologies must be understood. We use $\mathrm{PViCE}^{14}$ to calculate material demands for PV module manufacturing during 2010-2050 based on deployment in the Solar Futures scenarios. PViCE is a novel python-based tool with validated baseline scenarios and values. Its bottom-up approach estimates material demands and EOL materials dynamically over time and can evaluate trade-offs among CE pathways. It captures PV manufacturing and technology evolution, including improvements to cells, quality/reliability, and module lifetime.

PViCE estimates mass flow annually, representing different generations or cohorts of PV modules described by module design, performance, and material characteristics. The annual cohort properties capture a distribution of efficiency and material content for each of several module designs, obtained through an exhaustive literature review and harmonization of different sources further described in a Jupyter journal document on PViCE's GitHub web page. ${ }^{14}$ Average module efficiency starts at $14.7 \%$ in 2010 and increases to $25.1 \%$ by 2050 , based on published estimates from the International Technology Roadmap for Photovoltaic (ITRPV, on which the Solar Futures scenario efficiency improvements are also based) and on projections from "The 2020 Photovoltaic Technologies Roadmap." " The module designs considered are today's standard of a single glass layer and backsheet plus bifacial modules (glass-glass), 
following market trends from the ITRPV. Note the same annual module cohort characteristics apply no matter the scenario.

Each generation starts with year zero at installation. The modules "age" owing to predictable degradation rates, or they suddenly fail according to a Weibull distribution of annual early failure rates. EOL is defined as including three modes: a product failure to where it does not function, degradation resulting in modules that produce $80 \%$ of their initial power rating, or the end of the expected project lifetime. The failure rates, degradation rate, and project lifetimes improve over time, reflecting manufacturer improvements in module quality and reliability. ${ }^{15-18}$ Therefore, installed capacity in a given year equals the year's new installations plus all the previous generations deployed, minus power degradation and the three EOL modes.

Several PV module EOL pathways are possible in PViCE. Effects of repair, remanufacturing, and refurbishment can be quantified. However, for this analysis, these are set to zero to evaluate virgin material needs and EOL materials in a worst-case scenario of a completely linear economy.

In addition, we only examine c-Si modules, which are assumed to represent a constant $85 \%$ of new capacity in the Solar Futures scenarios. Our focus on c-Si excludes waste from other technologies and underestimates materials demands from all U.S. PV deployment, yet it could overestimate c-Si material demands if other technologies are deployed in the future at a higher rate. Details on the data assumptions and inputs can be found in Appendix B.

\subsubsection{Results: Manufacturing Material Demands}

We calculate virgin material demands for PV manufacturing for the three core Solar Futures scenarios: Reference, Decarb, and Decarb+E. The demands account for PV manufacturing efficiency, capturing manufacturing materials efficiency improvements over time. We assume no recycled content; if module manufacturing could use recycled materials, virgin demands would decrease proportionally. Thus, the estimates reported here are gross material demands and may overestimate material requirements if some manufacturers use secondary materials, although this does not appear to be a prevalent practice today.

Figure 5 compares cumulative virgin material demands for c-Si PV for 2020-2050 by scenario. Glass accounts for the majority of the mass in each scenario, which corresponds to typical PV module design. The Decarb $+\mathrm{E}$ scenario has the greatest cumulative material demand through 2050. Though high in value, silver is barely visible within the scale of the chart. See Appendix B for tabulated results. 


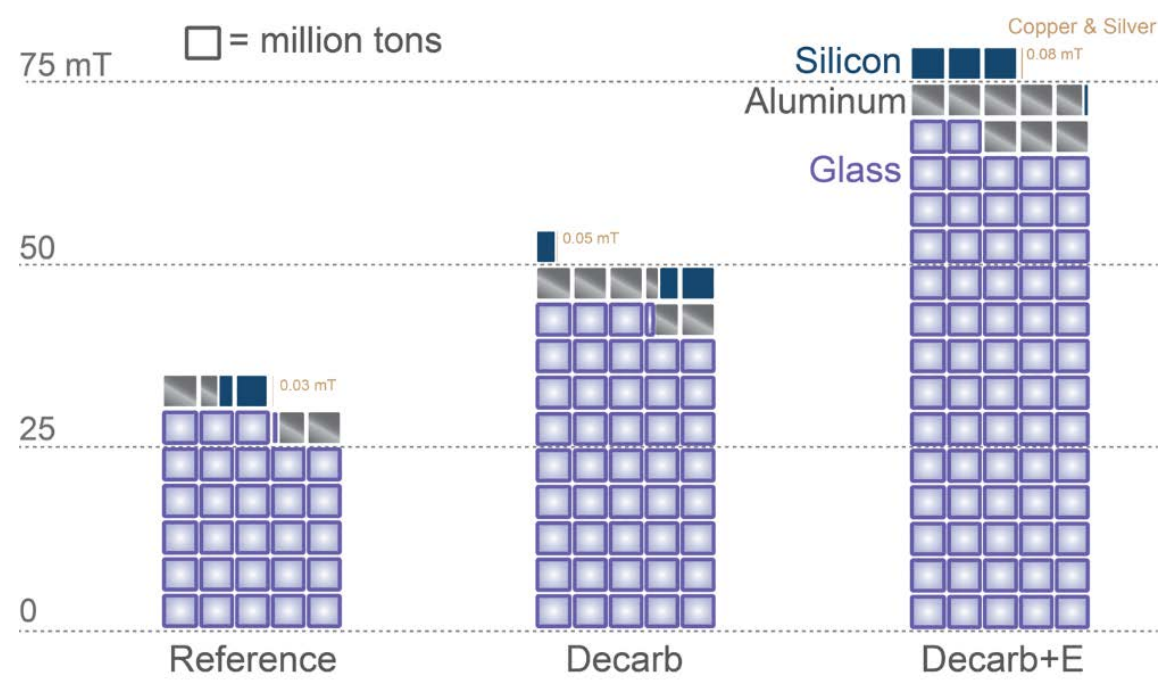

Figure 5. Comparison of virgin material demands for each silicon-based PV material cumulatively (2020-2050) across the three scenarios

Annual virgin material demands for each resource are shown by scenario in Figure 6. Figure 7 puts average annual c-Si module material demands in context of the 2020 global production of silver, silicon, and aluminum. No increase in mining is assumed for these analyses, and, for this comparison, material demands are not assumed to be met with either material stockpiles or recycled content. Thus, this analysis estimates "worst case" material demands and waste based on a completely linear economy (noncircular). Analysts project global PV deployment to average approximately $300 \mathrm{GW}_{\mathrm{DC}} /$ year, ${ }^{19}$ while a global decarbonization study estimated roughly 1 $\mathrm{TW}_{\mathrm{DC}} /$ year. ${ }^{20}$ Global PV deployment is assumed to be composed of $99 \% \mathrm{c}-\mathrm{Si}$ modules based on extrapolation of historical trends. ${ }^{21}$ Silver is the material demanded at the highest fraction of global supply. While the U.S. demand of silver is under $5 \%$ of global supply in the Decarb+E scenario, silver demand from PV could reach almost $40 \%$ of 2020 global production in a global decarbonization scenario. Concerns regarding the supply and expense of silver contacts have spurred research into copper substitutes. In addition, the mining industry has a history of adjusting capacity to meet demand.

Silver represents a major opportunity for CE strategies to alleviate future supply constraints by reducing material demands through dematerialized designs and by recovering materials from EOL solar technologies (see Section 5.1). In contrast to the silver projections, demand for copper within modules ${ }^{7}$ barely registers against 2020 global production, and the International Energy Agency found that global copper demands for the energy transition (including transmission and distribution infrastructure investments, as well as electric vehicles) double historical levels. ${ }^{3}$

\footnotetext{
${ }^{7}$ Copper within junction boxes, external connector wiring, and field wiring are not considered within PViCE.
} 

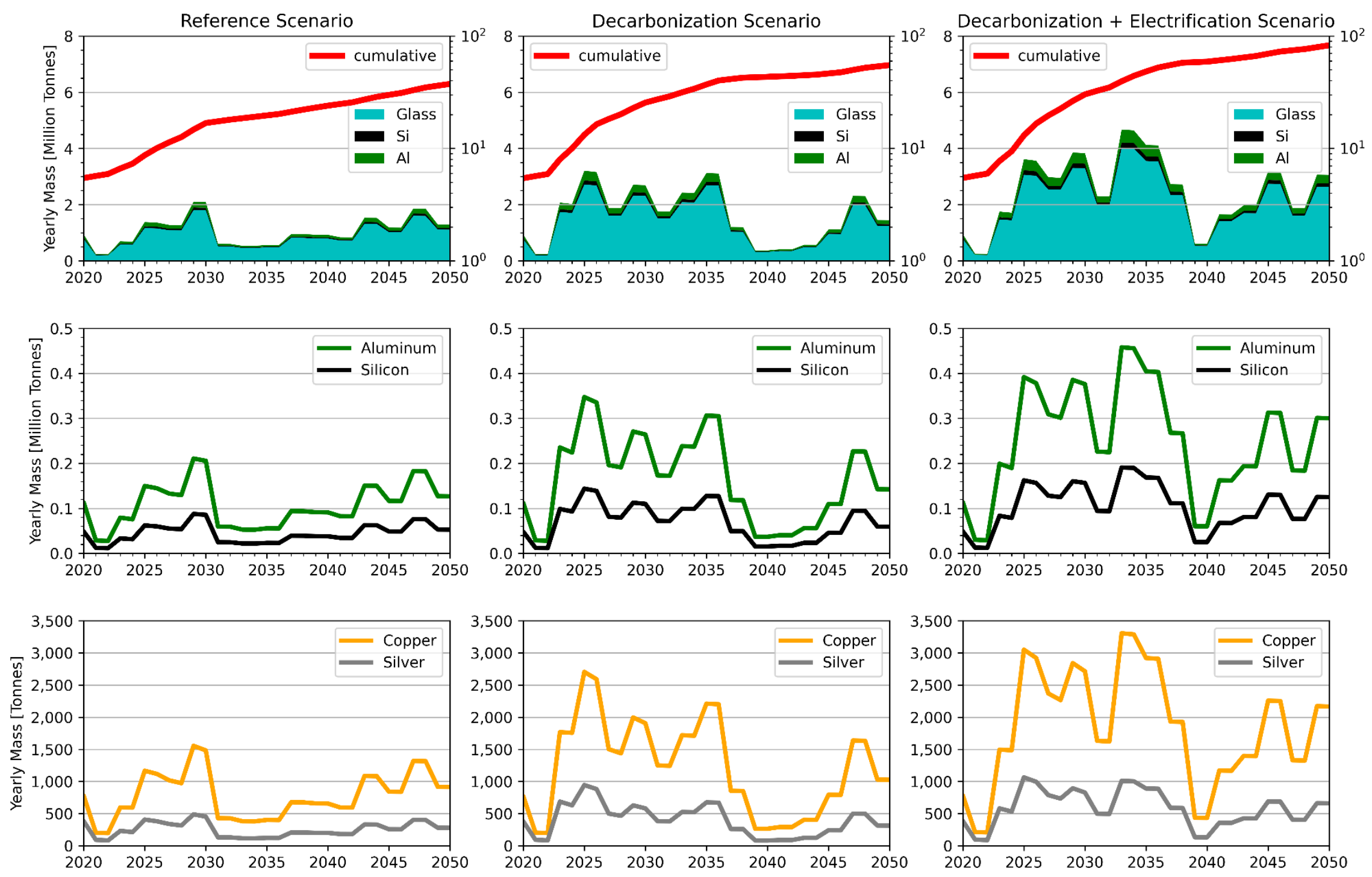

Figure 6. Annual demand of selected materials for PV manufacturing across the three core Solar Futures scenarios, 2020-2050

The red lines in the upper row of plots represent cumulative mass installed in each scenario (right axis; note that it uses a log scale). 


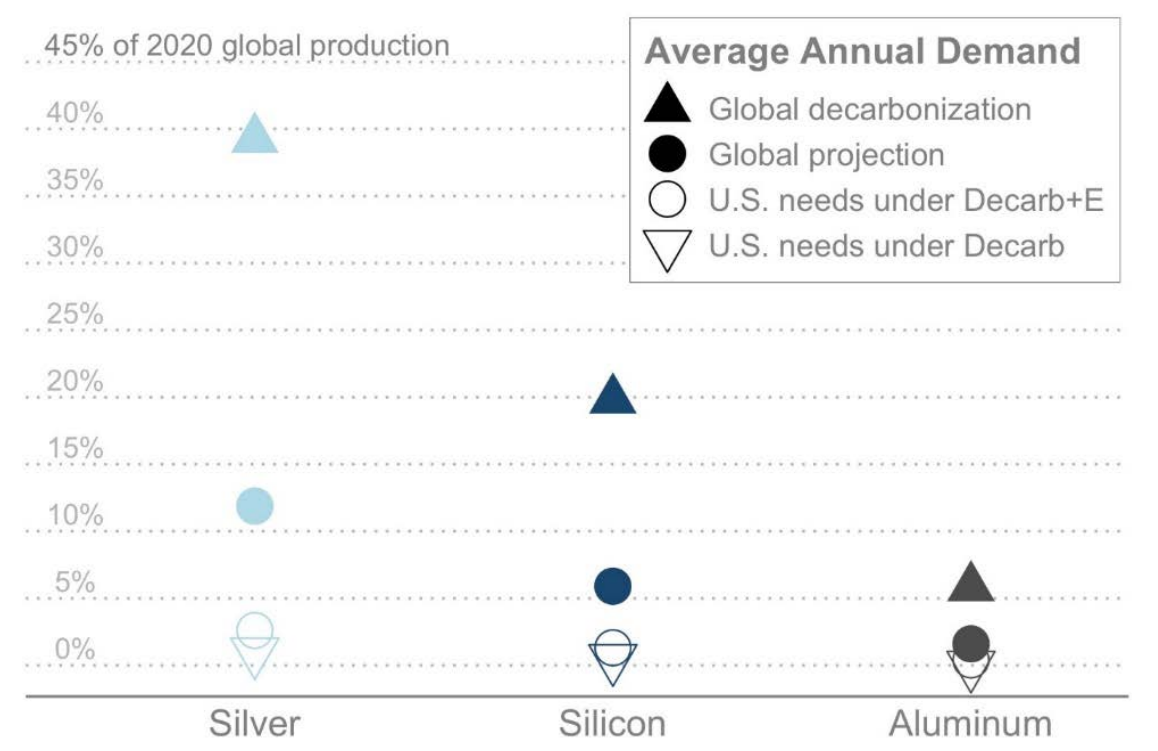

Figure 7. Percentage of 2020 global production of various materials needed to supply average annual virgin materials demand for C-Si PV in the two decarbonization-based Solar Futures Study scenarios

The material needs in the global projection scenario are based on projected global PV deployment from the International Renewable Energy Agency (IRENA). ${ }^{19}$ The material needs in the global decarbonization scenario are based on projected global PV deployment in Bogdanov et al. (2019). ${ }^{20} 2020$ mining production (metric tons): silver $22,260,{ }^{22}$ silicon $8,000,000,{ }^{23}$ aluminum $65,267,000,{ }^{24}$ copper $20,000,000,{ }^{25}$

\subsection{CSP Material Demands}

The material demand for CSP systems is a product of the installed capacity and the materials required per unit of installed capacity. The projected U.S. installations between 2020 and 2050 are from the Solar Futures study.

The material requirements are quantified for the manufacturing and construction of power tower CSP systems and include site improvement, the collector system, the receiver system, the thermal energy storage (TES) system, the steam generation system, and the electric power generation system. The material requirements for power tower CSP is sourced from a published study ${ }^{26}$ and detailed in Appendix D. This analysis assumes all CSP installations are power tower technology, because this technology accounts for the most electricity generated by CSP systems globally ${ }^{27}$ and is more economically competitive than other CSP alternatives. ${ }^{28}$

The results in Figure 8 demonstrate that concrete, aggregate, carbon steel, sodium nitrate, and solar glass are the most consumed materials in the manufacturing and construction of power tower CSP systems. Construction and manufacturing of the receiver and collector systems require $83 \%$ of the concrete, $99 \%$ of the aggregate is used in the site maintenance process, and the collector system accounts for $70 \%$ of the carbon steel requirement. The TES system and the collector system account for all the sodium nitrate and solar glass consumed respectively. Mining from natural sources accounts for $60 \%$ of sodium nitrate used in CSP. ${ }^{29}$ Alternatively, sodium 
nitrate can be produced synthetically, which is an order of magnitude more GHG-emission intensive than mined sodium nitrate. ${ }^{29}$

Beyond the bulk materials discussed above, the requirement for critical materials in the production of power tower CSP systems is unlikely to be constrained by supply. A recent study on critical materials required in a global transition to renewable energy systems showed that power tower CSP systems could necessitate a 75-fold increase in chromium (to $91 \mathrm{kt}$ ), 67-fold increase in copper (to $42 \mathrm{kt}$ ), 92-fold increase in manganese (to $105 \mathrm{kt}$ ), and 89-fold increase in nickel (to $35 \mathrm{kt}$ ) requirements from 2020 to 2040 in a high-deployment scenario. ${ }^{3}$ Despite the significant increase, the projected requirements of chromium, copper, manganese, and nickel in 2040 are unlikely to be constrained by supply, because they represent less than $0.1 \%$ of the global mine production levels in $2020 . .^{30-33}$

Scarcity in supply is unlikely to impact the raw material requirements for CSP installation. ${ }^{34}$ The list of all 27 materials required for the construction and manufacturing of power tower CSP plants is detailed in Appendix D. 

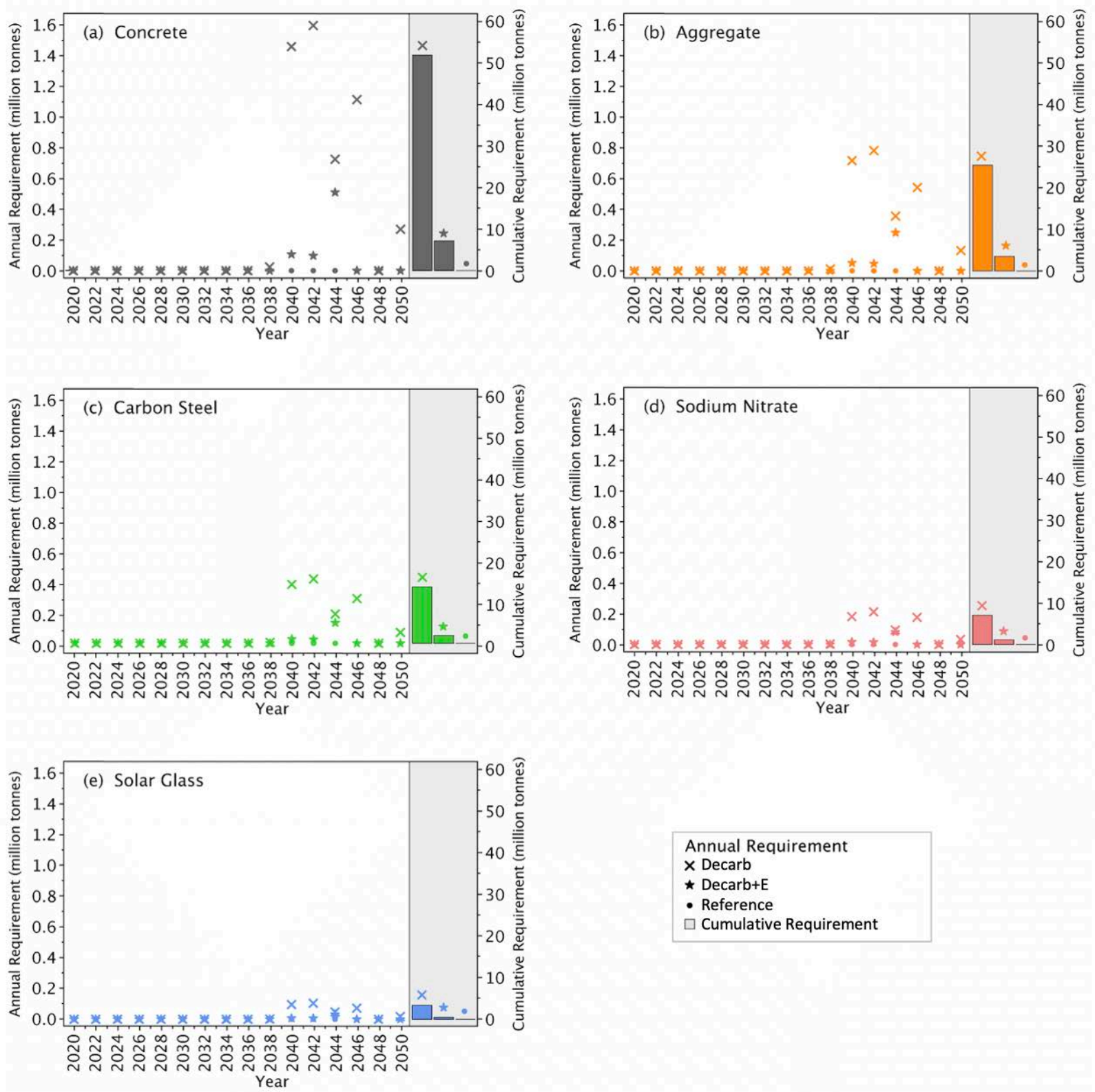

Annual Requirement

$\times$ Decarb

$\star$ Decarb+E

- Reference

$\square$ Cumulative Requirement

Figure 8. Five most-used materials in the manufacturing and construction of power tower CSP plants in the three core Solar Futures Study scenarios

The axis on the left plots the annual requirement from 2020 to 2050 based on projected U.S. installations. The bar graphs on the right with the gray background quantify the cumulative material requirement from 2020 to 2050 .

\subsection{Policies: Regulation}

Concerns about supply chain vulnerabilities and PV system equipment waste have led to government and industry discussions, policies, and initiatives that could have important impacts on domestic resource recovery and U.S. PV manufacturing. For example, Washington state implemented a product stewardship regulation that directly impacts solar module manufacturers. The regulation will require PV module manufacturers, beginning July 1, 2023, to finance the takeback and reuse or recycling of PV modules sold within or into the state, after July 1, 2017, at no cost to the owners. ${ }^{9}$ Although Washington is the only jurisdiction in the United States to 
implement manufacturer takeback requirements, policymakers and regulators in New York, North Carolina, Minnesota, and Maryland have considered similar stewardship policies in recent years. ${ }^{35}$

There are also policies in states, such as Washington and California, which could indirectly impact U.S. solar manufacturing through the CE. California regulators have recently allowed PV modules to be managed as universal waste, a subset of hazardous waste, which has less stringent handling, transport, and storage requirements. ${ }^{36-39}$ California's universal waste regulation may reduce some of the costs and liabilities associated with collecting, storing, and transporting PV modules classified as hazardous waste, as compared to fully regulated hazardous waste. ${ }^{35,40}$ However, some critics have warned that California's universal waste regulation may act as a barrier to PV module recycling under current market conditions, because the regulation treats disposal and recycling of hazardous PV modules in the same manner (e.g., the same handling, storage, and transport requirements and associated liabilities for noncompliance), and disposal is currently more economically favorable than recycling. Moreover, California's regulations prohibit universal waste handlers and universal waste destination facilities from using heat or chemicals to treat PV modules, which are processes used in most module recycling today. ${ }^{35,40}$ In contrast, Washington allows PV modules that are being recycled to be regulated under less stringent requirements than modules destined for disposal. ${ }^{41,42}$ Managing PV modules under an alternative regulatory scheme that treats recycling differently than disposal, such as Washington's policy, could reduce the costs and liability associated with regulatory compliance as compared to disposal, which could support increased rates of resource recovery and increase domestic supply of manufacturing material (e.g., glass, silicon, tellurium). ${ }^{40}$ States including Arizona, Hawaii, Illinois, Minnesota, New Jersey, and North Carolina are also considering a variety of policy mechanisms to mandate or incentivize PV module and BoS equipment recycling, which could enable investment in new and expanded domestic recycling opportunities. ${ }^{35,40}$

Moreover, industry-led policies, such as the NSF/ANSI 457 Sustainability Leadership Standard for PV Modules and Inverters and the Silicon Valley Toxics Coalition's Solar Scorecard, could impact solar manufacturing in the United States. The NSF/ANSI 457 standard sets sustainable performance objectives related to design, manufacturing, and EOL management of PV modules. ${ }^{35} \mathrm{PV}$ manufacturers may find that compliance with voluntary industry standards, such as NSF/ANSI 457, can enhance their corporate responsibility image and may in turn increase consumer trust and overall competitiveness in the marketplace. ${ }^{40}$

These recent government- and industry-led policies and initiatives may signal a paradigm shift toward increased domestic resource recovery and sustainable PV manufacturing. It may also present opportunities for growth in upstream U.S. manufacturing sectors, such as the U.S. flat glass industry. ${ }^{10}$

\subsection{Circular Economy Methods for PV Manufacturing}

A broad range of CE methods can be incorporated in the PV manufacturing stage to improve the economic and environmental performance of PV systems. 


\subsubsection{Reduced Material Intensity and Closed-Loop Recycling}

Efforts to reduce the material ${ }^{43-48}$ and energy ${ }^{49,50}$ intensity of $\mathrm{PV}$ manufacturing over the last two decades have predated the formal definition and integration of $\mathrm{CE}$ practices and have generated economic and environmental benefits. ${ }^{48,50,51}$

Of the mass of energetically intensive solar-grade silicon (which represents $25 \%$ of the total material cost of c-Si PV cells) ${ }^{43}$ a significant fraction ( $40 \%$ is reported by the ITRPV ${ }^{52}$ ) is wasted as kerf loss during the sawing of wafers from the purified c-Si ingot. In addition, solargrade silicon is lost as scrap when the top, bottom, and sides of the silicon ingot (the parts containing impurities) are cut. ${ }^{53}$ To reduce the material intensity of c-Si PV manufacturing, R\&D has focused on reducing the kerf losses by shifting to less wasteful sawing methods $\mathrm{s}^{54,55}$ and kerffree wafering ${ }^{56}$ the recovery and reuse of silicon from the kerf loss, ${ }^{57,58}$ and recycling and reuse of silicon from ingot cuts in manufacturing PV cells.

R\&D as well as developing and refining standards and guidelines to reuse secondary silicon from $\mathrm{PV}$ manufacturing waste can further accelerate CE practices. A key concern in the reuse of silicon recovered from kerf losses and ingot cuts are impurities that can degrade the PV cell performance. ${ }^{59}$ Further research is required to robustly characterize the level and type of impurities from ingot and kerf losses and benchmark the purity and properties of recovered silicon with those of virgin silicon. ${ }^{60}$ The CE in PV manufacturing can be facilitated via R\&D focused on optimizing the recovery process to minimize impurities ${ }^{57,61}$ as well as evaluating the trade-offs in cell performance, ${ }^{58}$ economic costs, and environmental impact from replacing virgin solar-grade silicon with secondary silicon ${ }^{62}$ across a broad range of silicon manufacturing conditions. In addition, the supply of kerf loss as feedstock in alternate applications (e.g., hydrogen production ${ }^{63}$ lithium-ion batteries ${ }^{64}$ ) may be economically and environmentally preferable to landfilling.

In closed-loop recycling, materials recovered from a PV module at EOL are reused in PV manufacturing. Beyond the reuse of silicon, as discussed above, bulk (e.g., glass) and other specialty (e.g., silver) materials can be recovered and potentially reused in the PV module, yielding life cycle GHG and energy-return-on-investment benefits, yet these have yet to be comprehensively researched alongside industry testing and validation to make these into marketready solutions.

\subsubsection{Open-Loop Recycling to Reuse Materials from Allied, Non-PV Industries}

The open-loop recycling pathway offers opportunities to reuse materials recovered from non-PV systems in PV manufacturing, which can be an economically and environmentally preferable pathway to source raw materials. For example, post-consumer plastic waste can be reused in the production of encapsulants in PV modules. ${ }^{65}$

\subsubsection{Use of Renewable Electricity}

Energy used in the extraction and purification of silicon accounts for half of the overall energetic footprint and climate impact of a c-Si PV module. ${ }^{66}$ The $\mathrm{CO}_{2}$ emitted from energy use in the early stages of the PV life cycle can significantly increase the climate footprint of PV systems. ${ }^{62,67} \mathrm{~A}$ switch from $\mathrm{CO}_{2}$-intensive fossil fuel electricity to renewable electricity, which is a widely pursued CE strategy, can significantly decrease the climate footprint of PV modules. ${ }^{62}$ 
The potential to decrease the climate footprint has motivated industry to explore opportunities to decarbonize the manufacturing process by using renewable electricity. ${ }^{68}$ Developing marketrecognized labels and valuations - which should be based on new, robust quantitative metricsfor the benefits of reduced embodied GHG emissions and energy is a promising research direction best accomplished in collaboration with industry and nongovernmental organization stakeholders.

\subsubsection{Design for Circularity}

The traditional approach to designing PV modules has been motivated by the need to drive down manufacturing costs, ${ }^{51}$ increase system durability ${ }^{69}$ and reliability,${ }^{70,71}$ and increase module efficiency ${ }^{72}$ with the overall goal of making PV cost-competitive with other sources of electricity. ${ }^{73}$ Beyond driving down the costs of PV electricity, there is a need to reassess and redefine the key parameters of PV system design to address emerging sustainability challenges as the volumes of raw materials required and waste produced have increased exponentially with global PV installations reaching several terawatts. ${ }^{74}$ For example, hazardous materials in c-Si PV modules (e.g., lead) ${ }^{74}$ fluorine in the backsheet, and the challenges of removing the ethylene vinyl acetate (EVA) laminate can hinder efficient recycling of PV waste. ${ }^{75-78}$

Design for circularity - which encompasses the use of novel PV module designs and materials in the manufacturing stage to enhance recyclability, transition away from supply-constrained materials to abundant materials,${ }^{79}$ and decrease risks to human health and the environment over the PV life cycle - can address these emerging sustainability challenges. Machine-learning (ML) and artificial intelligence (AI) methods can inform the selection of nonhazardous and environmentally benign materials during the design of PV modules. ${ }^{80}$ The use of recyclable materials in the PV module can enhance recyclability at EOL and decrease landfilling. ${ }^{81}$ Substituting abundant materials for constrained materials (e.g., copper metallization replacing silver metallization) ${ }^{82}$ can decrease the cost of manufacturing PV systems. ${ }^{44}$

Replacing hazardous materials in the PV module can decrease the environmental and human health risks during the use and EOL stages. For instance, for c-Si modules, substituting fluorinated backsheets with fluorine-free polymers or a double-glass design can decrease human health risks during EOL and allow for high-temperature recycling processes for faster and more efficient recycling of the spent PV module. ${ }^{76,77}$ Eliminating lead solders can prevent potential lead emissions during thermal recycling and potentially prevent c-Si PV modules from being classified as hazardous waste. ${ }^{83}$ Frameless modules help reduce the aluminum content, decrease transportation burdens, eliminate the need for deframing during recycling, and, thereby, simplify the recycling process and decrease the climate and energy footprint. ${ }^{84} \mathrm{~A}$ laminate-free design ${ }^{85}$ or replacing the EVA with edge sealants decreases the time and energy required for recycling by avoiding the need for thermal, chemical, or mechanical processes required to eliminate the EVA during PV recycling. ${ }^{83}$ The examples mentioned above focus on the currently dominant module technology - crystalline silicon. Other issues may emerge or not be relevant if newer technologies reach substantial market share, e.g., perovskite.

Design for circularity strategies may impose trade-offs in other life cycle stages of the PV system. Copper metallization can degrade cell performance and the durability of the PV module. ${ }^{86}$ A laminate-free design impacts the electricity generation profile and durability of the $\mathrm{PV}$ module, which impacts the economic and environmental performance of PV systems. ${ }^{87}$ Lead- 
free alternatives can increase costs and elevate temperatures for soldering, which can cause thermomechanical stress and breakage of the silicon wafer during manufacturing. ${ }^{88}$ Preliminary field studies have found that the durability of modules with fluorine-free backsheets is lower than the durability of those with fluorinated backsheets. ${ }^{89}$

A holistic approach assessing the trade-offs that material and design choices impose on both the technical performance of the module (e.g., electricity generation) and the life cycle economic and environmental impact ${ }^{90,91}$ will help in selecting the most sustainable design for circularity alternative. This will prioritize design for circularity methods that generate the highest net economic and environmental benefit over the life cycle of the PV system.

\subsection{Potential for Sustainability Factors to Be Preferentially Identified for Purchase}

The integration of CE strategies in the manufacturing phase is a potential strategy for PV module suppliers to improve sustainability across the PV supply chain and establish themselves as environmentally preferable PV suppliers, ${ }^{92}$ which is aligned with emerging procurement requirements defined in regulations. ${ }^{93,94}$

\subsubsection{Potential for Low-Carbon Solar to Reduce Life Cycle GHG Emissions}

The net $\mathrm{CO}_{2}$ benefit of a PV system is the difference between the $\mathrm{CO}_{2}$ avoided by displacing the marginal source of grid electricity (which in most U.S. balancing areas is still a fossil fuel source, but in some places and at sometimes could be another low-carbon source) during the use phase and the $\mathrm{CO}_{2}$ emitted when manufacturing the PV system. ${ }^{95}$ The net $\mathrm{CO}_{2}$ benefit can, therefore, be improved by decreasing the consumption and wastage of $\mathrm{CO}_{2}$-intensive raw materials and increasing use of low-carbon electricity in PV manufacturing, ${ }^{74}$ which are two widely recommended CE strategies. Studies show that energy and GHG payback times decrease significantly by locating PV manufacturing in less $\mathrm{CO}_{2}$-intensive geographies. ${ }^{62,66,96}$ Based on these findings, some in the PV industry are currently incorporating CE strategies in the PV supply chain and manufacturing to decrease PV's embodied carbon. ${ }^{68}$ Recovery and reuse of manufacturing scrap as well as EOL materials can provide similar benefits, yet they require quantification and promotion to raise awareness and increase uptake.

\subsubsection{Fluorine- and Lead-Free Modules}

To decrease potential downstream environmental and human health risks during use and recycling, R\&D has focused on decreasing the content of hazardous materials in PV modules. ${ }^{97}$ The industry currently manufacturers lead- and fluorine-free modules, ${ }^{97,98}$ and projections show that lead and fluorine content is expected to decrease in the future. ${ }^{44,84}$ Suppliers of modules with low or no lead and fluorine are incentivized by the potential to obtain higher sustainability scores in emerging standards than suppliers with high lead or fluorine content, and consumers could be motivated by the likelihood that when end of life is reached, those modules should be determined as nonhazardous thereby reducing costs and environmental impacts. ${ }^{99,100}$

\subsubsection{Ranking Mechanisms and Alliances}

PV sustainability scorecards, ${ }^{100}$ standards and regulations offer mechanisms to guide, ${ }^{8,101,102}$ operationalize, ${ }^{103}$ declare, and measure the adoption of industrywide CE practices and, thereby, help procurers and consumers rank PV suppliers based on key environmental performance 
indicators. ${ }^{99}$ The NSF/ANSI 457 standard ${ }^{99}$ incentivizes the incorporation of CE practices by assigning a higher rank to PV suppliers who declare the content of recycled material and substances of very high concern in the product, comply with existing directives (e.g., the European Restriction of Hazardous Substances [RoHS] directive), quantify and declare the environmental footprint through the use of quantitative tools such as LCA, and minimize use of water and energy in manufacturing. NSF/ANSI 457 further promotes CE solutions for EOL by requiring that manufacturers provide takeback services (including reuse, refurbishment, and recycling) to earn higher accreditation levels, define material recovery targets, and declare materials contained in the PV module and the availability of replacement components. Furthermore, recent regulatory mechanisms, such as the European Union's Ecodesign Directive in development, propose mandatory CE (e.g., repairability, refurbishment) and minimum environmental sustainability requirements for the different life cycle stages of PV systems to be procured in the European Union. ${ }^{102}$ With emerging clarity on the regulations and standards, alliances have developed to coordinate industrywide efforts to improve the sustainability of PV panels through $\mathrm{CE}$ strategies such as decreasing manufacturing energy requirements and carbon emissions. ${ }^{68}$

\subsection{Environmental Justice and Social Benefit Through Circular Economy During PV Manufacturing}

$\mathrm{CE}$ strategies in PV manufacturing offer significant potential to improve environmental justice outcomes and increase social benefits. The use of renewable electricity helps decrease the reliance on fossil fuels and thereby minimize climate change and health effects, including deaths, attributable to air pollutant emission from fossil fuel combustion, which disproportionately impact minority and low-income communities and the developing world while exacerbating socioeconomic inequities. ${ }^{104,105}$ By following closed-loop recycling and increasing emphasis on substituting hazardous materials with environmentally benign materials in the supply chain, $\mathrm{CE}$ strategies in PV manufacturing can significantly decrease the likelihood of environmental and health hazards, which have previously impacted communities in the vicinity of PV manufacturing facilities. ${ }^{106}$ The ratings provided by scorecards ${ }^{100}$ to rank socially responsible PV suppliers help incentivize transparency in the supply chain to avoid the sourcing of conflict minerals and prevent the violation of worker rights ${ }^{107}$ and health and safety requirements. Further, the emergence of industry alliances, which prioritize CE strategies in the PV supply chain, can increase PV manufacturing competitiveness and, thereby, increase employment potential in the U.S. PV sector. ${ }^{108}$ Finally, all CE strategies that reduce material demands consequently reduce burdens experienced in frontline communities neighboring the extraction industries. 


\section{Key Considerations for Site Selection, Construction, and Operation}

This section addresses solar impacts in the use phase related to land use, water requirements, and air quality, and it discusses CE approaches and environmental justice issues related to this phase.

\subsection{Land-Use Considerations}

The large-scale solar deployment envisioned in the Solar Futures scenarios will require land for ground-mounted solar systems. ${ }^{\text {viii }}$ Life cycle assessments ${ }^{\text {ix }}$ of large-scale solar systems have concluded that upstream and downstream land use is much less than operation phase land use both for PV and CSP solar systems (estimates range from less than $1 \%$ to $10 \%$ of operation phase land use). ${ }^{109,110}$ Therefore, in this analysis we focus on land requirements during the operation phase of solar electricity generation; however, we start with a brief review of prior investigations of life cycle land use for solar and other electricity generation technologies.

Comparing the life cycle land requirements of solar and other generation technologies is difficult owing to differences in land-use intensity, length of land use, and other factors. ${ }^{111}$ An early comparison of land-use impacts suggested PV requires amounts of land through its life cycle similar to the amounts used by nuclear, natural gas, and coal-fired electricity generation sources, and less than the amounts used by other renewable sources including biomass, geothermal, hydroelectric, and wind. ${ }^{109}$ Recent studies have updated and increased life cycle land-use projections for natural gas, ${ }^{112} \mathrm{PV},{ }^{113}$ and nuclear. ${ }^{114}$ Life cycle land-use estimates for wind have decreased, ${ }^{115}$ partially owing to excluding indirect land-use area (area between turbines). A harmonization effort comparing 39 land-use studies found that high-end land use intensity (area/MWh) for wind and geothermal is less than half of the high-end land use for PV and CSP. ${ }^{116}$

Our analysis here compares operation phase solar land use under Solar Futures scenarios with quantities of existing disturbed and contaminated land areas; we also examine methods for mitigating solar land-use impacts.

\subsubsection{Solar Futures Study Land Requirements}

This section evaluates solar land requirements under the three core Solar Futures Study scenarios. Technologies evaluated include utility-scale PV (UPV) sited in rural areas, distributed UPV (DUPV) sited in urban areas, and CSP. Although rooftop solar contributes a substantial portion of Solar Futures Study projections, this technology by definition does not require ground-mounted installation and is therefore excluded from this evaluation. Methods to quantify and evaluate land requirements are fundamentally similar to the methods outlined in Macknick et

\footnotetext{
viii Roof-mounted PV uses land already developed for another purpose, and thus no new land converted from other uses is required. Therefore, the added capacity of roof-mounted PV is not counted in this solar land use requirements assessment, which aims to assess how much additional land is required under the Solar Futures scenarios.

${ }^{\text {ix }}$ Life cycle land-use evaluations include land use at the location of energy generation as well as for upstream (mining of natural components such as fossil fuels or rare earth elements and manufacturing), and downstream (component disposal) uses.
} 
al. ${ }^{117}$ and Hartmann et al., ${ }^{118}$ with updated data to improve land-use and land-availability estimates.

\section{Methods}

Similar to the approach described in Hartmann et al., ${ }^{118}$ we calculate land requirements on a regional basis (by electric grid balancing areas, ${ }^{\mathrm{x}}$ then aggregated to states). We quantify future land requirements for utility-scale solar energy deployment additions and subtractions (decommissioning), and we quantify the amount of land potentially suitable for solar development, with emphasis on identifying the amount of potentially suitable disturbed and contaminated lands.

Land requirements are based on estimates of net future solar energy deployment derived from $\operatorname{ReEDS}^{120}$ and geospatial land exclusion categories as used in the Renewable Energy Potential (reV) model. ${ }^{121}$ Details on how the ReEDS model was developed for the Solar Futures Study are provided in the main study report. ${ }^{1}$ Future solar deployment is modeled for all solar technology types at 2-year intervals from 2020 to 2050. This analysis focuses on projections from the three core Solar Futures Study scenarios and the DUPV, UPV, and CSP technology types. Land-use requirements are estimated using recent, empirically derived estimates of land used by existing solar facilities per unit of installed capacity (MW). ${ }^{113,118,122}$ UPV and DUPV are assumed to require approximately 7.5 acres (3.0 hectares [ha]) per installed MW, and CSP is assumed to require approximately $10 \mathrm{ac}$ (4.0 ha) per installed $\mathrm{MW} .{ }^{\mathrm{xi}} \mathrm{We}$ refer to land use per unit of capacity as land-use intensity. Multiplying land-use intensity by estimated capacity yields an estimate of the total land area required for ground-based solar.

Our results represent conservatively high estimates of land requirements in 2030, 2040, and 2050 using the maximum predicted land requirement for each core scenario in each year. These land requirements are based on the cumulative capacity of solar energy facilities installed as of each year. Graphical representations of land requirements for the three core scenarios by state across all modeled years are provided in Appendix A.

Our analysis of land availability focuses on the regional availability of lands potentially suitable for solar development, with emphasis on previously disturbed and contaminated lands. We use a stepwise geographic information system framework. First, we spatially delineate the footprint of potentially available land for each technology type based on the exclusion criteria used by the

\footnotetext{
${ }^{x}$ A balancing (authority) area is defined as "The collection of generation, transmission, and loads within the metered boundaries of the balancing authority. The balancing authority maintains load resource balance within this area." 119 ${ }^{x i}$ The PV estimate is based primarily on analysis in Walston et al., ${ }^{122}$ which uses geographic information system (GIS) techniques to measure the total footprint of 192 UPV installations in the Midwest in 2018. The relationship between total footprint and nameplate capacity yields a total land-use requirement of about 7.5 ac (3.0 ha) per $\mathrm{MW}_{\mathrm{AC}}$. This estimate is supported by analysis in Bolinger, ${ }^{123}$ which also uses GIS techniques but measures the land directly occupied by arrays for 736 UPV installations across the United States in 2019. A median direct land-use requirement of $4.2 \mathrm{ac}(1.7 \mathrm{ha})$ per $\mathrm{MW}_{\mathrm{DC}}$ is calculated for systems with one-axis tracking, which equates to 5.5 ac (2.2 ha) per $\mathrm{MW}_{\mathrm{AC}}$ at a median inverter loading ratio (ILR) of 1.30. Accounting for non-array space used within the fenced PV system area (e.g., disturbed ground and operational facilities) would increase the area per MW $\mathrm{AC}_{\text {. }}$ A ratio of direct to total area of 0.73 , which broadly aligns with some anecdotal observations, would result in the same total footprint of $7.5 \mathrm{ac}$ (3.0 ha) per $\mathrm{MW}_{\mathrm{AC}}$ found in Walston et al. ${ }^{122}$ The CSP estimate of $10 \mathrm{ac}(4.0 \mathrm{ha})$ per $\mathrm{MW}$ AC is based on analysis in Ong et al. ${ }^{113}$ and Hartmann et al. ${ }^{118}$
} 
reV model. These exclusion criteria include slope, land cover type, land ownership and status, and amount of urban development. Next, starting with the potentially available lands footprint, we apply additional geospatial filters to identify previously disturbed areas that might be used for solar development (Table 1). Potentially suitable lands are first filtered by screening out areas protected from surface disturbance for natural or cultural resource protections, using the U.S. Geological Survey (USGS) Protected Areas Database (PADUS), Gap Codes 1 and 2. ${ }^{124}$ Then, remaining lands identified as developed or otherwise disturbed in land cover data ${ }^{125}$ are categorized as disturbed lands potentially suitable for solar development. The minimum parcel size assumed for PV development is the size of a single 90-m raster pixel used in the geospatial analysis (approximately 2 acres in size). The minimum area required for solar developments is likely somewhat larger than 2 acres; see the Uncertainties section on page 26 for additional discussion.

Table 1. Data and Filtering Criteria to Determine Suitability of Disturbed and Contaminated Lands for Solar Energy Development

\begin{tabular}{|c|c|c|}
\hline Data Set and Source & Purpose & Criteria \\
\hline $\begin{array}{l}\text { Protected Areas } \\
\text { Database }\end{array}$ & $\begin{array}{l}\text { To exclude areas protected for } \\
\text { natural and cultural resources from } \\
\text { available lands (USGS) }\end{array}$ & $\begin{array}{l}\text { Gap Codes } 1 \& 2 \text { excluded from } \\
\text { available lands }\end{array}$ \\
\hline $\begin{array}{l}2016 \text { LANDFIRE Existing } \\
\text { Vegetation Type }{ }^{125}\end{array}$ & $\begin{array}{l}\text { To filter available lands to suitable } \\
\text { disturbed lands, after excluding } \\
\text { protected areas (Protected Areas } \\
\text { Database) }\end{array}$ & $\begin{array}{l}\text { Land cover types considered to be } \\
\text { disturbed: } \\
\text { Developed } \\
\text { Developed (high intensity) } \\
\text { Developed (mod. Intensity) } \\
\text { Developed (low intensity) } \\
\text { Exotic/invasive species } \\
\text { Quarries, mines, wells, and pads }\end{array}$ \\
\hline Contaminated Sites ${ }^{126}$ & $\begin{array}{l}\text { To identify previously disturbed } \\
\text { lands that have been contaminated } \\
\text { and currently listed in a federal or } \\
\text { state remedial program, e.g., the } \\
\text { Resource Conservation and } \\
\text { Recovery Act (RCRA) or Superfund }\end{array}$ & $\begin{array}{l}\text { Suitable contaminated lands for solar } \\
\text { development are within the available } \\
\text { lands footprint and at least } 7.5 \text { ac in } \\
\text { size for } \mathrm{PV} \text { and at least } 500 \text { ac in } \\
\text { size and }>6 \mathrm{kWh} / \mathrm{m}^{2} / \text { day for CSP. }\end{array}$ \\
\hline
\end{tabular}

Siting installations on disturbed or contaminated lands is recommended for minimizing the landuse impacts of solar development (e.g., ${ }^{117,118}$ ). The USGS defines disturbed land as land in an altered and often non-vegetated state owing to prior disturbances. ${ }^{127}$ For the purposes of this study, disturbed lands include areas identified in the 2016 LANDFIRE program as developed areas, invasive species-impacted lands, and other types of non-vegetated lands such as quarries or gravel pits (Table 1). Disturbed lands are not designated by the U.S. Environmental Protection Agency (EPA) as reaching the necessary threshold to be considered environmentally contaminated, yet they still might not be suitable for productive agriculture or other beneficial use. 
One other category of previously disturbed lands considered here includes lands identified on federal and state lists as contaminated by improper handling or disposal of toxic and hazardous materials and wastes but remediated to make them suitable for some forms of reuse, such as industrial development. Such lands include Resource Conservation and Recovery Act and Superfund sites as well as landfills, abandoned mine lands, brownfields, and nonfederally-owned Resource Conservation and Recovery Act and Superfund sites. We evaluate the potential suitability of these contaminated sites for solar development using data from EPA's REPowering America's Land screening tool (Table 1). ${ }^{126}$ We filter contaminated lands to locations with a slope of less than $5 \%,{ }^{118}$ and we assume a minimum size of 7.5 ac (3.0 ha) for PV projects on contaminated lands. We assume CSP projects are at least $50 \mathrm{MW}$ in capacity and therefore require at least 500 ac (202 ha), with an additional restriction that insolation levels in CSP locations must be at least $6 \mathrm{kWh} / \mathrm{m}^{2} /$ day. ${ }^{128}$

Although the areas we identify as potentially suitable disturbed and contaminated lands pass a screening-level review for valuable resources (by excluding protected areas identified in the Protected Areas Database), actual solar siting requires location-specific and jurisdictional reviews and input from various stakeholders. Thus, although we identify these lands as potentially suitable for solar development, actual determination of suitability will require projectspecific analysis.

\section{Estimates of Land Requirements and Comparisons with Land Availability}

We calculate land requirements on a regional basis and then aggregate them to each state. Each state's projected deployment of ground-based solar varies in accordance with the economic optimization performed within the ReEDS model from 2020 to 2050. Estimates of land requirements and areas of land suitability within balancing areas at the target years $(2030,2040$, 2050) are provided in Appendix A. Maximum aggregated land-use requirements among the core scenarios at the target years are compared to the estimated areas of potentially suitable disturbed and contaminated lands. Scenario-based total land required for all modeled years, summed across all ground-based solar technologies, is also graphically illustrated by state in Appendix A.

Figure 9 shows national solar land-use projections for the three core scenarios from 2010 to 2050. In the scenario with the largest land requirement (Decarb+E), the total aggregated solar deployment area across the contiguous United States is approximately 10.3 million ac $(41,683$ $\mathrm{km}^{2}$ ) by 2050 - roughly equivalent to the combined surface area of Connecticut, Massachusetts, and Rhode Island. Table 2 shows that, in 2050, the maximum amount of land required among the three core scenarios is equivalent to just $6.4 \%$ of the area of potentially suitable disturbed lands; however, this maximum estimated land use area is about $20 \%$ larger than the area of all potentially suitable contaminated lands. In a larger context, maximum total land requirements across all technology types for ground-based solar in 2030, 2040, and 2050 are approximately $0.2 \%, 0.3 \%$, and $0.5 \%$, respectively, of the total contiguous U.S. surface area. Figure 10 compares the maximum modeled land requirement $(0.5 \%)$ with solar-suitable disturbed and contaminated land areas and examples of other areas in the United States. Table 3 shows maximum land requirements by state. The maximum total solar land requirements are not expected to exceed $5 \%$ of any state's land area by 2050 , with the exception of Rhode Island $(6.5 \%)$. 


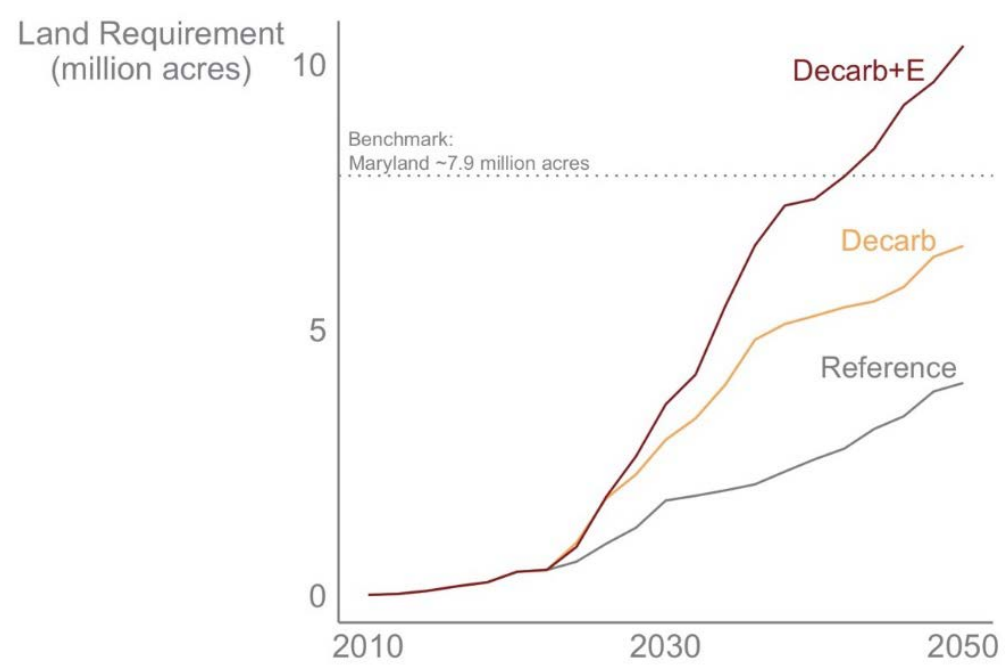

Figure 9. National solar land-use projections for the three core scenarios, 2010-2050

Table 2. Summary of Solar Energy Development Land Needs in 2030, 2040, and 2050 Aggregated Across the Contiguous United States

\begin{tabular}{cccc}
\hline $\begin{array}{c}\text { Solar Energy } \\
\text { Deployment }\end{array}$ & $\begin{array}{c}\text { Maximum Amount } \\
\text { of Land Required } \\
\text { Across Solar } \\
\text { Futures Study } \\
\text { Scenarios (ac) }\end{array}$ & $\begin{array}{c}\text { Percentage of Total } \\
\text { Potentially Available } \\
\text { U.S. Disturbed Lands }\end{array}$ & $\begin{array}{c}\text { Percentage of Total } \\
\text { Potentially Available U.S. } \\
\text { Contaminated Lands }\end{array}$ \\
\hline $\mathbf{2 0 3 0}$ & $3,578,000$ & $2.2 \%$ & $40 \%$ \\
PV & 19,000 & $<0.01 \%$ & $0.3 \%$ \\
CSP & $7,437,000$ & $4.5 \%$ & $83 \%$ \\
$\mathbf{2 0 4 0}$ & 22,000 & $0.1 \%$ & $1.4 \%$ \\
PV & & & \\
CSP & $10,292,000$ & $6.2 \%$ & $115 \%$ \\
$\mathbf{2 0 5 0}$ & 53,000 & $0.2 \%$ & $3.4 \%$ \\
PV & & & \\
CSP & & & \\
\hline 1
\end{tabular}

${ }_{1}$ PV deployment includes DUPV and UPV technologies.

2 Maximum cumulative land requirement estimated among the Solar Futures Study core scenarios. 


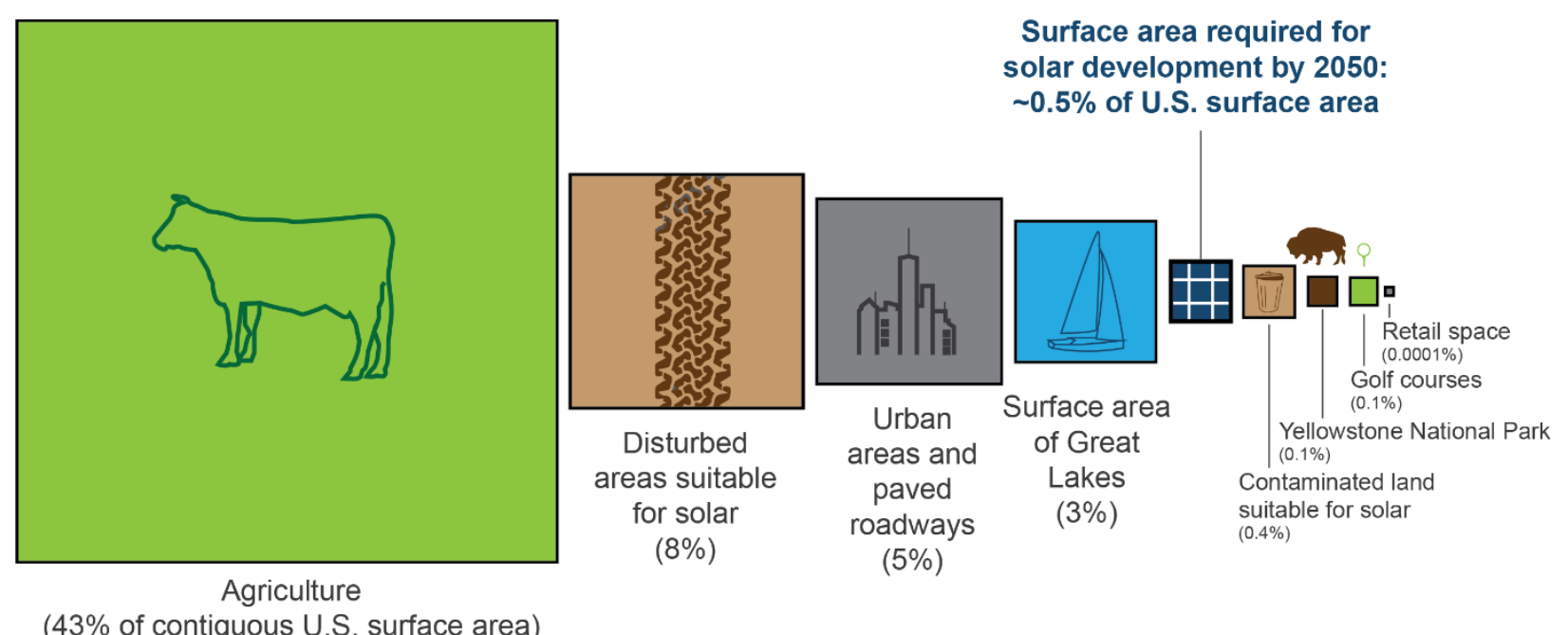

(43\% of contiguous U.S. surface area)

Figure 10. Maximum land use required for solar in 2050 in the Solar Futures Study scenarios compared with solar-suitable disturbed and contaminated areas and examples of other U.S. areas

Amounts of disturbed and contaminated lands depicted here represent the amounts suitable for solar energy development calculated in the Solar Futures Study. Sources: EPA, ${ }^{126}$ USDA, ${ }^{129}$ LANDFIRE. ${ }^{130}$

\section{Potential for Rural Economic Development, Social Justice, and Avoidance of Conflict with Other Land Uses}

Most of the contiguous 48 states contain enough potentially suitable disturbed lands for future ground-mounted solar projections through 2050 (Table 3), but not all states do, despite adequate potentially suitable disturbed and contaminated lands at the national level (Table 2). For example, many states do not have any suitable land area for CSP (Table 3 ), primarily because these states do not meet CSP insolation requirements ( $>6 \mathrm{kWh} / \mathrm{m}^{2} /$ day). Although some states do not have enough potentially suitable contaminated lands to meet maximum CSP and PV land requirements, development on contaminated lands could greatly contribute to meeting Solar Futures Study goals. These findings are consistent with previous DOE assessments of land requirements for utility-scale solar development. ${ }^{117,118}$ Many of the disturbed and contaminated lands identified as potentially suitable for solar development will not meet other siting requirements or requirements of project developers, local communities, or regulatory agencies. However, our analysis shows the potential of these lands to provide much of the area needed in the Solar Futures Study scenarios. Appendix A contains detailed results within balancing areas.

Many stakeholders have noted a preference for siting solar on nonproductive disturbed or formerly contaminated lands. These lands are often situated in rural areas or in marginal regions of urban areas, which may need economic revitalization. Siting a financially attractive project in an area without other productive land-use opportunities could improve temporary and permanent local economic conditions. Recognizing these potential advantages, EPA and DOE have explored the feasibility of renewable energy development on contaminated lands through the REPowering America's Land initaitve. ${ }^{126}$ When carefully implemented, using formerly contaminated lands (after cleanup, as needed) for solar can minimize stress on intact, undeveloped lands and - in some areas - improve soil stability and decrease potential health risks. Previously developed or contaminated lands may also have existing onsite infrastructure (e.g., roads, water service), potentially lower transaction costs, greater public support for 
development, and streamlined permitting and zoning processes, and they are often already close to roads, rail, and transmission lines. ${ }^{126}$

As solar development increases, more of it is expected to be in rural areas where an opportunity exists to target marginal or previously disturbed lands. Approximately $90 \%$ of projected Solar Futures Study PV deployment by 2050 is expected to be generated from UPV projects in rural settings. This development could benefit rural communities as an economically valuable local resource. ${ }^{131,132}$ Many rural development plans aim to invest in renewable energy on rural lands to boost economic development. ${ }^{132}$ The wind and solar industries have already begun investing in these rural areas. In fact, approximately two-thirds of existing utility-scale solar facilities tracked by the U.S. Energy Information Administration ${ }^{133}$ are in rural areas as defined by ReEDS. Solar is an economically valuable local resource with potential to benefit the local community, solar facility owners, and landowners leasing to solar facility operators. ${ }^{131}$ Powering a majority clean grid with large-scale PV can benefit these rural areas by increasing rural land use, providing tax benefits to rural communities, providing local workers with jobs, creating new markets for local contractors, diversifying income for landowners, and increasing available local resources. ${ }^{131,134,135}$ Solar projects also can serve underserved communities. In a study conducted in parts of Arizona and Mexico, researchers found that small-scale solar projects assisted women in meeting household and livelihood needs as part of community-level sustainability initiatives. ${ }^{136}$

Another siting consideration is avoiding sensitive ecological resources that may be affected by solar development. Our filtering criteria exclude areas protected for biodiversity conservation (PADUS, Table 1), removing many sensitive ecological areas from the potentially suitable lands for solar development. However, if the broader category of available lands identified by the reV model is eventually used for solar development, avoidance of other lands important for biodiversity conservation may need to be considered. For example, the U.S. Fish and Wildlife Service has designated over 111 million ac of critical habitat for 704 species listed as threatened or endangered under the Endangered Species Act. ${ }^{137}$ Approximately 90 million ac of designated critical habitat exist in the 48 contiguous states, of which approximately $20 \%$ (18 million ac) intersects lands identified as potentially available for utility-scale solar development estimated by the reV model. While critical habitat designation does not necessarily prohibit industrial land development, additional project siting considerations should be made within these areas to ensure solar development does not adversely impact sensitive species or critical habitat. ${ }^{137}$

Minimizing land-use conflicts with agriculture is also a goal. Avoiding solar siting on prime farmland - and instead focusing on marginal farmland or other disturbed areas - is one approach. Some states and local jurisdictions have developed guidelines and policies to restrict solar development on prime farmland, such as Minnesota's guidelines for solar energy production and prime farmlands. ${ }^{138}$ Another technique for minimizing conflicts that is receiving considerable interest is colocating solar with onsite restoration of native vegetation, providing habitat for pollinators such as bumblebees and possibly benefiting surrounding agriculture through increased pollination and pest-control services provided by managed and/or native pollinators (see Section 4.1.2). Seven or more states have developed pollinator "scorecards" to evaluate the quantity and quality of such pollinator habitat at solar facilities, in order to provide consistency and certification for facilities to be classified as "pollinator friendly." 139 Conflicts with 
agricultural interests many also be addressed by growing crops under and around solar panels, as described in Section 4.1.2.

\section{Uncertainties in Land-Use Estimates and Future Research Directions}

The following are uncertainties associated with future solar land-use estimates, aside from the uncertainties associated with the Solar Futures Study scenarios (see Section 2 of the Solar Futures Study $\left.{ }^{1}\right)$ :

- Increased Solar Technology Efficiency: The efficiency of solar cells and CSP facilities will likely increase over the study period, thus reducing land-use requirements. Assuming the reduction in land use would be approximately linear (e.g., a 10\% efficiency increase would reduce land use by $10 \%$ ), higher efficiency could decrease land use substantially.

- Non-Land-Based PV Technologies: Non-land-based PV technologies such as "floatovoltaics" 140 or solar cells incorporated into the sides of buildings (building integrated PV) ${ }^{141}$ or other infrastructure surfaces could decrease land use. Projections of their future use are not available, and thus their potential for reducing land requirements is not quantified but could be a productive future research topic.

- Energy Storage Impacts: Energy storage capacity increases to about 1,700 GW under the Decarb+E scenario in 2050 and, assuming the energy stored is obtained from groundmounted solar facilities, supplying energy for this storage capacity would require additional land for solar energy generation. The amount of additional land required for storage could increase the estimates herein substantially but will require further study to develop quantitative estimates.

- System Longevity: If goals for increasing the lifetime of PV modules and other system components are met, the same sites can be kept in service longer than were modeled in the Solar Futures Study. At end of facility life, it is expected that land previously used for solar can be returned to productive uses such as agriculture, unless the facility was constructed on previously contaminated lands.

- Life Cycle Considerations: Much is still unknown about solar life cycle land-use impacts, including land requirements of the full supply chain for manufacturing through EOL. Although the potential global impacts from mineral mining have been recognized, ${ }^{142}$ we found no quantification of land-use requirements related to mining solar-relevant minerals. Additionally, while there is hope for broad-scale recycling of solar materials at EOL, the fate of PV modules and other solar equipment is far from determined (see Section 5). Lack of recycling options for solar panels would result in increased downstream (disposal)-associated land use impacts if a high volume of solar panels are placed in landfills.

Considering the first four bullets, it is not clear whether our land-use results for the Solar Futures Study scenarios are overestimates or underestimates. Life cycle considerations are outside the scope of our analysis but would benefit from future study.

In addition, our calculation of available disturbed lands for PV development is based on the resolution of the input land cover data (90-m pixels). Each $90-\mathrm{m}$ pixel equates to approximately 2 ac, so the minimum PV parcel size is about 2 ac. However, UPV is generally considered to consist of facilities with a minimum capacity of $1 \mathrm{MW}$, and the corresponding minimum land required would be $7.5 \mathrm{ac}$. Nonetheless, the results reported in Table 2 do not apply a minimum 
PV parcel size to the GIS-based screening of available lands, because there is no robust citable source for PV development size thresholds, and there is great variability in PV project sizes in urban and rural settings. For example, a recent report indicates that utility scale may include smaller projects $(100 \mathrm{~kW})$ but that many developers and financiers would not invest in projects of less than $25 \mathrm{MW} .{ }^{143}$ To contextualize how a minimum parcel size threshold may affect the amount of available land for PV development, Table A-2 in Appendix A contains a comparison of disturbed land availability using conservative minimum parcel size thresholds of 7.5 ac $(\sim 1$ MW) for urban PV development and $15 \mathrm{ac}(\sim 2 \mathrm{MW})$ for rural PV developments. While these minimum size thresholds reduce the overall amount of available land and disturbed land, the potentially available disturbed land would still meet projected 2050 solar needs. 
Table 3. Availability of Disturbed and Contaminated Lands to Meet Maximum Net ${ }^{1}$ Solar Deployment in 2030, 2040, and 2050, by State and Solar Technology

\begin{tabular}{|c|c|c|c|c|c|c|c|c|c|c|c|}
\hline \multirow[b]{2}{*}{ State } & \multirow[b]{2}{*}{$\begin{array}{l}\text { Land Needed } \\
\text { for Solar as } \\
\text { Percent of } \\
\text { State Land } \\
\text { Area }\end{array}$} & \multicolumn{5}{|c|}{ CSP } & \multicolumn{5}{|c|}{ PV (DUPV and UPV) } \\
\hline & & $\begin{array}{l}2030 \\
\text { Land } \\
\text { Need } \\
\text { (ac) }\end{array}$ & $\begin{array}{l}2040 \\
\text { Land } \\
\text { Need } \\
\text { (ac) }\end{array}$ & $\begin{array}{l}2050 \\
\text { Land } \\
\text { Need } \\
\text { (ac) }\end{array}$ & $\begin{array}{l}\text { Potential } \\
\text { Disturbed } \\
\text { Land } \\
\text { Available for } \\
\text { CSP (ac) }\end{array}$ & $\begin{array}{l}\text { Potential } \\
\text { Contaminated } \\
\text { Land } \\
\text { Available for } \\
\text { CSP (ac) }\end{array}$ & $\begin{array}{l}2030 \\
\text { Land } \\
\text { Need (ac) }\end{array}$ & $\begin{array}{l}2040 \\
\text { Land } \\
\text { Need (ac) }\end{array}$ & $\begin{array}{l}2050 \text { Land } \\
\text { Need (ac) }\end{array}$ & $\begin{array}{l}\text { Potential } \\
\text { Disturbed } \\
\text { Land } \\
\text { Available for } \\
\text { PV (ac) }\end{array}$ & $\begin{array}{l}\text { Potential } \\
\text { Contaminated } \\
\text { Land } \\
\text { Available for } \\
\text { PV (ac) }\end{array}$ \\
\hline Alabama & $0.74 \%$ & - & 9,499 & 43,128 & - & - & 5,703 & 100,302 & 196,851 & $5,517,166$ & 40,735 \\
\hline Arkansas & $0.33 \%$ & - & 14,766 & 14,766 & - & - & 2,010 & 33,388 & 96,048 & $2,586,580$ & 18,855 \\
\hline Arizona & $0.48 \%$ & 3,049 & 3,505 & 34,331 & $2,399,098$ & $2,731,4842$ & 135,676 & 215,960 & 312,602 & $5,399,774$ & $2,737,590$ \\
\hline California & $0.55 \%$ & 13,720 & 9,655 & 4,883 & $2,930,086$ & 268,874 & 306,178 & 514,329 & 533,037 & $5,472,492$ & 617,554 \\
\hline Colorado & $0.11 \%$ & 300 & 2,680 & 11,188 & $1,497,196$ & 2,382 & 39,598 & 62,535 & 58,017 & $2,672,426$ & 27,212 \\
\hline Connecticut & $2.36 \%$ & - & - & - & - & - & 28,495 & 32,202 & 73,027 & 261,724 & 6,926 \\
\hline Delaware & $4.45 \%$ & - & - & - & - & - & 17,995 & 54,555 & 55,547 & 218,526 & 6,732 \\
\hline Florida & $3.29 \%$ & - & - & 543 & - & - & 448,632 & 936,835 & $1,126,931$ & $4,695,180$ & 219,018 \\
\hline Georgia & $0.50 \%$ & - & 59 & 569 & - & - & 91,585 & 136,998 & 184,964 & $6,223,300$ & 21,547 \\
\hline lowa & $0.42 \%$ & - & - & - & - & - & 34,629 & 62,589 & 150,683 & $3,329,102$ & 4,997 \\
\hline Idaho & $0.39 \%$ & - & - & - & 773,660 & - & 2,650 & 34,582 & 204,284 & $2,172,944$ & 581,383 \\
\hline Illinois & $0.90 \%$ & - & - & - & - & - & 167,397 & 227,734 & 320,071 & $3,832,176$ & 35,060 \\
\hline Indiana & $0.71 \%$ & - & - & - & - & - & 84,493 & 84,493 & 163,745 & $3,055,150$ & 75,956 \\
\hline Kansas & $0.13 \%$ & - & - & 3,595 & 333,276 & - & 65,238 & 65,238 & 65,978 & $4,700,026$ & 102,574 \\
\hline Kentucky & $2.52 \%$ & - & - & - & - & - & 181,530 & 489,785 & 635,645 & $1,754,846$ & 24,863 \\
\hline Louisiana & $0.87 \%$ & - & 27,637 & 92,612 & - & - & 73,417 & 121,719 & 146,598 & $3,575,836$ & 24,959 \\
\hline Massachusetts & $2.09 \%$ & - & - & - & - & - & 33,687 & 98,469 & 104,350 & 670,580 & 16,627 \\
\hline Maryland & $4.40 \%$ & - & - & - & - & - & 115,601 & 122,842 & 273,662 & 866,418 & 22,166 \\
\hline Maine & $0.07 \%$ & - & - & - & - & - & 5,718 & 6,856 & 14,127 & 701,490 & 4,642 \\
\hline Michigan & $0.70 \%$ & - & - & - & - & - & 121,644 & 218,386 & 252,629 & $3,560,912$ & 38,860 \\
\hline Minnesota & $0.17 \%$ & - & - & - & - & - & 28,374 & 83,175 & 85,130 & $3,771,980$ & 169,250 \\
\hline Missouri & $0.40 \%$ & - & - & - & - & - & 41,386 & 135,859 & 175,228 & $3,069,262$ & 86,632 \\
\hline Mississippi & $0.85 \%$ & - & 35,734 & 35,734 & - & - & 93,108 & 200,842 & 219,509 & $6,131,038$ & 11,213 \\
\hline Montana & $0.02 \%$ & - & - & - & - & - & 128 & 128 & 14,238 & $2,884,932$ & 233,608 \\
\hline
\end{tabular}




\begin{tabular}{|c|c|c|c|c|c|c|c|c|c|c|c|}
\hline \multirow[b]{2}{*}{ State } & \multirow[b]{2}{*}{$\begin{array}{l}\text { Land Needed } \\
\text { for Solar as } \\
\text { Percent of } \\
\text { State Land } \\
\text { Area }\end{array}$} & \multicolumn{5}{|c|}{ CSP } & \multicolumn{5}{|c|}{ PV (DUPV and UPV) } \\
\hline & & $\begin{array}{l}2030 \\
\text { Land } \\
\text { Need } \\
\text { (ac) }\end{array}$ & $\begin{array}{l}2040 \\
\text { Land } \\
\text { Need } \\
\text { (ac) }\end{array}$ & $\begin{array}{l}2050 \\
\text { Land } \\
\text { Need } \\
\text { (ac) }\end{array}$ & $\begin{array}{l}\text { Potential } \\
\text { Disturbed } \\
\text { Land } \\
\text { Available for } \\
\text { CSP (ac) }\end{array}$ & $\begin{array}{l}\text { Potential } \\
\text { Contaminated } \\
\text { Land } \\
\text { Available for } \\
\text { CSP (ac) }\end{array}$ & $\begin{array}{l}2030 \\
\text { Land } \\
\text { Need (ac) }\end{array}$ & $\begin{array}{l}2040 \\
\text { Land } \\
\text { Need (ac) }\end{array}$ & $\begin{array}{l}2050 \text { Land } \\
\text { Need (ac) }\end{array}$ & $\begin{array}{l}\text { Potential } \\
\text { Disturbed } \\
\text { Land } \\
\text { Available for } \\
\text { PV (ac) }\end{array}$ & $\begin{array}{l}\text { Potential } \\
\text { Contaminated } \\
\text { Land } \\
\text { Available for } \\
\text { PV (ac) }\end{array}$ \\
\hline North Carolina & $1.27 \%$ & - & - & - & - & - & 88,486 & 392,867 & 394,382 & $5,278,630$ & 14,158 \\
\hline North Dakota & $0.10 \%$ & - & - & - & - & - & 24,058 & 36,018 & 44,406 & $3,439,552$ & 2,110 \\
\hline Nebraska & $0.23 \%$ & - & - & - & - & - & 97,800 & 101,889 & 112,019 & $3,110,992$ & 78,739 \\
\hline New Hampshire & $0.88 \%$ & - & - & - & - & - & 8,633 & 22,779 & 50,185 & 284,880 & 1,147 \\
\hline New Jersey & $0.99 \%$ & - & - & - & - & - & 6,924 & 39,493 & 46,460 & 645,728 & 121,126 \\
\hline New Mexico & $0.06 \%$ & 10 & 9,113 & 26,422 & $2,048,696$ & $1,074,180$ & 18,024 & 17,799 & 13,664 & $2,175,718$ & $1,100,001$ \\
\hline Nevada & $0.10 \%$ & 1,785 & 1,100 & - & $3,678,096$ & 158,374 & 53,647 & 67,294 & 61,023 & $3,838,372$ & 164,063 \\
\hline New York & $0.81 \%$ & - & - & - & - & - & 86,048 & 195,200 & 253,204 & $2,044,416$ & 103,653 \\
\hline Ohio & $1.06 \%$ & - & - & - & - & - & 95,954 & 187,425 & 276,268 & $3,717,672$ & 25,440 \\
\hline Oklahoma & $0.44 \%$ & - & - & 18,928 & 213,898 & - & 75,409 & 112,448 & 172,301 & $5,693,936$ & 17,516 \\
\hline Oregon & $0.13 \%$ & - & - & - & 341,788 & - & 36,735 & 55,823 & 81,211 & $2,329,181$ & $1,054,427$ \\
\hline Pennsylvania & $0.98 \%$ & - & - & - & - & - & 360 & 137,091 & 281,288 & $1,663,470$ & 62,701 \\
\hline Rhode Island & $6.54 \%$ & - & - & - & - & - & 1,318 & 2,162 & 43,248 & 89,998 & 1,647 \\
\hline South Carolina & $4.06 \%$ & - & - & - & - & - & 302,341 & 560,455 & 780,244 & $3,526,486$ & 222,607 \\
\hline South Dakota & $0.19 \%$ & - & - & - & - & - & 377 & 83,041 & 91,037 & $3,731,440$ & 1,388 \\
\hline Tennessee & $1.31 \%$ & - & - & 2,829 & - & - & 51,587 & 54,804 & 342,998 & $2,749,216$ & 82,775 \\
\hline Texas & $0.86 \%$ & - & 19,724 & 107,030 & $8,336,526$ & 45,860 & 489,315 & $1,098,653$ & $1,322,869$ & $32,517,678$ & 246,054 \\
\hline Utah & $0.12 \%$ & 15 & 15 & 6,244 & $2,487,264$ & 2,520 & 13,705 & 49,491 & 56,623 & $2,896,994$ & 37,867 \\
\hline Virginia & $1.55 \%$ & - & - & 177 & - & - & 140,417 & 290,063 & 391,079 & $2,750,536$ & 79,662 \\
\hline Vermont & $0.21 \%$ & - & - & - & - & - & 917 & 5,078 & 12,222 & 154,896 & 1,987 \\
\hline Washington & $0.24 \%$ & - & - & - & - & - & 48,666 & 89,432 & 101,983 & $1,726,818$ & 344,202 \\
\hline Wisconsin & $0.75 \%$ & - & - & - & - & - & 103,775 & 131,864 & 261,032 & $2,800,868$ & 12,625 \\
\hline West Virginia & $0.52 \%$ & - & - & - & - & - & 76,571 & 76,682 & 79,519 & 288,666 & 46,100 \\
\hline Wyoming & $0.06 \%$ & - & - & - & 184,184 & - & 4,805 & 36,339 & 36,339 & $1,149,620$ & 10,048 \\
\hline
\end{tabular}

${ }^{1}$ Net of capacity additions and subtractions (decommissioning) in a given period.

${ }^{2}$ The large area of contaminated land in Arizona is attributable to classifying entire areas of Yuma Proving Ground and Goldwater Range as contaminated. 


\subsubsection{Opportunities to Improve Solar-Environmental Synergies with Regard to Land and Ecosystems}

Ground-based solar energy facilities are increasing in agricultural landscapes, due in large part to the siting of utility-scale solar energy development on former agricultural fields. ${ }^{144}$ Croplands are generally flat, open, and relatively undeveloped, making them ideal locations for solar energy development. ${ }^{144}$ The potential for future use is great; there are over 365 million ac of agricultural lands in the contiguous United States (in addition to the disturbed lands identified in Section 4.1.1). In fact, a recent study found that approximately $70 \%$ of utility-scale solar facilities in the Midwest are on sites formerly used for commercial agricultural production. ${ }^{122}$

There is increasing awareness of the pressure on land resources for food and energy production. Agricultural lands are under pressure owing to soil erosion caused by agricultural practices such as tilling and overgrazing. ${ }^{145}$ Increasing biodiversity loss indicates a need to protect additional land areas of high value for species of conservation concern. ${ }^{146-148}$ Studies also note that, in some cases, solar development has occurred in unsuitable locations, for example high-quality forested areas ${ }^{149}$ or near protected areas. ${ }^{150}$ Many recent research efforts have accordingly focused on strategies to improve the environmental compatibility of solar energy by integrating solar development with other beneficial land uses, which can maximize the co-benefits of multiple ecosystem services (including soil and water retention, carbon sequestration, and increasing biodiversity ${ }^{122}$ ) and improve surrounding agriculture. ${ }^{151-153} \mathrm{Few}$ estimates of the cost implications of dual use facility construction are available; one study estimated an increased cost of $\$ 0.07 / \mathrm{W}_{\mathrm{DC}}$ to $\$ 0.80 / \mathrm{W}_{\mathrm{DC}}$, with lower increases associated with $\mathrm{PV}$ plus pollinator habitat and higher increases associated with PV plus crops. ${ }^{154}$ Additional cost studies that account for other potential benefits provided by vegetation (such as water and soil retention benefits, changes in operation and maintenance costs, and changes in PV panel efficiency) are needed to fully understand the cost implications of various dual use strategies. These strategies, which are discussed below, are often interrelated and can be broadly categorized as vegetation management to provide ecosystem services at solar energy facilities, colocating agriculture (including grazing) and solar energy, and other opportunities such as installing solar panels on water.

\section{Vegetation Management to Provide Ecosystem Services}

With the large increase in U.S. utility-scale solar installations since about 2010, the feasibility and benefits of establishing a diverse plant community under solar panels and/or at the perimeters of solar facilities have been increasingly investigated as a means to mitigate land-use impacts. ${ }^{122,155-157}$ Conventional solar site preparation generally has involved grading and removal of all vegetation, to make installation easier, and then introduction of gravel or turf grass ground cover to minimize fire risk, dust generation, and panel shading. ${ }^{155}$ Establishing a varied, deeprooted plant community (often but not always consisting of species native to the facility location) has many potential ecological benefits. Such habitat has been termed "solar-pollinator" habitat ${ }^{152}$ although it can benefit many ecological and other endpoints in addition to pollinators. Solar-pollinator habitat has been characterized as representing a techno-ecological synergy, where technical and ecological benefits are achieved simultaneously. ${ }^{153}$ A study of potential ecosystem services provided by solar-pollinator habitat in the U.S. Midwest indicated a potential threefold increase in pollinator supply, $65 \%$ increase in carbon storage potential, $95 \%$ increase in soil/sediment retention, and $19 \%$ increase in water retention. ${ }^{122}$ However, these potential 
ecosystem services will vary by geographic region, and they remain largely unquantified for other U.S. regions. Other potential benefits include pest control, eased permitting requirements, increased aesthetic quality of the solar facility, and greater community acceptance, ${ }^{152,158}$ as well as potentially increased pollination services and crop yields for nearby agricultural lands. ${ }^{152}$

Cost impacts from installing solar-pollinator habitat remain understudied, although one analysis suggests an approximate $6 \%$ increase in the value of energy produced per acre from solar facilities with pollinator habitat established throughout, versus conventional vegetation management (assumed to be turf grass). ${ }^{159}$ This increase in value is due to efficiency gains from a cooler microclimate under solar panels. Lifetime costs to facility owners largely depend on the cost of the seed mixes used, extent of solar-pollinator habitat established at the facility, and sitespecific changes in required mowing frequency and vegetation management over the life of the facility.

Siegner et al. also estimated social and environmental benefits (in addition to those accruing to solar facility owners) from establishing pollinator-supportive habitat at solar facilities. ${ }^{159}$ The benefits they quantified include avoided carbon emissions, reduced soil erosion, additional groundwater recharge, and increased crop yields (although other benefits, such as avoided health impacts, could also be estimated). The authors found a cost benefit of about $13 \%$ for facilities with solar-pollinator habitat near pollinator-dependent soy crops, owing to higher soil retention and crop yields. Walston et al. also estimated substantial potential benefits for pollinatordependent crops near solar facilities owing to increased yields. ${ }^{152}$ Some assumptions (e.g., amount of crop yield increase) used in these studies lack empirical supporting data, although other studies of pollination benefit for soy crops support the increased yield assumptions. ${ }^{160}$ DOE's Solar Energy Technologies Office is supporting new research on the economic, ecological, and performance impacts of colocated pollinator plantings that may answer some of the outstanding questions regarding costs and benefits of various vegetation management practices at utility-scale solar facilities. ${ }^{161}$

\section{Colocation of Agriculture and Solar Energy}

In recent years, the U.S. Department of Agriculture has supported use of "integrated agricultural systems" to provide improved agricultural sustainability. ${ }^{162}$ The colocation of solar energy and agriculture, often termed "agrivoltaic systems," can be considered a form of integrated agricultural systems that improve the total value of these dual-use sites from energy and food production. ${ }^{163-167}$ In some locations, agrivoltaic systems can decrease yields because of crop shading, but for some crops the microclimate created by the solar panels can benefit vegetation growth and agricultural yields. Additionally, a recent study showed increased PV panel efficiency when vegetation is present under the panels, ${ }^{167}$ although this effect requires further investigation. Overall, combined energy and crop production from agrivoltaic systems can increase land productivity by $70 \% .{ }^{168}$

Dinesh and Pierce found that, in the United States, from 40 to $70 \mathrm{GW}$ of PV could be supported if farms growing lettuce (a shade-tolerant crop) converted to agrivoltaic systems. ${ }^{164}$ Another study showed that PV arrays benefited the growth and production of crops such as Chiltepin peppers (Capsicum annuum var. glabriusculum), jalapenos (C. annuиm var. annuиm), and tomatoes (Solanum lycopersicum var. cerasiforme) by increasing yields and reducing water requirements while creating cooler microclimate conditions that improve solar energy 
production. ${ }^{167}$ Novel systems for combining agriculture and PV energy production are being demonstrated to increase crop yields even for shade-intolerant crops. ${ }^{169}$

In many locations, rural development guidelines recommend avoidance of prime farmland (e.g., ${ }^{138}$ ) and focusing on areas of marginally productive or disturbed soils, so solar development locations may not be the most suitable sites for crop production. However, methods are being developed to maximize the efficiency of solar fields for colocated agricultural production. ${ }^{163}$ For example, water used for cleaning panels can be conserved for irrigation to benefit soil moisture. In semi-arid pastures with wet winters, agrivoltaic systems increase water use efficiency, where water is stored in shaded areas of the field. ${ }^{170}$ Another potential benefit of agrivoltaic systems is to provide off-grid power to rural communities, increasing their resiliency while adding economic value to the crops produced. ${ }^{168}$

Approximately $26 \%$ of Earth's terrestrial surface is used for livestock grazing. ${ }^{171}$ If done improperly, livestock grazing can lead to negative ecosystem impacts such as intensified desertification of rangeland; ecologically sustainable grazing requires careful management to maintain light to moderate intensity. ${ }^{172}$ Grazing is another form of agricultural land use that is proving to be compatible with PV facilities. ${ }^{173-175}$ Solar panels placed in pasturelands open for grazing have a positive impact on soil moisture and biomass. ${ }^{170}$ Solar grazing can benefit livestock, because the PV facilities provide food and shade, and they can decrease water needs. ${ }^{174,176}$ Grazing can reduce solar facility operation and maintenance costs by decreasing the need for mowing. Well-managed grazing has proven to benefit plant diversity through a natural process of winter and spring sheep grazing. ${ }^{177}$ To date, most solar grazing operations have employed sheep. ${ }^{175}$ Research is also being done on combining rabbit farming with solar energy production. ${ }^{178}$ Additionally, DOE's Solar Energy Technologies Office has recently funded research on the feasibility of developing solar facilities that will support cattle grazing. ${ }^{161}$

Honey production may also be a natural agricultural pairing for solar facilities. The colocation of beekeeping operations with solar facilities that have established pollinator-friendly vegetation could provide multiple benefits to honeybees and native pollinators. ${ }^{159}$ By establishing varied plant species that flower from spring through fall, among other requirements, these solar facilities would receive high scores on state pollinator-friendly scorecards. ${ }^{179}$ In addition to benefiting apiary operations, honeybee hives likely benefit surrounding agriculture by providing pollination services. ${ }^{179}$ There are questions as to whether the presence of honeybee colonies would adversely impact native bees, although studies showing these effects are inconclusive. ${ }^{180}$ In a study where both native and managed bees were present, native bee abundance and species diversity positively correlated with honey production, indicating that locations supporting successful honeybee colonies also supported successful wild bee communities. ${ }^{181}$

\section{Floating Photovoltaic Systems}

Floating PV systems, also known as "floatovoltaics," provide an alternative to land-based PV systems. Floating PV systems may produce energy more efficiently than land-based systems owing to lower operating temperatures; performance is also enhanced because of the lower temperatures that result from higher wind speeds which occur over water. ${ }^{140,182,183}$ Siting floating PV on water also reduces shading loss and dusting of panels. Floating PV systems may have positive ecosystem services for the hosting water body overall, reducing algal blooms and decreasing the rate of water evaporation. ${ }^{140,182,183}$ Potential long-term impacts to aquatic 
ecosystems require further investigation. ${ }^{184}$ Challenges associated with floating PV systems include susceptibility to fouling organisms, corrosion, and high maintenance costs. ${ }^{140,182}$

To date, most floating PV systems have been installed in enclosed freshwater reservoirs (often associated with artificial dams) and small lakes. Deployment of floating PV systems in the marine environment has been infrequent. The cumulative global installed capacity of floating PV rose from $132 \mathrm{MW}$ in 2016 to $1.1 \mathrm{GW}$ in mid-2018; Asia had the highest installed capacity, followed by Europe. ${ }^{185}$

Spencer et al. estimated the potential electricity requirements that could be provided from floating PV systems on suitable human-created water bodies in the United States. ${ }^{182}$ Suitable water bodies were defined as having a surface area greater than $1 \mathrm{ac}$, depth greater than or equal to $7 \mathrm{ft}(2 \mathrm{~m})$, and transmission lines within $80 \mathrm{~km}(50 \mathrm{mi})$ and being used for recreation, navigation, fish and wildlife, or tailings storage. If equipped with floating PV systems, the area of these suitable water bodies could produce almost $10 \%$ of current national generation. These systems could be particularly useful in areas with high land-acquisition costs and electricity prices.

Another recent study estimated the potential for use of the $6,350-\mathrm{km}$ California canal network for generating electricity using PV mounted over the canals. ${ }^{186}$ The authors estimated that the net present value of this system would exceed the value of conventional overground solar by $20 \%-$ $50 \%$, and that the system would reduce annual evaporation by an average of $39,000 \mathrm{~m}^{3}$ per $\mathrm{km}$ of canal. Such systems show particular promise for water-constrained areas such as California.

\subsection{Water Requirements}

Water is a key sustainability factor for electricity generation. The power sector accounted for $41 \%$ of total U.S. water withdrawals in $2015 .{ }^{187}$ Spatial and temporal variations in water supply (e.g., from drought, climatic changes) increase the importance of considering water use in energy scenarios. Water availability can constrain power plant operations; for instance, without enough cooling water, thermal power plants cannot operate safely. ${ }^{188}$ A version of ReEDS has been created to account for water availability and its effect on generation. Running ReEDS under water-constrained conditions requires a simulated plant to obtain access to water over the entire plant lifetime at the time of construction. To model this, ReEDS uses water-constraint supply curves that reflect the impact of water rights, the cost of access to water, and the impact of water seasonal variability on generation decisions when the plant is built.

For the analysis reported in this section, all the Solar Futures Study core scenarios were run with the version of ReEDS including water constraints (and thus differ in this way from ReEDS results reported in the main Solar Futures Study). Results show that water withdrawals decline over time, mainly from retirements of coal, nuclear, and natural gas combined-cycle plants (Figure 11). The Decarb+E scenario achieves the lowest yearly water withdrawals, declining from 48,500 billion gals/yr (bgal/yr) in 2010 to 6,040 bgal/yr in 2050; this is roughly equivalent to reducing annual power sector withdrawals of 51 times the Hoover Dam's capacity (2010) to withdrawals of only six times that capacity (2050). Over the 2010-2050 time frame, CSP never contributes more than $1 \%$ of total power-system withdrawals. Water withdrawals for PV generation are only for panel washing activities and are effectively zero when compared to other technologies. ${ }^{189}$ However, CSP can account for a large portion of state-level power-sector water 
withdrawals even when dry cooling technologies are used (some water is still needed), rising to almost 100\% of power-sector withdrawals in Colorado and New Mexico starting in 2040 for the Decarb scenario (Figure 12). These values are still less than current power-sector water withdrawals in both states, given the reliance on thermal (fossil) power plants in both states. There are minor differences $(\sim 3 \%)$ in water withdrawals between water-constrained and nonwater-constrained ReEDS runs; water constraints affect system build-out, but not drastically for a given year. Also, the difference in overall system price between water-constrained and nonwater constrained runs is minimal ( $\sim 0.50 / \mathrm{MWh}$ in a given year).

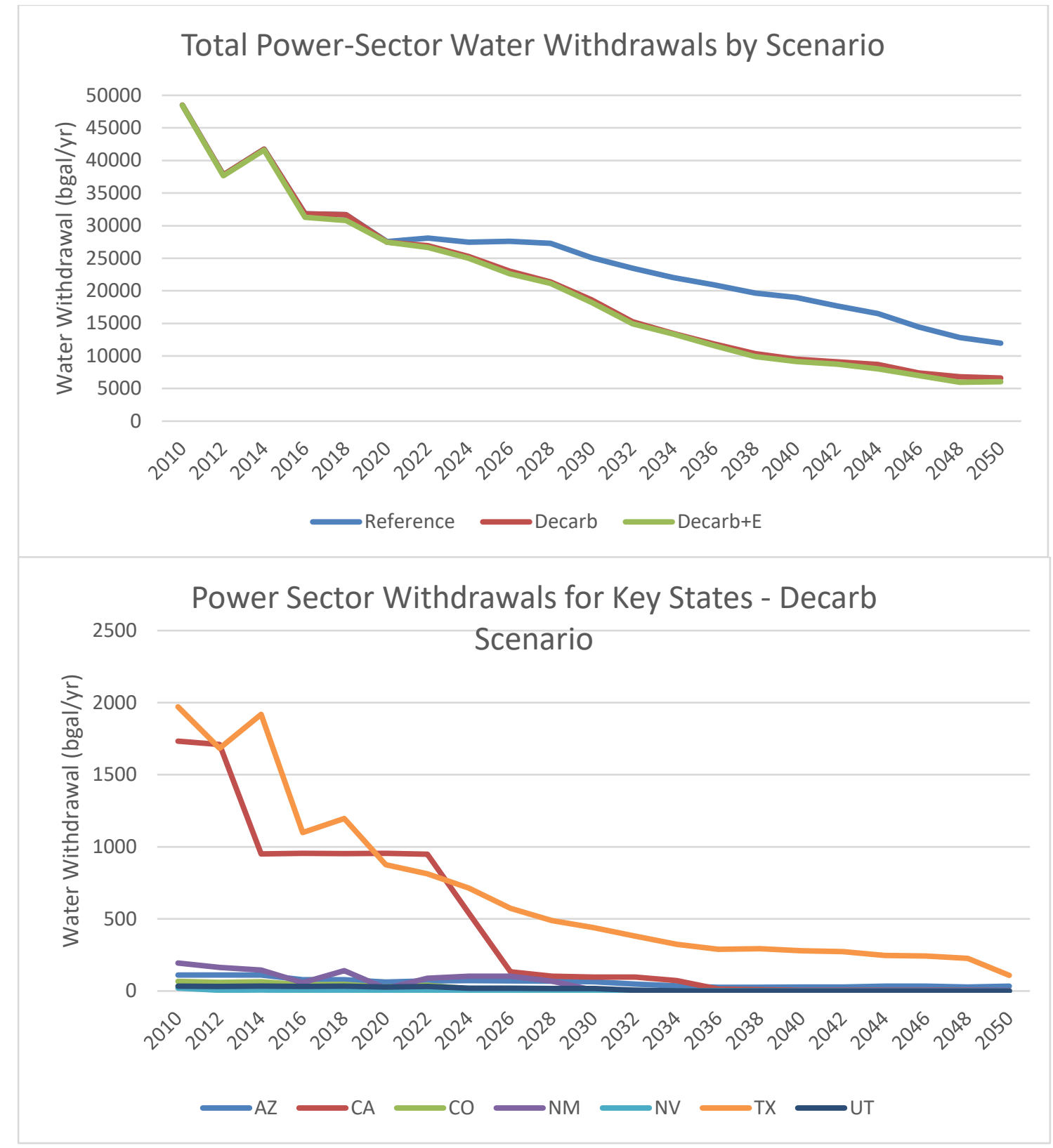

Figure 11. Total U.S. power-sector water withdrawals under the Solar Futures Study core scenarios (top) and withdrawals for key states in the Decarb scenario (bottom), assuming water constraints 


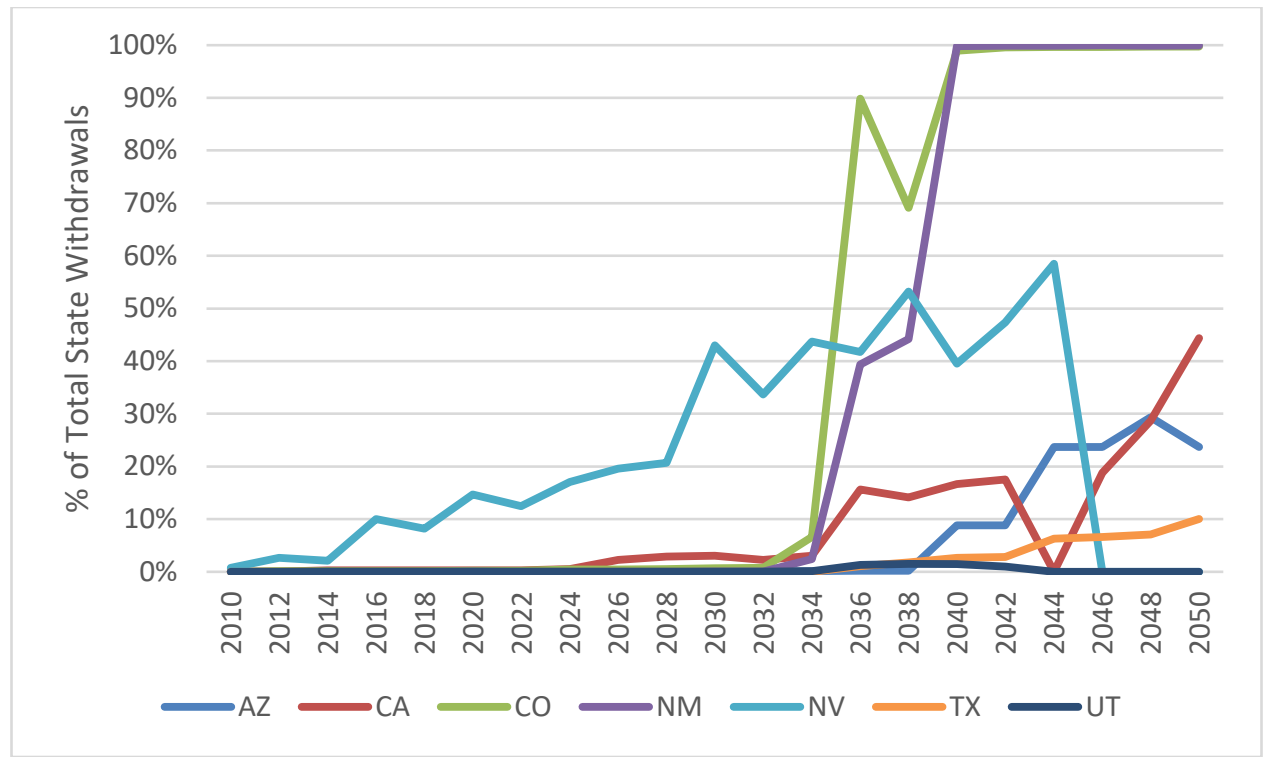

Figure 12. CSP water withdrawals as percentage of total power-sector water withdrawals in key states in the Decarb scenario

\subsection{Estimated Air-Quality Benefits}

Here we present order-of-magnitude monetary estimates of the air-quality benefits of the Solar Futures Study scenarios, based on reduced electricity-generation and vehicle emissions. Our simplifying assumptions and methods are detailed in Appendix C.

\subsubsection{Results Summary}

Figure 13 and Figure 14 summarize the results. In the Decarb scenario, reducing air pollution from electricity generation results in air-quality and health benefits worth roughly $\$ 300$ billion, based on the discounted value of all emission reductions (compared with the Reference scenario) between 2021 and 2050. Approximately $\$ 100$ billion of additional health benefits could be realized from the Decarb+E scenario owing to the replacement of gasoline and diesel vehicles by electric vehicles and the associated reduction in pollutant emissions. Only a small portion of total vehicle air pollution damages are eliminated under the Decarb+E scenario. The remaining damages are largely due to heavy-duty diesel emissions, because the Decarb+E scenario focuses primarily on electrifying light-duty vehicles. Vehicle electrification is held constant between the Reference and Decarb scenarios. 


\section{NPV Health Damages (Billion 2018\$)}

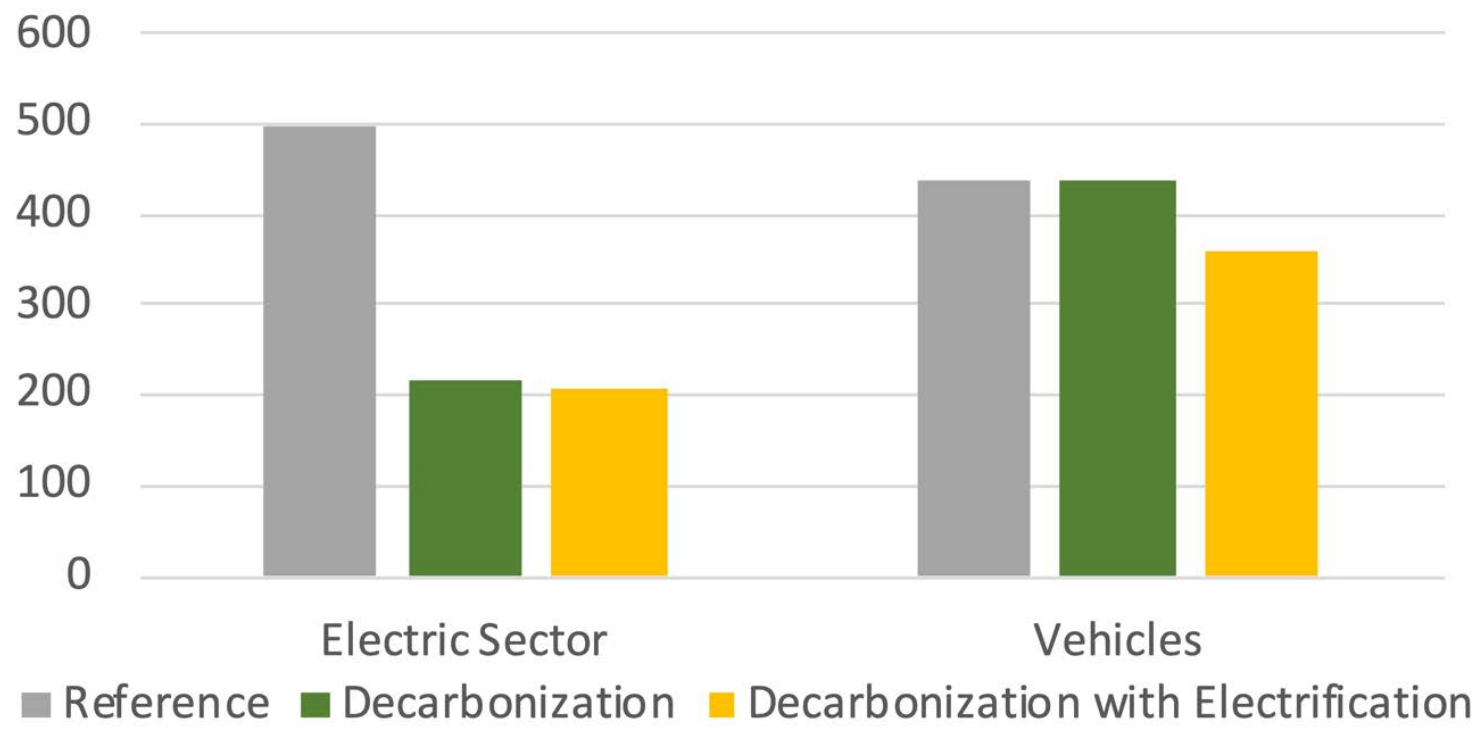

Figure 13. Net present value of health damages from electric-sector and vehicle emissions, 2021-2050

NPV Benefits (Billion 2018\$)

Decarbonization

Decarbonization with

Electrification

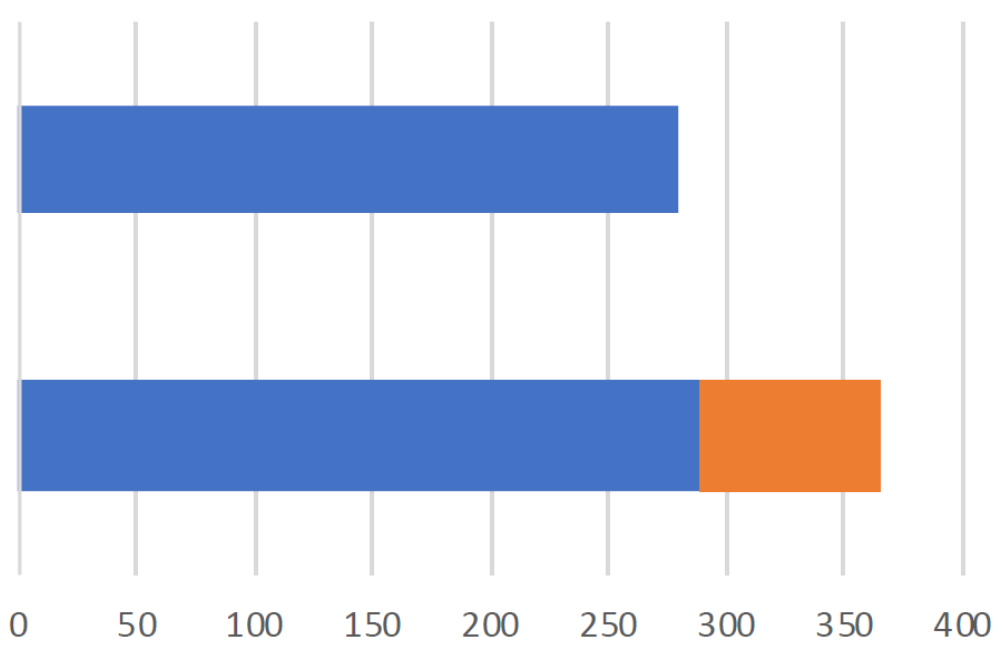

Electric Sector Benefits - Transportation Emission Benefits

Figure 14. Net present value of the benefits from the Decarb and Decarb+E scenarios 


\subsubsection{Approach and Discussion}

Reducing air pollution helps reduce heart attacks, asthma, hospitalizations, and deaths as well as lost work and school days. Air pollution can also damage agricultural productivity, and emissions of heavy metals can lead to neurological damage. An in-depth discussion of these impacts is available. ${ }^{190} \mathrm{We}$ focus on a subset of air pollution impacts, primarily the impact of particulate matter (PM) on premature mortality, but for more context regarding various damage pathways see Fann et al. ${ }^{191}$ Of outdoor air pollutants, PM is the leading contributor to increased premature mortality and therefore accounts for the vast majority of monetized damages. We analyze the impacts of three important pollutants: directly emitted PM as well as sulfur dioxide $\left(\mathrm{SO}_{2}\right)$ and nitrogen oxides $\left(\mathrm{NO}_{\mathrm{x}}\right)$, which can both be transformed into $\mathrm{PM}$ after their release through chemical reactions in the atmosphere. Electricity generation is a major U.S. source of $\mathrm{SO}_{2}$ and $\mathrm{NO}_{\mathrm{x}}$, and vehicles are a major source of $\mathrm{NO}_{\mathrm{x}}$ and directly emitted PM. Although we focus on a subset of pollutants and damage pathways, this subset captures a large portion of the total value of reducing emissions.

We estimate the value of emissions reductions across the full study period (2021-2050). The forward-looking scope means we must capture the dynamics of changes to electricity-generating plants and vehicles. For example, replacing an old vehicle provides much greater health benefits than replacing a new vehicle that already contains state-of-the-art emission-control systems. In fact, the differences in emissions rates between old and new vehicles can span orders of magnitude; thus, it is critical to track emission rates as they change over time. Similarly, and for certain pollutants, emissions rates can vary by orders of magnitude across electric power plant types (e.g., coal versus natural gas). Fortunately, electric-sector pollutant emissions are calculated directly within the Solar Futures Study scenario modeling, so variations in emissions rates between power plant types are taken into account. In contrast, we must estimate vehicle emissions externally to the scenario modeling. We use the total fuel use specified in the Reference and Decarb+E scenarios and estimated future vehicle emission rates, developed from a default formulation of the EPA MOtor Vehicle Emission Simulator (MOVES) model, ${ }^{192}$ to estimate total vehicle emissions by year.

Over the past two decades, $\mathrm{SO}_{2}$ and $\mathrm{NO}_{\mathrm{x}}$ emissions from the electricity sector have declined dramatically. For example, in 2020, the 3,100 premature deaths and $\$ 40$ billion of air pollution health damages from electricity generation accounted for less than $10 \%$ of the damages from the sector in $2005 .{ }^{193}$ Despite this progress, substantial health benefits can still be realized if powersector emissions are further reduced. The Decarb scenario anticipates the elimination of greater than $85 \%$ of power-sector $\mathrm{SO}_{2}$ and $\mathrm{NO}_{\mathrm{x}}$ emissions by 2035, with complete elimination by 2050 . $\mathrm{NO}_{\mathrm{x}}$ emissions are shown in Figure 15, and $\mathrm{SO}_{2}$ emissions are shown in Appendix C. Emissions associated with renewable combustion turbines are omitted from this analysis. Overall fuel use from renewable combustion turbines is expected to be fairly low, so this omission should not have a large impact on the national totals. However, if these turbines are powered by biofuels (rather than hydrogen), they may have important local impacts on air quality, which may also be important to consider from an environmental justice perspective. 


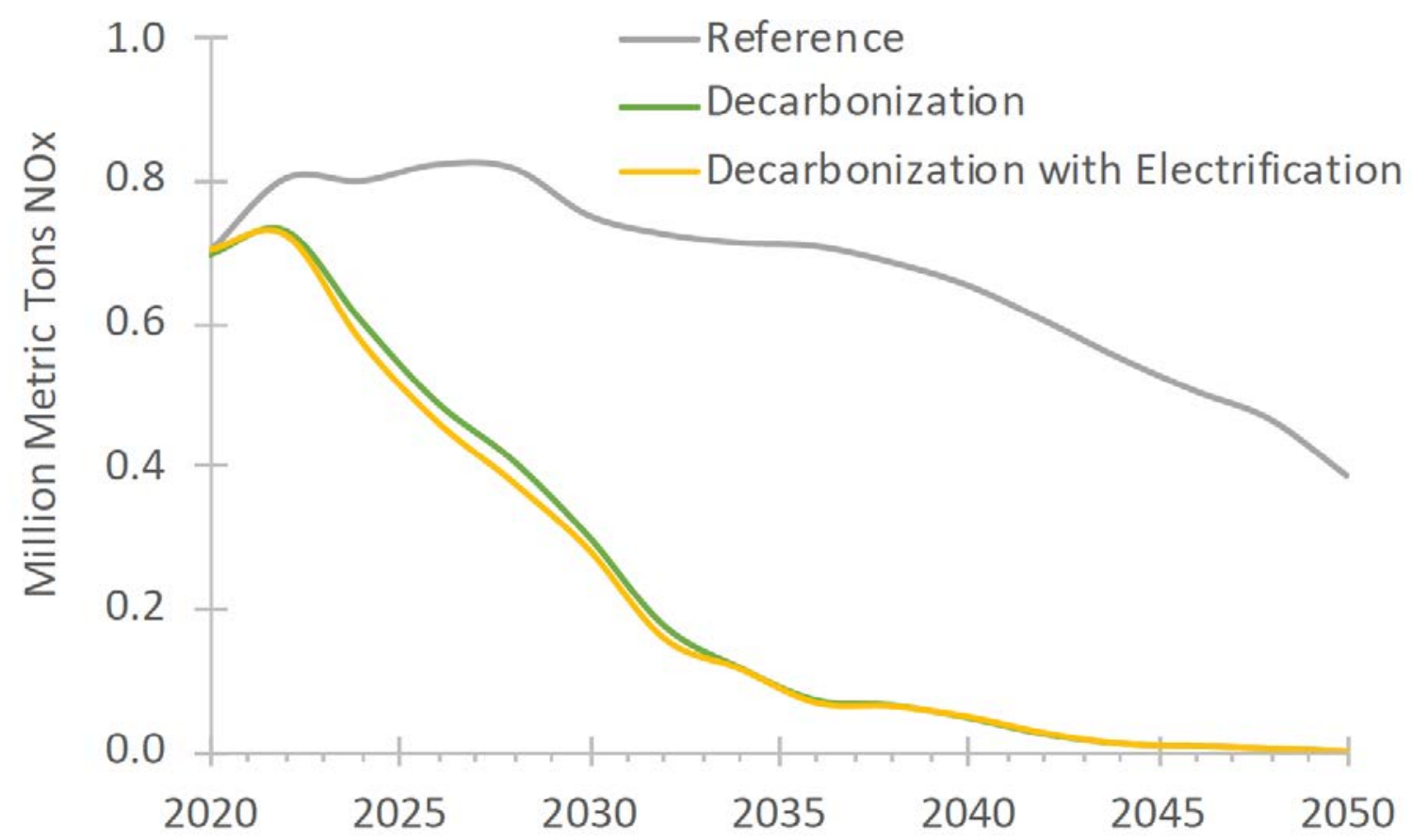

Figure 15. Total $\mathrm{NO}_{x}$ emissions from the power sector in the Solar Futures Study core scenarios

Emissions from vehicles have also declined dramatically over the past two decades. Figure 16 shows the observed decline in U.S. on-road-fleet average $\mathrm{NO}_{\mathrm{x}}$ emissions per unit of fuel input ("emission rate") due to emissions controls on cars and trucks. ${ }^{x i}$ Declines in PM emission rates have been even more rapid (see Appendix C). Fleet emission rates are expected to continue declining, as vehicle turnover leads to more vehicles equipped with state-of-the-art emissionscontrol equipment. Figure 17 shows estimated $\mathrm{NO}_{\mathrm{x}}$ emission rates from light-duty gasoline vehicles and heavy-duty diesel trucks into the future (PM rates are shown in Appendix C). The forecasted emission rates roughly match recent observed fleet-average rates in 2020, and then continue to decline through 2030.

Combining fuel use from the Reference and Decarb+E scenarios with the fuel-normalized fleet average emission rates allows us to develop order-of-magnitude estimates of total $\mathrm{NO}_{\mathrm{x}}$ and $\mathrm{PM}$ emissions from the vehicle sector (Figure 18; see Appendix C for total PM emissions). Most vehicle emissions reductions in the Decarb $+E$ scenario occur after 2030, which contrasts with earlier reductions in power-sector emissions.

\footnotetext{
xii In accordance with the goal of an order-of-magnitude estimate of vehicle emissions, we only consider gasolinepowered cars and diesel-powered heavy-duty vehicles, because only small amounts of other fuels are used in those vehicles.
} 


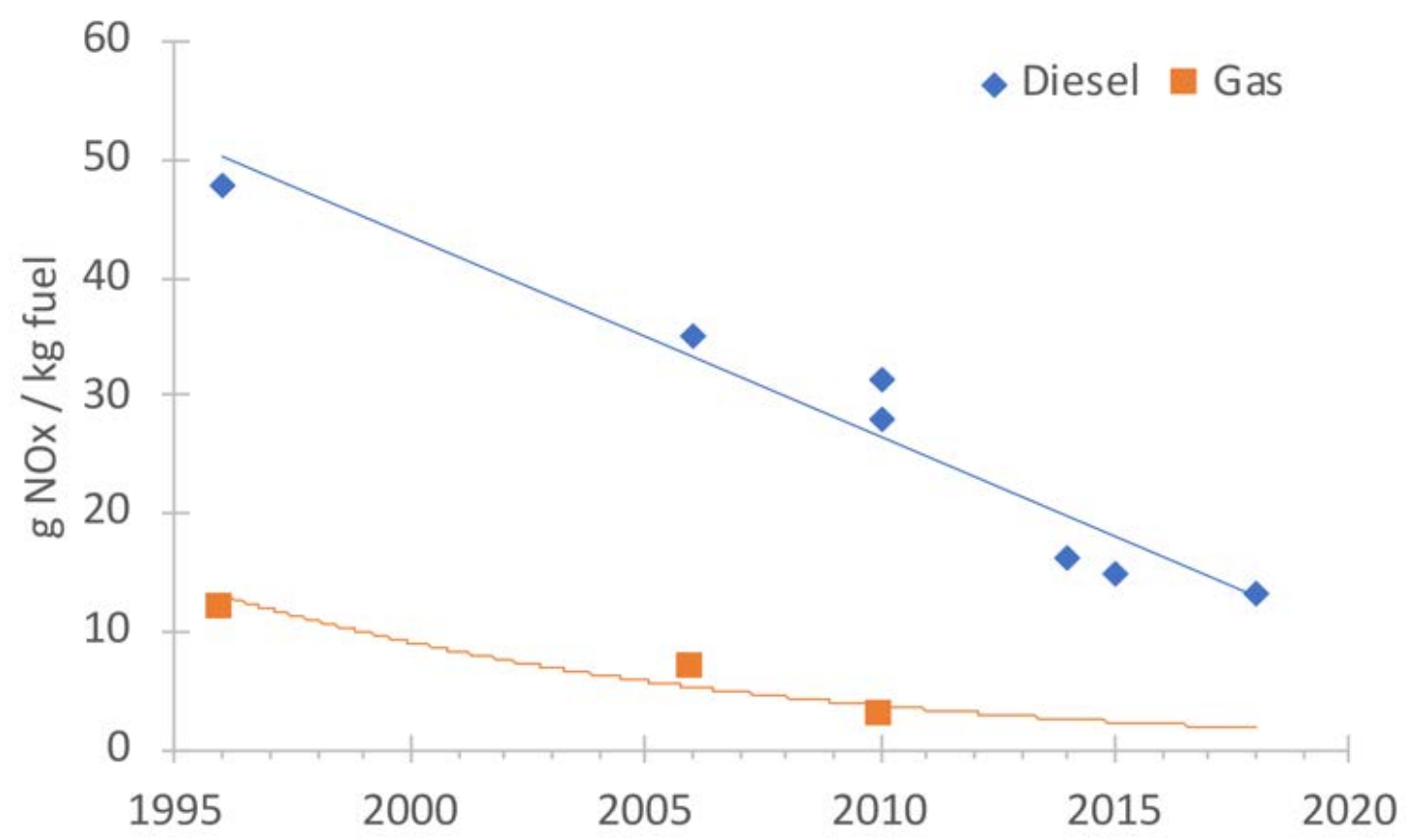

Figure 16. Fleet-average $\mathrm{NO}_{\mathrm{x}}$ emission rates of U.S. light-duty gasoline vehicles and heavy-duty diesel trucks, based on observed emissions ${ }^{194-197}$

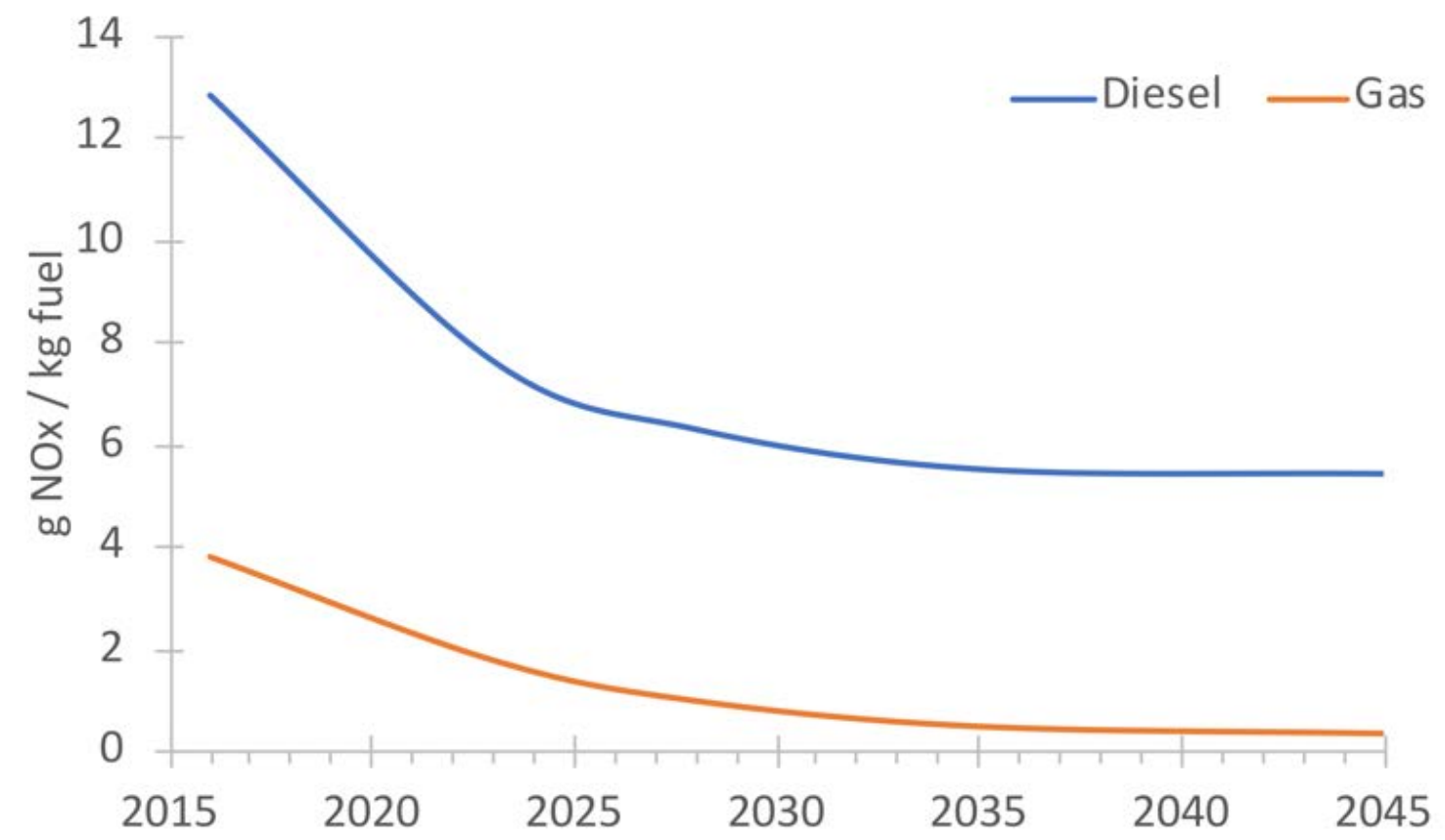

Figure 17. Future fleet-average $\mathrm{NO}_{x}$ emission rates for U.S. light-duty gasoline vehicles and heavyduty diesel trucks based on the EPA MOVES model 


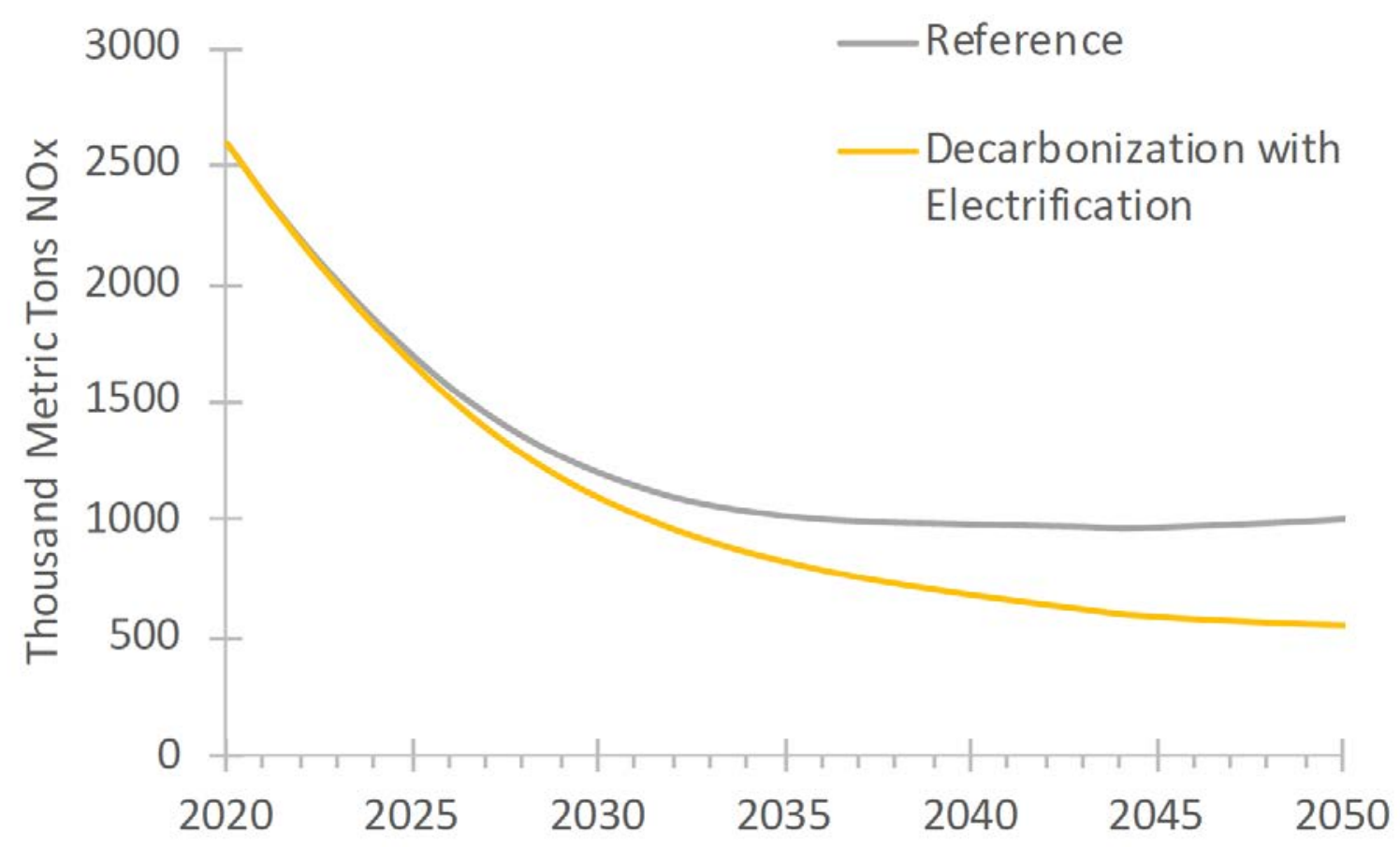

Figure 18. Total vehicle $\mathrm{NO}_{\mathrm{x}}$ emissions in the Reference and Decarb+E scenarios

We use these results to estimate the health impacts of emissions in each scenario. In the Reference scenario, the present value of cumulative air-quality health damages from 2021 to 2050 is roughly $\$ 500$ billion each for the power sector and vehicle sector (Figure 13). The Decarb scenario saves roughly $\$ 300$ billion in cumulative health damages due to reductions in power-sector pollution, and the Decarb+E scenario saves roughly an additional $\$ 100$ billion in cumulative health damages from reduced vehicle emissions (Figure 14).

The Decarb+E scenario does not eliminate emissions from the vehicle sector in the same manner as the Decarb and Decarb+E scenarios eliminate emissions from the power sector. The additional Decarb $+E$ savings mostly derive from the electrification of light-duty vehicles (in which gasoline use is reduced by $\sim 75 \%$ by 2050 ). Additional savings would be created by electrifying a greater portion of diesel trucks (the Decarb+E scenario reduces diesel use by roughly $40 \%$ by 2050 ) and electrifying all vehicle types sooner. The savings are particularly sensitive to the timing of electrification, because fleet-average emission rates decline with time; thus, retiring an average truck in 2025 would provide a greater benefit than retiring an average truck in 2035 . For example, an electrification program that focused on replacing older trucks or other high-emitting vehicles in the near term would reap greater cumulative health benefits owing to retirement of higher-emitting vehicles and benefits accumulating over a greater number of years.

\subsubsection{Emission Reduction Valuation}

We estimate damages from emissions, or the total benefits of avoided emissions, using literaturebased "marginal emission damage factors" or "benefit-per-ton" estimates. ${ }^{190,198}$ For example, the damage factor we use to value 1 metric ton of $\mathrm{NO}_{\mathrm{x}}$ emissions from vehicles is roughly $\$ 7,000 .{ }^{198}$ The damage factors consider premature mortality and morbidity (all other health effects that are not mortality), although by far the largest monetary damages from air pollution are due to premature deaths. The value of eliminating a premature death is calculated based on the value of 
reducing the risk of mortality for each individual across the population. This concept of value is often referenced as the "value of statistical life." The overall "benefit-per-ton" approach is discussed elsewhere. ${ }^{190}$

Estimates of marginal damage factors depend on the health risks associated with exposure to the pollutant and the size of the total population exposed to the pollutant. These risks vary significantly by pollutant, and by the location of the emission. Because we are producing orderof-magnitude estimates, we use literature-based national average marginal damage factors for three different pollution sources (power plants, light-duty gasoline vehicles, and heavy-duty diesel vehicles). A more detailed analysis would estimate emission benefits based on the location and height above ground of emissions. In our case, the location information is embedded in the national average estimate for each source. Our national marginal damage factors are based on two sources. ${ }^{190,198}$ Details can be found in Appendix C.

\subsection{Circular Economy Approaches During the PV Use Phase}

Figure 3 presents the CE approaches currently being applied in the installation and use of PV systems. The emergence of commercial entities leveraging digital platforms and information systems ${ }^{199}$ and business models ${ }^{200-203}$ has helped delink ownership of PV modules from the service provided by the PV system (generation of PV electricity). For example, $39 \%$ of modules in U.S. residential markets are owned by third-party owners. ${ }^{204}$ Delinking ownership of the PV system from the consumption of PV electricity is aligned with the product service system (PSS, aka third-party ownership) strategy for a CE. ${ }^{205}$ PSS lowers the cost barrier and upfront capital costs for individual customers to consume PV electricity, ${ }^{206}$ transfers the economic and operational burdens of purchase and maintenance from the individual customer to the third-party owner of the PV system, ${ }^{207}$ and could address social and energy justice issues by widening access to PV electricity. By operating at a greater scale of PV ownership and maintenance than an individual owner, the third-party owner may be better positioned to realize the benefits from economies of scale and learning, which can further decrease the cost of PV electricity. Despite the promise of PSS for PV, there is a need to address information barriers that prevent financiers from evaluating the economics of PV PSS projects, ${ }^{200}$ optimally design policy incentives to accelerate PSS for PV systems, ${ }^{208,209}$ increase funding for PSS PV projects, ${ }^{200}$ and continually assess the environmental and social efficacy of PV PSS projects at a national scale.

Repowering refers to the replacement of aging PV system components with newer components to improve performance and durability, address maintenance issues (e.g., hard-to-find parts), extend project lifetime, and prevent outages due to increased frequency of faults in older components. ${ }^{210-213}$ Repowering helps increase renewable electricity generation over the lifetime of the PV project with decreased maintenance of parts. ${ }^{211}$ For example, inverters for $100 \mathrm{GW}_{\mathrm{DC}}$ of PV systems are expected to be repowered by 2025 in Europe, ${ }^{214}$ because inverter lifetimes (10 to 15 years) are shorter than PV system lifetimes (25 to 30 years). Repowering should be combined with proper EOL management of decommissioned components (e.g., recycling or reuse of decommissioned components) to prevent unfavorable outcomes when an influx of decommissioned PV systems (from repowering) is landfilled or improperly managed. For example, in 2017, a 30\% increase in used PV modules on a platform for trading secondhand modules was ascribed to decommissioned modules from repowering. ${ }^{210}$ Importantly, repowering can be a material demand reduction (CE) strategy, because many of the same BoS components 
could be retained while modules or inverters (or other) system components (as well as interconnection infrastructure) are replaced, with significant material savings compared to a case where a power plant is retired and a completely new one is built in its place. Repowering can also reduce land requirements compared to a case where the retired plant is replaced at a new site, occupying additional land.

During system operation, owners and operators may need to repair PV modules and BoS equipment because of manufacturing defects, faulty installations, and extreme weather events, among other factors. Poor manufacturing practices alone have led to more than $10 \mathrm{GW}$ of PV modules with faulty backsheets deployed worldwide. ${ }^{215-217}$ Dupont's 2019 Global Field Reliability Study showed a 47\% increase in backsheet defects over 2018 results. ${ }^{218}$ Backsheets made with polyamide, polyethylene, and polyvinylidene fluoride have shown signs of rapid infield degradation with failures as early as 5 years after installation. ${ }^{89,216}$ One estimate found that $1.1 \mathrm{GW}$ of the forecasted $112 \mathrm{GW}$ of installed capacity in 2020 risk some degree of backsheet failure, which could result in $\$ 500$ million worth of repairs. ${ }^{219}$

Growing concerns about backsheet failures and overall system efficiencies have led to industry discussions and initiatives around in-field module repair. Seen as the most cost-effective solution for system owners, solar companies (such as Cybrid Technologies) and research institutes (such as the Polymer Competence Center Leoben $\mathrm{GmbH}$ ) are working on new technologies that could be used in the field to repair module backsheets. ${ }^{40}$ These technologies may provide a solution to module backsheet repair and may drive innovation toward other repair technologies.

However, many questions must be answered before the commercialization of these technologies and others can be realized. There are questions about the module inspection process and the safety and reliability of the repair product, as well as the regulatory requirements and legal liability associated with the technology and the installation. ${ }^{40}$ Currently, there is no publicly available guidance on the initial module inspection process, the types of repairs that are possible or equitable, repaired module installation, and the tests necessary to ensure the safety and reliability of repaired modules. ${ }^{40}$ Moreover, there is no publicly available information about the regulatory compliance and legal liability associated with repaired modules or the installation of repaired modules. ${ }^{40}$ Unanswered regulatory and legal questions include the following:

- Who bears the legal liability of a repaired module (e.g., manufacturer or repair technology company)?

- How may interconnection, fire, building, electric, and equipment regulations and other laws impact the viability of using a repaired module in all or certain installations (e.g., grid-tied, rooftop)?

- Can a repaired module use the original manufacturer safety and reliability certifications?

- Do new labels need to be applied to a repaired module?

- Can the repair technology and technicians installing the repairs be certified instead of requiring certificate review of each module?

Because backsheet durability plays a critical role in extending the life of modules and the PV system, industry experts are working to provide solutions for durable, safe, and cost-effective module repair. In the meantime, system owners and operators are left with limited guidance, which - beyond performance issues and increased operation and maintenance costs - has raised 
several safety concerns. ${ }^{216,219-221}$ The application of repair as a CE strategy for PV is described further in Section 5.4.2.

\subsection{Environmental Justice and Social Benefit Through Circular Economy During the PV Use Stage}

Repowering reduces the cost of renewable electricity generation by substituting older PV system components with newer and more efficient system components. The reduction in PV electricity costs could ameliorate the cost barriers that prevent low-income communities from accessing renewable electricity. Decommissioned modules from repowering can be supplied to the reuse PV markets. ${ }^{222}$ Markets for reused PV systems can help ensure access to PV electricity at a lower cost in the developing world, ${ }^{222}$ thereby decreasing reliance on energy from fossil fuels.

By delinking ownership of PV systems from use of PV electricity, PSS decreases upfront capital costs and could increase access to PV electricity for low- and medium-income residents. Thus, PSS can be a socio-environmentally just mechanism to leverage low- and medium-income rooftops, which account for $42 \%$ of the U.S. rooftops that are PV viable. ${ }^{209}$ See Heeter et al. ${ }^{223}$ for more on this topic. 


\section{Key Considerations at End of Life}

In 2019, cumulative PV operating capacity reached $76 \mathrm{GW}_{\mathrm{DC}}$ in the United States. ${ }^{13}$ As capacity increases, so eventually will the volume of EOL PV modules and BoS equipment. ${ }^{40,74}$ In addition, a growing stockpile of early-retired modules in the United States still have reuse potential. ${ }^{40}$ Industry experts have observed a large volume of PV modules in the United States being retired after only 10 to 12 years in service, long before the life expectancy of 25-30 years. ${ }^{40,220,221}$ Anecdotal evidence suggests this growing trend is largely driven by partial and full system repowering due to increased extreme weather events and efficiency upgrades. ${ }^{35,40,220,221}$ While there is no available quantitative tracking of PV modules stockpiled, this section projects the mass of EOL materials from PV modules considering just the known degradation and failure rates that affect lifetime. Using a more simplified approach, we make the same projection of EOL materials for CSP systems. We review policy considerations and the literature on many CE strategies relevant at EOL. Finally, benefits of the application of CE approaches at EOL with regard to environmental justice are discussed.

\subsection{PV End-of-Life Materials Projection}

Figure 19 shows projected PV EOL materials by scenario through 2050 as calculated by $\mathrm{PViCE}^{\mathrm{xiii}}$ for c-Si installations, which are assumed to constitute $85 \%$ of all installations following past market trends for the United States. ${ }^{\text {xiv }}$ PViCE calculates module lifetime based on PV project life expectations over time, ${ }^{18}$ Weibull failure probability curves, and cohortdependent degradation. PV module lifetimes have continually improved and are currently above 32 years for utility scale projects ${ }^{18}$. This means a module installed in 2028 will not reach EOL until 2060. Therefore, most of the modules deployed in these scenarios do not reach EOL until after 2050. Figure 19's pre-2050 EOL modules are due to older installations (e.g., installations from 2010 to 2020) and premature failures. The Solar Futures Study Decarb and Decarb+E scenarios result in nearly identical 2050 cumulative EOL material (approximately 6.43 million metric tons each). Overall, because glass is such a large fraction of PV module weight (for historical and future module designs), it makes up an equally large fraction of total EOL materials in all scenarios.

\footnotetext{
xiii PViCE was validated by reproducing the mass of PV in service and cumulative PV EOL materials from a 2016 report from the International Energy Agency PV Power Systems Task 12 and IRENA. ${ }^{224}$ The material demand results are also compared to a recent EOL material projection from the CSA Group. ${ }^{301}$ A comparison of predictions is presented in Appendix B.

xiv The effect of a nontrivial market share for thin-film PV technologies on EOL module materials as well as manufacturing scrap is beyond the current capability of PViCE, and it can be the subject of future research. In most years, the market share in U.S. deployment for thin-film modules is less than $10 \%$, so the results presented here would change to a commensurate degree, though the precise answer depends on modeling of cohort-dependent degradation, expected lifetimes, and other factors. Furthermore, thin-film technologies such as cadmium telluride (CdTe) are largely recycled via product takeback programs of the largest CdTe manufacturer, First Solar.
} 

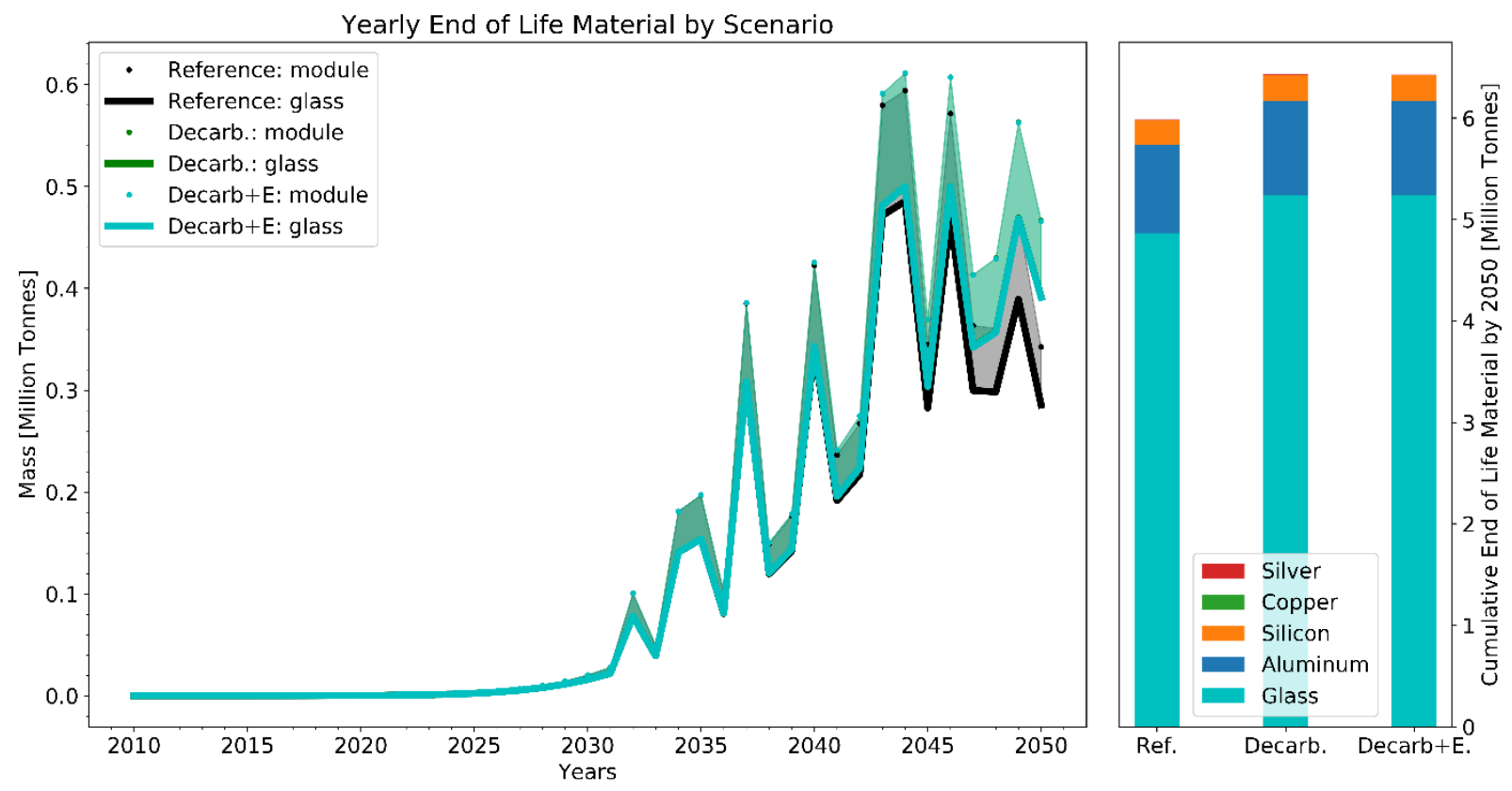

Figure 19. Annual and cumulative PV EOL material mass by Solar Futures Study scenario
through 2050

Glass has such a high magnitude in this chart that copper and silver cannot be seen, though are included.

A unique feature of PViCE is that manufacturing scrap is accounted for separately and additionally from EOL materials. Comparing the cumulative quantities (bar graphs of Figure 20 and Figure 19), manufacturing scrap is approximately half of the mass of materials in EOL modules but better aligned in time with virgin material demands, emphasizing the importance of efficient manufacturing and closed-loop manufacturing scrap recycling to reduce virgin material needs. Silicon makes up a large proportion of manufacturing scrap due to manufacturing inefficiencies, including ingot wafering, whereas glass manufacturing is a more efficient manufacturing process in terms of materials. In fact, silicon scrap in manufacturing is even greater than that in EOL modules, cumulatively, which reflects that modules deployed under the Solar Futures Study scenarios are largely still operational by 2050 . As expected, the highest deployment scenario, Decarb $+E$, generates the most manufacturing scrap, annually and cumulatively. 

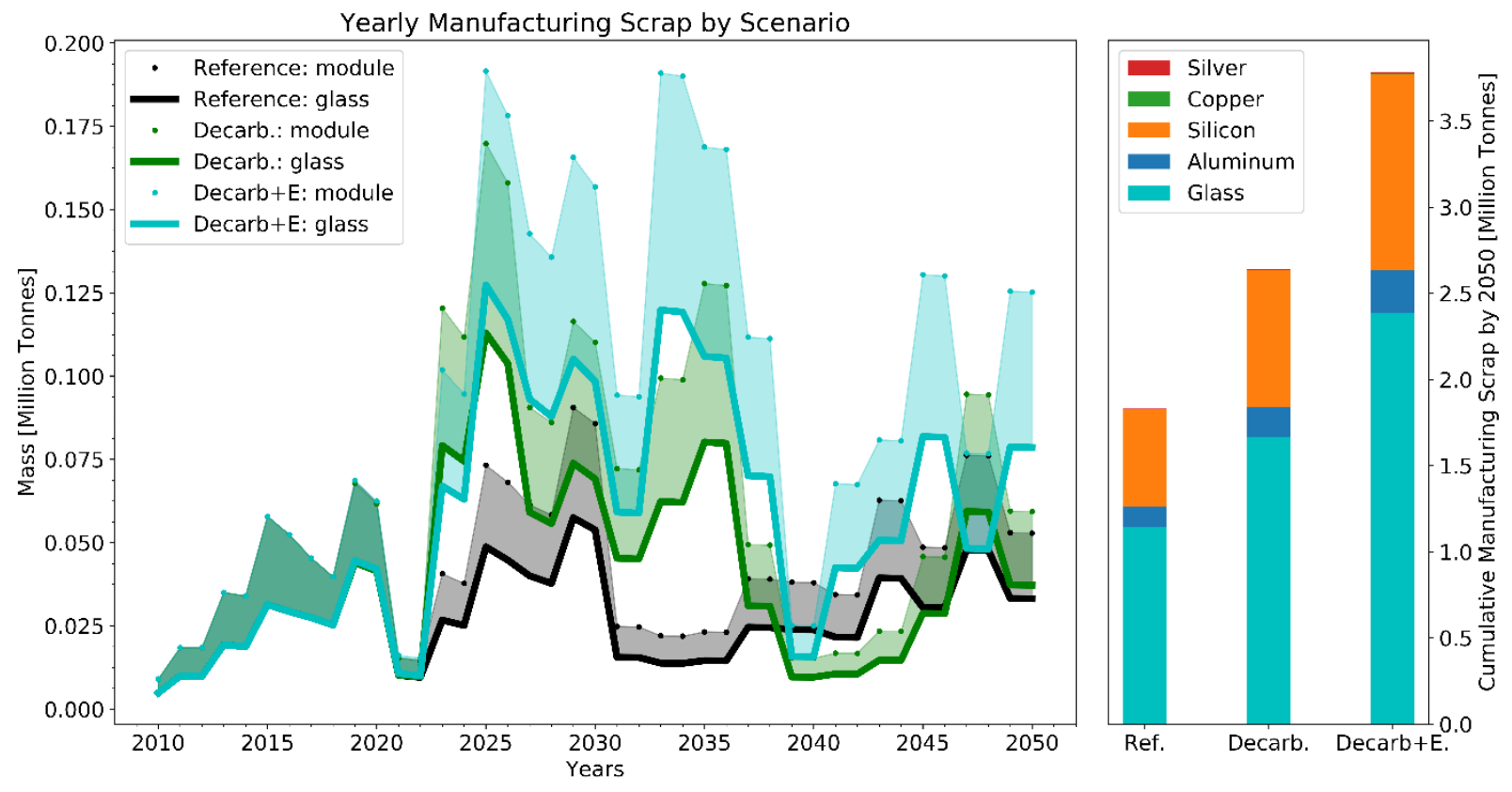

Figure 20. Annual and cumulative mass of c-Si PV manufacturing scrap by Solar Futures Study scenario through 2050

Glass and silicon have such high magnitudes in this chart that copper and silver cannot be seen, though are included.

Another novel feature of PViCE is the capability to track a deployed cohort by location. Figure 21 shows cumulative regional PV EOL glass (as a proxy for all PV EOL materials) through 2050 by scenario. Relative magnitude differences are similar among scenarios, with the largest difference among scenarios regionally in the Southeast.

Such geospatial results could enable stakeholders to plan proactively for EOL materials on a regional basis, which can lead to more efficient deployment of capital for recycling and other EOL management infrastructure. Efficient infrastructure build-out can accelerate trends toward a sustainable CE. For example, tighter circular loops, such as repair and reuse, could keep PV modules in the field longer (offsetting material demands and EOL) and create regional, higherskilled jobs in the sustainability sector. Longer circular loops, such as recycling, could enable industries (e.g., glass manufacturing) to use a local supply of EOL materials from PV modules. Further analysis of PV module lifetime extensions, recycling, and the associated social, environmental, and economic impacts of each can clarify potential pathways toward circular, symbiotic, cross-sector economic opportunities to address challenges communities will face in coming decades. 

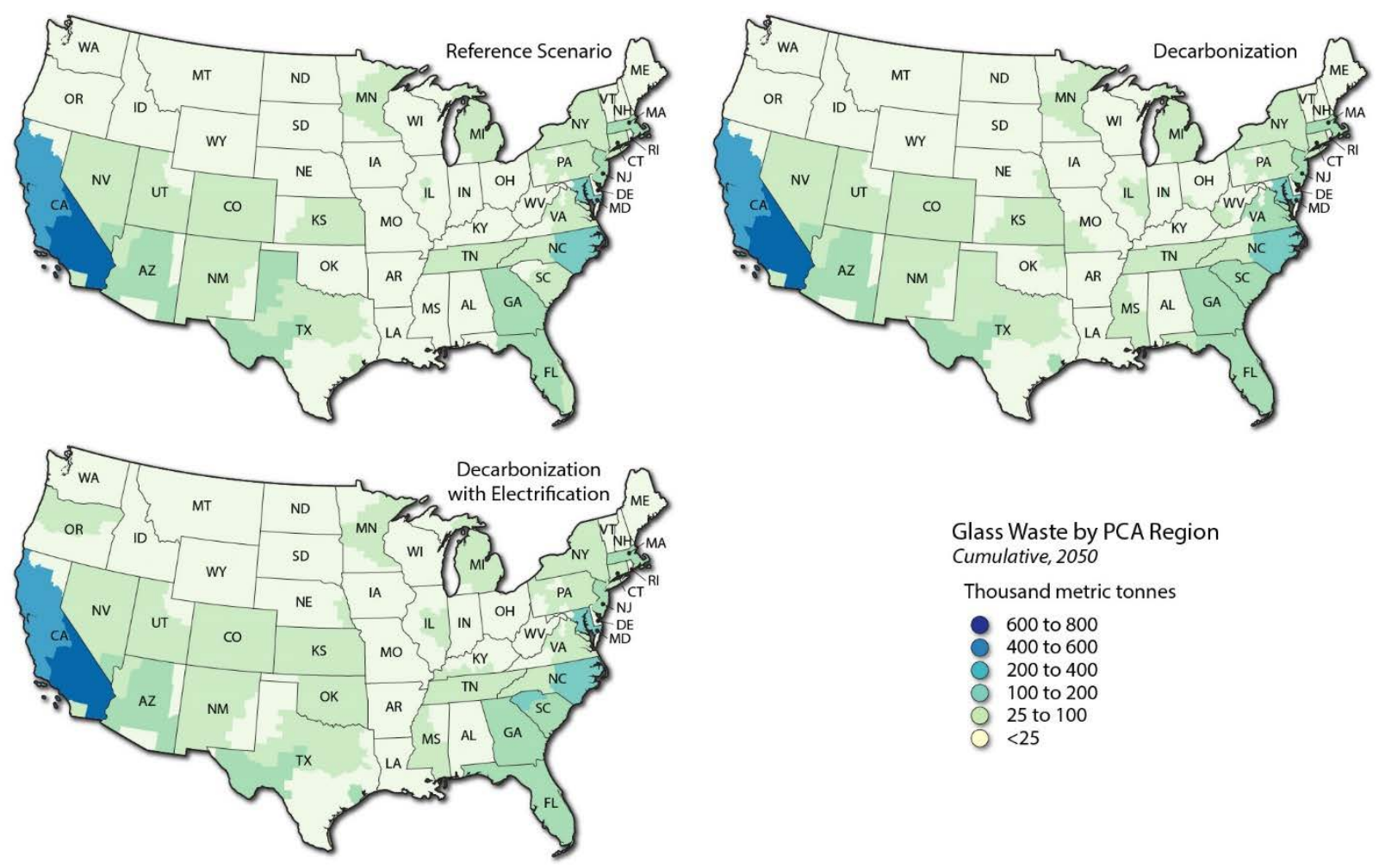

Figure 21. Cumulative regional EOL PV glass through 2050 by scenario

Finally, an important potential strategy to mitigate material demands in a growing PV sector while improving resilience of supply chains is to substitute EOL materials for virgin materials. Additional benefits of such a strategy include reduced environmental and social justice burdens of mining, providing markets for recycling facilities looking to sell recovered materials, reducing critical material demands, and so forth. Figure 22 displays the annual installations and decommissions in terawatts from 2020 through 2050 for the Reference and Decarb+E scenarios. Decommissions outpace installations by 2032 in the Reference scenario, and by 2038 in the Decarb $+E$ scenario. Thus, module reuse, refurbishment, and recycling could offset a portion of the needed PV installations, primarily closer to 2030. 


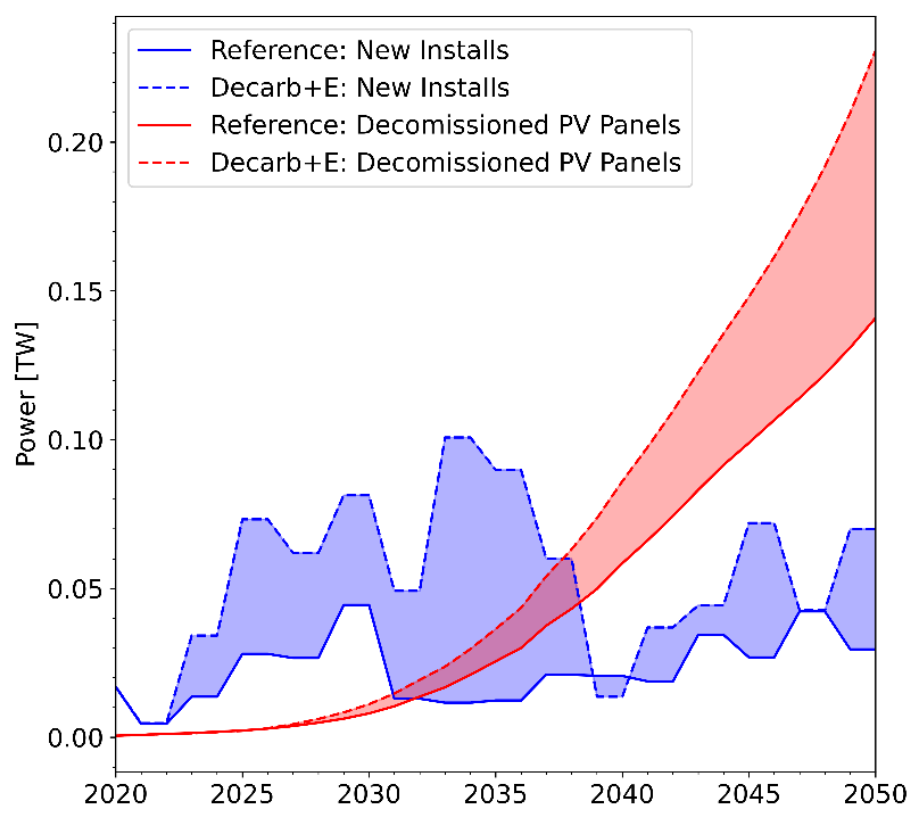

Figure 22. Annual installations and decommissions for 2020 through 2050

Figure 23 shows how silver, aluminum and silicon material demands can be met partially with EOL materials for the Decarb+E scenario. Pre-2040, at the high deployment rate, EOL material can supply less than $20 \%$ of material demands. After 2040 , when deployment slows, EOL material can supply $25 \%$ to $30 \%$ of these material demands. EOL material depends on the material composition of the generations of PV modules being decommissioned, which is accounted for in PViCE's cohort framework. Due to the ReEDS simulation and optimization methods, the annual deployment rate appears highly variable. The sudden decrease in deployment rate in 2040 is not industry realistic and should be considered an outlier.
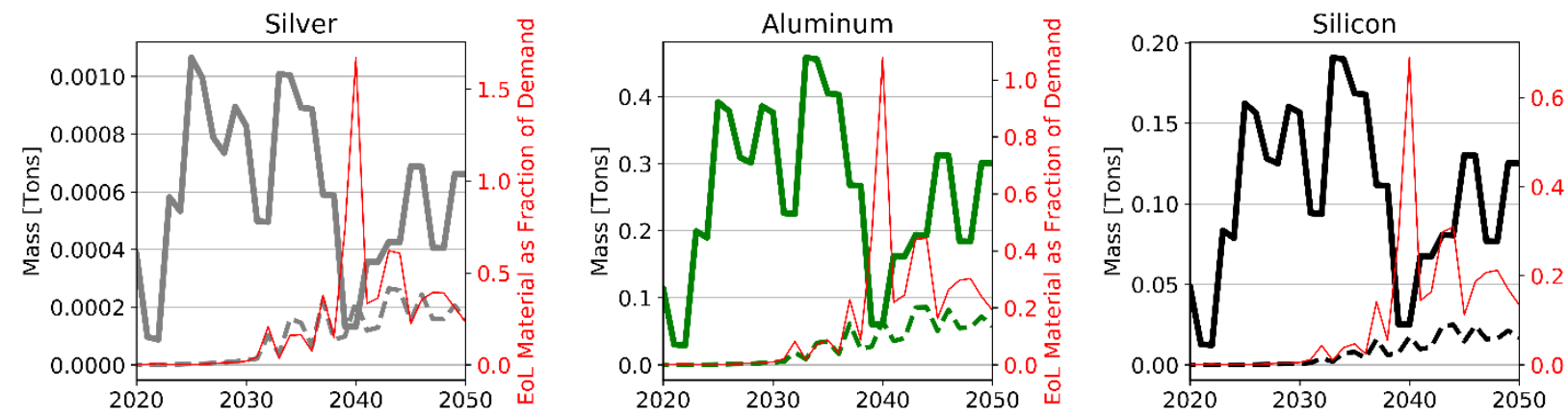

ב Virgin material demands $\equiv \equiv \equiv \equiv$ EOL material —— EOL material as fraction of demand

Figure 23. Yearly virgin material demands and EOL silver, aluminum, and silicon, with right axis showing the fraction of Decarb+E scenario demand that could be supplied by the EOL material 


\subsection{CSP Waste Projection}

The material waste for CSP systems (Figure 24) is a product of the decommissioned capacity and the materials recovered per unit of decommissioned capacity. The decommissioned capacity between 2020 and 2050 was determined via ReEDS (see Appendix D for details). With no publicly available data on the rate of material recovery from decommissioned CSP systems, this analysis assumes the material recovered per unit of decommissioned capacity is the same as the material required per unit of installed capacity as described in Section 3.2.

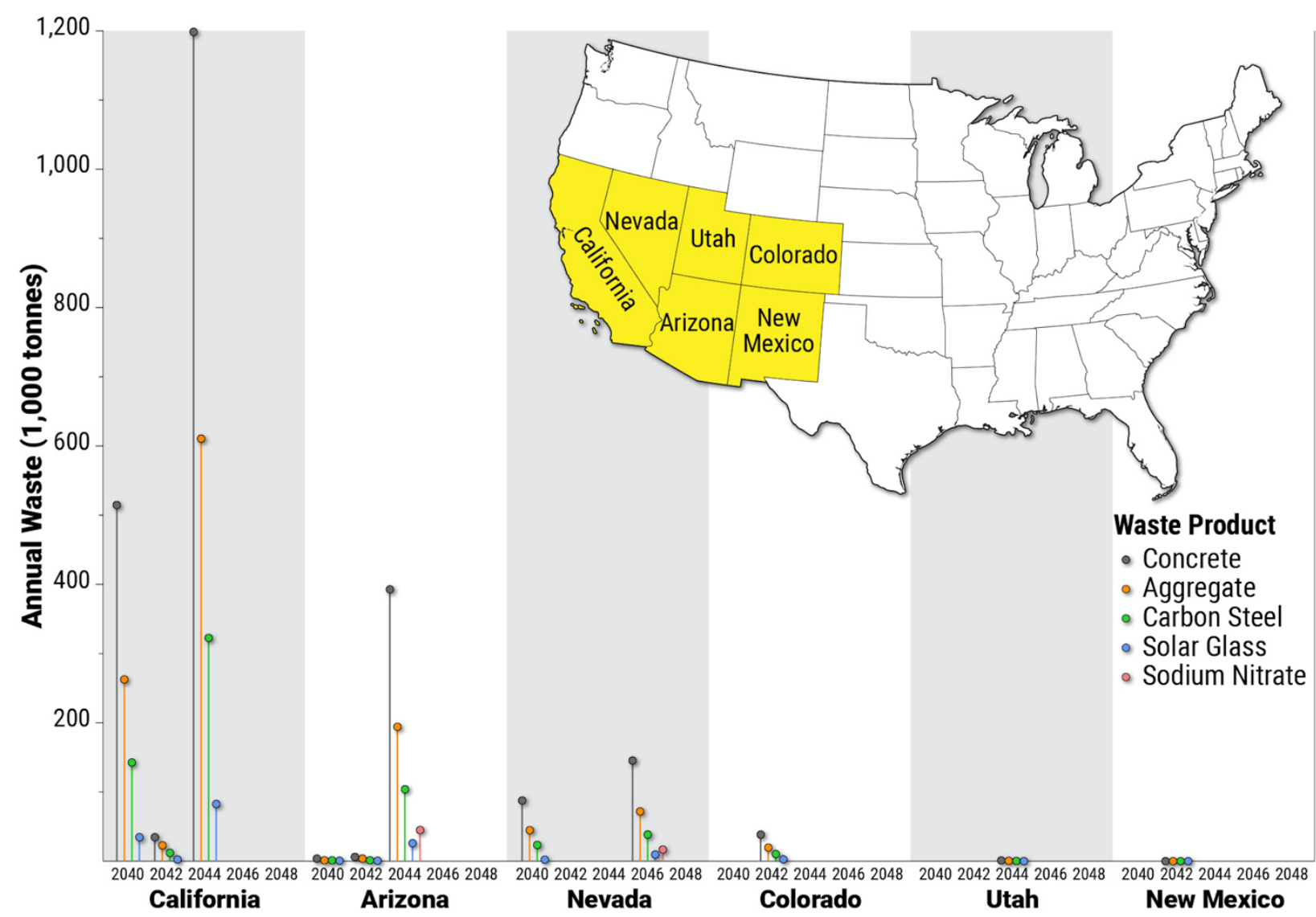

Figure 24. Five materials that contribute most to projected waste from power tower CSP plants between 2020 and 2050 in the Decarb scenario

In the Decarb scenario, CSP waste occurs only in the six states shown and only between 2040 and 2050 . The results for the Reference and Decarb+E scenarios are identical to the Decarb scenario as the waste projections are driven by the CSP installations before 2020 , which are the same across the three scenarios.

Four of the materials - concrete, aggregate, carbon steel, and solar glass - in Figure 24 are bulk materials and can leverage existing recycling infrastructure. The likelihood of recycling the concrete and aggregate waste as aggregates can be increased by supplying them to the construction and demolition waste market. ${ }^{225,226}$ While carbon steel and solar glass represent significant volumes in the waste, they can be recycled through the existing network of glass and steel recyclers. Given the geographical spread of the projected CSP waste volumes, the recovered materials can leverage the existing network of glass and metal recyclers in the Southwest. ${ }^{227-229}$ 
No publicly available data exist on the recycling of sodium nitrate and the associated economic and environmental impacts. However, if recycling is available in practice, it could potentially offset the production of sodium nitrate from mines or the more environmentally intensive synthetic route.

A recent study combined the metrics of LCA and material circularity to quantify the environmental benefits of recycling and reusing the TES system of CSP systems. ${ }^{230}$ The results show that reuse and recycling of materials from the TES system reduce the environmental impact by $23 \%$ on a life cycle basis when compared to a scenario without reuse or recycling. The study also identifies the current lack of reuse or recycling pathways for molten salts as an obstacle to further reducing the environmental impact of TES on a life cycle basis.

\subsection{Policy, Market, and Regulatory Considerations for Recycling, Reuse, and Repair}

Despite the potential economic and environmental benefits of reuse and recycling, there is evidence that EOL and early-retired PV modules are often stored in warehouses or discarded in landfills in the United States. ${ }^{35,40}$ Industry experts have noted several technical, economic, and regulatory barriers to repair for reuse, direct reuse, and recycling of PV modules. ${ }^{35,40,220,221,231-233}$ For example, although direct reuse of a PV module is arguably more viable than current repair for reuse and recycling options, direct reuse may be prohibited by interconnection and equipment standards, and fire, building, and electric codes for certain applications. ${ }^{40}$ For instance, older modules that are not compatible with smart inverters are prohibited for grid-tied applications in jurisdictions that have adopted the IEEE 1547 Standard or UL 1741 Standard. ${ }^{40,234,235}$

Modules are not designed for easy repair or recycling, and a limited number of U.S. companies provide repair and recycling services. ${ }^{40}$ In addition, current technology, infrastructure, and processes are not designed for cost-effective repair or recycling. ${ }^{40}$ Moreover, most U.S. solid and hazardous waste regulations do not incentivize recycling modules over disposal, because the requirements as well as the financial and legal liability associated are often the same. ${ }^{40}$ As a result, U.S. solid and hazardous waste regulations may not incentivize recycling over disposal especially under current market conditions which favor disposal over recycling in terms of cost and accessibility. ${ }^{35,40,220,221,232}$

Concerns about current practices, supply chain vulnerabilities, and PV system waste-as well as the potential for new and expanded opportunities - have led to government and industry discussions, policies, and initiatives that could have important impacts on material management options for early-retired and EOL PV modules and BoS equipment in the United States. ${ }^{9,35,40}$ Industry-led initiatives, such as the Solar Energy Industries Association's (SEIA) National PV Recycling Program, are also focused on providing sustainable solutions for EOL PV modules and BoS equipment. SEIA's National PV Recycling Program, launched in 2016, provides EOL material management best practices for asset owners and recycling resources to encourage module and BoS equipment recycling among its membership. ${ }^{40}$ These recent government and industry-led policies and initiatives signal a growing trend in the United States to prioritize sustainable material management practices for early-retired and EOL PV modules and BoS equipment and may present new and expanded market opportunity for the solar industry. 


\subsection{Circular Economy as an Approach to Addressing EOL Issues}

\subsubsection{Recycling}

Recycling is the most widely applied and analyzed PV CE strategy (Figure 4). A detailed analysis of the literature on recycling c-Si PV modules (Figure 25) reveals that R\&D has focused extensively on recovering the bulk module materials; 46 and 23 data sets have focused on the recovery of silicon wafer and glass respectively.

Literature reveals open-loop recycling pathways wherein materials recovered from PV modules are used in non-PV applications. The materials recovered from c-Si PV modules can potentially be reused in lithium-ion batteries, ${ }^{236}$ cement and concrete, ${ }^{237-239}$ paper production, ${ }^{240}$ ceramic tiles ${ }^{241}$ geopolymers, ${ }^{242}$ clay bricks, ${ }^{243}$ and medical applications ${ }^{244}$ (Figure 3). Conversely, there is scope to reuse materials recovered from non-PV products in PV systems. By comprehensively reviewing existing $R \& D$ efforts and commercial operations, three recent studies ${ }^{245-247}$ have identified key trends and challenges for c-Si PV recycling, which are highlighted below.

$\mathrm{R} \& \mathrm{D}$ has focused less on the recovery of trace materials (tin, lead, copper, and silver), which occur at significantly lower concentrations than glass and silicon in a c-Si module. The reduced R\&D focus may be attributed to the existence of mass-based recovery targets specified in PV recycling regulations, wherein a minimum portion of module mass must be recycled. For example, the Waste Electrical and Electronic Equipment (WEEE) Directive mandates that $85 / 80 \%$ of the mass of a PV module must be recovered/recycled, respectively ${ }^{248}$ which makes bulk materials attractive candidates for recycling because they contribute around $90 \%$ of the module weight. ${ }^{249}$ However, the exponential growth in PV waste may motivate an expansion in the scope of regulations to include recovery of both bulk and trace materials. This will help manage hazardous materials, such as lead, in an environmentally responsible manner and prevent toxicity and environmental risks in scenarios of improper management at EOL. ${ }^{250}$

The rightmost vertical bar in Figure 25 demonstrates that only one study focuses on the recovery of bulk and trace materials from c-Si PV modules. However, this study recovers the trace materials as a part of larger aggregates containing other bulk materials, which is not well suited for direct reuse and requires further downstream processing. ${ }^{251}$ Furthermore, only $33.2 \%$ of the mass of silver present in the module is recovered, which leads to a potential loss in revenue. Another study uses sequential electrowinning to recover the trace metals from a simulated solution of metals, which falls short of demonstrating an integrated process with the ability to recover the trace metals from the leachate obtained during module recycling. ${ }^{252}$ In addition, the use of platinum electrodes in the electrowinning process may increase recycling process costs. The above shortcomings demonstrate the need for a low-cost, integrated, high-value recycling process that can recover bulk and trace materials at high efficiencies from c-Si PV modules. ${ }^{245}$

Another key recycling challenge is delamination to eliminate the EVA and separate the glass and silicon wafer. ${ }^{253}$ The use of organic solvents to dissolve the EVA is time intensive and increases human health risks, ${ }^{75,254}$ mechanical processes increase energy consumption, ${ }^{91}$ and hightemperature processes present the risk of releasing hazardous emissions ${ }^{77}$ While commercial processes use combinations of mechanical, thermal, and optical processes, there is scope to facilitate easier delamination through design for circularity approaches such as laminate-free design..$^{85,255}$ 
There is a lack of robust and publicly available assessments of the economic viability of PV recycling at a commercial scale. Such assessments could help in designing better policies and incentives to transition to a CE for PV systems. Despite existing commercial operations, ${ }^{256,257}$ estimates show significant variability in recycling costs based on the recycling technology, ${ }^{246}$ and recyclers charge a fee because the revenue from the recovered materials alone cannot economically sustain PV recycling. ${ }^{246,247}$

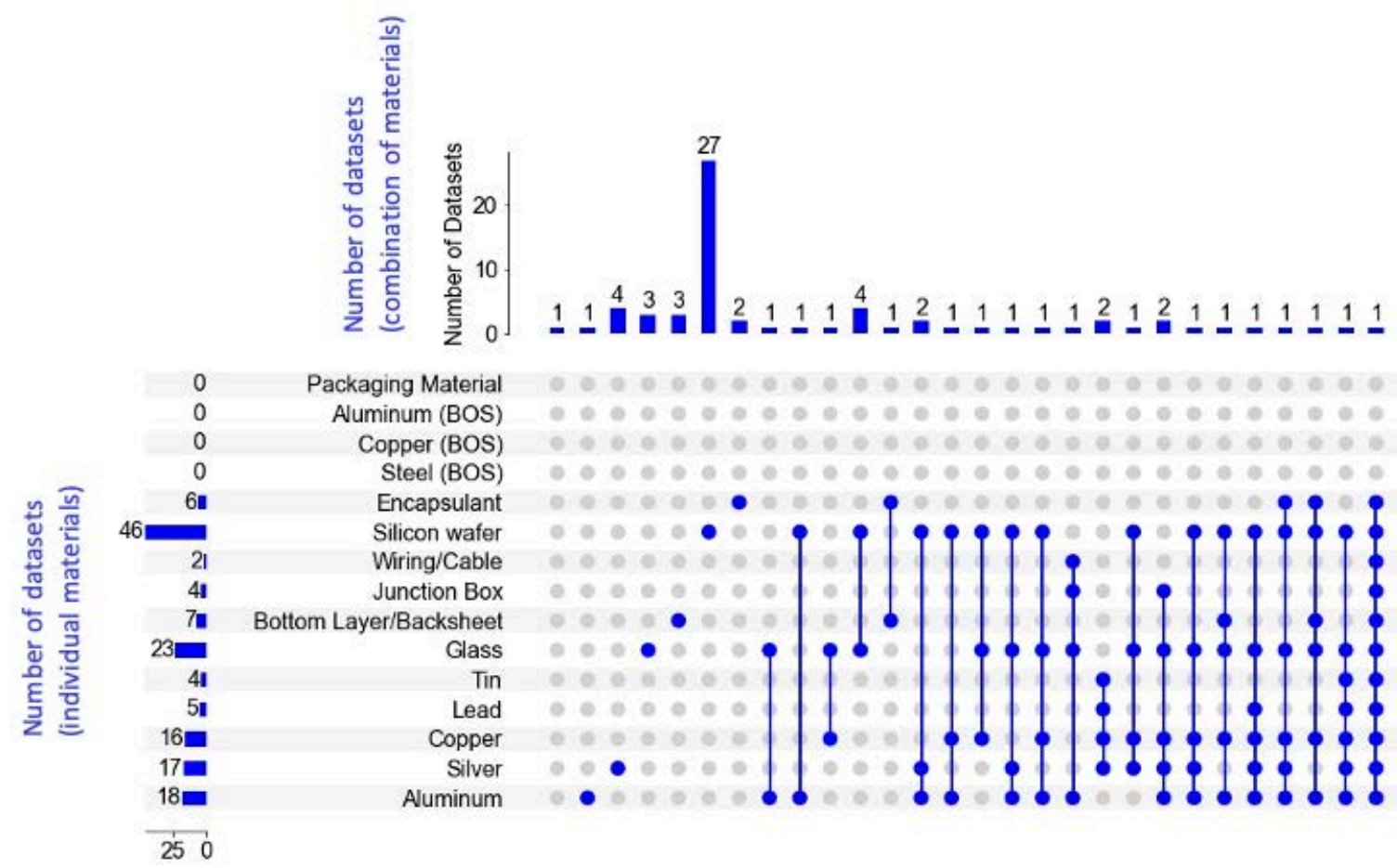

Figure 25. Literature on material recovery from recycling c-Si PV modules

The horizontal bars represent the number of data sets focusing on the recovery of an individual material from a c-Si PV module. For example, the 10th row from the top shows that 23 data sets focus on recovery of glass. The vertical bars represent the number of data sets focusing on the recovery of a combination of materials from a c-Si PV module. The combination of materials is identified by the solid blue circles in the column corresponding to the bar. For example, the 11th column from the left indicates that four studies recover both the silicon wafer and glass.

Variability in the designs and evolution of manufacturing trends across legacy and currentgeneration PV modules may pose challenges to the commercialization and economic viability of recycling technologies. The decline in silver content and the reduction of silicon wafer thickness ${ }^{44}$ decrease the potential to generate revenue by reselling the recovered materials. The use of high-temperature recycling processes, while being well suited for glass-glass and fluorinefree PV modules, may release hazardous fluorinated emissions when Tedlar is used as a backsheet. ${ }^{76}$ The variability in the design and material content of PV modules can introduce variability in the results for toxicity compliance (e.g., toxicity characteristic leaching procedure [TCLP]), so the toxicity test will change based on the method used to obtain samples from the PV module. 258

To address recycling challenges due to the variability in module design and material content, a repository of the different PV module designs and material content, which stakeholders can 
access and continually update, could be beneficial. The repository could facilitate collaboration and information sharing between PV manufacturers and recyclers, address the concerns of data confidentiality of the manufacturer, increase transparency on the design and material constitution of past and present PV modules, ensure repeatability of results and compliance with toxicity tests (e.g., TCLP ${ }^{259}$ ), and help better customize recycling strategies. Manufacturers can share information with recyclers through bill of materials, material passport, radio-frequency identification, or ecolabels. ${ }^{260,261}$

Given the above challenges, there is a need to prospectively quantify economic and environmental impacts to identify and accelerate the commercialization of the most promising novel PV recycling technologies. The application of anticipatory analytical methods ${ }^{262}$ in the early stages of technology development can help prospectively quantify and compare the economic and environmental effectiveness of novel recycling technologies.

The growth in PV capacity additions globally will require the collection and transport of waste modules from geographically dispersed installation sites to centralized recycling facilities. Recycling the modules at the installation site in small-scale decentralized plants can avoid the $\mathrm{CO}_{2}$ emitted from transporting PV modules. However, recycling in smaller-scale recycling plants forgoes the opportunity to realize efficiency gains from economies of scale in a centralized recycling plant. As a result, there is opportunity to optimally locate recycling facilities to minimize the economic and environmental cost of PV recycling, ${ }^{75,263-266}$ when transitioning to a CE for PV systems.

\subsubsection{Repairs}

We discuss repair in this section dedicated to EOL CE strategies because repair is required before reuse of PV modules, although repair can also occur in the use phase.

The results from the literature review (Figure 4) identify repair as an emerging and alternative $\mathrm{CE}$ strategy to recycling. Repair can address defects in parts such as the junction box, backsheet, bypass diodes, encapsulant, breakage in glass, and connectors without the destructive processing of the module. ${ }^{248,267-269}$ As shown in Figure 3, repair can also be applied in the use phase to address module degradation and enhance electricity generation, durability, and reliability. The repairs to external module components such as backsheets and junction boxes most likely to occur, with some solutions emerging, include; data are not available about the efficacy, performance and reliability effects, cost, equipment and skill requirements, and so forthpresenting a clear research opportunity.

In addition, repair is not limited to modules, but is also an important strategy for the full suite of BoS components, from inverters and switchgear to racking and cabling. Little research has been focused on these components, yet repair of these components is expected to yield financial and environmental savings in supporting a CE.

Repair avoids the economic and environmental burdens associated with the destructive processes of disassembly, separation, and recycling of individual material constituents and extends the lifetime of PV modules, which is a key CE strategy. ${ }^{270}$ The promise in the repair of PV systems is demonstrated by estimates showing that the repair and maintenance market for PV is expected to be worth $\$ 9$ billion by $2025 .{ }^{214}$ In addition, repaired PV modules on the secondhand market 
cost less than new PV modules and decrease the cost barrier to purchase PV systems in pricesensitive markets. ${ }^{222}$

Repair opportunities and needs can be identified through real-time monitoring, infrared thermographic imaging, ${ }^{271,272}$ electroluminescence imaging, ${ }^{273}$ and leveraging ML- and AI-based diagnostic approaches. ${ }^{268}$ The emergence of information system/digital service providers has helped link suppliers with potential buyers and expand the markets internationally for repaired and reusable PV systems. ${ }^{6,7}$

Despite the promise of repair and reuse of EOL PV modules, there is a need to address the lack of publicly available data on reliability, failure mechanisms, and standards to ensure quality and performance of repaired and reused modules, which can provide an objective mechanism to price and improve market confidence for these modules. Furthermore, there is a need to robustly assess and compare the economic and environmental trade-offs between module repair/reuse and alternative CE strategies (e.g., recycling). ${ }^{274}$ This assessment could help decrease the variability $^{248,275}$ in the economic costs of repairing PV systems, how the costs vary based on module conditions (e.g., type of defect, age of module, reason for decommissioning), diagnostic approach being used for repair, and market conditions (e.g., cost of repaired module versus revenue from recycling the module). ${ }^{274,276}$

\subsection{Environmental Justice and Social Benefit Through Circular Economy at PV End of Life}

The recycling, repair, and maintenance of PV systems could increase employment opportunities; this area is emerging as among the fastest-growing job categories in the U.S. economy. ${ }^{108}$ Further research is required to quantify the trade-offs related to increased employment opportunities in repair, which may diminish the volumes of PV waste and, thereby, the downstream job creation in recycling or landfilling. In addition, there is need to enhance planning and collaboration between various stakeholders (e.g., researchers, policymakers, the PV and waste management industries) to identify relevant skill sets and develop training programs to ensure creation of a workforce to staff U.S. PV repair, repowering, and recycling jobs without the need to export the PV waste.

By managing hazardous materials (e.g., lead) in an environmentally responsible manner, the potential negative impacts on human health are minimized, and environmental justice outcomes are improved. Historically, minority and low-income communities have disproportionally borne the negative health impacts from waste management operations. ${ }^{277-281}$

To design policies that maximize potential social benefits and improve environmental justice outcomes, there is a critical need to develop tools to explore the behavioral responses of stakeholders to incentives (e.g., recycle versus landfill PV waste), account for policy incentives (e.g., tax rebates), include market signals (e.g., price of secondary materials), and determine the social outcomes (e.g., decrease in energy poverty) of CE strategies. Frameworks such as social LCA, ${ }^{282}$ agent-based modeling, ${ }^{283,284}$ and discrete event simulation, ${ }^{285,286}$ and tools such as ML and AI, are promising candidates to determine the social outcomes of CE at PV EOL. ${ }^{287}$ 


\section{Conclusions and Recommendations}

This report uses novel analysis and literature synthesis to assess prioritized environmental challenges and opportunities for solar energy technologies in the context of the tremendous growth envisioned in the Solar Futures Study. Key issues include materials, land and water availability, ecosystem health, air quality, waste generation, environmental justice, and GHG emissions.

The role of solar technologies in mitigating GHG emissions from the power sector is presented in the Solar Futures Study. ${ }^{1}$ Also, solar mitigates air pollutants such as $\mathrm{NO}_{\mathrm{x}}$ and $\mathrm{SO}_{2}$, which react in the atmosphere to form ozone and fine particulate matter $\left(\mathrm{PM}_{2.5}\right)$. Based on preliminary analysis, reducing these emissions via the Solar Futures Study Decarb scenario (power-sector reductions) and Decarb + E scenario (power- and transportation-sector reductions) could produce air-quality and health benefits worth roughly $\$ 300$ billion-\$400 billion between 2021 and 2050 . Both scenarios also reduce power-sector water withdrawals dramatically. With regard to these traditional environmental indicators, solar deployment under the Solar Futures Study scenarios provides important contributions to tackling critical national and international challenges such as climate change, respiratory health effects (including premature death), and future water availability under a changing climate.

Although solar requires similar or less land per unit of capacity than other generation technologies, the deployment envisioned in the Solar Futures Study scenarios will entail significant land use: in the Decarb $+E$ scenario, about 10 million ac for ground-mounted PV and CSP installations by 2050 , which is equivalent to about $0.5 \%$ of the total contiguous U.S. surface area. Solar land requirements are not expected to exceed 5\% of any state's land area by 2050 , with the exception of Rhode Island (6.5\%). Our siting analysis excludes protected lands and identifies ample potentially suitable disturbed and contaminated lands to host the vast majority of the ground-mounted solar capacity. Using such lands would reduce land-use conflicts and could provide local societal and ecological benefits. We explore various ways to further reduce solar land-use conflicts and enhance land value via solar deployment, including managing vegetation to provide ecosystem services at solar facilities, co-locating solar with agriculture (including grazing) in agrivoltaic systems, and other pursuing opportunities such as installing PV panels on water (floatovoltaics).

Our analysis of U.S. solar material demands under the Solar Futures Study scenarios suggests material supplies likely will not limit solar deployment growth, especially if EOL materials are recovered and used. In any case, management of EOL solar materials will become both a critical challenge for the expanding solar industry and an environmental, economic, and social opportunity. CE strategies - such as recycling, repair, reuse, dematerialization, and use of renewable energy to power manufacturing supply chains - can improve outcomes across the full solar life cycle. In addition, management of information flows can enhance CE strategies across the full life cycle, for instance leveraging AI/ML methods for alternative material selection or development during manufacturing and securely containing information about materials in material passports using blockchain or radio-frequency identification. Real-time monitoring (to get ahead of failures that could lead to early decommissioning) and PSS business models (thirdparty ownership) are also information-centered CE strategies. These various CE strategies merit additional R\&D, analytical, and policy-oriented efforts. 
A benchmark global projection of PV EOL materials estimated approximately 80 million metric tons will be cumulatively produced by 2050 based on projections for deployment developed in $2014 .{ }^{288}$ We find that under the Solar Futures Study scenarios, and using more accurate and upto-date data on PV reliability and performance, EOL materials from PV modules in the United States are projected to be under $10 \%$ of this global figure: $\sim 6.5$ million metric tons. The benchmark report also estimated the value of materials in the cumulative EOL PV modules at $\$ 15$ billion, with enough raw materials to produce approximately 2 billion new PV modules if recovered in closed-loop recycling - equivalent to $630 \mathrm{GW}$ of capacity - to which our results here can be similarly scaled. ${ }^{288}$ Our projection of cumulative EOL materials in PV modules in the United States can be compared with global electronic waste, of which PV is a category: annual global electronic waste in 2050 is estimated at approximately 111 million metric tons per year. ${ }^{289}$

We also find connections between solar impacts and social and environmental justice. Solar, especially in the use phase - but also along the value chain (especially if manufacturing facilities are powered by renewable energy) - reduces air pollution by offsetting incumbent combustionbased energy sources. Air pollution from incumbent electricity generation contributes significantly to health disparities for disadvantaged populations. In addition, industrial facility locations correlate with the locations of disadvantaged populations, where near-source exposure to air pollutant emissions likewise causes health disparities. With regard to land, solar deployment can boost rural economies in terms of increased tax base and employment. Using degraded or contaminated lands can enhance societal and ecological land value, leading to conversion of previously underutilized lands to beneficial use, increased tax bases for rural communities, provision of local workers with jobs, creation of new markets for local contractors, diversification of income for landowners, and an increase in available local resources, including for underserved populations. And agrivoltaic systems can provide off-grid power to rural communities, increasing their resilience along with the income streams of agricultural families.

Solar CE strategies can provide social and environmental justice benefits as well. For example, design for circularity approaches that decrease use of hazardous materials can prevent negative health impacts related to release of those materials. Scorecards, ecolabels, and preferential purchasing schemes incentivize transparency in supply chains and manufacturing, prevent sourcing of conflict minerals, and improve worker health and safety. PSS and reuse decrease upfront capital costs for residential PV ownership and could widen access to PV electricity. Recycling decreases upstream social, environmental, and health impacts from PV manufacturing supply chains, increases domestic employment opportunities, leads to synergies with allied industries, and prevents negative health impacts from environmental release of hazardous materials. Recycling also prevents perpetuation of historically disproportionate burdens experienced by disadvantaged communities in the siting of landfills and hazardous waste management facilities.

\section{Key Recommendations}

There has been almost no quantitative investigation of the potential of CE strategies to further cost-effective decarbonization and environmental justice. Anticipatory analytical methods, such as life cycle assessments and techno-economic assessments, are important for fairly comparing $\mathrm{CE}$ strategies and clarifying the economic and environmental impacts of technology and policy design. However, such analyses are currently lacking across the range of CE pathways. LCAs are 
one approach to comprehensively quantifying GHG emissions and the mitigation potential of CE strategies; when assembled from across several pathways, integrated scenarios and the overall system potential can be evaluated. Promising quantitative approaches for considering environmental justice include near-source air-quality modeling, complex system science methods such as agent-based or systems dynamics modeling (which apply behavioral science principles to assess adoption potential), and social LCA.

There is need to study the employment trade-offs and workforce-development needs related to CE strategies. For example, increased employment opportunities in repair may diminish the volumes of PV waste and, thereby, the downstream job creation in recycling or landfilling. In addition, there is need to enhance planning and collaboration between various stakeholders (e.g., researchers, policymakers, the PV and waste management industries) to identify relevant skill sets and develop training programs to ensure creation of a workforce to staff U.S. PV repair, repowering, and recycling jobs without the need to export the PV waste.

R\&D investments in partnerships or consortiums involving multiple actors in the value chainincluding allied industries - would be valuable, especially for larger investments. In addition, there is need for a repository of different PV module designs and material content, which stakeholders could access and continually update.

Although recycling is the most studied CE strategy, recycling R\&D should continue. This includes (1) clarifying the benefits and costs of different policy designs and (2) connecting the full value chain of recyclers, raw material manufacturers, and customers to identify the most viable market pathways for using recovered materials. For instance, determining how the impurity profile of recovered silicon might necessitate change to silicon manufacturing processes, manufacturer cost structures, and product characteristics is an important research area. Development of high-value products and markets for the largest PV module constituentglass - is another area deserving significant research attention. Additional challenges for PV recycling technology design include the lack of an integrated method to completely recover bulk and specialty materials (lead, tin, silver, copper); delamination; variability in module design; lower silver content; fluorinated polymers; and lead content.

Lead is the primary metal of concern with regard to regulatory characterization of module toxicity. Reducing or eliminating lead content in modules could address questions about treatment as hazardous material at EOL. Working with industry on recognizable standards to ensure modules have lower lead content than the TCLP conformance limit (the strongest demonstration of which would be lead-free), final owners could be relieved of the costs of testing and burdens of potential hazardous waste treatment. Developing a standard protocol for sampling of PV modules before TCLP testing is also needed to reduce the demonstrated variability in results when using unstructured sampling.

Fluorine is also a concern for module recycling. Clarifying the costs of treatment and the corrosive effects on equipment in recycling of fluorine-containing modules could inform manufacturers' and purchasers' decisions about the continued use of fluorine-containing backsheets. 
Because PV and CSP are undergoing rapid technological change, the capital-intensive recycling industry should carefully consider how their infrastructure could be designed to be as adaptive as possible to handle not only anticipated amounts of EOL materials but also changes to form factor, materials content, assembly, and so forth.

Design for circularity R\&D should include holistic assessment of the trade-offs that material and design choices impose on module technical performance as well as their life cycle impacts. Such efforts could prioritize design for circularity methods that generate the highest net economic and environmental benefit over the PV life cycle.

In general, product service systems are understudied with regard to quantifying differences in PV performance and lifetime between this ownership model and others, as well as developing metrics to quantify the effectiveness of PSS as a CE strategy. Given the prevalence of this ownership model for U.S. PV, this topic is important for further research.

Other than anecdotal data, no data exist on the reasons for and total flow of PV modules reaching EOL. Partnering across the PV value chain (from owners to installers/servicers, insurers, and financiers) to develop commitments for regular surveying of modules reaching EOL could provide the data needed to reduce investment risks in the nascent EOL management industry (inclusive of repair, recycling, reuse, and secondary markets). Conceptually, a tagging system akin to a vehicle identification number could be considered for more robust tracking from first sale to EOL disposition. As the resolution of satellite imagery continues to increase, empirically tracking module removal and replacement at the facility or even per-module level might become conceivable.

Developing standards to evaluate the performance of in-field repairs is critical for assuring owners, insurers, and financiers about the efficacy and safety of repaired PV. Doing so could ultimately reduce the total cost of ownership and improve circularity by keeping existing products in service longer.

Renewable electricity use significantly increases the life cycle-climate benefit from PV by providing earlier GHG emission reductions, thus reducing cumulative radiative forcing. Use of this or a similar metric to understand the relative benefits of the role that different CE strategies can play in mitigating climate change could be pursued.

Circularity studies could reflect the current recycled content of each material as well as more extensive CE pathways. For example, for each scenario, some percentage of virgin material demand could be offset by recycling the annual EOL PV materials in a closed loop back into PV material feedstock. This pathway would require research into reverse logistics and high-quality recycling of PV modules. Alternatively, increasing the longevity of PV modules (e.g., via reduced degradation or repair) would reduce required annual deployments, because fewer panels would be required to attain and maintain capacity and generation levels - resulting in reduced virgin material demands and, eventually, EOL materials. This pathway would require research into module and system reliability, degradation modes, repairs, and optimized system design. Also, the PV industry is also moving toward modules with higher energy yield per unit area, which will also affect material demands. 
To ensure fulfillment of the implicit promise that solar will be sustainable throughout its life cycle - including EOL - technical and policy solutions better than landfilling should be identified, studied, piloted, demonstrated, and deployed throughout the country. Additional efforts to characterize the landfill volume required for solar components under the Solar Futures Study scenarios could serve to prioritize solar component recycling development. Additionally, increased awareness of the upstream land use and other impacts of mineral mining for solar components is important for avoiding unforeseen social equity impacts within the United States and globally. 


\section{References}

(1) DOE. Solar Futures Study; GO-102021-5621; U.S. Department of Energy: Washington, D.C., 2021.

(2) Hertwich, E.; Gibon, T.; Bouman, E.; Arvesen, A.; Suh, S.; Heath, G.; Bergesen, J.; Ramirez, A.; Vega, M.; Shi, L. Integrated Life-Cycle Assessment of Electricity-Supply Scenarios Confirms Global Environmental Benefit of Low-Carbon Technologies. Proceedings of the National Academy of Sciences 2014, 112 (20), 6277-6282. https://doi.org/10.1073/pnas.1312753111.

(3) International Energy Agency. The Role of Critical Minerals in Clean Energy Transitions; International Energy Agency: Paris, 2021.

(4) Kirchherr, J.; Reike, D.; Hekkert, M. Conceptualizing the Circular Economy: An Analysis of 114 Definitions. Resources, Conservation and Recycling 2017, 127, 221232.

(5) World Economic Forum. Towards the Circular Economy: Accelerating the Scale-up across Global Supply Chains; World Economic Forum: Geneva, Switzerland, 2014.

(6) Secondsol. Secondsol https://www.secondsol.com/en/company/portrait/.

(7) PV Magazine. From eBay to pvBay getting used to used PV https://www.pvmagazine.com/magazine-archive/from-ebay-to-pvbay-getting-used-to-usedpv_100024935/ (accessed $2016-01-01)$.

(8) European Union. EN 50625-2-4:2018 - Collection, logistics \& treatment requirements for WEEE - Part 2-4: Treatment requirements for photovoltaic panels https://standards.iteh.ai/catalog/standards/clc/2151feda-4cc1-426f-ab6a2f38a10b22a1/en-50625-2-4-2017.

(9) Washington State Legislature. Wash. Rev. Code $\$ 70$ A.510.010 - Photovoltaic Module Stewardship and Takeback Program.

(10) Smith, B. L.; Margolis, R. Expanding the Photovoltaic Supply Chain in the United States: Opportunities and Challenges; NREL/TP-6A20-73363; National Renewable Energy Laboratory, 2019.

(11) Xiaojing, S.; Smith, C.; Manghani, R. Coronavirus: U.S. Solar PV Supply Chain and Utility Scale Market Risk; Wood Mackenzie, 2020.

(12) Mints, P. Photovoltaic Manufacturer Capacity, Shipments, Price \& Revenues (Report SPV-Supply8); SPV-Supply8; SPV Market Research, 2020.

(13) Perea, A.; Smith, C.; Davis, M.; Sun, X.; White, B.; Cox, M.; Curtin, G.; Rumery, S.; Goldstein, R.; Silver, C.; Baca, J. U.S. Solar Market Insight (Full Report): Q3 2020; Wood Mackenzie, 2020.

(14) Ayala Pelaez, S.; Mirletz, H.; Silverman, T. NREL/PV_ICE: First Release v0.1.0; https://doi.org/10.5281/zenodo.4324011; Zenodo, 2020.

https://doi.org/10.5281/zenodo.4324011.

(15) Wilson, G. M.; Al-Jassim, M.; Metzger, W. K.; Glunz, S. W.; Verlinden, P.; Xiong, G.; Mansfield, L. M.; Stanbery, B. J.; Zhu, K.; Yan, Y.; Berry, J. J.; Ptak, A. J.; Dimroth, F.; Kayes, B. M.; Tamboli, A. C.; Peibst, R.; Catchpole, K.; Reese, M. O.; Klinga, C. S.; Denholm, P.; Morjaria, M.; Deceglie, M. G.; Freeman, J. M.; Mikofski, M. A.; Jordan, D. C.; TamizhMani, G.; Sulas-Kern, D. B. The 2020 Photovoltaic Technologies Roadmap. J Phys D: Appl Phys 2020, 53 (49), 493001. https://doi.org/doi:10.1088/13616463/ab9c6a. 
(16) Jordan, D. C.; Kurtz, S. R.; VanSant, K.; Newmiller, J. Compendium of Photovoltaic Degradation Rates. Progress in Photovoltaics: Research and Applications 2016, 24 (7), 978-989. https://doi.org/doi:10.1002/pip.2744.

(17) Jordan, D. C.; Marion, B.; Deline, C.; Barnes, T.; Bolinger, M. PV Field Reliability Status-Analysis of 100000 Solar Systems. Progress in Photovoltaics: Research and Applications 2020. https://doi.org/doi:10.1002/pip.3262.

(18) Wiser, R.; Bolinger, M.; Seel, J. Benchmark Utility-Scale PV Operational Expenses and Project Lifetimes; LBNL Technical Brief; Lawrence Berkeley National Laboratory: Berkeley, CA, 2020.

(19) IRENA. Future of Solar Photovoltaic: Deployment, Investment, Technology, Grid Integration and Socio-Economic Aspects; A Global Energy Transformation; International Renewable Energy Agency: Abu Dhabi, United Arab Emirates, 2019.

(20) Bogdanov, D.; Farfan, J.; Sadovskaia, K.; Aghahosseini, A.; Child, M.; Gulagi, A.; Oyewo, A. S.; de Souza Noel Simas Barbosa, L.; Breyer, C. Radical Transformation Pathway towards Sustainable Electricity via Evolutionary Steps. Nat Commun 2019, 10 (1), 1077. https://doi.org/10.1038/s41467-019-08855-1.

(21) Feldman, D.; Wu, K.; Margolis, R. H1 2021: Solar Industry Update; NREL/PR-7A4079758; National Renewable Energy Laboratory: Golden, CO, 2021. https://doi.org/10.2172/1784533.

(22) The Silver Institute. World Silver Survey 2020; The Silver Institute: Washington, D.C., 2020.

(23) U.S. Geologic Survey. Silicon Statistics and Information https://www.usgs.gov/centers/nmic/silicon-statistics-and-information. International Aluminium. World Aluminium - Primary Aluminium Production https://www.world-aluminium.org/statistics/ (accessed 2021 -02 -01).

Hernandez, S.; Yusheng, L.; Labo, R. World Copper Factbook 2017; International Copper Study Group, 2017.

Whitaker, M. B.; Heath, G. A.; Burkhardt, J. J.; Turchi, C. S. Life Cycle Assessment of a Power Tower Concentrating Solar Plant and the Impacts of Key Design Alternatives. Environ Sci Technol 2013, 47 (11), 5896-5903.

NREL. NREL Concentrating Solar Power Projects, 2020.

Turchi, C.; Kurup, P.; Akar, S.; Flores, F. Domestic Material Content in Molten-Salt Concentrating Solar Power Plants; National Renewable Energy Laboratory (NREL), 2015.

Burkhardt, J. J., 3rd; Heath, G. A.; Turchi, C. S. Life Cycle Assessment of a Parabolic Trough Concentrating Solar Power Plant and the Impacts of Key Design Alternatives. Environ Sci Technol 2011, 45 (6), 2457-2464. https://doi.org/10.1021/es1033266.

USGS. Chromium https://pubs.usgs.gov/periodicals/mcs2021/mcs2021-chromium.pdf. USGS. Copper https://pubs.usgs.gov/periodicals/mcs2021/mcs2021-copper.pdf.

USGS. Manganese https://pubs.usgs.gov/periodicals/mcs2021/mcs2021-manganese.pdf. USGS. Nickel https://pubs.usgs.gov/periodicals/mcs2021/mcs2021-nickel.pdf.

Pihl, E.; Kushnir, D.; Sandén, B.; Johnsson, F. Material Constraints for Concentrating Solar Thermal Power. Energy 2012, 44 (1), 944-954. https://doi.org/10.1016/j.energy.2012.04.057. 
(35) Curtis, T. L.; Buchanan, H.; Heath, G.; Smith, L.; Shaw, S. Solar Photovoltaic Module Recycling: A Survey of U.S. Policies and Initiatives; Technical Report NREL/TP-6A2074124; National Renewable Energy Laboratory: Golden, CO, 2021.

(36) California Legislative Information. California Health and Safety Code $\$ 25189 ; 2018$.

(37) DTSC (California Department of Toxic Substances Control). Cal. Code Regs. Tit. 22 \$\$ 66260.1 - 66260.12, Hazardous Waste Management System: General, Definitions; 2020.

(38) DTSC (California Department of Toxic Substances Control). Cal. Code Regs. Tit. 22 $\oint$ 66273.1 - 66273.101, Standards for Universal Waste Management; 2020.

(39) DTSC (California Department of Toxic Substances Control). Cal. Code Regs. Tit. $22 \S$ 66261.9, Requirements for Universal Waste; 2020.

(40) Curtis, T. L.; Buchanan, H.; Smith, L.; Heath, G. A Circular Economy for Solar

Photovoltaic System Materials: Drivers, Barriers, Enablers, and U.S. Policy

Considerations; NREL/TP-6A20-74550; National Renewable Energy Laboratory: Golden, CO, 2021.

(41) Washington State Legislature. WAC 173-303-040, Dangerous Waste Regulations Definitions; 2020.

(42) Washington State Department of Ecology. Interim Enforcement Policy - Conditional Exclusion for Electronic Wastes; 2007.

(43) International Technology Roadmap for Photvoltaic (ITRPV). International Technology Roadmap for Photvoltaic (ITRPV) Results 2018. 2019.

(44) International Technology Roadmap for Photvoltaic (ITRPV). International Technology Roadmap for Photvoltaic (ITRPV) 2019 Results. 2020.

(45) Sopian, K.; Cheow, S. L.; Zaidi, S. H. An Overview of Crystalline Silicon Solar Cell Technology: Past, Present, and Future; 2017; Vol. 1877, p 020004. https://doi.org/10.1063/1.4999854.

(46) International Technology Roadmap for Photovoltaic (ITRPV). International Technology Roadmap for Photovoltaic (ITRPV) 2013 Results. 2014.

(47) International Technology Roadmap for Photovoltaic (ITRPV). International Technology Roadmap for Photovoltaic (ITRPV) 2014 Results. 2015.

(48) Fraunhofer Institute for Solar Energy Systems ISE. Fraunhofer Institute for Solar Energy Systems ISE Photovoltaics Report; 2020.

(49) Dwarakanath, T. R.; Wender, B. A.; Seager, T.; Fraser, M. P. Towards Anticipatory Life Cycle Assessment of Photovoltaics. In 2013 IEEE 39th Photovoltaic Specialists Conference (PVSC); IEEE, 2013; pp 2392-2393.

(50) Bhandari, K. P.; Collier, J. M.; Ellingson, R. J.; Apul, D. S. Energy Payback Time (EPBT) and Energy Return on Energy Invested (EROI) of Solar Photovoltaic Systems: A Systematic Review and Meta-Analysis. Renewable and Sustainable Energy Reviews 2015, 47, 133-141. https://doi.org/10.1016/j.rser.2015.02.057.

(51) Woodhouse, M.; Smith, B.; Ramdas, A.; Margolis, R. Crystalline Silicon Photovoltaic Module Manufacturing Costs and Sustainable Pricing: 1 H 2018 Benchmark and Cost Reduction Road Map; National Renewable Energy Laboratory, 2019.

(52) Yang, H. L.; Liu, I. T.; Liu, C. E.; Hsu, H. P.; Lan, C. W. Recycling and Reuse of KerfLoss Silicon from Diamond Wire Sawing for Photovoltaic Industry. Waste Manag 2019, 84, 204-210. https://doi.org/10.1016/j.wasman.2018.11.045. 
(53) Bronsveld, P. C. P.; Manshanden, P.; Lenzmann, F. O.; Gjerstad, Ø.; Øvrelid, E. J. Recycling of P-Type Mc-Si Top Cuts into p-Type Mono c-Si Solar Cells. Energy Procedia 2013, 38, 536-541. https://doi.org/10.1016/j.egypro.2013.07.314.

(54) Kumar, A.; Melkote, S. N. Diamond Wire Sawing of Solar Silicon Wafers: A Sustainable Manufacturing Alternative to Loose Abrasive Slurry Sawing. Procedia Manufacturing, 2018, 21, 549-566.

(55) Schwinde, S.; Berg, M.; Kunert, M. New Potential for Reduction of Kerf Loss and Wire Consumption in Multi-Wire Sawing. Solar Energy Materials and Solar Cells 2015, 136, 44-47.

(56) Henley, F.; Kang, S.; Brailove, A.; Fujisaka, A. Kerf-Free Wafering for High-Volume, High-Efficiency c-Si Cell. In Proceedings of the 26th European Photovoltaic Solar Energy Conference 2011; 2011.

(57) Li, J.; Lin, Y.; Wang, F.; Shi, J.; Sun, J.; Ban, B.; Liu, G.; Chen, J. Progress in Recovery and Recycling of Kerf Loss Silicon Waste in Photovoltaic Industry. Separation and Purification Technology 2021, 254. https://doi.org/10.1016/j.seppur.2020.117581.

(58) Wang, T. Y.; Lin, Y. C.; Tai, C. Y.; Sivakumar, R.; Rai, D. K.; Lan, C. W. A Novel Approach for Recycling of Kerf Loss Silicon from Cutting Slurry Waste for Solar Cell Applications. Journal of Crystal Growth 2008, 310 (15), 3403-3406. https://doi.org/10.1016/j.jcrysgro.2008.04.031.

(59) Davis, J. R.; Rohatgi, A.; Hopkins, R. H.; Blais, P. D.; Rai-Choudhury, P.; Mccormick, J. R.; Mollenkopf, H. C. Impurities in Silicon Solar Cells. IEEE Transactions on electron devices 1980, 27 (4), 677-687.

(60) SEMI. SEMI PV17 - Specification for Virgin Silicon Feedstock Materials for Photovoltaic Applications; 2021.

(61) Drouiche, N.; Cuellar, P.; Kerkar, F.; Medjahed, S.; Boutouchent-Guerfi, N.; Ould Hamou, M. Recovery of Solar Grade Silicon from Kerf Loss Slurry Waste. Renewable and Sustainable Energy Reviews 2014, 32, 936-943. https://doi.org/10.1016/j.rser.2014.01.059.

(62) Ravikumar, D.; Wender, B.; Seager, T. P.; Fraser, M. P.; Tao, M. A Climate Rationale for Research and Development on Photovoltaics Manufacture. Applied Energy 2017, 189, 245-256. https://doi.org/10.1016/j.apenergy.2016.12.050.

(63) Kao, T.-L.; Huang, W.-H.; Tuan, H.-Y. Kerf Loss Silicon as a Cost-Effective, HighEfficiency, and Convenient Energy Carrier: Additive-Mediated Rapid Hydrogen Production and Integrated Systems for Electricity Generation and Hydrogen Storage. Journal of Materials Chemistry A 2016, 4 (33), 12921-12928. https://doi.org/10.1039/c6ta03657k.

(64) Kim, J.; Kim, S. Y.; Yang, C. M.; Lee, G. W. Possibility of Recycling SiOx Particles Collected at Silicon Ingot Production Process as an Anode Material for Lithium Ion Batteries. Sci Rep 2019, 9 (1), 13313.

(65) DuPont Teijin Films. Mylar UVPHET - Sustainability Without Compromise. 2020.

(66) Yue, D.; You, F.; Darling, S. B. Domestic and Overseas Manufacturing Scenarios of Silicon-Based Photovoltaics: Life Cycle Energy and Environmental Comparative Analysis. Solar Energy 2014, 105, 669-678. https://doi.org/10.1016/j.solener.2014.04.008. 
(67) Ravikumar, D.; Seager, T. P.; Chester, M. V.; Fraser, M. P. Intertemporal Cumulative Radiative Forcing Effects of Photovoltaic Deployments. Environmental Science \& Technology 2014, 48 (17), 10010-10018.

(68) Ultra Low Carbon Solar Alliance. The Ultra Low-Carbon Solar Era is Here https:/ultralowcarbonsolar.org/ultra-low-carbon-solar/.

(69) UL. IEC / UL 61730 -New Harmonized Safety Standard for PV Modules

https://www.ul.com/news/iec-ul-61730-new-harmonized-safety-standard-pv-modules (accessed $2021-01-01$ ).

(70) International Electrotechnical Commission. IEC 61215 https://webstore.iec.ch/publication/24312.

(71) International Electrotechnical Commission. IEC 61215-1-2:2016.

(72) NREL. Best Research-Cell Efficiency Chart https://www.nrel.gov/pv/cellefficiency.html.

(73) Lazard. Levelized Cost of Energy and Levelized Cost of Storage - 2020; Lazard, 2020.

(74) Weckend, S.; Wade, A.; Heath, G. A. End of Life Management: Solar Photovoltaic Panels; NREL/TP-6A20-73852, 1561525; IRENA, 2016; p NREL/TP-6A20-73852, 1561525. https://doi.org/10.2172/1561525.

(75) Ravikumar, D.; Seager, T.; Sinha, P.; Fraser, M. P.; Reed, S.; Harmon, E.; Power, A. Environmentally Improved CdTe Photovoltaic Recycling through Novel Technologies and Facility Location Strategies. Progress in Photovoltaics: Research and Applications 2020, 28 (9), 887-898.

(76) Aryan, V.; Font-Brucart, M.; Maga, D. A Comparative Life Cycle Assessment of End-ofLife Treatment Pathways for Photovoltaic Backsheets. Progress in Photovoltaics: Research and Applications 2018, 26 (7), 443-459. https://doi.org/10.1002/pip.3003.

(77) Fraunhofer UMSICHT. End-of-Life Pathways for Photovoltaic Backsheets. 2017.

(78) Ardente, F.; Latunussa, C. E. L.; Blengini, G. A. Resource Efficient Recovery of Critical and Precious Metals from Waste Silicon PV Panel Recycling. Waste Management 2019, 91, 156-167. https://doi.org/10.1016/j.wasman.2019.04.059.

(79) Lennon, A.; Yao, Y.; Wenham, S. Evolution of Metal Plating for Silicon Solar Cell Metallisation. Progress in Photovoltaics: Research and Applications 2013, 21 (7), 14541468.

(80) PV Magazine. Safely Meeting Demand for Renewable Energy with Innovative Material Design for Health and Sustainability. 2020.

(81) DSM. The recyclable backsheet https://www.dsm.com/dsm-insolar/en_US/technologies/pv-backsheets/the-recyclable-backsheet.html (accessed 2021 $01-01)$.

(82) Karas, J.; Michaelson, L.; Munoz, K.; Jobayer Hossain, M.; Schneller, E.; Davis, K. O.; Bowden, S.; Augusto, A. Degradation of Copper-plated Silicon Solar Cells with Damp Heat Stress. Progress in Photovoltaics: Research and Applications 2020, 28 (11), 11751186. https://doi.org/10.1002/pip.3331.

(83) Goris, M. J. A. A.; Rosca, V.; Geerligs, L. J.; de Gier, B. Production of Recyclable Crystalline Si PV Modules; 2015; pp 1925-1929.

(84) Norgren, A.; Carpenter, A.; Heath, G. Design for Recycling Principles Applicable to Selected Clean Energy Technologies- Crystalline-Silicon Photovoltaic Modules, Electric Vehicle Batteries, and Wind Turbine Blades. 2020. 
(85) Einhaus, R.; Madon, F.; Degoulange, J.; Wambach, K.; Denafas, J.; Lorenzo, F. R.; Abalde, S. C.; Garcia, T. D.; Bollar, A. Recycling and Reuse Potential of NICE PVModules; EU Horizon 2020, 2018; p 4.

(86) Phua, B.; Shen, X.; Hsiao, P.-C.; Kong, C.; Stokes, A.; Lennon, A. Degradation of Plated Silicon Solar Module Due to Copper Diffusion: The Role of Capping Layer Formation and Contact Adhesion. Solar Energy Materials and Solar Cells 2020, 215. https://doi.org/10.1016/j.solmat.2020.110638.

(87) Couderc, R.; Amara, M.; Degoulange, J.; Madon, F.; Einhaus, R. Encapsulant for GlassGlass PV Modules for Minimum Optical Losses: Gas or EVA? Energy Procedia 2017, No. 124, 470-477.

(88) Song, H.-J.; Yoon, H. sang; Ju, Y.; Kim, S. M.; Shin, W. G.; Lim, J.; Ko, S.; Hwang, H. mi; Kang, G. H. Conductive Paste Assisted Interconnection for Environmentally Benign Lead-Free Ribbons in c-Si PV Modules. Solar Energy 2019, 184, 273-280. https://doi.org/10.1016/j.solener.2019.04.011.

(89) DuPont. DuPont Global Field Reliability Report. 2020.

(90) Ravikumar, D.; Seager, T. P.; Cucurachi, S.; Prado, V.; Mutel, C. Novel Method of Sensitivity Analysis Improves the Prioritization of Research in Anticipatory Life Cycle Assessment of Emerging Technologies. Environ Sci Technol 2018, 52 (11), 6534-6543. Ravikumar, D., Sinha, P. ,. Seager, T. P. ,. Fraser, M. P. An Anticipatory Approach to Quantify Energetics of Recycling CdTe Photovoltaic Systems. Progress in Photovoltaics: Research and Applications 2016, 24 (5), 735-746. https://doi.org/10.1002/pip.2711.

(92) Hemlock Semiconductor. Making Solar Energy Even Cleaner. 2021.

(93) PV Magazine. South Korea to prioritize PV projects with low carbon footprint, highefficiency modules https:/www.pv-magazine.com/2019/03/11/south-korea-to-prioritizepv-projects-with-low-carbon-footprint-high-efficiency-modules/.

(94) PV Magazine. French Regulator Proposes Tightening up Controversial Carbon Footprint Rules. PV Magazine. 2019.

(95) Hsu, D. D.; O’Donoughue, P.; Fthenakis, V.; Heath, G. A.; Kim, H. C.; Sawyer, P.; Choi, J.-K.; Turney, D. E. Life Cycle Greenhouse Gas Emissions of Crystalline Silicon Photovoltaic Electricity Generation. Journal of Industrial Ecology 2012, 16, S122-S135. https://doi.org/10.1111/j.1530-9290.2011.00439.x.

(96) Grant, C. A.; Hicks, A. L. Effect of Manufacturing and Installation Location on Environmental Impact Payback Time of Solar Power. Clean Technologies and Environmental Policy 2019, 22 (1), 187-196. https://doi.org/10.1007/s10098-019-01776$\mathrm{Z}$.

(97) Dziedzic, A.; Graczyk, I. Lead-Free Solders and Isotropically Conductive Adhesives in Assembling of Silicon Solar Cells-Preliminary Results; IEEE, 2003; pp 127-132.

(98) Mitsubishi Electric Solar. High-efficiency, eco-friendly modules https://www.mitsubishielectricsolar.com/products/commercial/solar-modules/ (accessed $2021-01-01)$.

(99) NSF International Standard / American National Standard. NSF/ANSI 457 - 2019 Sustainability Leadership Standard for Photovoltaic Modules and Photovoltaic Inverters. 2019.

(100) The Silicon valley Toxics Coalition. Solar Scorecard Guidelines https://www.solarscorecard.com/2016-17/score-guidelines.php. 
(101) CSA Group. Photovoltaic (PV) Recycling, Reusing, and Decommissioning - Current Landscape and Opportunities for Standardization. 2020.

(102) Polverini, D.; Dodd, N.; Espinosa, N. Potential Regulatory Approaches on the Environmental Impacts of Photovoltaics: Expected Improvements and Impacts on Technological Innovation. Progress in Photovoltaics: Research and Applications 2020, 1-15. https://doi.org/10.1002/pip.3344.

(103) Wagner, M.; Bavec, S.; Herreras, L.; et al. Technical Guideline Tools for Harmonization of Data Collection on WEEE/PV Panels. 2019.

(104) Vohra, K.; Vodonos, A.; Schwartz, J.; Marais, E. A.; Sulprizio, M. P.; Mickley, L. J. Global Mortality from Outdoor Fine Particle Pollution Generated by Fossil Fuel Combustion: Results from GEOS-Chem. Environmental Research 2021. https://doi.org/10.1016/j.envres.2021.110754.

(105) Diffenbaugh, N. S.; Burke, M. Global Warming Has Increased Global Economic Inequality. Proc Natl Acad Sci U S A 2019, 116 (20), 9808-9813.

(106) Washington Post. Solar Energy Firms Leave Waste Behind in China https://www.washingtonpost.com/wpdyn/content/article/2008/03/08/AR2008030802595.html (accessed 2008 -01 -01).

(107) Politico. Fears over China's Muslim forced labor loom over EU solar power https://www.politico.eu/article/xinjiang-china-polysilicon-solar-energy-europe/ (accessed $2021-01-01)$.

(108) U.S. Bureau of Labor Statistics. Solar Photovoltaic Installers, 2021.

(109) Fthenakis, V.; Kim, H. C. Land Use and Electricity Generation: A Life-Cycle Analysis. Renewable and Sustainable Energy Reviews 2009, 13 (6-7), 1465-1474. https://doi.org/10.1016/j.rser.2008.09.017.

(110) Murphy, D. J.; Horner, R. M.; Clark, C. E. The Impact of Off-Site Land Use Energy Intensity on the Overall Life Cycle Land Use Energy Intensity for Utility-Scale Solar Electricity Generation Technologies. J. Renewable Sustainable Energy 2015, 7 (3), 033116. https://doi.org/10.1063/1.4921650.

(111) Horner, R. M.; Clark, C. E. Characterizing Variability and Reducing Uncertainty in Estimates of Solar Land Use Energy Intensity. Renewable and Sustainable Energy Reviews 2013, 23, 129-137. https://doi.org/10.1016/j.rser.2013.01.014.

(112) Jordaan, S. M.; Heath, G. A.; Macknick, J.; Bush, B. W.; Mohammadi, E.; Ben-Horin, D.; Urrea, V.; Marceau, D. Understanding the Life Cycle Surface Land Requirements of Natural Gas-Fired Electricity. Nature Energy 2017, 2 (10), 804-812. https://doi.org/10.1038/s41560-017-0004-0.

(113) Ong, S.; Campbell, C.; Denholm, P.; Margolis, R.; Heath, G. Land-Use Requirements for Solar Power Plants in the United States; Technical Report NREL/TP-6A20-56290; National Renewable Energy Laboratory, 2013; p 47.

(114) Lovins, A. B. Renewable Energy's 'Footprint' Myth. The Electricity Journal 2011, 24 (6), 40-47. https://doi.org/10.1016/j.tej.2011.06.005.

(115) Ong, S.; Campbell, C.; Heath, G. Land Use for Wind, Solar, and Geothermal Electricity Generation Facilities in the United States. National Renewable Energy Laboratory, Golden, CO 2012, 88.

(116) Asdrubali, F.; Baldinelli, G.; D’Alessandro, F.; Scrucca, F. Life Cycle Assessment of Electricity Production from Renewable Energies: Review and Results Harmonization. 
Renewable and Sustainable Energy Reviews 2015, 42, 1113-1122.

https://doi.org/10.1016/j.rser.2014.10.082.

(117) Macknick, J.; Lee, C.; Mosey, G.; Melius, J. Solar Development on Contaminated and Disturbed Lands; NREL/TP-6A20-58485; National Renewable Energy Lab. (NREL), Golden, CO (United States), 2013. https://doi.org/10.2172/1260337.

(118) Hartmann, H. M.; Grippo, M. A.; Heath, G. A.; Macknick, J.; Smith, K. P.; Sullivan, R. G.; Walston, L. J.; Wescott, K. L. Understanding Emerging Impacts and Requirements Related to Utility-Scale Solar Development; ANL/EVS-16/9; Argonne National Lab. (ANL), Argonne, IL (United States), 2016. https://doi.org/10.2172/1329640.

(119) OpenEI. Definition: Balancing Authority Area. Balancing Authority Area.

(120) Brown, M.; et al. Regional Energy Deployment System (ReEDS) Model Documentation: Version 2019; NREL/TP-6A20-74111; National Renewable Energy Laboratory: Golden, $\mathrm{CO}, 2020$.

(121) Maclaurin, G. J.; Grue, N. W.; Lopez, A. J.; Heimiller, D. M. The Renewable Energy Potential (ReV) Model: A Geospatial Platform for Technical Potential and Supply Curve Modeling; NREL/TP-6A20-73067, 1563140; 2019; p NREL/TP-6A20-73067, 1563140. https://doi.org/10.2172/1563140.

(122) Walston, L. J.; Li, Y.; Hartmann, H. M.; Macknick, J.; Hanson, A.; Nootenboom, C.; Lonsdorf, E.; Hellmann, J. Modeling the Ecosystem Services of Native Vegetation Management Practices at Solar Energy Facilities in the Midwestern United States. Ecosystem Services 2021, 47, 101227. https://doi.org/10.1016/j.ecoser.2020.101227.

(123) Bolinger, M. Land Requirements for Utility-Scale PV: An Empirical Update on Power Density (MW/Acre) and Energy Density (MWh/Acre); ASES Solar 2021, 2021.

(124) USGS. Protected Areas | USGS.gov https://www.usgs.gov/core-science-systems/scienceanalytics-and-synthesis/gap/science/protected-areas (accessed 2021 -03 -02).

(125) U.S. Geological Survey. LANDFIRE: Existing Vegetation Type, 2016.

(126) EPA. RE-Powering America's Land https://www.epa.gov/re-powering (accessed 2021 $03-02)$.

(127) USGS (U.S. Geological Survey). Land Cover Trends Project: Classification System, 2012.

(128) Mehos, M.; Turchi, C.; Jorgenson, J.; Denholm, P.; Ho, C.; Armijo, K. On the Path to SunShot - Advancing Concentrating Solar Power Technology, Performance, and Dispatchability; NREL/TP-5500-65688 SAND-2016-2237 R; EERE Publication and Product Library, 2016. https://doi.org/10.2172/1344199.

(129) USDA. Farms and Farmland: Numbers, Acreage, Ownership, and Use; USDA: Washington, D.C., 2014.

(130) LANDFIRE. Existing Vegetation Type.

(131) Brummer, V. Community Energy - Benefits and Barriers: A Comparative Literature Review of Community Energy in the UK, Germany and the USA, the Benefits It Provides for Society and the Barriers It Faces. Renewable and Sustainable Energy Reviews 2018, 94, 187-196. https://doi.org/10.1016/j.rser.2018.06.013.

(132) Poggi, F.; Firmino, A.; Amado, M. Planning Renewable Energy in Rural Areas: Impacts on Occupation and Land Use. Energy 2018, 155, 630-640. https://doi.org/10.1016/j.energy.2018.05.009.

(133) EIA. Form EIA-860 detailed data with previous form data (EIA-860A/860B) https://www.eia.gov/electricity/data/eia860/ (accessed 2021 -03-02). 
(134) SEIA. SEIA How Community Solar Supports American Farmers; 2020.

(135) Siegner, K.; Brehm, K.; Dyson, M. Seeds of Opportunity: How Rural America Is Reaping Economic Development Benefits from the Growth of Renewables https://rmi.org/insight/seeds-of-opportunity/ (accessed 2021 -03 -02).

(136) Buechler, S.; Vázquez-García, V.; Martínez-Molina, K. G.; Sosa-Capistrán, D. M. Patriarchy and (Electric) Power? A Feminist Political Ecology of Solar Energy Use in Mexico and the United States. Energy Research \& Social Science 2020, 70, 101743. https://doi.org/10.1016/j.erss.2020.101743.

(137) USFWS. ECOS: USFWS Threatened \& Endangered Species Active Critical Habitat Report https://ecos.fws.gov/ecp/report/table/critical-habitat.html (accessed 2021 -03 -02).

Birkholz, D.; Miltich, L.; Wachtler, J.; Roos, S.; Patton, R.; Bucholtz, J. Solar Energy Production and Prime Farmland, Guidance for Evaluating Prudent and Feasible Alternatives; Minnesota Commerce Department, 2020; p 6.

(139) Clean Energy States Alliance. State Pollinator-Friendly Solar Initiatives. 2020, 12.

(140) Hooper, T.; Armstrong, A.; Vlaswinkel, B. Environmental Impacts and Benefits of Marine Floating Solar. Solar Energy 2020, S0038092X2031063X. https://doi.org/10.1016/j.solener.2020.10.010.

(141) Hughes, M. D.; Smith, D. E.; Borca-Tasciuc, D.-A. Performance of Wedge-Shaped Luminescent Solar Concentrators Employing Phosphor Films and Annual Energy Estimation Case Studies. Renewable Energy 2020, 160, 513-525.

https://doi.org/10.1016/j.renene.2020.07.005.

(142) MacLeod, K.; DiLorenzo, F. Minerals in the Green Economy: Solar panels and lithiumion batteries https://www.igfmining.org/minerals-green-economy-solar-panels-lithiumion-batteries/ (accessed $2021-05-20)$.

(143) Bolinger, M.; Seel, J. Utility-Scale Solar: Empirical Trends in Project Technology, Cost, Performance, and PPA Pricing in the United States - 2018 Edition; 1477381; Lawrence Berkeley National Laboratory, 2018. https://doi.org/10.2172/1477381.

(144) Adeh, E. H.; Good, S. P.; Calaf, M.; Higgins, C. W. Solar PV Power Potential Is Greatest Over Croplands. Scientific Reports 2019, 9 (1), 11442. https://doi.org/10.1038/s41598019-47803-3.

(145) Borrelli, P.; Robinson, D. A.; Panagos, P.; Lugato, E.; Yang, J. E.; Alewell, C.; Wuepper, D.; Montanarella, L.; Ballabio, C. Land Use and Climate Change Impacts on Global Soil Erosion by Water (2015-2070). Proc Natl Acad Sci USA 2020, 117 (36), 21994-22001. https://doi.org/10.1073/pnas.2001403117.

(146) Raven, P. H.; Wagner, D. L. Agricultural Intensification and Climate Change Are Rapidly Decreasing Insect Biodiversity. Proc Natl Acad Sci USA 2021, 118 (2), e2002548117. https://doi.org/10.1073/pnas.2002548117.

(147) Rehbein, J. A.; Watson, J.; Lane, J.; Sonter, L.; Venter, O.; Atkinson, S.; Allan, J. Renewable Energy Development Threatens Many Globally Important Biodiversity Areas. Global Change Biology 2020, 26. https://doi.org/10.1111/gcb.15067.

(148) Zhu, G.; Papeş, M.; Giam, X.; Cho, S.-H.; Armsworth, P. R. Are Protected Areas WellSited to Support Species in the Future in a Major Climate Refuge and Corridor in the United States? Biological Conservation 2021, 255, 108982. https://doi.org/10.1016/j.biocon.2021.108982. 
(149) Dias, L.; Gouveia, J. P.; Lourenço, P.; Seixas, J. Interplay between the Potential of Photovoltaic Systems and Agricultural Land Use. Land Use Policy 2019, 81, 725-735. https://doi.org/10.1016/j.landusepol.2018.11.036.

(150) Hernandez, R. R.; Hoffacker, M. K.; Murphy-Mariscal, M. L.; Wu, G. C.; Allen, M. F. Solar Energy Development Impacts on Land Cover Change and Protected Areas. PNAS 2015, 112 (44), 13579-13584. https://doi.org/10.1073/pnas.1517656112.

(151) Moore-O’Leary, K. A.; Hernandez, R. R.; Johnston, D. S.; Abella, S. R.; Tanner, K. E.; Swanson, A. C.; Kreitler, J.; Lovich, J. E. Sustainability of Utility-Scale Solar Energy Critical Ecological Concepts. Front Ecol Environ 2017, 15 (7), 385-394. https://doi.org/10.1002/fee.1517.

(152) Walston, L. J.; Mishra, S. K.; Hartmann, H. M.; Hlohowskyj, I.; McCall, J.; Macknick, J. Examining the Potential for Agricultural Benefits from Pollinator Habitat at Solar Facilities in the United States. Environ. Sci. Technol. 2018, 52 (13), 7566-7576. https://doi.org/10.1021/acs.est.8b00020.

(153) Hernandez, R. R.; Armstrong, A.; Burney, J.; Ryan, G.; Moore-O’Leary, K.; Diédhiou, I.; Grodsky, S. M.; Saul-Gershenz, L.; Davis, R.; Macknick, J.; Mulvaney, D.; Heath, G. A.; Easter, S. B.; Hoffacker, M. K.; Allen, M. F.; Kammen, D. M. Techno-Ecological Synergies of Solar Energy for Global Sustainability. Nat Sustain 2019, 2 (7), 560-568. https://doi.org/10.1038/s41893-019-0309-z.

(154) Horowitz, K.; Ramasamy, V.; Macknick, J.; Margolis, R. Capital Costs for Dual-Use Photovoltaic Installations: 2020 Benchmark for Ground-Mounted PV Systems with Pollinator-Friendly Vegetation, Grazing, and Crops; NREL/TP-6A20-77811; National Renewable Energy Laboratory: Golden, CO, 2020.

(155) Macknick, J.; Beatty, B.; Hill, G. Overview of Opportunities for Co-Location of Solar Energy Technologies and Vegetation; NREL/TP--6A20-60240, 1115798; 2013; p NREL/TP--6A20-60240, 1115798. https://doi.org/10.2172/1115798.

(156) Armstrong, A.; Ostle, N. J.; Whitaker, J. Solar Park Microclimate and Vegetation Management Effects on Grassland Carbon Cycling. Environ. Res. Lett. 2016, 11 (7), 074016. https://doi.org/10.1088/1748-9326/11/7/074016.

(157) Beatty, B.; Macknick, J.; McCall, J.; Braus, G.; Buckner, D. Native Vegetation Performance under a Solar PV Array at the National Wind Technology Center; NREL/TP--1900-66218, 1357887; 2017; p NREL/TP--1900-66218, 1357887. https://doi.org/10.2172/1357887.

(158) Wratten, S. D.; Gillespie, M.; Decourtye, A.; Mader, E.; Desneux, N. Pollinator Habitat Enhancement: Benefits to Other Ecosystem Services. Agriculture, Ecosystems \& Environment 2012, 159, 112-122. https://doi.org/10.1016/j.agee.2012.06.020.

(159) Siegner, K.; Wentzell, S.; Urrutia, M.; Mann, W.; Kennan, H. Maximizing Land Use Benefits from Utility Scale Solar: A Cost-Benefit Analysis of Pollinator- Friendly Solar in Minnesota. 2019, 25.

(160) Cunningham-Minnick, M. J.; Peters, V. E.; Crist, T. O. Nesting Habitat Enhancement for Wild Bees within Soybean Fields Increases Crop Production. Apidologie 2019, 50 (6), 833-844. https://doi.org/10.1007/s13592-019-00691-y.

(161) DOE. SETO 2020 - Solar and Agriculture https://www.energy.gov/eere/solar/seto-2020solar-and-agriculture (accessed $2021-03-02$ ).

(162) Liebig, M. A.; Herrick, J. E.; Archer, D. W.; Dobrowolski, J.; Duiker, S. W.; Franzluebbers, A. J.; Hendrickson, J. R.; Mitchell, R.; Mohamed, A.; Russell, J.; 
Strickland, T. C. Aligning Land Use with Land Potential: The Role of Integrated Agriculture. Agric. environ. lett. 2017, 2 (1), 170007.

https://doi.org/10.2134/ael2017.03.0007.

(163) Ravi, S.; Macknick, J.; Lobell, D.; Field, C. Co-Location Opportunities for Renewable Energy and Agriculture. Applied Energy 2016, 165, 383-392.

(164) Dinesh, H.; Pearce, J. M. The Potential of Agrivoltaic Systems. Renewable and Sustainable Energy Reviews 2016, 54, 299-308. https://doi.org/10.1016/j.rser.2015.10.024.

(165) Hoffacker, M. K.; Allen, M. F.; Hernandez, R. R. Land-Sparing Opportunities for Solar Energy Development in Agricultural Landscapes: A Case Study of the Great Central Valley, CA, United States. Environ. Sci. Technol. 2017, 51 (24), 14472-14482. https://doi.org/10.1021/acs.est.7b05110.

(166) Malu, P. R.; Sharma, U. S.; Pearce, J. M. Agrivoltaic Potential on Grape Farms in India. Sustainable Energy Technologies and Assessments 2017, 23, 104-110. https://doi.org/10.1016/j.seta.2017.08.004.

(167) Barron-Gafford, G. A.; Pavao-Zuckerman, M. A.; Minor, R. L.; Sutter, L. F.; BarnettMoreno, I.; Blackett, D. T.; Thompson, M.; Dimond, K.; Gerlak, A. K.; Nabhan, G. P.; Macknick, J. E. Agrivoltaics Provide Mutual Benefits across the Food-Energy-Water Nexus in Drylands. Nature Sustainability 2019, 2 (9), 848-855. https://doi.org/10.1038/s41893-019-0364-5.

(168) Weselek, A.; Ehmann, A.; Zikeli, S.; Lewandowski, I.; Schindele, S.; Högy, P. Agrophotovoltaic Systems: Applications, Challenges, and Opportunities. A Review. Agron. Sustain. Dev. 2019, 39 (4), 35. https://doi.org/10.1007/s13593-019-0581-3.

(169) Sekiyama, T.; Nagashima, A. Solar Sharing for Both Food and Clean Energy Production: Performance of Agrivoltaic Systems for Corn, A Typical Shade-Intolerant Crop. Environments 2019, 6 (6), 65. https://doi.org/10.3390/environments6060065.

(170) Adeh, E. H.; Selker, J. S.; Higgins, C. W. Remarkable Agrivoltaic Influence on Soil Moisture, Micrometeorology and Water-Use Efficiency. PLOS ONE 2018, 13 (11), e0203256. https://doi.org/10.1371/journal.pone.0203256.

(171) UNFAO. Livestock's Long Shadow. 2006.

(172) Heitschmidt, R. K.; Vermeire, L. T.; Grings, E. E. Is Rangeland Agriculture Sustainable? Journal of Animal Science 2004, 82, 9.

(173) Andrew, A. C. Lamb Growth and Pasture Production in Agrivoltaic Production System, Oregon State University, 2020.

(174) Campos Maia, A. S.; de Andrade Culhari, E.; de França Carvalho Fonsêca, V.; Maia Milan, H. F.; Gebremedhin, K. G. Photovoltaic Panels as Shading Resources for Livestock. Journal of Cleaner Production 2020, 258, 120551.

(175) American Solar Grazing Association. What and Why - American Solar Grazing Association, 2021.

(176) Hernandez, R. R.; Hoffacker, M. K.; Field, C. B. Land-Use Efficiency of Big Solar. Environmental Science \& Technology 2014, 48 (2), 1315-1323. https://doi.org/10.1021/es4043726.

(177) Montag, H.; Parker, G.; Clarkson, T. The Effects of Solar Farms on Local Biodiversity. Clarkson and Woods and Wychwood Biodiversity 2016, 53.

(178) Lytle, W.; Meyer, T. K.; Tanikella, N. G.; Burnham, L.; Engel, J.; Schelly, C.; Pearce, J. M. Conceptual Design and Rationale for a New Agrivoltaics Concept: Pasture-Raised 
Rabbits and Solar Farming. Journal of Cleaner Production 2021, 282, 124476. https://doi.org/10.1016/j.jclepro.2020.124476.

(179) Jacob, J.; Davis, R. Flowering Solar Farms — "Agrivoltaics:” A Powerful Sweet Synergy. American Bee Journal 2019.

(180) Paini, D. Impact of the Introduced Honey Bee (Apis Mellifera) (Hymenoptera: Apidae) on Native Bees: A Review. Austral Ecology 2004, 29, 399-407. https://doi.org/10.1111/j.1442-9993.2004.01376.x.

(181) Evans, E.; Smart, M.; Cariveau, D.; Spivak, M. Wild, Native Bees and Managed Honey Bees Benefit from Similar Agricultural Land Uses. Agriculture, Ecosystems \& Environment 2018, 268, 162-170. https://doi.org/10.1016/j.agee.2018.09.014.

(182) Spencer, R. S.; Macknick, J.; Aznar, A.; Warren, A.; Reese, M. O. Floating Photovoltaic Systems: Assessing the Technical Potential of Photovoltaic Systems on Man-Made Water Bodies in the Continental United States. Environ. Sci. Technol. 2019, 53 (3), 1680-1689. https://doi.org/10.1021/acs.est.8b04735.

(183) Golroodbari, S. Z.; Sark, W. van. Simulation of Performance Differences between Offshore and Land-Based Photovoltaic Systems. Progress in Photovoltaics: Research and Applications 2020, 28 (9), 873-886. https://doi.org/10.1002/pip.3276.

(184) Armstrong, A.; Page, T.; Thackeray, S. J.; Hernandez, R. R.; Jones, I. D. Integrating Environmental Understanding into Freshwater Floatovoltaic Deployment Using an Effects Hierarchy and Decision Trees. Environ. Res. Lett. 2020, 15 (11), 114055. https://doi.org/10.1088/1748-9326/abbf7b.

(185) Oliveira-Pinto, S.; Stokkermans, J. Assessment of the Potential of Different Floating Solar Technologies - Overview and Analysis of Different Case Studies. Energy Conversion and Management 2020, 211, 112747. https://doi.org/10.1016/j.enconman.2020.112747.

(186) McKuin, B.; Zumkehr, A.; Ta, J.; Bales, R.; Viers, J. H.; Pathak, T.; Campbell, J. E. Energy and Water Co-Benefits from Covering Canals with Solar Panels. Nature Sustainability 2021, 1-9. https://doi.org/10.1038/s41893-021-00693-8.

(187) Dieter, C. A.; Maupin, M. A.; Caldwell, R. R.; Harris, M. A.; Ivahnenko, T. I.; Lovelace, J. K.; Barber, N. L.; Linsey, K. S. Estimated Use of Water in the United States in 2015. U.S. Geological Survey Circular 14412018.

(188) McCall, J.; Macknick, J.; Hillman, D. Water-Related Power Plant Curtailments: An Overview of Incidents and Contributing Factors; NREL/TP-6A20-67084; National Renewable Energy Lab.(NREL), Golden, CO (United States), 2016.

(189) Macknick, J.; Newmark, R.; Heath, G.; Hallett, K. Operational Water Consumption and Withdrawal Factors for Electricity Generating Technologies: A Review of Existing Literature. Environmental Research Letters 2012, 7 (4), 045802.

(190) EPA. Regulatory Impact Analysis for the Clean Power Plan Final Rule; EPA-452/R-15003; U.S. Environmental Protection Agency: Washington, D.C., 2015.

(191) Fann, N.; Fulcher, C. M.; Baker, K. The Recent and Future Health Burden of Air Pollution Apportioned across US Sectors. Environmental science \& technology 2013, 47, 3580-3589.

(192) EPA. Overview of EPA's MOtor Vehicle Emission Simulator (MOVES3); EPA-420-R21-004; U.S. Environmental Protection Agency: Washington, D.C., 2021. 
(193) Wiser, R. H.; Millstein, D.; Rand, J.; Donohoo-Vallett, P.; Gilman, P.; Mai, T. Halfway to Zero: Progress towards a Carbon-Free Power Sector; Lawrence Berkeley National Laboratory: Berkeley, CA, 2021.

(194) Dallmann, T. R.; Harley, R. A. Evaluation of Mobile Source Emission Trends in the United States. Journal of Geophysical Research: Atmospheres 2010, 115.

(195) McDonald, B. C.; Dallmann, T. R.; Martin, E. W.; Harley, R. A. Long-term Trends in Nitrogen Oxide Emissions from Motor Vehicles at National, State, and Air Basin Scales. Journal of Geophysical Research: Atmospheres 2012, 117.

(196) McDonald, B. C.; Goldstein, A. H.; Harley, R. A. Long-Term Trends in California Mobile Source Emissions and Ambient Concentrations of Black Carbon and Organic Aerosol. Environmental science \& technology 2015, 49, 5178-5188.

(197) Preble, C. V.; Harley, R. A.; Kirchstetter, T. W. Control Technology-Driven Changes to in-Use Heavy-Duty Diesel Truck Emissions of Nitrogenous Species and Related Environmental Impacts. Environmental science \& technology 2019, 53, 14568-14576.

(198) Wolfe, P.; Davidson, K.; Fulcher, C.; Fann, N.; Zawacki, M.; Baker, K. R. Monetized Health Benefits Attributable to Mobile Source Emission Reductions across the United States in 2025. Science of the Total Environment 2019, 650, 2490-2498.

(199) deX. New marketplaces for energy services https://dex.energy/about-dex/ (accessed 2020 $-01-01)$.

(200) Svatikova, K.; Artola, I.; Slingerland, S.; Fischer, S. Selling Solar Services as a Contribution to a Circular Economy. 2015.

(201) blueleaf energy. blueleaf energy - Services https://www.blueleafenergy.com/services (accessed $2021-01-01$ ).

(202) DZ-4. DZ-4 - Germany's first provider of solar systems for rent https://www.dz4.de/ueber-uns (accessed 2021 -01 -01).

(203) Loritz, M. Dutch Solar Rental Startup Solease Raises €3 Million from New York Investment Fund. EU-Startups. December 7, 2018.

(204) Barbose, G.; Darghouth, N.; O’Shaughnessy, E.; Forrester, S. Distributed Solar 2020 Data Update; Lawrence Berkeley National Laboratory: Berkeley, CA, 2020.

(205) Schmidt-Costa, J. R.; Uriona-Maldonado, M.; Possamai, O. Product-Service Systems in Solar PV Deployment Programs: What Can We Learn from the California Solar Initiative? Resources, Conservation and Recycling 2019, 140, 145-157. https://doi.org/10.1016/j.resconrec.2018.09.017.

(206) Rai, V.; Sigrin, B. Diffusion of Environmentally-Friendly Energy Technologies: Buy versus Lease Differences in Residential PV Markets. Environmental Research Letters 2013, 8 (1), 014022.

(207) Rai, V.; Reeves, D. C.; Margolis, R. Overcoming Barriers and Uncertainties in the Adoption of Residential Solar PV. Renewable Energy 2016, 89 (498-505).

(208) Lam, P. T. I.; Yu, J. S. Developing and Managing Photovoltaic Facilities Based on Third-Party Ownership Business Models in Buildings. Facilities 2016, 34 (13/14), 855872. https://doi.org/10.1108/f-04-2015-0019.

(209) O’Shaughnessy, E.; Barbose, G.; Wiser, R.; Forrester, S.; Darghouth, N. The Impact of Policies and Business Models on Income Equity in Rooftop Solar Adoption. Nature Energy 2020, 6 (1), 84-91. https://doi.org/10.1038/s41560-020-00724-2.

(210) Longi Solar. Making Every Photon Count; Power PV Tech; 2018; p 112. 
(211) Jean, J.; Woodhouse, M.; Bulović, V. Accelerating Photovoltaic Market Entry with Module Replacement. Joule 2019, 3 (11), 2824-2841.

https://doi.org/10.1016/j.joule.2019.08.012.

(212) REC Solar. Repowering Breathes New Life into Aging Solar Installations https://www.recsolar.com/blogs/repower-solar/ (accessed 2019 -01 -01).

(213) Longi Solar. Retrofit Technical Approaches to Maximise PV Plant Returns; Longi Solar, 2018.

(214) Mackenzie, W. Annual solar repairs and maintenance spend to grow to $\$ 9$ billion by $2025 \mathrm{https}: / / \mathrm{www} . w o o d m a c . c o m / p r e s s-r e l e a s e s / a n n u a l-s o l a r-r e p a i r s-a n d-m a i n t e n a n c e-$ spend-to-grow-to-\$9-billion-by-2025/ (accessed 2020 -01 -01).

(215) Osborne, M. DuPont's 2019 'Global PV Reliability Study' Warns of Rising Backsheet Delamination and Cracking. PVTech. June 19, 2019.

(216) Pickerel, K. Solar's Silent Killer: Backsheets Are Shortening Some Project Lifespans. Solar Power World. January 15, 2020.

(217) Oreski, G. Co-Extruded Backsheets for PV Modules: Past Approaches and Recent Developments; Polymer Competence Center Leoben GmbH: Leoben, Austria, 2020.

(218) DuPont. DuPont Issues 2019 Global PV Reliability Study. 2019.

(219) Chaturvedi, V. How Backsheet Quality Impacts Modern Solar PV Modules. Solar Power World. July 27, 2020.

(220) CALSSA (California Solar + Storage Association). New Regulations for End-of-Life PV Modules Webinar, 2020.

(221) ASES (American Solar Energy Society). PV Recycling Webinar, 2020.

(222) Solar Power World. Think before trashing: The second-hand solar market is booming https://www.solarpowerworldonline.com/2021/01/think-before-trashing-the-secondhand-solar-market-is-booming/ (accessed 2021 -01 -01).

(223) Heeter, J.; Sekar, A.; Fekete, E.; Shah, M.; Cook, J. Affordable and Accessible Solar for All: Barriers, Solutions, and On-Site Adoption Potential; NREL/TP-6A20-80532; National Renewable Energy Laboratory: Golden, CO, 2021.

(224) Weckend, S.; Wade, A.; Heath, G. A. End of Life Management: Solar Photovoltaic Panels; NREL/TP-6A20-73852, 1561525; IRENA, 2016; p NREL/TP-6A20-73852, 1561525. https://doi.org/10.2172/1561525.

(225) Environmental Protection Agency (EPA). Advancing Sustainable Materials Management: 2018 Fact Sheet; https://www.epa.gov/sites/production/files/202101/documents/2018_ff_fact_sheet_dec_2020_fnl_508.pdf, 2018.

(226) Construction \& Demolition Recycling Association. Construction \& Demolition Recycling Association https://cdrecycling.org (accessed 2021 -01 -01).

(227) Construction \& Demolition Recycling Association. Find a C\&D Recycler, 2021.

(228) Glass Recycling Coalition. Glass Recycling Coalition, 2021.

(229) American Iron and Steel Association. Recycling, 2021.

(230) Abokersh, M. H.; Norouzi, M.; Boer, D.; Cabeza, L. F.; Casa, G.; Prieto, C.; Jiménez, L.; Vallès, M. A Framework for Sustainable Evaluation of Thermal Energy Storage in Circular Economy. Renewable Energy 2021, 175, 686-701. https://doi.org/10.1016/j.renene.2021.04.136.

(231) Salim, H. K.; Stewart, R. A.; Sahin, O.; Dudley, M. Drivers, Barriers and Enablers to End-of-Life Management of Solar Photovoltaic and Battery Energy Storage Systems: A 
Systematic Literature Review. Journal of Cleaner Production 2019, 211, 537-554. https://doi.org/10.1016/j.jclepro.2018.11.229.

(232) CPUC (California Public Utilities Commission). From Cradle to Grave: Addressing Endof-Life Management for Photovoltaic Panels and Batteries for Electric Vehicles and Energy Storage Workshop, 2019.

(233) DTSC (California Department of Toxic Substances and Control). Public Seminar on Universal Waste and Proposed Regulations for the Management of Waste Photovoltaic Modules as Universal Waste, 2019.

(234) UL. 1741 Standard for Inverters, Converters, Controllers and Interconnection System Equipment for Use with Distributed Energy Resources.

(235) IEEE. IEEE 1547 Standard for Interconnection and Interoperability of Distributed Energy Resources with Associated Electric Power System Interfaces https://standards.ieee.org/standard/1547-2018.html.

(236) Eshraghi, N.; Berardo, L.; Schrijnemakers, A.; Delaval, V.; Shaibani, M.; Majumder, M.; Cloots, R.; Vertruyen, B.; Boschini, F.; Mahmoud, A. Recovery of Nano-Structured Silicon from End-of-Life Photovoltaic Wafers with Value-Added Applications in Lithium-Ion Battery. ACS Sustainable Chemistry \& Engineering 2020, 8 (15), 58685879. https://doi.org/10.1021/acssuschemeng.9b07434.

(237) Fernández, L. J.; Ferrer, R.; Aponte, D. F.; Fernández, P. Recycling Silicon Solar Cell Waste in Cement-Based Systems. Solar Energy Materials and Solar Cells 2011, 95 (7), 1701-1706. https://doi.org/10.1016/j.solmat.2011.01.033.

(238) Guojian, C.; Chao, S.-J.; Cheng, A.; Hsu, H.-M.; Chang, J.-R.; Teng, L.-W.; Chen, S.-C.; Muhammad, Y. Durability Quality Research of Concrete Containing Solar PV Cells. MATEC Web of Conferences 2015, 27. https://doi.org/10.1051/matecconf/20152701004.

(239) Stehlík, M.; Knapová, J.; Kostka, V. Possibilities of Use of Glass Recyclate from Photovoltaic Panels for Concrete Masonry Units. IOP Conference Series: Materials Science and Engineering 2019, 549 (1), 012006.

(240) Palitzsch, W.; Loser, U. A New and Intelligent De-Metalization Step of Broken Silicon Cells and Silicon Cell Production Waste in the Recycling Procedure of Crystalline Si Modules; 2011; pp 003269-003270.

(241) Lin, K.-L.; Lee, T.-C.; Hwang, C.-L. Effects of Sintering Temperature on the Characteristics of Solar Panel Waste Glass in the Production of Ceramic Tiles. Journal of Material Cycles and Waste Management 2014, 17, 194-200. https://doi.org/10.1007/s10163-014-0240-3.

(242) Hao, H.; Lin, K. L.; Wang, D.; Chao, S. J.; Shiu, H. S.; Cheng, T. W.; Hwang, C. L. Elucidating Characteristics of Geopolymer with Solar Panel Waste Glass. Environmental Engineering \& Management Journal 2015, 14 (1), 79-87.

(243) Lin, K. L.; Huang, L. S.; Shie, J. L.; Cheng, C. J.; Lee, C. H.; Chang, T. C. Elucidating the Effects of Solar Panel Waste Glass Substitution on the Physical and Mechanical Characteristics of Clay Bricks. Environmental Technology 2013, 34 (1), 15-24. https://doi.org/10.1080/09593330.2012.679693.

(244) Qin, B.; Lin, M.; Zhang, X.; Xu, Z.; Ruan, J. Recovering Polyethylene Glycol Terephthalate and Ethylene-Vinyl Acetate Copolymer in Waste Solar Cells via a Novel Vacuum-Gasification-Condensation Process. ACS ES\&T Engineering 2020. https://doi.org/10.1021/acsestengg.0c00091. 
(245) Heath, G. A.; Silverman, T. J.; Kempe, M.; Deceglie, M.; Ravikumar, D.; Remo, T.; Cui, H.; Sinha, P.; Libby, C.; Shaw, S.; Komoto, K.; Wambach, K.; Butler, E.; Barnes, T.; Wade, A. Research and Development Priorities for Silicon Photovoltaic Module Recycling to Support a Circular Economy. Nature Energy 2020, 5 (7), 502-510. https://doi.org/10.1038/s41560-020-0645-2.

(246) Deng, R.; Chang, N. L.; Ouyang, Z.; Chong, C. M. A Techno-Economic Review of Silicon Photovoltaic Module Recycling. Renewable and Sustainable Energy Reviews 2019, 109, 532-550.

(247) Tao, M.; Fthenakis, V.; Ebin, B.; Steenari, B.-M.; Butler, E.; Sinha, P.; Corkish, R.; Wambach, K.; Simon, E. S. Major Challenges and Opportunities in Silicon Solar Module Recycling. Progress in Photovoltaics: Research and Applications 2020, 28 (10), 10771088. https://doi.org/10.1002/pip.3316.

(248) Tsanakas, J. A.; Heide, A. van der; Radavičius, T.; Denafas, J.; Lemaire, E.; Wang, K.; Poortmans, J.; Voroshazi, E. Towards a Circular Supply Chain for PV Modules: Review of Today's Challenges in PV Recycling, Refurbishment and Re-Certification. Progress in Photovoltaics: Research and Applications 2020, 28 (6), 454-464. https://doi.org/10.1002/pip.3193.

(249) Farrell, C. C.; Osman, A. I.; Doherty, R.; Saad, M.; Zhang, X.; Murphy, A.; Harrison, J.; Vennard, A. S. M.; Kumaravel, V.; Al-Muhtaseb, A. H.; Rooney, D. W. Technical Challenges and Opportunities in Realising a Circular Economy for Waste Photovoltaic Modules. Renewable and Sustainable Energy Reviews 2020, 128, 109911. https://doi.org/10.1016/j.rser.2020.109911.

(250) Motta, C. M.; Cerciello, R.; De Bonis, S.; Mazzella, V.; Cirino, P.; Panzuto, R.; Ciaravolo, M.; Simoniello, P.; Toscanesi, M.; Trifuoggi, M.; Avallone, B. Potential Toxicity of Improperly Discarded Exhausted Photovoltaic Cells. Environ Pollut 2016, 216, 786-792. https://doi.org/10.1016/j.envpol.2016.06.048.

(251) Akimoto, Y.; Iizuka, A.; Shibata, E. High-Voltage Pulse Crushing and Physical Separation of Polycrystalline Silicon Photovoltaic Panels. Minerals Engineering 2018, 125, 1-9. https://doi.org/10.1016/j.mineng.2018.05.015.

(252) Huang, W.-H.; Shin, W. J.; Wang, L.; Sun, W.-C.; Tao, M. Strategy and Technology to Recycle Wafer-Silicon Solar Modules. Solar Energy 2017, 144, 22-31. https://doi.org/10.1016/j.solener.2017.01.001.

(253) Komoto, K., Lee, J. S. ,. Zhang, J. ,. Ravikumar, D. ,. Sinha, P. ,. Wade, A. ,. Heath, G. ,. End-of-Life Management of Photovoltaic Panels: Trends in PV Module Recycling Technologies, IEA PVPS Task 12, International Energy Agency Power Systems Programme, Report IEA-PVPS T12-10:2018.; 2018.

(254) Doi, T.; Tsuda, I.; Unagida, H.; Murata, A.; Sakuta, K.; Kurokawa, K. Experimental Study on PV Module Recycling with Organic Solvent Method. Solar Energy Materials and Solar Cells 2001, 67 (1-4), 397-403.

(255) Mittag, M.; Eitner, U.; Neff, T. TPedge: Progress on Cost-Efficient and Durable EdgeSealed PV Modules; 2017; pp 48-54.

(256) Veolia. Veolia Opens the First European Plant Entirely Dedicated to Recycling Photovoltaic Panels, 2018.

(257) Renew Economy. Australia's First Solar Panel Recycling Facility to Be Established in Adelaide., 2021. 
(258) TamizhMani, G., Shaw, S. ,. Libby, C. ,. Patankar, A. and Bicer, B. ,. Assessing Variability in Toxicity Testing of PV Modules; 2019; pp 2475-2481.

(259) ASTM International. New Practice for Toxicity Testing of Photovoltaic (PV) Modules by Waterjet Cutting Method for Use with EPA Method 1311 https://www.astm.org/DATABASE.CART/WORKITEMS/WK74146.htm (accessed $2021-01-01)$.

(260) Arup. Circular Photovoltaics - Circular Business Models for Australia's Solar Photovoltaics Industry. 2020.

(261) Chowdhury, B.; Chowdhury, M. U. RFID-Based Real-Time Smart Waste Management System; 2007; pp 175-180.

(262) Wender, B. A.; Foley, R. W.; Prado-Lopez, V.; Ravikumar, D.; Eisenberg, D. A.; Hottle, T. A.; Sadowski, J.; Flanagan, W. P.; Fisher, A.; Laurin, L.; Bates, M. E.; Linkov, I.; Seager, T. P.; Fraser, M. P.; Guston, D. H. Illustrating Anticipatory Life Cycle Assessment for Emerging Photovoltaic Technologies. Environ Sci Technol 2014, 48 (18), $10531-10538$.

(263) Choi, J.-K.; Fthenakis, V. Design and Optimization of Photovoltaics Recycling Infrastructure. Environmental Science \& Technology 2010, 44 (22), 8678-8683.

(264) Choi, J.-K.; Fthenakis, V. Crystalline Silicon Photovoltaic Recycling Planning: Macro and Micro Perspectives. Journal of Cleaner Production 2014, 66, 443-449. https://doi.org/10.1016/j.jclepro.2013.11.022.

(265) Goe, M.; Gaustad, G.; Tomaszewski, B. System Tradeoffs in Siting a Solar Photovoltaic Material Recovery Infrastructure. Journal of Environmental Management 2015, 160, 154-166. https://doi.org/10.1016/j.jenvman.2015.05.038.

(266) Guo, Q.; Guo, H. A Framework for End-of-Life Photovoltaics Distribution Routing Optimization. Sustainable Environment Research 2019, 29 (1).

(267) Rinovasol. Refurbishment https://www.rinovasol.com/refurbishment/.

(268) Haque, A.; Bharath, K. V. S.; Khan, M. A.; Khan, I.; Jaffery, Z. A. Fault Diagnosis of Photovoltaic Modules. Energy Science \& Engineering 2019, 7 (3), 622-644. https://doi.org/10.1002/ese3.255.

(269) Ahmad, J.; Ciocia, A.; Fichera, S.; Murtaza, A. F.; Spertino, F. Detection of Typical Defects in Silicon Photovoltaic Modules and Application for Plants with Distributed MPPT Configuration. Energies 2019, 12 (23). https://doi.org/10.3390/en12234547.

(270) PV Europe. Repairing solar modules: sometimes easier than buying new ones https://www.pveurope.eu/solar-generator/repairing-solar-modules-sometimes-easierbuying-new-ones.

(271) Tsanakas, J. A.; Ha, L.; Buerhop, C. Faults and Infrared Thermographic Diagnosis in Operating C-Si Photovoltaic Modules: A Review of Research and Future Challenges. Renewable and Sustainable Energy Reviews 2016, 62, 695-709. https://doi.org/10.1016/j.rser.2016.04.079.

(272) Tsanakas, J. A.; Vannier, G.; Plissonnier, A.; Ha, D. L.; Barruel, F. Fault Diagnosis and Classification of Large-Scale Photovoltaic Plants through Aerial Orthophoto Thermal Mapping.; 2015; pp 1783-1788.

(273) Djordjevic, S.; Parlevliet, D.; Jennings, P. Detectable Faults on Recently Installed Solar Modules in Western Australia. Renewable Energy 2014, 67, 215-221. 
(274) Wade, A., Sinha, P. ,. Drozdiak, K. and Brutsch, E. Beyond Waste-the Fate of End-ofLife Photovoltaic Panels from Large Scale PV Installations in the EU the SocioEconomic Benefits of High Value Recycling Compared to Re-Use; 2017; pp 25-29.

(275) Enbar, N.; Weng, D.; Klise, G. T. Budgeting for Solar PV Plant Operations \& Maintenance: Practices and Pricing (No. SAND-2016-0649R).; Sandia National Lab, 2016.

(276) Rajagopalan, N.; Smeets, A.; Peeters, K.; De Regel, S.; Rommens, T.; Wang, K.; Stolz, P.; Frischknecht, R.; Heath, G. Preliminary Environmental and Financial Viability Analysis of PV Panel Reuse. 2021.

(277) Kramar, D. E.; Anderson, A.; Hilfer, H.; Branden, K.; Gutrich, J. J. A Spatially Informed Analysis of Environmental Justice: Analyzing the Effects of Gerrymandering and the Proximity of Minority Populations to U.S. Superfund Sites. Environmental Justice 2018, 11 (1), 29-39. https://doi.org/10.1089/env.2017.0031.

(278) Mohai, P.; Saha, R. Which Came First, People or Pollution? Assessing the Disparate Siting and Post-Siting Demographic Change Hypotheses of Environmental Injustice. Environmental Research Letters 2015, 10 (11). https://doi.org/10.1088/17489326/10/11/115008.

(279) Burwell-Naney, K., Zhang, H. ,. Samantapudi, A. ,. Jiang, C. ,. Dalemarre, L. ,. Rice, L. ,. Williams, E. and Wilson, S. ,. Spatial Disparity in the Distribution of Superfund Sites in South Carolina: An Ecological Study. Environmental Health 2013, 12 (1), 1-11.

(280) Maranville, A. R., Ting, T. F. and Zhang, Y. ,. An Environmental Justice Analysis: Superfund Sites and Surrounding Communities in Illinois. Environmental Justice 2009, 2 (2), 49-58.

(281) Martuzzi, M.; Mitis, F.; Forastiere, F. Inequalities, Inequities, Environmental Justice in Waste Management and Health. European Journal of Public Health 2010, 20 (1), 21-26. https://doi.org/10.1093/eurpub/ckp216.

(282) van Haaster, B.; Ciroth, A.; Fontes, J.; Wood, R.; Ramirez, A. Development of a Methodological Framework for Social Life-Cycle Assessment of Novel Technologies. The International Journal of Life Cycle Assessment 2016, 22 (3), 423-440. https://doi.org/10.1007/s11367-016-1162-1.

(283) Walzberg, J.; Carpenter, A.; Heath, G. Closing the Loops on Solar Photovoltaics Modules: An Agent-Based Modeling Approach for the Study of Circular Economy Strategies, 2020.

(284) Tong, X.; Nikolic, I.; Dijkhuizen, B.; van den Hoven, M.; Minderhoud, M.; Wäckerlin, N.; Wang, T.; Tao, D. Behaviour Change in Post-Consumer Recycling: Applying AgentBased Modelling in Social Experiment. Journal of Cleaner Production 2018, 187, 10061013. https://doi.org/10.1016/j.jclepro.2018.03.261.

(285) Walzberg, J.; Lonca, G.; Hanes, R. J.; Eberle, A. L.; Carpenter, A.; Heath, G. A. Do We Need a New Sustainability Assessment Method for the Circular Economy? A Critical Literature Review. Frontiers in Sustainability 2021, 1. https://doi.org/10.3389/frsus.2020.620047.

(286) Charnley, F.; Tiwari, D.; Hutabarat, W.; Moreno, M.; Okorie, O.; Tiwari, A. Simulation to Enable a Data-Driven Circular Economy. Sustainability 2019, 11 (12). https://doi.org/10.3390/su11123379. 
(287) Ghoreishi, M.; Happonen, A. Key Enablers for Deploying Artificial Intelligence for Circular Economy Embracing Sustainable Product Design: Three Case Studies; 2020; Vol. 2233, p 050008. https://doi.org/10.1063/5.0001339.

(288) Weckend, S.; Wade, A.; Heath, G. A. End-of-Life Management Solar Photvoltaic Panels; International Renewable Energy Agency, 2016; p 100.

(289) Parajuly, K.; Kuehr, R.; Awasthi, A. K.; Fitzpatrick, C.; Lepawsky, J.; Smith, E.; Widmer, R.; Zeng, X. Future E-Waste Scenarios; StEP, UNU ViE-SCYCLE, and UNEP IETC: Bonn \& Osaka, 2019.

(290) Wambach, K.; Baumann, K.; Seitz, M.; Mertvoy, B.; Reinelt, B. Photovoltaic (PV) Recycling, Reusing, and Decommissioning: Current Landscape and Opportunities for Standardization; Standards Research; bifa Umweltinstitut GmbH, CSA Group, 2020.

(291) IEA PVPS Task 1 1997; Barnes, H., Series Ed.; IEA PVPS T1:1997; IEA-PVPS, 1997.

(292) Goetzberger, A.; Hebling, C. Photovoltaic Materials, Past, Present, Future. Solar Energy Materials and Solar Cells 2000, 62 (1-2), 1-19. https://doi.org/10.1016/S09270248(99)00131-2.

(293) Green, M. A. Consolidation of Thin-Film Photovoltaic Technology: The Coming Decade of Opportunity. Progress in Photovoltaics: Research and Applications 2006, 14 (5), 383392. https://doi.org/10.1002/pip.702.

(294) Bolinger, M.; Seel, J.; Robson, D. Utility-Scale Solar 2019; Utility-Scale Solar; LBNL, 2019.

(295) Mahmoudi, S.; Huda, N.; Behnia, M. Critical Assessment of Renewable Energy Waste Generation in OECD Countries: Decommissioned PV Panels. Resources, Conservation and Recycling 2020, 164, 105145. https://doi.org/10.1016/j.resconrec.2020.105145.

(296) Domínguez, A.; Geyer, R. Photovoltaic Waste Assessment of Major Photovoltaic Installations in the United States of America. Renewable Energy 2019, 133, 1188-1200. https://doi.org/10.1016/j.renene.2018.08.063.

(297) Mints, P. Photovoltaic Manufacturer Capacity, Shipments, Price \& Revenues 2018/2019; Report SPV-Supply7; SPV Market Research, 2019; p 134.

(298) Philipps, S.; Warmuth, W. Photovoltaics Report; Fraunhofer Ise, PSE Projects GmbH, 2020; p 48.

(299) Fraunhofer ISE. Photovoltaics Report; Fraunhofer ISE: Freiburg, 2014.

(300) Rue, D. Cullet Supply Issues and Technologies. October 2018.

(301) Glass Packaging Institute. Glass Recycling Facts - Glass Packaging Institute https://www.gpi.org/glass-recycling-facts (accessed 2020 -07 -17).

(302) Rousseau, J.-F.; Schoenberger, L.; Marschke, M.; Hoffmann, M. Roving Bandits and Looted Coastlines: How the Global Appetite for Sand Is Fuelling a Crisis. The Conversation.

(303) UN Environment Programme. Sand and Sustainability: Finding New Solutions for Environmental Governance of Global Sand Resources; UNEP: Geneva, Switzerland, 2019.

(304) Butler, J. H.; Hooper, P. D. Chapter 15 - Glass Waste. In Waste (Second Edition); Letcher, T. M., Vallero, D. A., Eds.; Academic Press, 2019; pp 307-322. https://doi.org/10.1016/B978-0-12-815060-3.00015-3.

(305) Ovaitt, S.; Mirletz, H.; Seetharaman, S.; Barnes, T. PV in the Circular Economy, a Dynamic Framework Analyzing Technology Evolution and Reliability Impacts. iScience 2022, 25 (1), 103488. https://doi.org/10.1016/j.isci.2021.103488. 
(306) Wambach, K.; Baumann, K.; Seitz, M.; Mertvoy, B.; Reinelt, B. Photovoltaic (PV) Recycling, Reusing, and Decommissioning: Current Landscape and Opportunities for Standardization; Standards Research; bifa Umweltinstitut GmbH, CSA Group, 2020.

(307) Weckend, S.; Heath, G. A. End-of-Life Management Solar Photovoltaic Panels; IRENA and IEA International Energy Agency Photovoltaic Power Systems Programme, 2016.

(308) U.S. Energy Information Administration. Gasoline Explained, 2021.

(309) Krewski, D.; Jerrett, M.; Burnett, R. T.; Ma, R.; Hughes, E.; Shi, Y.; Turner, M. C.; Pope III, C. A.; Thurston, G.; Calle, E. E. Extended Follow-up and Spatial Analysis of the American Cancer Society Study Linking Particulate Air Pollution and Mortality. Res. Rep. Health Eff. Inst. 2009, 5-114.

(310) Lepeule, J.; Laden, F.; Dockery, D.; Schwartz, J. Chronic Exposure to Fine Particles and Mortality: An Extended Follow-up of the Harvard Six Cities Study from 1974 to 2009. Environ. Health Perspect. 2012, 120, 965.

(311) Millstein, D.; Wiser, R.; Bolinger, M.; Barbose, G. The Climate and Air-Quality Benefits of Wind and Solar Power in the United States. Nature Energy 2017, 2 (9). https://doi.org/10.1038/nenergy.2017.134.

(312) Davidson, K.; Fann, N.; Zawacki, M.; Fulcher, C.; Baker, K. R. The Recent and Future Health Burden of the US Mobile Sector Apportioned by Source. Environ. Res. Lett. 2020, 15, 075009.

(313) Heo, J.; Adams, P. J.; Gao, H. O. Public Health Costs of Primary PM2.5 and Inorganic PM2.5 Precursor Emissions in the United States. Environ. Sci. Technol. 2016, 50, 60616070. https://doi.org/10.1021/acs.est.5b06125. 


\section{Appendix A. Supplemental Information Regarding Land Requirements}

Table A-1. Total Land Area Required for All Ground-Mounted Solar Technologies by Balancing Area (BA)

\begin{tabular}{|c|c|c|c|c|c|c|c|c|c|c|c|c|c|}
\hline \multirow[b]{2}{*}{ BA } & \multirow[b]{2}{*}{ State } & \multirow[b]{2}{*}{$\begin{array}{l}\text { BA Size } \\
\text { (ac) }\end{array}$} & \multirow{2}{*}{$\begin{array}{l}\text { Total } \\
\text { Solar } \\
\text { Land } \\
\text { Need } \\
\text { Relative } \\
\text { to BA } \\
\text { Size (\%) }\end{array}$} & \multicolumn{5}{|c|}{ CSP } & \multicolumn{5}{|c|}{ PV (DUPV and UPV) } \\
\hline & & & & $\begin{array}{l}2030 \\
\text { CSP } \\
\text { Land } \\
\text { Need } \\
\text { (ac) }\end{array}$ & $\begin{array}{l}2040 \\
\text { CSP } \\
\text { Land } \\
\text { Need } \\
\text { (ac) }\end{array}$ & $\begin{array}{l}2050 \\
\text { CSP } \\
\text { Land } \\
\text { Need } \\
\text { (ac) }\end{array}$ & $\begin{array}{l}\text { Available } \\
\text { Dist. } \\
\text { Land for } \\
\text { CSP (ac) }\end{array}$ & $\begin{array}{l}\text { Available } \\
\text { Contam. } \\
\text { Land for } \\
\text { CSP (ac) }\end{array}$ & $\begin{array}{l}2030 \text { PV } \\
\text { Land } \\
\text { Need } \\
\text { (ac) }\end{array}$ & $\begin{array}{l}2040 \\
\text { PV } \\
\text { Land } \\
\text { Need } \\
\text { (ac) }\end{array}$ & $\begin{array}{l}2050 \text { PV } \\
\text { Land } \\
\text { Need } \\
\text { (ac) }\end{array}$ & $\begin{array}{l}\text { Available } \\
\text { Dist. Land } \\
\text { for PV (ac) }\end{array}$ & $\begin{array}{l}\text { Available } \\
\text { Contam. } \\
\text { Land for PV } \\
\text { (ac) }\end{array}$ \\
\hline 1 & Washington & $10,712,462$ & $0.1 \%$ & 0 & 0 & 0 & 0 & 0 & 11,287 & 14,727 & 14,540 & 626,183 & 33,969 \\
\hline 2 & Washington & $16,094,383$ & $0.1 \%$ & 0 & 0 & 0 & 0 & 0 & 44 & 4,061 & 16,943 & 668,134 & 375,968 \\
\hline 3 & Washington & $13,455,441$ & $0.0 \%$ & 0 & 0 & 0 & 0 & 0 & 5,273 & 5,273 & 5,129 & 545,595 & 987 \\
\hline 4 & Washington & $2,969,526$ & $2.2 \%$ & 0 & 0 & 0 & 0 & 0 & 32,062 & 65,371 & 65,371 & 229,001 & 7,680 \\
\hline 5 & Oregon & $29,732,910$ & $0.1 \%$ & 0 & 0 & 0 & 0 & 0 & 7,656 & 21,183 & 20,110 & 914,572 & 16,107 \\
\hline 6 & Oregon & $12,091,160$ & $0.2 \%$ & 0 & 0 & 0 & 46,674 & 0 & 12,771 & 15,017 & 28,336 & 174,938 & 237 \\
\hline 7 & Oregon & $20,225,942$ & $0.2 \%$ & 0 & 0 & 0 & 300,931 & 0 & 16,308 & 19,623 & 32,764 & 572,073 & 373 \\
\hline 8 & California & $9,773,474$ & $0.1 \%$ & 0 & 0 & 0 & 394,227 & 0 & 2,772 & 2,922 & 7,479 & 412,500 & 38,618 \\
\hline 9 & California & $47,101,279$ & $0.4 \%$ & 335 & 300 & 0 & $1,378,926$ & 0 & 59,655 & 190,283 & 201,944 & $4,229,580$ & 259,059 \\
\hline 10 & California & $41,595,674$ & $0.7 \%$ & 13,322 & 9,292 & 0 & $1,919,289$ & $1,420,046$ & 228,253 & 295,140 & 298,459 & $2,869,663$ & $1,449,894$ \\
\hline 11 & California & $2,711,562$ & $1.0 \%$ & 63 & 63 & 0 & 121,448 & 0 & 15,498 & 25,984 & 25,155 & 217,789 & 3,759 \\
\hline 12 & Nevada & $65,580,867$ & $0.0 \%$ & 1,100 & 1,100 & 0 & $3,709,534$ & 53,500 & 8,409 & 8,476 & 5,103 & $3,757,841$ & 54,030 \\
\hline 13 & Nevada & $5,177,948$ & $1.1 \%$ & 685 & 0 & 0 & 249,878 & 12,641 & 45,238 & 58,818 & 55,920 & 249,878 & 13,128 \\
\hline 14 & Idaho & $4,933,855$ & $0.0 \%$ & 0 & 0 & 0 & 0 & 0 & 30 & 148 & 148 & 135,069 & 40 \\
\hline 15 & Idaho & $34,771,769$ & $0.5 \%$ & 0 & 0 & 0 & 737,439 & 0 & 1,500 & 14,781 & 179,833 & $1,345,072$ & 6,701 \\
\hline 16 & Idaho & $13,777,720$ & $0.2 \%$ & 0 & 0 & 0 & 88,334 & 0 & 1,120 & 19,653 & 24,302 & 740,588 & 21,096 \\
\hline 17 & Montana & $23,814,686$ & $0.1 \%$ & 0 & 0 & 0 & 0 & 0 & 0 & 0 & 14,238 & 424,719 & 189,743 \\
\hline 18 & Montana & $32,971,048$ & $0.0 \%$ & 0 & 0 & 0 & 0 & 0 & 105 & 105 & 0 & $1,201,613$ & 19,600 \\
\hline 19 & Montana & $6,341,652$ & $0.0 \%$ & 0 & 0 & 0 & 0 & 0 & 0 & 0 & 0 & 166,129 & 0 \\
\hline 20 & Montana & $15,569,992$ & $0.0 \%$ & 0 & 0 & 0 & 0 & 0 & 23 & 23 & 0 & 487,878 & 174 \\
\hline 21 & Wyoming & $31,658,850$ & $0.0 \%$ & 0 & 0 & 0 & 190,115 & 0 & 690 & 690 & 690 & 445,403 & 100 \\
\hline 22 & Wyoming & $4,289,013$ & $0.7 \%$ & 0 & 0 & 0 & 0 & 0 & 159 & 31,025 & 31,025 & 30,289 & 0 \\
\hline
\end{tabular}




\begin{tabular}{|c|c|c|c|c|c|c|c|c|c|c|c|c|c|}
\hline \multirow[b]{2}{*}{ BA } & \multirow[b]{2}{*}{ State } & \multirow[b]{2}{*}{$\begin{array}{l}\text { BA Size } \\
\text { (ac) }\end{array}$} & \multirow{2}{*}{$\begin{array}{l}\text { Total } \\
\text { Solar } \\
\text { Land } \\
\text { Need } \\
\text { Relative } \\
\text { to BA } \\
\text { Size (\%) }\end{array}$} & \multicolumn{5}{|c|}{ CSP } & \multicolumn{5}{|c|}{ PV (DUPV and UPV) } \\
\hline & & & & $\begin{array}{l}2030 \\
\text { CSP } \\
\text { Land } \\
\text { Need } \\
\text { (ac) }\end{array}$ & $\begin{array}{l}2040 \\
\text { CSP } \\
\text { Land } \\
\text { Need } \\
\text { (ac) }\end{array}$ & $\begin{array}{l}2050 \\
\text { CSP } \\
\text { Land } \\
\text { Need } \\
\text { (ac) }\end{array}$ & $\begin{array}{l}\text { Available } \\
\text { Dist. } \\
\text { Land for } \\
\text { CSP (ac) }\end{array}$ & $\begin{array}{l}\text { Available } \\
\text { Contam. } \\
\text { Land for } \\
\text { CSP (ac) }\end{array}$ & $\begin{array}{l}2030 \text { PV } \\
\text { Land } \\
\text { Need } \\
\text { (ac) }\end{array}$ & $\begin{array}{l}2040 \\
\text { PV } \\
\text { Land } \\
\text { Need } \\
\text { (ac) }\end{array}$ & $\begin{array}{l}2050 \mathrm{PV} \\
\text { Land } \\
\text { Need } \\
\text { (ac) }\end{array}$ & $\begin{array}{l}\text { Available } \\
\text { Dist. Land } \\
\text { for PV (ac) }\end{array}$ & $\begin{array}{l}\text { Available } \\
\text { Contam. } \\
\text { Land for PV } \\
\text { (ac) }\end{array}$ \\
\hline 23 & Wyoming & $6,446,075$ & $0.1 \%$ & 0 & 0 & 0 & 0 & 0 & 3,904 & 4,572 & 4,572 & 128,682 & 560 \\
\hline 24 & Wyoming & $20,206,020$ & $0.0 \%$ & 0 & 0 & 0 & 28 & 0 & 53 & 53 & 53 & 554,890 & 11,825 \\
\hline 25 & Utah & $45,842,812$ & $0.1 \%$ & 15 & 15 & 6,244 & $2,447,482$ & 814,718 & 10,780 & 44,905 & 48,229 & $2,938,658$ & 869,736 \\
\hline 26 & Utah & $8,490,314$ & $0.1 \%$ & 0 & 0 & 0 & 119,571 & 0 & 2,925 & 4,586 & 8,394 & 143,931 & 160 \\
\hline 27 & Arizona & $8,622,006$ & $2.3 \%$ & 0 & 0 & 0 & 268,376 & 0 & 69,461 & 98,616 & 199,245 & 268,376 & 0 \\
\hline 28 & Arizona & $50,426,520$ & $0.1 \%$ & 2,979 & 2,954 & 15,027 & $2,276,696$ & 16,312 & 14,861 & 17,553 & 14,734 & $2,277,368$ & 19,156 \\
\hline 29 & Arizona & $7,179,819$ & $0.0 \%$ & 0 & 0 & 0 & 119,835 & 0 & 136 & 1,673 & 1,610 & 119,835 & 0 \\
\hline 30 & Arizona & $6,584,705$ & $1.8 \%$ & 70 & 550 & 19,303 & 534,916 & 14,265 & 51,218 & 98,118 & 97,012 & 534,916 & 14,832 \\
\hline 31 & New Mexico & $64,114,256$ & $0.0 \%$ & 10 & 10 & 0 & $3,185,227$ & $1,369,855$ & 16,289 & 16,064 & 13,598 & $3,185,227$ & $1,369,855$ \\
\hline 32 & South Dakota & $5,861,877$ & $0.0 \%$ & 0 & 0 & 0 & 0 & 0 & 0 & 712 & 712 & 225,036 & 0 \\
\hline 33 & Colorado & $30,443,408$ & $0.1 \%$ & 0 & 0 & 317 & 600,481 & 0 & 36,381 & 41,787 & 40,230 & $1,805,084$ & 62,356 \\
\hline 34 & Colorado & $36,176,102$ & $0.1 \%$ & 300 & 2,679 & 10,870 & $1,161,027$ & 162,349 & 3,218 & 20,748 & 17,786 & $1,170,909$ & 162,862 \\
\hline 35 & Montana & $15,403,475$ & $0.0 \%$ & 0 & 0 & 0 & 0 & 0 & 0 & 0 & 0 & 631,695 & 71 \\
\hline 36 & North Dakota & $21,315,649$ & $0.2 \%$ & 0 & 0 & 0 & 0 & 0 & 24,058 & 24,058 & 32,445 & $1,445,760$ & 1,477 \\
\hline 37 & North Dakota & $23,929,002$ & $0.0 \%$ & 0 & 0 & 0 & 0 & 0 & 0 & 11,961 & 11,961 & $2,020,952$ & 372,963 \\
\hline 38 & South Dakota & $43,491,916$ & $0.2 \%$ & 0 & 0 & 0 & 0 & 0 & 377 & 82,329 & 90,326 & $3,541,059$ & 1,109 \\
\hline 39 & Nebraska & $12,526,114$ & $0.1 \%$ & 0 & 0 & 0 & 0 & 0 & 251 & 4,340 & 14,607 & 714,794 & 4,257 \\
\hline 40 & Nebraska & $32,494,327$ & $0.0 \%$ & 0 & 0 & 0 & 0 & 0 & 3,749 & 3,749 & 3,659 & $2,053,118$ & 59,115 \\
\hline 41 & Nebraska & $4,485,510$ & $2.1 \%$ & 0 & 0 & 0 & 0 & 0 & 93,800 & 93,800 & 93,753 & 449,883 & 23,370 \\
\hline 42 & Minnesota & $13,194,031$ & $0.1 \%$ & 0 & 0 & 0 & 0 & 0 & 0 & 19,722 & 19,722 & 797,027 & 70 \\
\hline 43 & Minnesota & $30,498,050$ & $0.1 \%$ & 0 & 0 & 0 & 0 & 0 & 5,535 & 15,838 & 14,442 & $2,454,806$ & 61,131 \\
\hline 44 & Minnesota & $4,901,332$ & $0.6 \%$ & 0 & 0 & 0 & 0 & 0 & 779 & 25,555 & 29,255 & 409,207 & 0 \\
\hline 45 & lowa & $13,896,983$ & $0.9 \%$ & 0 & 0 & 0 & 0 & 0 & 15,261 & 43,181 & 131,353 & $1,174,954$ & 452 \\
\hline 46 & Wisconsin & $12,831,660$ & $0.5 \%$ & 0 & 0 & 0 & 0 & 0 & 163 & 19,855 & 66,279 & 757,473 & 831 \\
\hline 47 & New Mexico & $13,703,130$ & $0.2 \%$ & 0 & 9,103 & 26,422 & 889,175 & 81,480 & 1,735 & 1,735 & 65 & 889,175 & 81,577 \\
\hline 48 & Texas & $22,257,743$ & $0.4 \%$ & 0 & 11,411 & 14,928 & $1,831,769$ & 25,760 & 66,932 & 66,932 & 66,932 & $1,961,884$ & 29,726 \\
\hline
\end{tabular}




\begin{tabular}{|c|c|c|c|c|c|c|c|c|c|c|c|c|c|}
\hline \multirow[b]{2}{*}{ BA } & \multirow[b]{2}{*}{ State } & \multirow[b]{2}{*}{$\begin{array}{l}\text { BA Size } \\
\text { (ac) }\end{array}$} & \multirow{2}{*}{$\begin{array}{l}\text { Total } \\
\text { Solar } \\
\text { Land } \\
\text { Need } \\
\text { Relative } \\
\text { to BA } \\
\text { Size (\%) }\end{array}$} & \multicolumn{5}{|c|}{ CSP } & \multicolumn{5}{|c|}{ PV (DUPV and UPV) } \\
\hline & & & & $\begin{array}{l}2030 \\
\text { CSP } \\
\text { Land } \\
\text { Need } \\
\text { (ac) }\end{array}$ & $\begin{array}{l}2040 \\
\text { CSP } \\
\text { Land } \\
\text { Need } \\
\text { (ac) }\end{array}$ & $\begin{array}{l}2050 \\
\text { CSP } \\
\text { Land } \\
\text { Need } \\
\text { (ac) }\end{array}$ & $\begin{array}{l}\text { Available } \\
\text { Dist. } \\
\text { Land for } \\
\text { CSP (ac) }\end{array}$ & $\begin{array}{l}\text { Available } \\
\text { Contam. } \\
\text { Land for } \\
\text { CSP (ac) }\end{array}$ & $\begin{array}{l}2030 \text { PV } \\
\text { Land } \\
\text { Need } \\
\text { (ac) }\end{array}$ & $\begin{array}{l}2040 \\
\text { PV } \\
\text { Land } \\
\text { Need } \\
\text { (ac) }\end{array}$ & $\begin{array}{l}2050 \text { PV } \\
\text { Land } \\
\text { Need } \\
\text { (ac) }\end{array}$ & $\begin{array}{l}\text { Available } \\
\text { Dist. Land } \\
\text { for PV (ac) }\end{array}$ & $\begin{array}{l}\text { Available } \\
\text { Contam. } \\
\text { Land for PV } \\
\text { (ac) }\end{array}$ \\
\hline 49 & Oklahoma & $3,652,841$ & $1.6 \%$ & 0 & 0 & 220 & 216,127 & 0 & 0 & 0 & 59,961 & 250,266 & 0 \\
\hline 50 & Oklahoma & $33,539,151$ & $0.2 \%$ & 0 & 0 & 18,707 & 0 & 0 & 33,977 & 33,977 & 33,767 & $4,836,268$ & 160,835 \\
\hline 51 & Oklahoma & $7,543,105$ & $1.0 \%$ & 0 & 0 & 0 & 0 & 0 & 41,431 & 78,470 & 78,573 & 897,353 & 29,369 \\
\hline 52 & Kansas & $13,162,268$ & $0.2 \%$ & 0 & 0 & 1,374 & 282,217 & 0 & 20,263 & 20,263 & 20,254 & 852,683 & 362 \\
\hline 53 & Kansas & $39,494,876$ & $0.1 \%$ & 0 & 0 & 2,220 & 55,749 & 0 & 44,975 & 44,975 & 45,724 & $4,066,474$ & 45,722 \\
\hline 54 & Missouri & $10,511,702$ & $0.0 \%$ & 0 & 0 & 0 & 0 & 0 & 189 & 2,456 & 2,268 & $1,069,244$ & 5,038 \\
\hline 55 & Missouri & $9,158,815$ & $0.7 \%$ & 0 & 0 & 0 & 0 & 0 & 37,260 & 47,055 & 61,296 & 670,367 & 513,200 \\
\hline 56 & Arkansas & $9,162,466$ & $1.0 \%$ & 0 & 0 & 0 & 0 & 0 & 45 & 25,425 & 87,644 & 436,278 & 72,465 \\
\hline 57 & Texas & $3,709,787$ & $2.7 \%$ & 0 & 0 & 0 & 0 & 0 & 21,669 & 98,152 & 98,903 & 596,708 & 26,481 \\
\hline 58 & Louisiana & $25,511,691$ & $0.5 \%$ & 0 & 27,637 & 92,611 & 0 & 0 & 5,325 & 6,260 & 31,140 & $3,333,748$ & 272,662 \\
\hline 59 & Texas & 641,656 & $8.2 \%$ & 0 & 0 & 395 & 133,656 & 125,295 & 52,081 & 52,081 & 51,966 & 133,820 & 126,234 \\
\hline 60 & Texas & $13,627,085$ & $0.6 \%$ & 0 & 160 & 2,784 & $1,191,467$ & 0 & 54,121 & 56,769 & 76,247 & $3,080,757$ & 1,869 \\
\hline 61 & Texas & $32,040,227$ & $0.3 \%$ & 0 & 7,770 & 8,741 & $3,374,282$ & 0 & 57,187 & 74,780 & 66,830 & $6,093,698$ & 10,523 \\
\hline 62 & Texas & $6,834,311$ & $2.0 \%$ & 0 & 0 & 22,045 & $2,064,707$ & 859 & 11,700 & 11,700 & 111,278 & $2,065,074$ & 1,721 \\
\hline 63 & Texas & $34,956,126$ & $0.4 \%$ & 0 & 381 & 57,585 & 0 & 0 & 7,713 & 74,643 & 92,425 & $9,856,011$ & 242,608 \\
\hline 64 & Texas & $17,913,989$ & $1.4 \%$ & 0 & 0 & 131 & 0 & 0 & 56,648 & 212,264 & 256,445 & $3,836,456$ & 1,434 \\
\hline 65 & Texas & $25,723,675$ & $0.0 \%$ & 0 & 0 & 418 & 0 & 0 & 1,612 & 6,958 & 10,586 & $4,611,799$ & 19,412 \\
\hline 66 & Texas & $8,595,962$ & $1.5 \%$ & 0 & 0 & 0 & 0 & 0 & 9,283 & 81,748 & 128,706 & $1,172,332$ & 17,163 \\
\hline 67 & Texas & $2,883,527$ & $12.6 \%$ & 0 & 0 & 0 & 0 & 0 & 150,369 & 362,625 & 362,550 & $1,194,057$ & 25,002 \\
\hline 68 & Minnesota & $5,381,751$ & $0.4 \%$ & 0 & 0 & 0 & 0 & 0 & 22,060 & 22,060 & 21,711 & 453,657 & 313 \\
\hline 69 & lowa & $4,794,677$ & $0.4 \%$ & 0 & 0 & 0 & 0 & 0 & 18,767 & 18,808 & 18,781 & 496,907 & 647 \\
\hline 70 & lowa & $17,321,803$ & $0.0 \%$ & 0 & 0 & 0 & 0 & 0 & 601 & 601 & 549 & $1,776,144$ & 7,199 \\
\hline 71 & Missouri & $3,685,935$ & $0.7 \%$ & 0 & 0 & 0 & 0 & 0 & 182 & 24,686 & 24,665 & 276,170 & 5,109 \\
\hline 72 & Missouri & $9,876,393$ & $0.0 \%$ & 0 & 0 & 0 & 0 & 0 & 76 & 76 & 23 & 925,855 & 58,623 \\
\hline 73 & Missouri & $3,339,003$ & $0.9 \%$ & 0 & 0 & 0 & 0 & 0 & 3,647 & 4,028 & 29,437 & 104,459 & 987 \\
\hline 74 & Michigan & $7,686,288$ & $1.0 \%$ & 0 & 0 & 0 & 0 & 0 & 3 & 49,561 & 80,679 & 226,279 & 1,366 \\
\hline
\end{tabular}




\begin{tabular}{|c|c|c|c|c|c|c|c|c|c|c|c|c|c|}
\hline \multirow[b]{2}{*}{ BA } & \multirow[b]{2}{*}{ State } & \multirow[b]{2}{*}{$\begin{array}{l}\text { BA Size } \\
\text { (ac) }\end{array}$} & \multirow{2}{*}{$\begin{array}{l}\text { Total } \\
\text { Solar } \\
\text { Land } \\
\text { Need } \\
\text { Relative } \\
\text { to BA } \\
\text { Size (\%) }\end{array}$} & \multicolumn{5}{|c|}{ CSP } & \multicolumn{5}{|c|}{ PV (DUPV and UPV) } \\
\hline & & & & $\begin{array}{l}2030 \\
\text { CSP } \\
\text { Land } \\
\text { Need } \\
\text { (ac) }\end{array}$ & $\begin{array}{l}2040 \\
\text { CSP } \\
\text { Land } \\
\text { Need } \\
\text { (ac) }\end{array}$ & $\begin{array}{l}2050 \\
\text { CSP } \\
\text { Land } \\
\text { Need } \\
\text { (ac) }\end{array}$ & $\begin{array}{l}\text { Available } \\
\text { Dist. } \\
\text { Land for } \\
\text { CSP (ac) }\end{array}$ & $\begin{array}{l}\text { Available } \\
\text { Contam. } \\
\text { Land for } \\
\text { CSP (ac) }\end{array}$ & $\begin{array}{l}2030 \text { PV } \\
\text { Land } \\
\text { Need } \\
\text { (ac) }\end{array}$ & $\begin{array}{l}2040 \\
\text { PV } \\
\text { Land } \\
\text { Need } \\
\text { (ac) }\end{array}$ & $\begin{array}{l}2050 \text { PV } \\
\text { Land } \\
\text { Need } \\
\text { (ac) }\end{array}$ & $\begin{array}{l}\text { Available } \\
\text { Dist. Land } \\
\text { for PV (ac) }\end{array}$ & $\begin{array}{l}\text { Available } \\
\text { Contam. } \\
\text { Land for PV } \\
\text { (ac) }\end{array}$ \\
\hline 75 & Wisconsin & $7,936,635$ & $0.1 \%$ & 0 & 0 & 0 & 0 & 0 & 5,022 & 5,022 & 5,022 & 568,921 & 2,868 \\
\hline 76 & Wisconsin & $6,344,000$ & $0.6 \%$ & 0 & 0 & 0 & 0 & 0 & 30,990 & 39,377 & 39,336 & 704,704 & 976 \\
\hline 77 & Wisconsin & $4,702,521$ & $1.0 \%$ & 0 & 0 & 0 & 0 & 0 & 19,057 & 19,057 & 46,048 & 308,949 & 72,834 \\
\hline 78 & Wisconsin & $1,631,388$ & $2.9 \%$ & 0 & 0 & 0 & 0 & 0 & 46,877 & 46,877 & 46,808 & 226,453 & 509 \\
\hline 79 & Wisconsin & $2,425,431$ & $2.4 \%$ & 0 & 0 & 0 & 0 & 0 & 1,667 & 1,677 & 57,539 & 636,729 & 2,653 \\
\hline 80 & Illinois & $8,097,197$ & $1.3 \%$ & 0 & 0 & 0 & 0 & 0 & 13,200 & 64,835 & 102,880 & $1,885,136$ & 32,426 \\
\hline 81 & Illinois & $16,978,069$ & $0.3 \%$ & 0 & 0 & 0 & 0 & 0 & 780 & 947 & 56,397 & $1,814,504$ & 20,081 \\
\hline 82 & Illinois & $2,384,692$ & $3.3 \%$ & 0 & 0 & 0 & 0 & 0 & 70,649 & 79,184 & 78,081 & 325,892 & 1,285 \\
\hline 83 & Illinois & $8,597,011$ & $1.0 \%$ & 0 & 0 & 0 & 0 & 0 & 82,768 & 82,768 & 82,712 & 943,281 & 12,452 \\
\hline 84 & Missouri & $8,038,882$ & $0.7 \%$ & 0 & 0 & 0 & 0 & 0 & 32 & 57,558 & 57,539 & 371,138 & 85 \\
\hline 85 & Arkansas & $24,872,087$ & $0.1 \%$ & 0 & 14,766 & 14,766 & 0 & 0 & 1,965 & 7,963 & 8,404 & $2,235,121$ & 70,944 \\
\hline 86 & Louisiana & $4,401,604$ & $2.6 \%$ & 0 & 0 & 0 & 0 & 0 & 68,092 & 115,459 & 115,459 & 555,368 & 359 \\
\hline 87 & Mississippi & $22,391,371$ & $0.3 \%$ & 0 & 35,733 & 35,733 & 0 & 0 & 31,357 & 32,281 & 31,823 & $4,578,807$ & 10,677 \\
\hline 88 & Mississippi & $8,114,532$ & $2.3 \%$ & 0 & 0 & 0 & 0 & 0 & 61,751 & 168,561 & 187,686 & $1,627,525$ & 4,144 \\
\hline 89 & Alabama & $14,074,123$ & $0.0 \%$ & 0 & 0 & 1,545 & 0 & 0 & 2,429 & 3,574 & 3,410 & $2,017,789$ & 15,677 \\
\hline 90 & Alabama & $18,985,895$ & $1.2 \%$ & 0 & 9,498 & 41,582 & 0 & 0 & 3,273 & 96,728 & 193,441 & $3,703,831$ & 14,993 \\
\hline 91 & Florida & $4,926,046$ & $2.9 \%$ & 0 & 0 & 543 & 0 & 0 & 118,574 & 141,324 & 140,995 & 809,247 & 470,155 \\
\hline 92 & Tennessee & $26,971,838$ & $1.3 \%$ & 0 & 0 & 2,828 & 0 & 0 & 51,587 & 54,804 & 342,998 & $2,988,445$ & 112,477 \\
\hline 93 & Kentucky & $6,304,778$ & $2.7 \%$ & 0 & 0 & 0 & 0 & 0 & 32,857 & 135,280 & 167,865 & 611,532 & 5,530 \\
\hline 94 & Georgia & $37,651,815$ & $0.5 \%$ & 0 & 59 & 568 & 0 & 0 & 91,585 & 136,998 & 184,964 & $6,614,742$ & 524,281 \\
\hline 95 & ReEDS & $5,123,447$ & $8.2 \%$ & 0 & 0 & 0 & 0 & 0 & 233,248 & 318,347 & 420,935 & 965,792 & 4,777 \\
\hline 96 & ReEDS & $14,685,332$ & $2.4 \%$ & 0 & 0 & 0 & 0 & 0 & 69,093 & 242,108 & 359,308 & $2,799,811$ & 277,036 \\
\hline 97 & North Carolina & $12,639,527$ & $2.4 \%$ & 0 & 0 & 0 & 0 & 0 & 58,659 & 282,426 & 302,429 & $1,579,409$ & 18,522 \\
\hline 98 & North Carolina & $18,953,980$ & $0.6 \%$ & 0 & 0 & 0 & 0 & 0 & 29,827 & 110,442 & 91,953 & $4,067,643$ & 156,735 \\
\hline 99 & Virginia & $16,304,858$ & $1.8 \%$ & 0 & 0 & 177 & 0 & 0 & 122,484 & 222,916 & 296,037 & $2,779,293$ & 115,192 \\
\hline 100 & Virginia & $1,202,690$ & $2.8 \%$ & 0 & 0 & 0 & 0 & 0 & 10,994 & 10,994 & 33,939 & 69,962 & 705 \\
\hline
\end{tabular}




\begin{tabular}{|c|c|c|c|c|c|c|c|c|c|c|c|c|c|}
\hline \multirow[b]{2}{*}{ BA } & \multirow[b]{2}{*}{ State } & \multirow[b]{2}{*}{$\begin{array}{l}\text { BA Size } \\
\text { (ac) }\end{array}$} & \multirow{2}{*}{$\begin{array}{l}\text { Total } \\
\text { Solar } \\
\text { Land } \\
\text { Need } \\
\text { Relative } \\
\text { to BA } \\
\text { Size (\%) }\end{array}$} & \multicolumn{5}{|c|}{ CSP } & \multicolumn{5}{|c|}{ PV (DUPV and UPV) } \\
\hline & & & & $\begin{array}{l}2030 \\
\text { CSP } \\
\text { Land } \\
\text { Need } \\
\text { (ac) }\end{array}$ & $\begin{array}{l}2040 \\
\text { CSP } \\
\text { Land } \\
\text { Need } \\
\text { (ac) }\end{array}$ & $\begin{array}{l}2050 \\
\text { CSP } \\
\text { Land } \\
\text { Need } \\
\text { (ac) }\end{array}$ & $\begin{array}{l}\text { Available } \\
\text { Dist. } \\
\text { Land for } \\
\text { CSP (ac) }\end{array}$ & $\begin{array}{l}\text { Available } \\
\text { Contam. } \\
\text { Land for } \\
\text { CSP (ac) }\end{array}$ & $\begin{array}{l}2030 \text { PV } \\
\text { Land } \\
\text { Need } \\
\text { (ac) }\end{array}$ & $\begin{array}{l}2040 \\
\text { PV } \\
\text { Land } \\
\text { Need } \\
\text { (ac) }\end{array}$ & $\begin{array}{l}2050 \text { PV } \\
\text { Land } \\
\text { Need } \\
\text { (ac) }\end{array}$ & $\begin{array}{l}\text { Available } \\
\text { Dist. Land } \\
\text { for PV (ac) }\end{array}$ & $\begin{array}{l}\text { Available } \\
\text { Contam. } \\
\text { Land for PV } \\
\text { (ac) }\end{array}$ \\
\hline 101 & Florida & $26,043,389$ & $2.7 \%$ & 0 & 0 & 0 & 0 & 0 & 196,485 & 499,878 & 692,462 & $4,772,221$ & 152,527 \\
\hline 102 & Florida & $5,265,718$ & $5.6 \%$ & 0 & 0 & 0 & 0 & 0 & 133,572 & 295,634 & 293,474 & $1,188,395$ & 174,979 \\
\hline 103 & Michigan & $27,694,609$ & $0.3 \%$ & 0 & 0 & 0 & 0 & 0 & 36,195 & 80,405 & 80,005 & $3,768,527$ & 30,544 \\
\hline 104 & Michigan & $1,800,456$ & $5.1 \%$ & 0 & 0 & 0 & 0 & 0 & 85,446 & 88,420 & 91,945 & 319,477 & 2,863 \\
\hline 105 & Indiana & $12,398,515$ & $0.5 \%$ & 0 & 0 & 0 & 0 & 0 & 3,180 & 3,180 & 62,874 & $2,104,360$ & 25,882 \\
\hline 106 & Indiana & 515,690 & $19.5 \%$ & 0 & 0 & 0 & 0 & 0 & 80,655 & 80,655 & 100,609 & 291,448 & 1,810 \\
\hline 107 & Indiana & $10,242,331$ & $0.0 \%$ & 0 & 0 & 0 & 0 & 0 & 659 & 659 & 262 & $1,235,055$ & 16,273 \\
\hline 108 & Kentucky & $3,547,916$ & $4.7 \%$ & 0 & 0 & 0 & 0 & 0 & 134,900 & 150,278 & 165,012 & 309,258 & 1,331 \\
\hline 109 & Kentucky & $13,229,165$ & $2.2 \%$ & 0 & 0 & 0 & 0 & 0 & 8,239 & 196,963 & 292,203 & 987,717 & 132,676 \\
\hline 110 & Kentucky & $2,779,927$ & $0.4 \%$ & 0 & 0 & 0 & 0 & 0 & 5,534 & 7,264 & 10,566 & 35,303 & 351 \\
\hline 111 & Ohio & $5,207,548$ & $2.5 \%$ & 0 & 0 & 0 & 0 & 0 & 248 & 44,669 & 131,849 & $1,665,991$ & 18,158 \\
\hline 112 & Ohio & $17,584,366$ & $0.1 \%$ & 0 & 0 & 0 & 0 & 0 & 2,555 & 11,307 & 11,212 & $2,055,791$ & 20,618 \\
\hline 113 & Ohio & $2,179,286$ & $3.6 \%$ & 0 & 0 & 0 & 0 & 0 & 53,521 & 77,510 & 77,378 & 448,379 & 9,683 \\
\hline 114 & Ohio & $1,435,518$ & $3.9 \%$ & 0 & 0 & 0 & 0 & 0 & 39,630 & 53,938 & 55,828 & 395,272 & 2,999 \\
\hline 115 & Pennsylvania & $3,789,478$ & $1.3 \%$ & 0 & 0 & 0 & 0 & 0 & 10 & 28,127 & 49,989 & 249,321 & 76,757 \\
\hline 116 & 'West Virginia & $10,986,993$ & $0.4 \%$ & 0 & 0 & 0 & 0 & 0 & 44,594 & 44,705 & 46,252 & 222,564 & 14,183 \\
\hline 117 & West Virginia & $4,520,034$ & $0.7 \%$ & 0 & 0 & 0 & 0 & 0 & 31,977 & 31,977 & 33,267 & 102,203 & 8,436 \\
\hline 118 & Virginia & $7,703,829$ & $0.8 \%$ & 0 & 0 & 0 & 0 & 0 & 6,189 & 55,403 & 61,103 & 278,554 & 6,520 \\
\hline 119 & Pennsylvania & $2,766,191$ & $0.6 \%$ & 0 & 0 & 0 & 0 & 0 & 11 & 11 & 15,924 & 64,168 & 11,799 \\
\hline 120 & Pennsylvania & 774,818 & $0.0 \%$ & 0 & 0 & 0 & 0 & 0 & 0 & 0 & 0 & 56,902 & 2,205 \\
\hline 121 & Maryland & $1,421,175$ & $6.1 \%$ & 0 & 0 & 0 & 0 & 0 & 944 & 944 & 86,469 & 104,121 & 334 \\
\hline 122 & Pennsylvania & $21,662,069$ & $1.0 \%$ & 0 & 0 & 0 & 0 & 0 & 339 & 108,954 & 215,374 & $1,844,699$ & 204,085 \\
\hline 123 & Maryland & $5,020,301$ & $3.7 \%$ & 0 & 0 & 0 & 0 & 0 & 114,657 & 121,899 & 187,193 & $1,088,954$ & 18,552 \\
\hline 124 & Virginia & 374,900 & $0.2 \%$ & 0 & 0 & 0 & 0 & 0 & 750 & 750 & 0 & 43,742 & 32 \\
\hline 125 & Delaware & $1,288,004$ & $4.3 \%$ & 0 & 0 & 0 & 0 & 0 & 17,995 & 54,555 & 55,547 & 289,841 & 10,903 \\
\hline 126 & New Jersey & $4,828,772$ & $1.0 \%$ & 0 & 0 & 0 & 0 & 0 & 6,924 & 39,493 & 46,460 & $1,288,096$ & 63,952 \\
\hline
\end{tabular}




\begin{tabular}{|c|c|c|c|c|c|c|c|c|c|c|c|c|c|}
\hline \multirow[b]{2}{*}{ BA } & \multirow[b]{2}{*}{ State } & \multirow[b]{2}{*}{$\begin{array}{l}\text { BA Size } \\
\text { (ac) }\end{array}$} & \multirow{2}{*}{$\begin{array}{l}\text { Total } \\
\text { Solar } \\
\text { Land } \\
\text { Need } \\
\text { Relative } \\
\text { to BA } \\
\text { Size (\%) }\end{array}$} & \multicolumn{5}{|c|}{ CSP } & \multicolumn{5}{|c|}{ PV (DUPV and UPV) } \\
\hline & & & & $\begin{array}{l}2030 \\
\text { CSP } \\
\text { Land } \\
\text { Need } \\
\text { (ac) }\end{array}$ & $\begin{array}{l}2040 \\
\text { CSP } \\
\text { Land } \\
\text { Need } \\
\text { (ac) }\end{array}$ & $\begin{array}{l}2050 \\
\text { CSP } \\
\text { Land } \\
\text { Need } \\
\text { (ac) }\end{array}$ & $\begin{array}{l}\text { Available } \\
\text { Dist. } \\
\text { Land for } \\
\text { CSP (ac) }\end{array}$ & $\begin{array}{l}\text { Available } \\
\text { Contam. } \\
\text { Land for } \\
\text { CSP (ac) }\end{array}$ & $\begin{array}{l}2030 \text { PV } \\
\text { Land } \\
\text { Need } \\
\text { (ac) }\end{array}$ & $\begin{array}{l}2040 \\
\text { PV } \\
\text { Land } \\
\text { Need } \\
\text { (ac) }\end{array}$ & $\begin{array}{l}2050 \text { PV } \\
\text { Land } \\
\text { Need } \\
\text { (ac) }\end{array}$ & $\begin{array}{l}\text { Available } \\
\text { Dist. Land } \\
\text { for PV (ac) }\end{array}$ & $\begin{array}{l}\text { Available } \\
\text { Contam. } \\
\text { Land for PV } \\
\text { (ac) }\end{array}$ \\
\hline 127 & New York & $30,349,585$ & $0.8 \%$ & 0 & 0 & 0 & 0 & 0 & 85,120 & 194,272 & 252,661 & $2,399,365$ & 302,786 \\
\hline 128 & New York & 768,786 & $0.1 \%$ & 0 & 0 & 0 & 0 & 0 & 929 & 929 & 543 & 432,775 & 12,776 \\
\hline 129 & Vermont & $6,153,046$ & $0.2 \%$ & 0 & 0 & 0 & 0 & 0 & 917 & 5,078 & 12,222 & 163,184 & 2,206 \\
\hline 130 & New Hampshire & $5,929,194$ & $0.8 \%$ & 0 & 0 & 0 & 0 & 0 & 8,633 & 22,779 & 50,185 & 322,886 & 5,943 \\
\hline 131 & Massachusetts & $5,195,760$ & $2.0 \%$ & 0 & 0 & 0 & 0 & 0 & 33,687 & 98,469 & 104,350 & $1,017,034$ & 12,232 \\
\hline 132 & Connecticut & $3,184,259$ & $2.3 \%$ & 0 & 0 & 0 & 0 & 0 & 28,495 & 32,202 & 73,027 & 482,105 & 9,372 \\
\hline 133 & Rhode Island & 696,877 & $6.2 \%$ & 0 & 0 & 0 & 0 & 0 & 1,318 & 2,162 & 43,248 & 170,722 & 2,574 \\
\hline 134 & Maine & $20,780,154$ & $0.1 \%$ & 0 & 0 & 0 & 0 & 0 & 5,718 & 6,856 & 14,127 & 731,477 & 15,740 \\
\hline
\end{tabular}

Dist. $=$ disturbed Contam. $=$ contaminated 

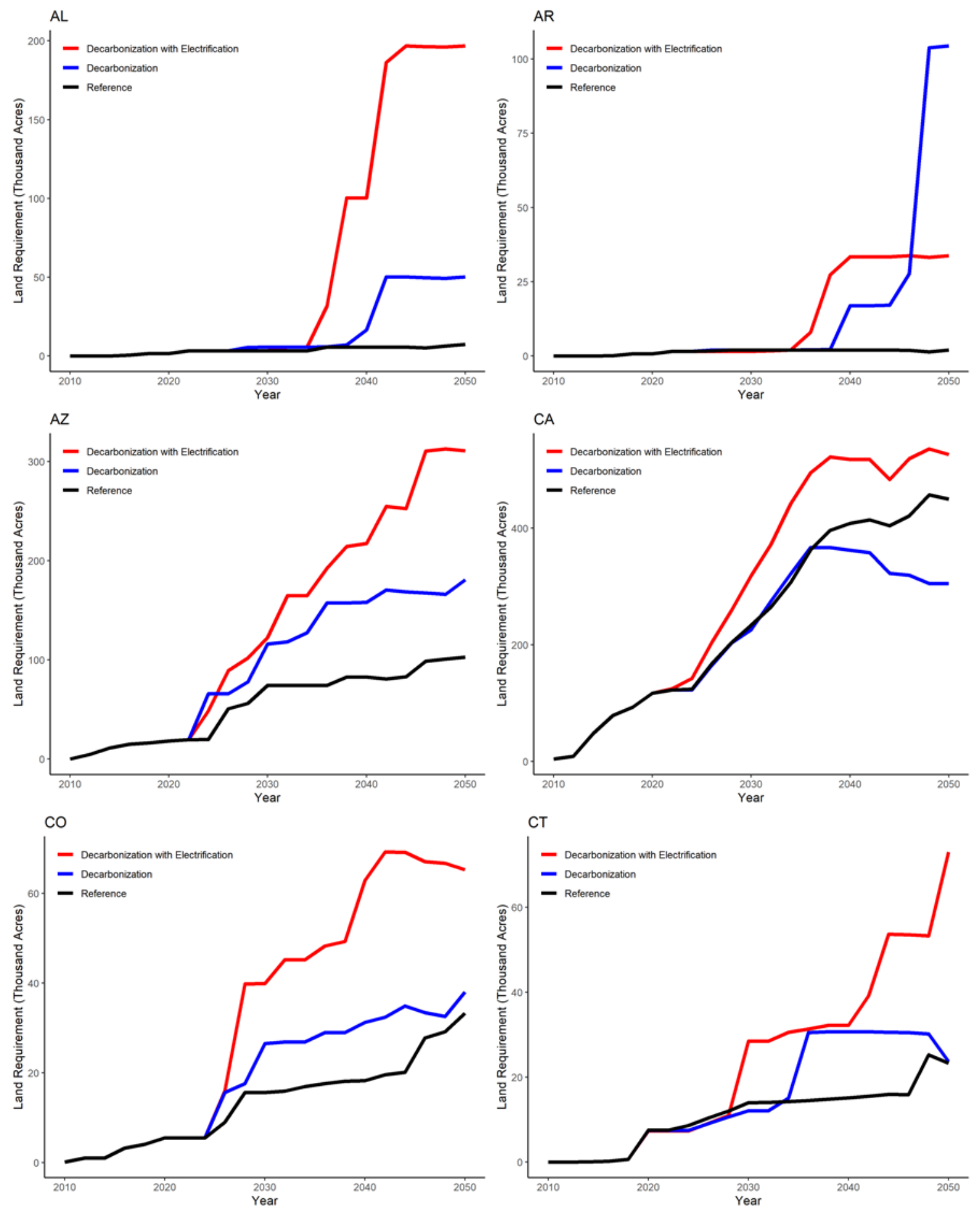

Figure A-1. Estimated cumulative solar land requirement by state for the three core scenarios projected by the ReEDS model by year from 2020 to 2050 

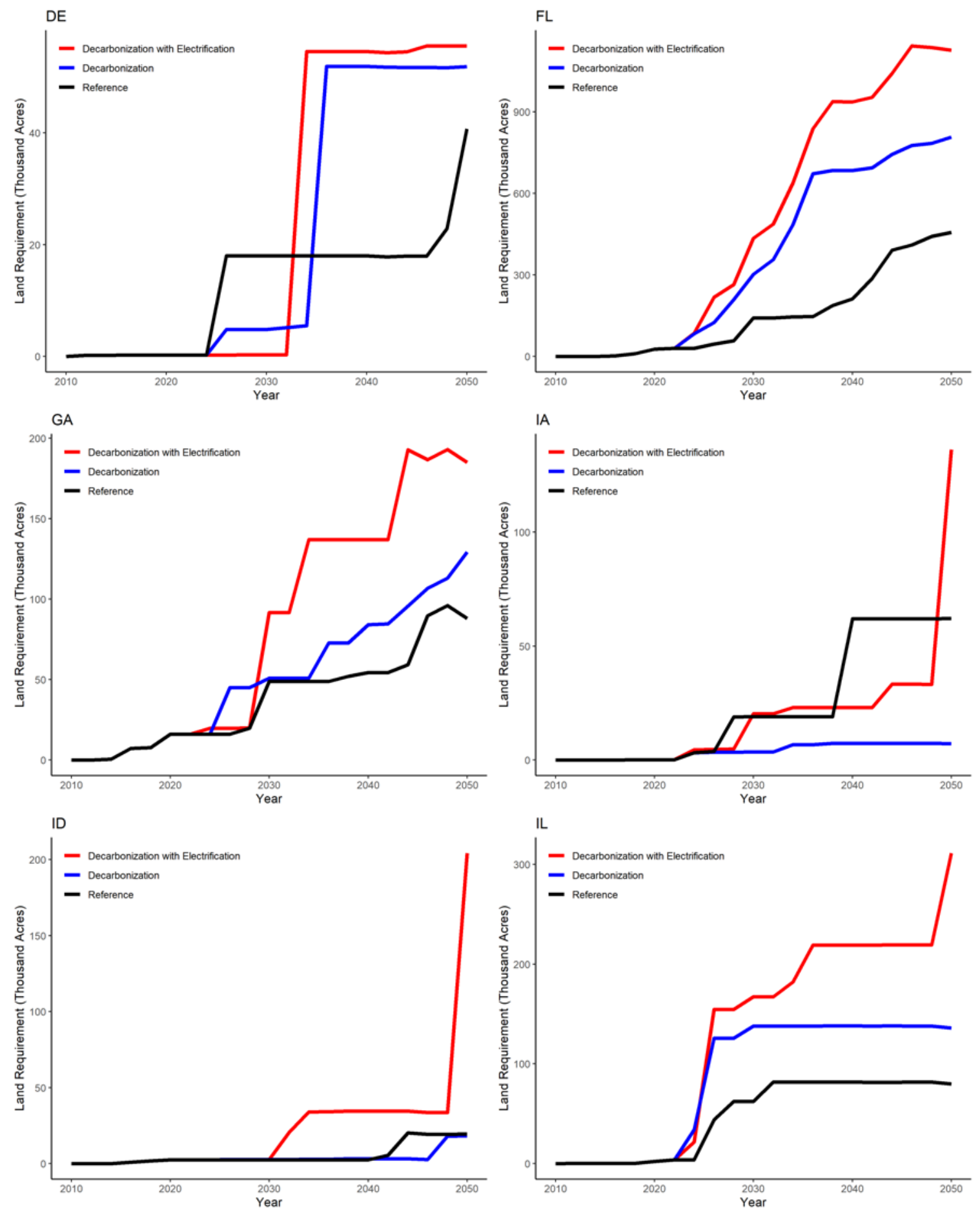

Figure A-1 (continued). Estimated cumulative solar land requirement by state for the three core scenarios projected by the ReEDS model by year from 2020 to 2050 

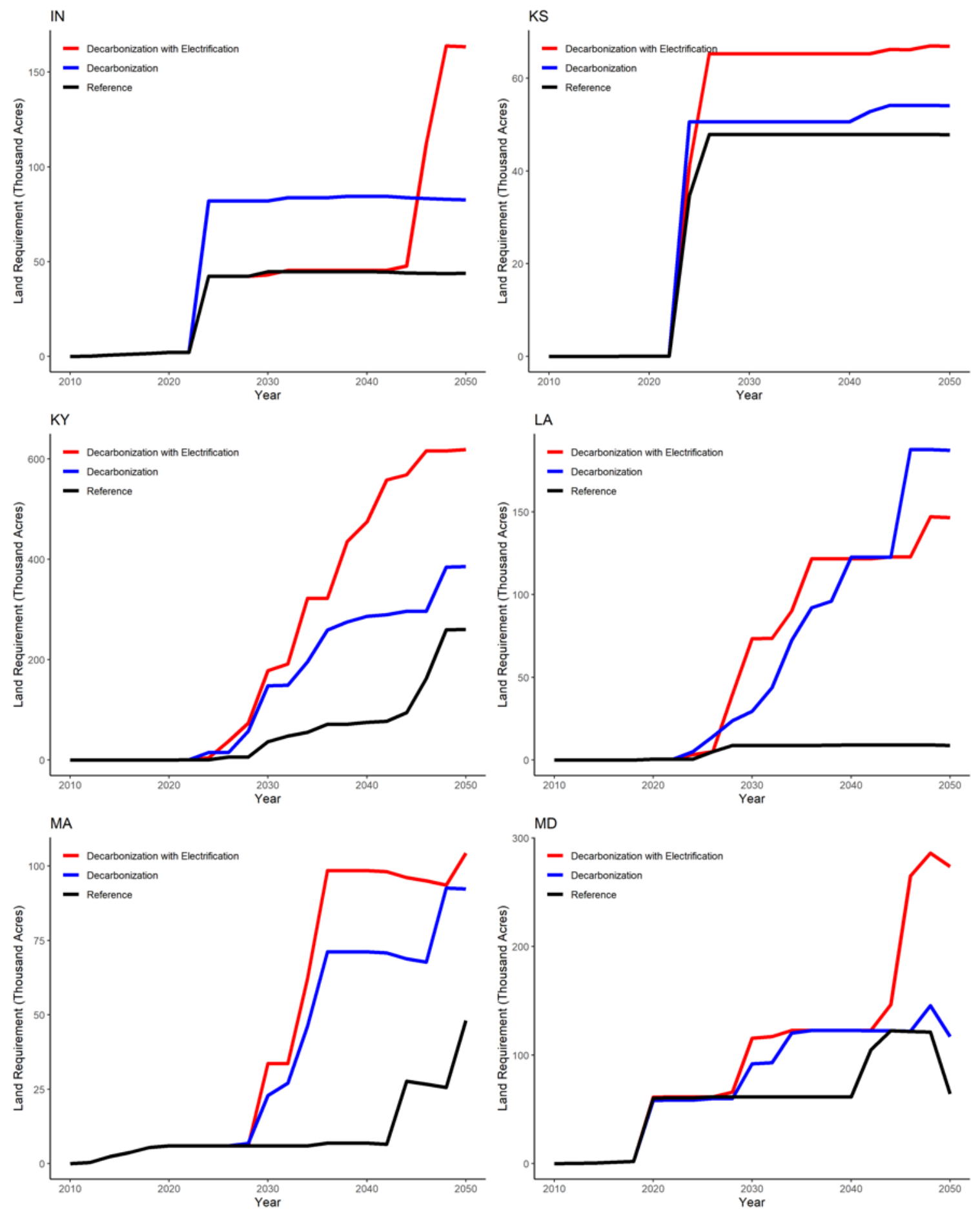

Figure A-1 (continued). Estimated cumulative solar land requirement by state for the three core scenarios projected by the ReEDS model by year from 2020 to 2050 

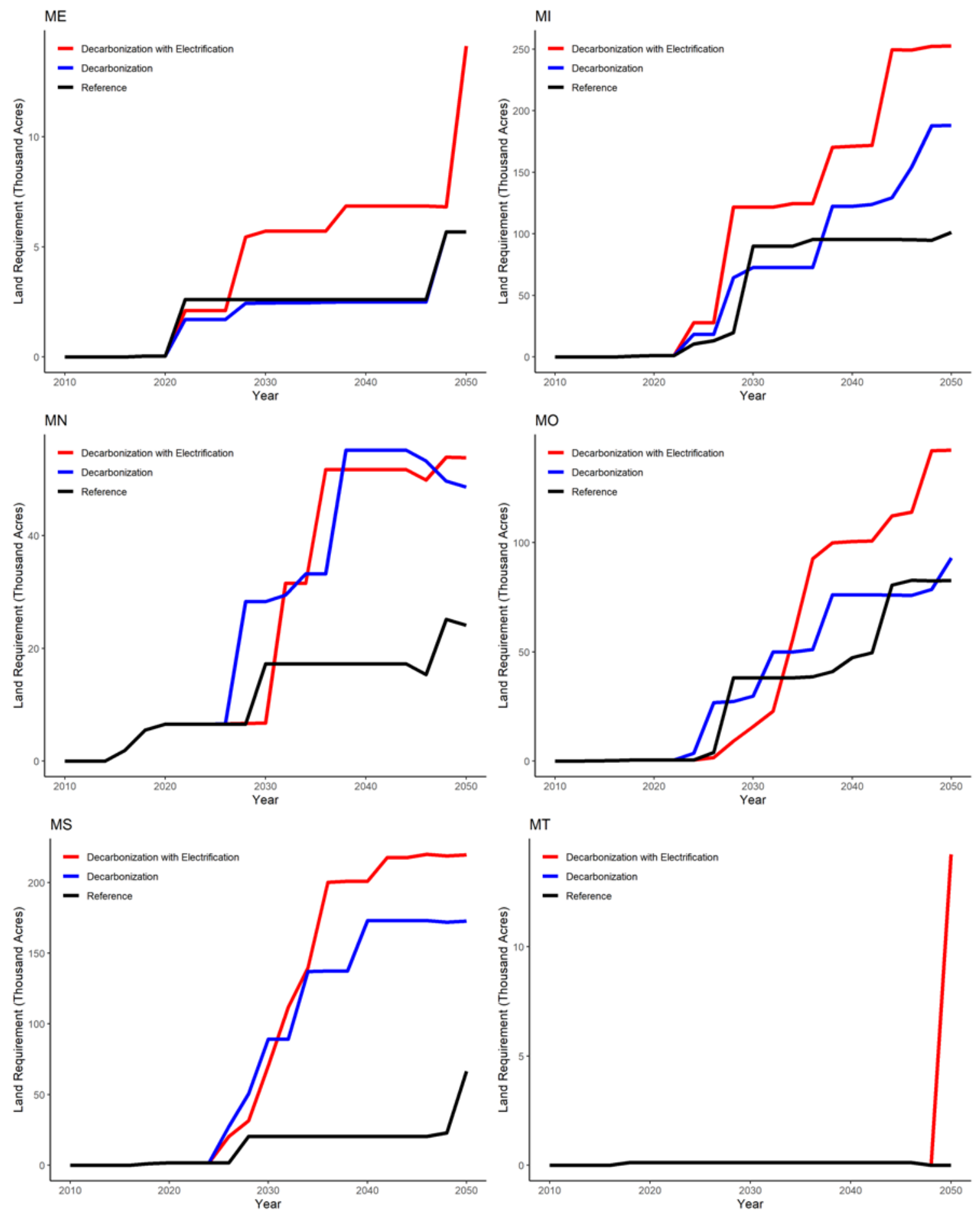

Figure A-1 (continued). Estimated cumulative solar land requirement by state for the three core scenarios projected by the ReEDS model by year from 2020 to 2050 

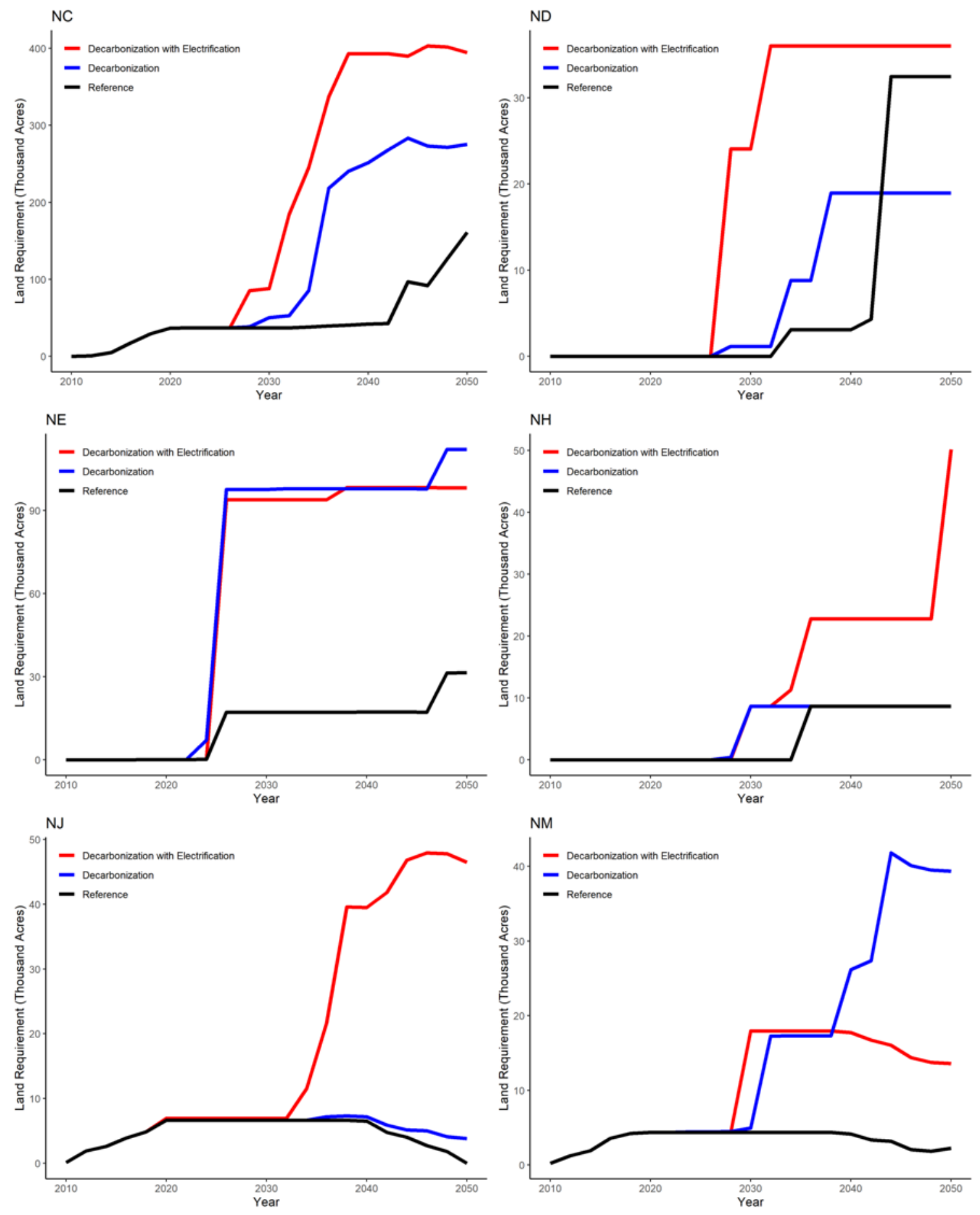

Figure A-1 (continued). Estimated cumulative solar land requirement by state for the three core scenarios projected by the ReEDS model by year from 2020 to 2050 

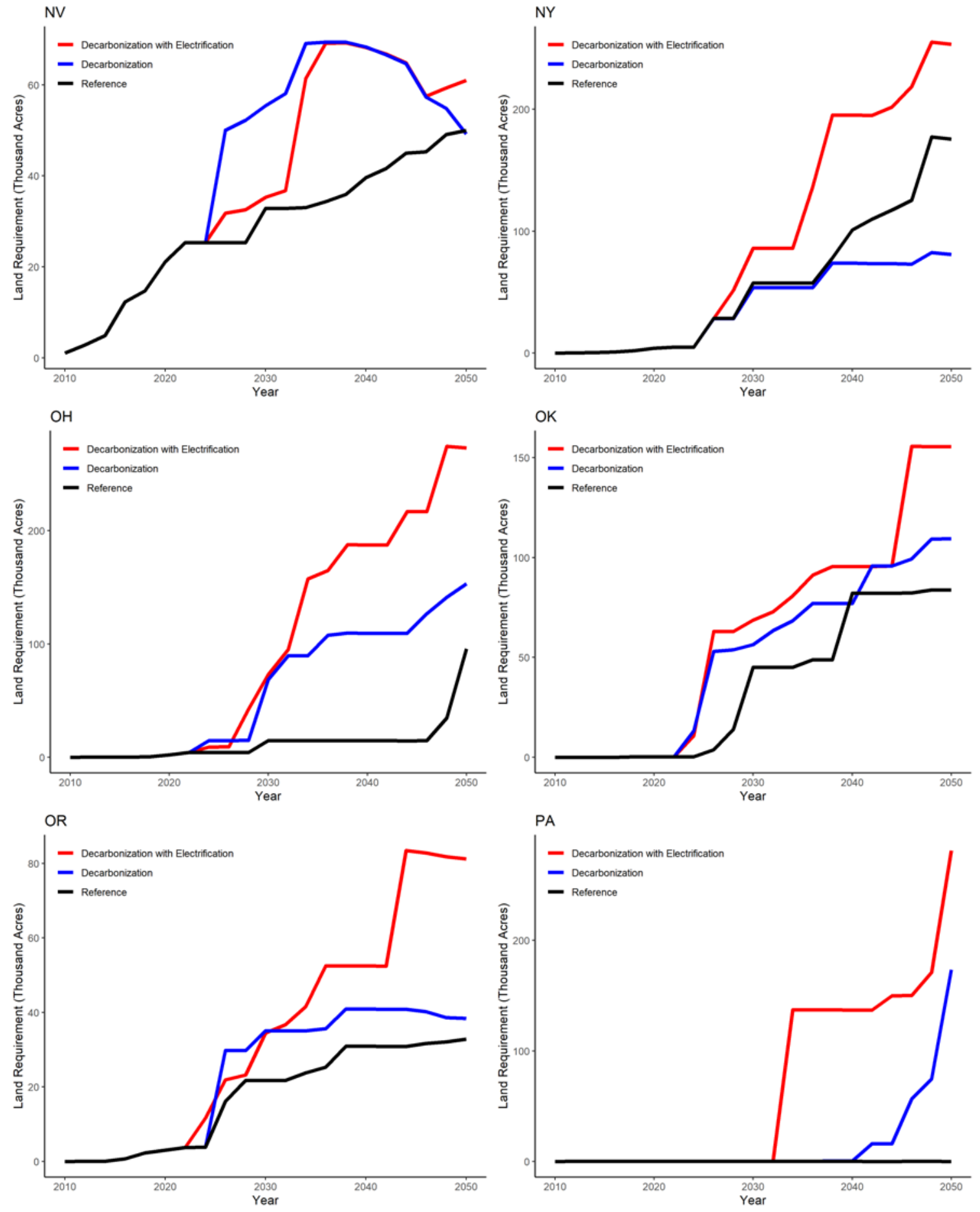

Figure A-1 (continued). Estimated cumulative solar land requirement by state for the three core scenarios projected by the ReEDS model by year from 2020 to 2050 

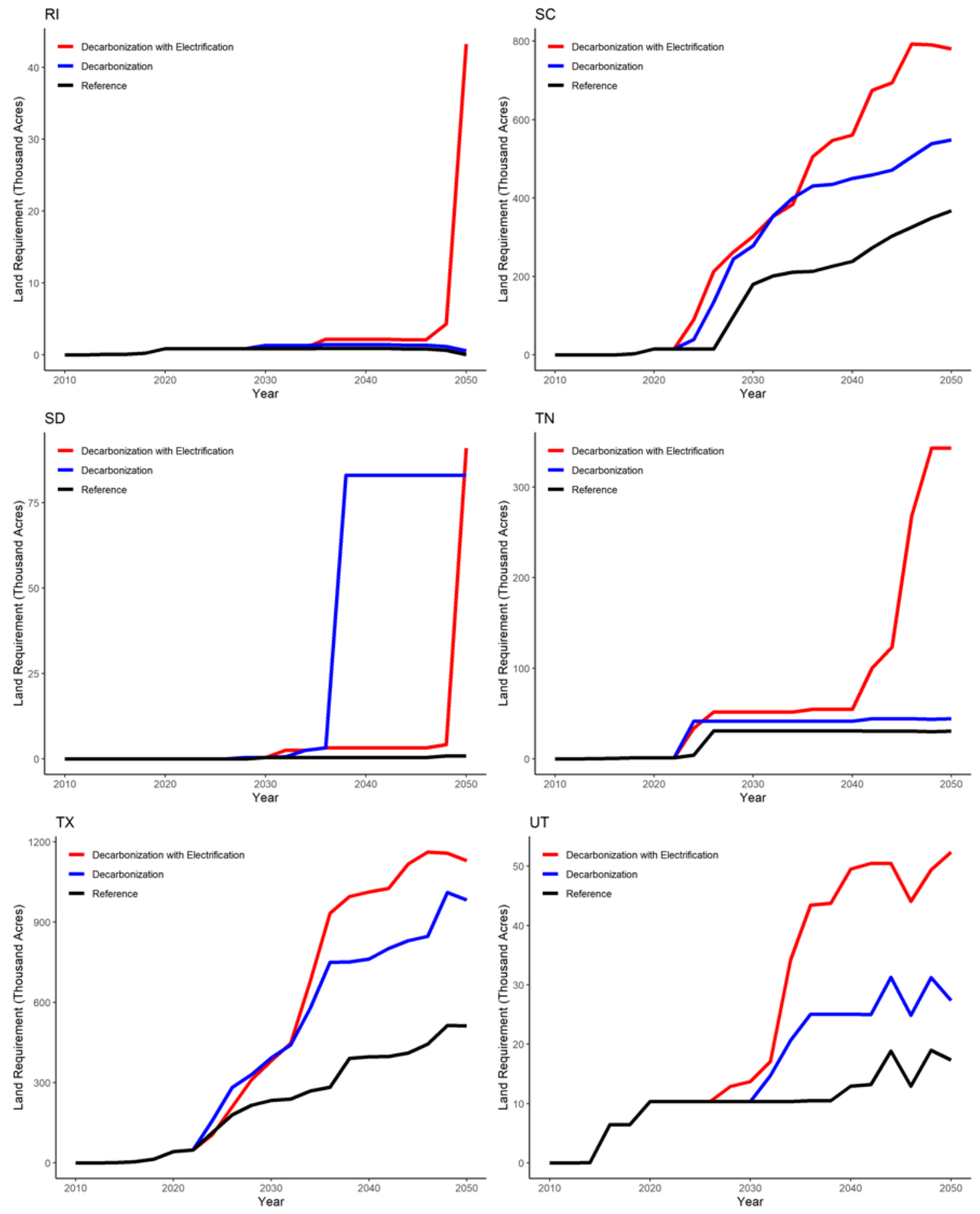

Figure A-1 (continued). Estimated cumulative solar land requirement by state for the three core scenarios projected by the ReEDS model by year from 2020 to 2050 

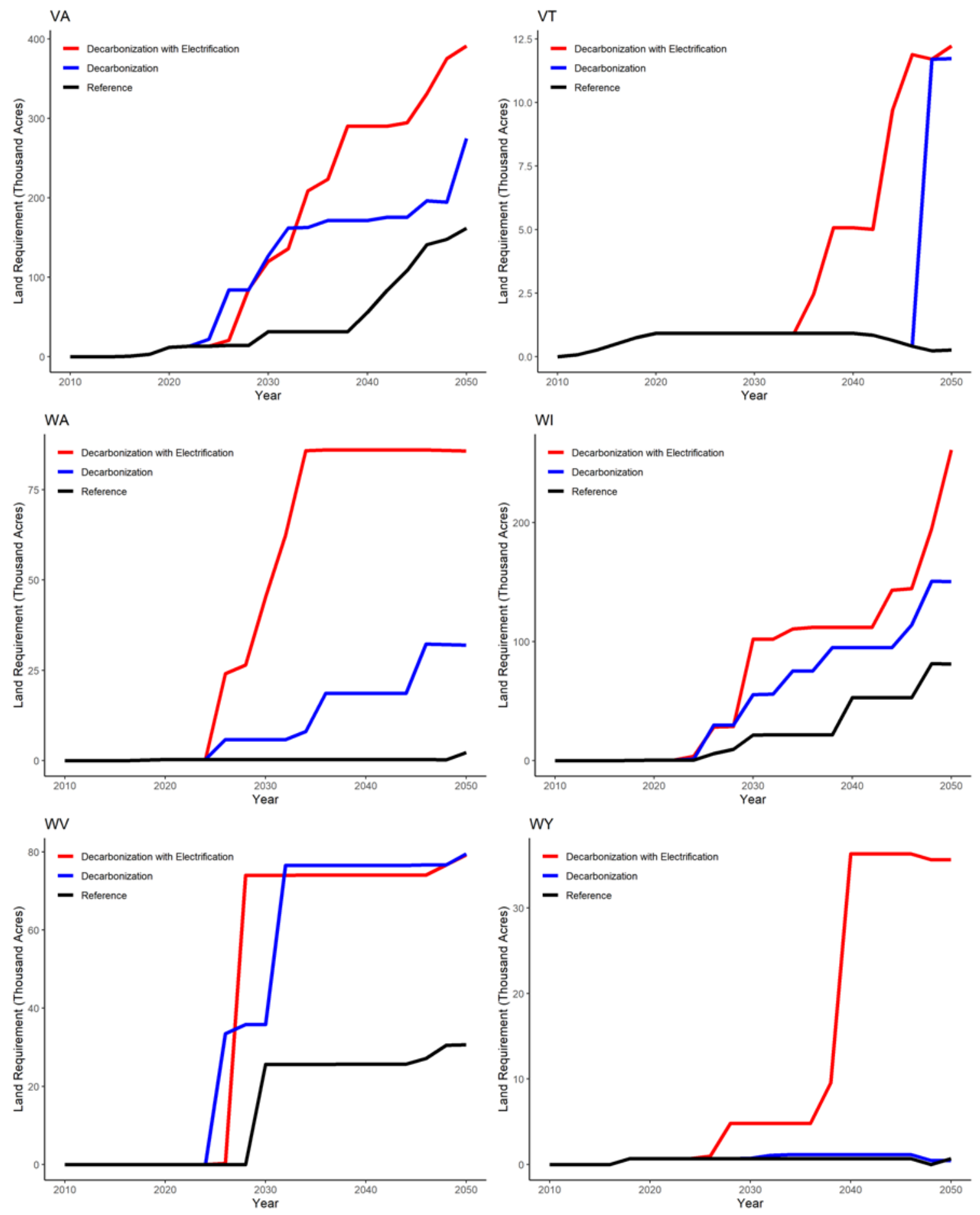

Figure A-1 (continued). Estimated cumulative solar land requirement by state for the three core scenarios projected by the ReEDS model by year from 2020 to 2050 
Table A-2. Comparison of Disturbed Land Availability for Ground-Mounted PV with and without a Minimum Parcel Size Threshold

\begin{tabular}{|c|c|c|c|c|c|}
\hline \multirow[b]{2}{*}{ State Name } & \multicolumn{2}{|c|}{$\begin{array}{l}\text { Original Calculation of } \\
\text { Available Lands }\end{array}$} & \multicolumn{3}{|c|}{$\begin{array}{c}\text { Revised Lands Available } \\
\text { (based on minimum parcel size) }{ }^{1}\end{array}$} \\
\hline & $\begin{array}{l}\text { Total } \\
\text { Disturbed } \\
\text { Acres }\end{array}$ & $\begin{array}{c}\text { Total } \\
\text { Contaminated } \\
\text { Acres }\end{array}$ & $\begin{array}{l}\text { Total } \\
\text { Disturbed } \\
\text { Acres }\end{array}$ & $\begin{array}{c}\text { Percentage } \\
\text { Change in } \\
\text { Disturbed } \\
\text { Acres }\end{array}$ & $\begin{array}{c}\text { Total } \\
\text { Contaminated } \\
\text { Acres }^{2}\end{array}$ \\
\hline Alabama & $5,517,166$ & 40,735 & $3,043,214$ & $-45 \%$ & 40,735 \\
\hline Arkansas & $2,586,580$ & 18,855 & $1,347,024$ & $-48 \%$ & 18,855 \\
\hline Arizona & $5,399,774$ & $2,737,590$ & $1,654,272$ & $-69 \%$ & $2,737,590$ \\
\hline California & $5,472,492$ & 617,554 & $3,842,784$ & $-30 \%$ & 617,554 \\
\hline Colorado & $2,672,426$ & 27,212 & $1,646,746$ & $-38 \%$ & 27,212 \\
\hline Connecticut & 261,724 & 6,926 & 130,586 & $-50 \%$ & 6,926 \\
\hline Delaware & 218,526 & 6,732 & 144,272 & $-34 \%$ & 6,732 \\
\hline Florida & $4,695,180$ & 219,018 & $3,385,182$ & $-28 \%$ & 219,018 \\
\hline Georgia & $6,223,300$ & 21,547 & $3,200,294$ & $-49 \%$ & 21,547 \\
\hline lowa & $3,329,102$ & 4,997 & $2,126,860$ & $-36 \%$ & 4,997 \\
\hline Idaho & $2,172,944$ & 581,383 & $1,368,366$ & $-37 \%$ & 581,383 \\
\hline Illinois & $3,832,176$ & 35,060 & $2,349,168$ & $-39 \%$ & 35,060 \\
\hline Indiana & $3,055,150$ & 75,956 & $1,904,190$ & $-38 \%$ & 75,956 \\
\hline Kansas & $4,700,026$ & 102,574 & $3,034,064$ & $-35 \%$ & 102,574 \\
\hline Kentucky & $1,754,846$ & 24,863 & 761,866 & $-57 \%$ & 24,863 \\
\hline Louisiana & $3,575,836$ & 24,959 & $2,365,354$ & $-34 \%$ & 24,959 \\
\hline Massachusetts & 670,580 & 16,627 & 470,606 & $-30 \%$ & 16,627 \\
\hline Maryland & 866,418 & 22,166 & 537,526 & $-38 \%$ & 22,166 \\
\hline Maine & 701,490 & 4,642 & 248,450 & $-65 \%$ & 4,642 \\
\hline Michigan & $3,560,912$ & 38,860 & $2,071,902$ & $-42 \%$ & 38,860 \\
\hline Minnesota & $3,771,980$ & 169,250 & $2,536,306$ & $-33 \%$ & 169,250 \\
\hline Missouri & $3,069,262$ & 86,632 & $1,578,872$ & $-49 \%$ & 86,632 \\
\hline Mississippi & $6,131,038$ & 11,213 & $3,860,580$ & $-37 \%$ & 11,213 \\
\hline Montana & $2,884,932$ & 233,608 & $1,614,150$ & $-44 \%$ & 233,608 \\
\hline North Carolina & $5,278,630$ & 14,158 & $3,196,862$ & $-39 \%$ & 14,158 \\
\hline North Dakota & $3,439,552$ & 2,110 & $2,104,170$ & $-39 \%$ & 2,110 \\
\hline Nebraska & $3,110,992$ & 78,739 & $1,767,336$ & $-43 \%$ & 78,739 \\
\hline New Hampshire & 284,880 & 1,147 & 146,360 & $-49 \%$ & 1,147 \\
\hline New Jersey & 645,728 & 121,126 & 478,454 & $-26 \%$ & 121,126 \\
\hline New Mexico & $2,175,718$ & $1,100,001$ & $1,294,890$ & $-40 \%$ & $1,100,001$ \\
\hline
\end{tabular}




\begin{tabular}{|l|cc|ccc|}
\hline & \multicolumn{1}{|c|}{$\begin{array}{c}\text { Original Calculation of } \\
\text { Available Lands }\end{array}$} & \multicolumn{3}{|c|}{$\begin{array}{c}\text { Revised Lands Available } \\
\text { (based on minimum parcel size) }\end{array}$} \\
\cline { 2 - 6 } State Name & $\begin{array}{c}\text { Total } \\
\text { Disturbed } \\
\text { Acres }\end{array}$ & $\begin{array}{c}\text { Total } \\
\text { Contaminated } \\
\text { Acres }\end{array}$ & $\begin{array}{c}\text { Total } \\
\text { Disturbed } \\
\text { Acres }\end{array}$ & $\begin{array}{c}\text { Percentage } \\
\text { Change in } \\
\text { Disturbed } \\
\text { Acres }\end{array}$ & $\begin{array}{c}\text { Total } \\
\text { Contaminated } \\
\text { Acres }{ }^{2}\end{array}$ \\
\hline Nevada & $3,838,372$ & 164,063 & $2,820,142$ & $-27 \%$ & 164,063 \\
New York & $2,044,416$ & 103,653 & $1,080,802$ & $-47 \%$ & 103,653 \\
Ohio & $3,717,672$ & 25,440 & $2,514,390$ & $-32 \%$ & 25,440 \\
Oklahoma & $5,693,936$ & 17,516 & $3,898,650$ & $-32 \%$ & 17,516 \\
Oregon & $2,329,181$ & $1,054,427$ & 731,852 & $-69 \%$ & $1,054,427$ \\
Pennsylvania & $1,663,470$ & 62,701 & 771,242 & $-54 \%$ & 62,701 \\
Rhode Island & 89,998 & 1,647 & 58,756 & $-35 \%$ & 1,647 \\
South Carolina & $3,526,486$ & 222,607 & $1,976,990$ & $-44 \%$ & 222,607 \\
South Dakota & $3,731,440$ & 1,388 & $2,641,802$ & $-29 \%$ & 1,388 \\
Tennessee & $2,749,216$ & 82,775 & $1,592,840$ & $-42 \%$ & 82,775 \\
Texas & $32,517,678$ & 246,054 & $24,141,566$ & $-26 \%$ & 246,054 \\
Utah & $2,896,994$ & 37,867 & $2,048,988$ & $-29 \%$ & 37,867 \\
Virginia & $2,750,536$ & 79,662 & $1,358,094$ & $-51 \%$ & 79,662 \\
Vermont & 154,896 & 1,987 & 60,656 & $-61 \%$ & 1,987 \\
Washington & $1,726,818$ & 344,202 & 982,950 & $-43 \%$ & 344,202 \\
Wisconsin & $2,800,868$ & 12,625 & $1,528,572$ & $-45 \%$ & 12,625 \\
West Virginia & 288,666 & 46,100 & 116,778 & $-60 \%$ & 46,100 \\
Wyoming & $1,149,620$ & 10,048 & 543,010 & $-53 \%$ & 10,048 \\
\hline
\end{tabular}

${ }^{1}$ Assumed minimum parcel size of 7.5 ac $(\sim 1 \mathrm{MW})$ for urban PV developments and 15 ac $(\sim 2 \mathrm{MW})$ for rural PV developments. ${ }^{2}$ There is no change for contaminated lands because all contaminated lands in the EPA database of contaminated lands are at least these minimum sizes. 


\section{Appendix B. PViCE Material Demand and EOL Material Projections}

PV historical technology data needed for the bottom-up dynamic mass flow are sparse and scattered, so it was necessary to blend and reconcile information from multiple sources. Our material and module baselines, used as inputs to PViCE, capture the average characteristics of the various deployed PV module technologies in any given year. Therefore, averages and/or market share weightings are used to reconcile differences in sourced data. Additionally, where U.S.-specific data were not available, world average data are used as a proxy. Given that our tool is concerned with the flow of material in and out of the field (i.e., actively producing energy in a solar farm or on a roof), and there can be a 6- to 18-month time lag between advances made on the manufacturing line and their deployment in the field, the deployment date data are used whenever available.

These varying data were collected, averaged, and normalized to create a best approximation of an average PV module deployed for each year from 1995 through 2050, per technology. Figure B-1 shows the market share of c-Si technology both in the United States and globally. The PViCE market share (black line) was used to weight the installation projections from ReEDS to account for c-Si (PViCE currently neglects other technologies). After 2019-2020, all data are based on projections. The complete descriptions of the baseline average PV technology module are detailed in the online documentation of PViCE on GitHub. ${ }^{14}$

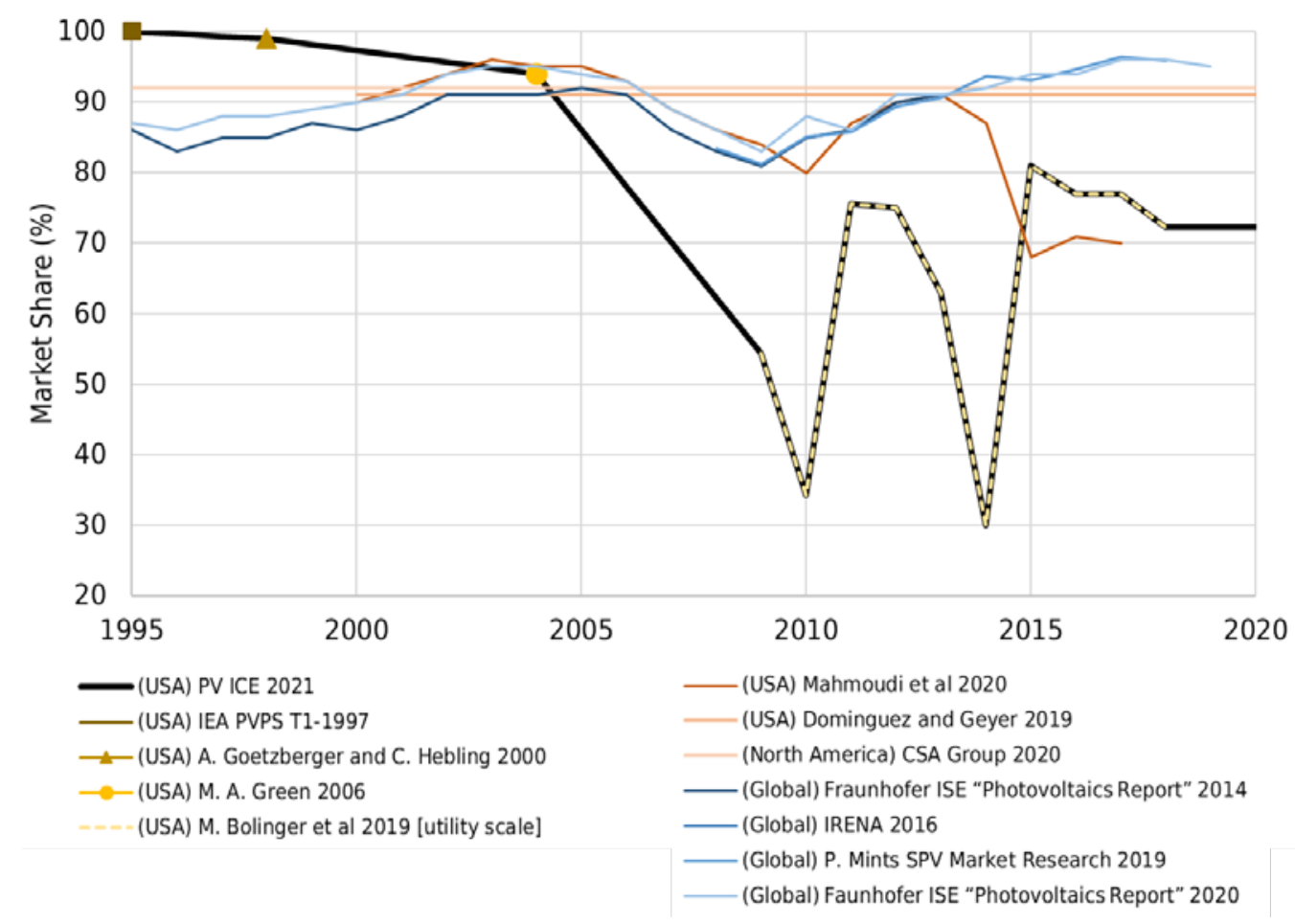

Figure B-1. Market share of C-Si technologies from various literature sources and PViCE averaged market share (black)

Yellow sources were used to create PViCE U.S. c-Si market share, orange sources were referenced for the United States, and blue sources are global c-Si market shares ${ }^{288,290-299}$ 
Throughout the mass flow analysis, some processes are defined in terms of the module's properties and some in terms of the material. This enables flexibility to work at different scales, because, throughout the mass flow, the materials are at times embedded into the PV modules.

Figure B-2 shows the (a) mass per module area of the materials considered, demonstrating an evolving material composition. Figure B-2 (b) shows the manufacturing efficiencies of the materials considered, which dictates the amount of manufacturing scrap created annually. These material manufacturing efficiencies were derived from historical data using a diverse set of sources or reasonable assumptions where data were lacking. Silicon manufacturing efficiencies are primarily associated with sawing/wafering losses, which have improved with time with the advent of diamond wire sawing and larger wafer sizes. Improvements from 2020 through 2030 were taken from ITRPV projections and then held constant through 2050. Glass manufacturing efficiency was derived from a variety of sources ${ }^{300-304}$ Forward projections for glass efficiency were not available; therefore, 2020 levels were maintained through 2050. Simple assumptions were used for aluminum, copper, and silver and were held constant through 2050. Table B-1 notes the material yields and circular settings in PViCE as used for this analysis. For a complete derivation of manufacturing efficiency baselines, refer to the open-source PViCE documentation on GitHub. ${ }^{14}$
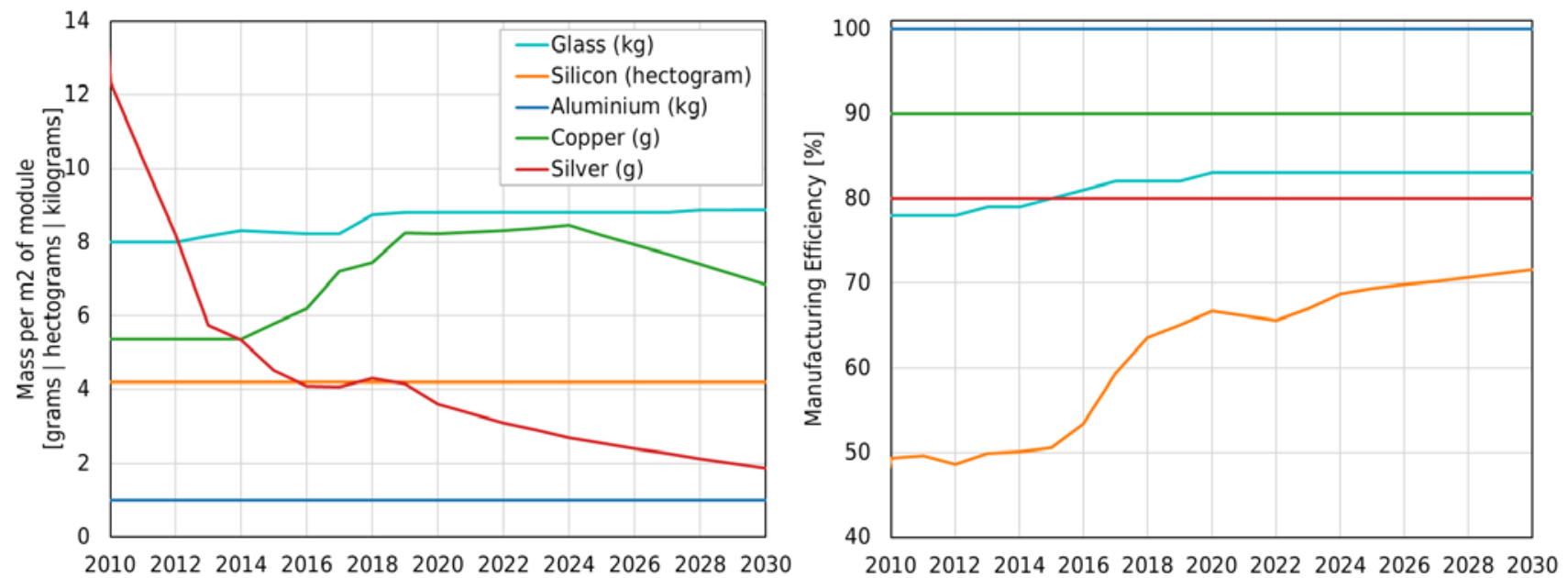

Figure B-2. All materials on a mass per meter squared of module basis over time (a) and the manufacturing efficiency of all materials over time (b)

Note the different units of grams (silver and copper), hectograms (silicon), and kilograms (glass and aluminum). All 2030 values are held constant through 2050. With all circular loops set to zero, the mass losses associated with these manufacturing efficiencies contribute to the EOL stream.

Table B-1. Baseline Material Circularity and Yield Settings for PViCE Calculations

\begin{tabular}{ll}
\hline Virgin material efficiency & $100 \%$ \\
Manufacturing material efficiency & Material-dependent; see Figure B-2. \\
Manufacturing recycling & $0 \%$ \\
Reuse, repair, refurbish & $0 \%$ \\
EOL collection and CE pathways & $0 \%$ \\
\hline
\end{tabular}


Material manufacturing efficiencies were recorded from historical data from a diverse set of sources, with some reasonable assumptions where data were lacking. Silicon manufacturing efficiencies are primarily associated with sawing/wafering losses, which have improved with time with the advent of diamond wire sawing and larger wafer sizes. Improvements from 2020 through 2030 were taken from ITRPV projections, then held constant through 2050. Glass manufacturing efficiency was derived from a variety of sources. ${ }^{300-304}$ Forward projections for glass efficiency were not available; therefore, 2020 levels were maintained through 2050. Simple assumptions were used for aluminum, copper, and silver and were held constant through 2050. For a complete derivation of manufacturing efficiency baselines, refer to the open-source PViCE documentation on GitHub. ${ }^{14}$

PViCE was validated against published installations and waste projections. This was accomplished by using the parameters and inputs of those projections when available. Table B-2 compares prior material demand estimates to our new projections using PViCE baselines and methods. The recent CSA Group estimate is close in installed capacity by 2030 to the Decarb scenario. Excluding the copper, which PViCE currently only considers within the module, all estimates are at a comparable order of magnitude, indicating that differences are most likely derived from varying predictions of future technology improvements and the underlying bottomup baseline mass approach in PViCE. Furthermore, the CSA case includes all types of PV module technologies, whereas the PViCE tool only include monocrystalline and multicrystalline silicon (because CdTe waste is already addressed successfully by First Solar, and other technologies will have a negligible market share). Please note that different from the results provided in the report, Appendix Tables B-2 and B-4 also consider polymers, including backsheet and encapsulants, which have recently been added to PViCE, documented in Ovaitt et al. $(2022){ }^{305}$

Table B-2. Comparison of 2030 Installed PV Mass, with Material Breakdown, Between CSA Group's Recent 2030 Material Demands Projection and PViCE + ReEDS Projections

\begin{tabular}{|c|c|c|c|c|}
\hline \multirow[b]{3}{*}{ Material } & \multicolumn{4}{|c|}{ Metric Tons Installed in Field in 2030} \\
\hline & \multirow{2}{*}{$\begin{array}{l}\text { CSA Group } \\
(437 \text { GW })^{306}\end{array}$} & \multicolumn{3}{|c|}{ PViCE Results by Scenario } \\
\hline & & $\begin{array}{c}\text { Reference } \\
(314 \mathrm{GW})\end{array}$ & $\begin{array}{l}\text { Decarb } \\
\text { (488 GW) }\end{array}$ & $\begin{array}{c}\text { Decarb+E } \\
(586 \text { GW) }\end{array}$ \\
\hline Module & $27,200,000$ & $17,500,000$ & $26,700,000$ & $31,700,000$ \\
\hline Glass & $20,600,000$ & $13,400,000$ & $20,500,000$ & $24,400,000$ \\
\hline Polymers & $2,800,000$ & $1,752,900$ & $2,650,000$ & $3,091,200$ \\
\hline Aluminum & $2,100,000$ & $1,850,000$ & $2,760,000$ & $3,210,000$ \\
\hline Copperxv & 239,000 & 11,200 & 17,500 & 21,000 \\
\hline Silicon & $1,270,000$ & 535,000 & 799,000 & 935,000 \\
\hline Silver & 11,000 & 5,000 & 7,000 & 8,000 \\
\hline Other & 170,000 & - & - & - \\
\hline
\end{tabular}

${ }^{\mathrm{xv}}$ Other material compositions include copper external to the module, including junction boxes and cabling, while currently the baseline used in PViCE only includes the busbar and cell stringing internal to the module. 
Table B-3 shows a similar comparison for U.S. installed capacity. Installed capacity considers all new installations in previous years minus the retired modules due to failures or EOL. In the table, IEA/IRENA's Regular Loss and Early Loss lifetime assumptions are compared with PViCE lifetime assumptions. EOL is determined by three modes in PViCE: project lifetime, degradation beyond $80 \%$ nameplate, and Weibull-based failures. The Weibull functions used in PViCE are calculated based on the expected number of functioning modules at the end of the project lifetime. In contrast, the IEA/IRENA approach used by the CSA Group ${ }^{307,306}$ uses the same Weibull function for both failure and wear-out, and it classifies $64 \%$ of the cohort as waste by the $30^{\text {th }}$ year in the field. Because of this, by 2050, PViCE lifetime assumptions predict a $30 \%$ higher capacity compared with Early Loss assumptions ${ }^{307}$ and a 10\% higher capacity compared with Regular Loss assumptions.

Table B-3. Comparison of U.S. Installed Capacity (GW) up to 2030 and 2050

\begin{tabular}{|l|c|c|c|c|c|c|}
\hline \multirow{2}{*}{} & \multicolumn{5}{|c|}{2030} & \multicolumn{3}{c|}{2050} \\
\cline { 2 - 7 } & \multicolumn{5}{|c|}{ Lifetime Assumptions } \\
\cline { 2 - 7 } Installation Scenario & $\begin{array}{c}\text { Early } \\
\text { Loss }\end{array}$ & $\begin{array}{c}\text { Regular } \\
\text { Loss }\end{array}$ & PViCE & $\begin{array}{c}\text { Early } \\
\text { Loss }\end{array}$ & $\begin{array}{c}\text { Regular } \\
\text { Loss }\end{array}$ & PViCE \\
\hline IEA/IRENA 307 & - & 240 & - & - & 512 & - \\
\hline CSA $^{306}$ & - & 437 & - & - & NA & - \\
\hline $\begin{array}{l}\text { Solar Futures Study } \\
\text { Reference }\end{array}$ & 277 & 312 & 314 & 376 & 520 & 642 \\
\hline $\begin{array}{l}\text { Solar Futures Study } \\
\text { Decarb }\end{array}$ & 448 & 487 & 489 & 416 & 714 & 952 \\
\hline $\begin{array}{l}\text { Solar Futures Study } \\
\text { Decarb+E }\end{array}$ & 547 & 585 & 587 & 769 & 1,230 & 1,530 \\
\hline
\end{tabular}

NA = not applicable; "--" = no data available

Table B-4 compares cumulative EOL material for the U.S. developed in three projections - by IEA/IRENA, the CSA Group and in the Solar Futures Study using PViCE. Manufacturing waste is excluded from the IEA/IRENA ${ }^{307}$ and CSA $^{306}$ sources, because this mass would enter the waste stream in areas other than North America. While PViCE does calculate manufacturing waste for each year, that waste is not included in the table to enable direct comparison with the published literature. 
Table B-4. Comparison of Cumulative U.S. EOL Materials for Various Years Based on Different Lifetime Assumptions

\begin{tabular}{|c|c|c|c|c|c|c|}
\hline \multirow{3}{*}{ Year } & \multirow{3}{*}{$\begin{array}{l}\text { Lifetime } \\
\text { Assumptions }\end{array}$} & \multicolumn{5}{|c|}{$\begin{array}{c}\text { Cumulative EOL Material } \\
\text { (metric tons) }\end{array}$} \\
\hline & & \multirow{2}{*}{$\begin{array}{l}\text { IEA/IRENA } \\
307\end{array}$} & \multirow{2}{*}{$\mathrm{CSA}^{306}$} & \multicolumn{3}{|c|}{ Solar Futures Study Scenarios } \\
\hline & & & & Reference & Decarb & Decarb+E \\
\hline \multirow{3}{*}{2016} & Early Loss & 24,000 & - & 6950 & 6950 & 6950 \\
\hline & Regular Loss & 6,500 & - & 35 & 35 & 35 \\
\hline & PViCE & NA & - & 10 & 10 & 10 \\
\hline \multirow{3}{*}{2020} & Early Loss & 85,000 & - & 52,800 & 52,800 & 52,800 \\
\hline & Regular Loss & 13,000 & - & 1000 & 1000 & 1000 \\
\hline & PViCE & NA & - & 400 & 400 & 400 \\
\hline \multirow{3}{*}{2030} & Early Loss & $1,000,000$ & $1,200,000$ & 821,000 & 920,000 & 922,000 \\
\hline & Regular Loss & 170,000 & 214,900 & 112,000 & 113,000 & 113,000 \\
\hline & PViCE & NA & NA & 71,100 & 71,100 & 71,100 \\
\hline \multirow{3}{*}{2040} & Early Loss & $4,000,000$ & 一- & $3,900,000$ & $5,510,000$ & $6,110,000$ \\
\hline & Regular Loss & $1,700,000$ & 一 & $1,590,000$ & $1,800,000$ & $1,830,000$ \\
\hline & PViCE & NA & NA & $2,090,000$ & $2,090,000$ & $2,090,000$ \\
\hline \multirow{3}{*}{2050} & Early Loss & $10,000,000$ & - & $10,200,000$ & $16,400,000$ & $20,300,000$ \\
\hline & Regular Loss & $7,500,000$ & - & $7,450,000$ & $10,500,000$ & $11,600,000$ \\
\hline & PViCE & NA & - & $6,740,000$ & $7,240,000$ & $7,240,000$ \\
\hline
\end{tabular}

NA = not applicable, "--" = no data available

Installed capacity by 2050 in the Solar Futures Study Reference scenario is $25 \%$ more the installed capacity projected in IEA/IRENA, ${ }^{307}$ and waste projections in 2050 are comparable between IRENA ${ }^{307}$ with the Regular Loss and Early Loss assumption (7.5 million metric tons). Past projections of waste (2016 and 2020) differ in magnitude because Solar Future Study scenarios installation data start in 2010. IRENA's data for 2016 may or may not include installations back to 1985 and potentially uses a ton per watt calculation in excess of 100 metric tons per $\mathrm{kW}$. Recall that PViCE does not use a mass-power factor but also a dynamic baseline. Furthermore, PViCE analysis only considers market share of c-Si. Unfortunately, there is no empirical data at a national scale to evaluate whether the waste generated in 2016 and 2020 match any of the literature projections. The Decarb and Decarb $+E$ scenarios have more deployment (1 TW and 1.5 TW) in 2050 than PViCE installed capacity projections, which consider degradation as well as PV modules retired due to failures or EOL. While early-loss and regular-loss lifetime assumptions predict large quantities of EOL material prior to 2050, PViCE predicts that the majority of EOL materials will leave the field after 2050 owing to use of more 
recent, and better, module performance data incorporated into the model than what was assumed in the other two projections. 


\section{Additional Tables}

Table B-5. U.S. Annual Demand by Material for Select Years (metric tons)

\begin{tabular}{|l|r|r|r|r|}
\hline Material & Year & Reference & Decarb & \multicolumn{1}{c|}{ Decarb+E } \\
\hline Glass & 2030 & $1,810,000$ & $2,320,000$ & $3,300,000$ \\
\cline { 2 - 5 } & 2040 & 799,000 & 322,000 & 528,000 \\
\cline { 2 - 5 } & 2050 & $1,110,000$ & $1,250,000$ & $2,640,000$ \\
\hline \multirow{4}{*}{ Aluminum } & 2030 & 206000 & 264000 & 376,000 \\
\cline { 2 - 5 } & 2040 & 91100 & 36700 & 60100 \\
\cline { 2 - 5 } & 2050 & 127,000 & 142,000 & 300,000 \\
\hline \multirow{4}{*}{ Sopper } & 2030 & 1,480 & 1,910 & 2,710 \\
\cline { 2 - 5 } & 2040 & 657 & 265 & 434 \\
\cline { 2 - 5 } & 2050 & 915 & 1,030 & 2,170 \\
\cline { 2 - 5 } & 2030 & 85,700 & 110,000 & 157,000 \\
\cline { 2 - 5 } & 2040 & 37,900 & 15,300 & 25,000 \\
\hline \multirow{4}{*}{ Silver } & 2050 & 5,2800 & 59,300 & 125,000 \\
\cline { 2 - 5 } & 2030 & 453 & 582 & 132 \\
\cline { 2 - 5 } & 2040 & 200 & 80 & 661 \\
\cline { 2 - 5 } & 2050 & 279 & 313 & 828 \\
\hline
\end{tabular}

Table B-6. U.S. Cumulative Demand by Material for Select Years (metric tons)

\begin{tabular}{|l|l|r|r|r|}
\hline Material & \multicolumn{1}{|c|}{ Year } & Reference & Decarb & Decarb+E \\
\hline Glass & 2030 & $14,100,000$ & $21,500,000$ & $25,500,000$ \\
\cline { 2 - 5 } & 2040 & $20,200,000$ & $36,800,000$ & $50,300,000$ \\
\cline { 2 - 5 } & 2050 & $31,800,000$ & $46,900,000$ & $70,600,000$ \\
\hline \multirow{4}{*}{ Aluminum } & 2030 & $1,920,000$ & 2850,000 & $3,320,000$ \\
\cline { 2 - 5 } & 2040 & $2,620,000$ & $4,590,000$ & $6,150,000$ \\
\cline { 2 - 5 } & 2050 & $3,940,000$ & $5,740,000$ & $8,460,000$ \\
\hline \multirow{5}{*}{ Copper } & 2030 & 12,700 & 19,900 & 23,400 \\
\cline { 2 - 5 } & 2040 & 17,800 & 32,500 & 43,800 \\
\cline { 2 - 5 } & 2050 & 27,300 & 40,800 & 60,500 \\
\hline \multirow{5}{*}{ Silicon } & 2030 & 847,000 & $1,240,000$ & $1,430,000$ \\
\cline { 2 - 5 } & 2040 & $1,140,000$ & $1,960,000$ & $2,610,000$ \\
\cline { 2 - 5 } & 2050 & $1,690,000$ & $2,440,000$ & $3,570,000$ \\
\hline \multirow{5}{*}{ Silver } & 2030 & 5,970 & 8,450 & 9,570 \\
\cline { 2 - 5 } & 2040 & 7,520 & 12,300 & 15,800 \\
\cline { 2 - 5 } & 2050 & 10,400 & 14,800 & 20,900 \\
\hline
\end{tabular}


Table B-7. Yearly Material Requirements (metric tons) for Scenario 1: Reference

\begin{tabular}{|c|c|c|c|c|c|c|c|c|c|c|c|c|c|c|c|}
\hline \multirow[b]{2}{*}{ State } & \multicolumn{3}{|c|}{ Glass } & \multicolumn{3}{|c|}{ Silicon } & \multicolumn{3}{|c|}{ Silver } & \multicolumn{3}{|c|}{ Copper } & \multicolumn{3}{|c|}{ Aluminum } \\
\hline & 2030 & 2040 & 2050 & 2030 & 2040 & 2050 & 2030 & 2040 & 2050 & 2030 & 2040 & 2050 & 2030 & 2040 & 2050 \\
\hline Mississippi & 2200 & 1260 & 125000 & 104 & 59 & 5920 & 0 & 0 & 31 & 1 & 1 & 103 & 250 & 143 & 14200 \\
\hline North Carolina & 14700 & 9310 & 121000 & 696 & 442 & 5720 & 3 & 2 & 30 & 12 & 7 & 99 & 1670 & 1060 & 13700 \\
\hline Florida & 294000 & 76400 & 95200 & 13900 & 3620 & 4520 & 73 & 19 & 23 & 241 & 62 & 78 & 33500 & 8700 & 10900 \\
\hline South Carolina & 251000 & 37600 & 88400 & 11900 & 1780 & 4200 & 63 & 9 & 22 & 206 & 30 & 72 & 28600 & 4280 & 10100 \\
\hline Texas & 103000 & 32900 & 84100 & 4870 & 1560 & 3990 & 25 & 8 & 21 & 84 & 27 & 69 & 11700 & 3750 & 9580 \\
\hline Virginia & 61000 & 76500 & 71300 & 2890 & 3630 & 3380 & 15 & 19 & 17 & 50 & 62 & 58 & 6950 & 8720 & 8130 \\
\hline Massachusetts & 1980 & 1170 & 64600 & 94 & 55 & 3060 & 0 & 0 & 16 & 1 & 0 & 53 & 226 & 133 & 7350 \\
\hline California & 112000 & 56700 & 64100 & 5320 & 2690 & 3040 & 28 & 14 & 16 & 92 & 46 & 52 & 12800 & 6460 & 7300 \\
\hline Delaware & 1770 & 254 & 49900 & 83 & 12 & 2370 & 0 & 0 & 12 & 1 & 0 & 41 & 201 & 29 & 5680 \\
\hline Nevada & 25200 & 14300 & 20800 & 1200 & 680 & 987 & 6 & 3 & 5 & 20 & 11 & 17 & 2870 & 1630 & 2370 \\
\hline Colorado & 4540 & 4200 & 17800 & 215 & 199 & 843 & 1 & 1 & 4 & 3 & 3 & 14 & 517 & 478 & 2020 \\
\hline Connecticut & 7280 & 1560 & 14200 & 345 & 74 & 674 & 1 & 0 & 3 & 5 & 1 & 11 & 830 & 178 & 1620 \\
\hline Arizona & 60000 & 1860 & 11600 & 2850 & 88 & 551 & 15 & 0 & 2 & 49 & 1 & 9 & 6840 & 212 & 1320 \\
\hline Washington & 3240 & 1220 & 7710 & 154 & 57 & 366 & 0 & 0 & 1 & 2 & 1 & 6 & 369 & 139 & 879 \\
\hline Utah & 1400 & 8160 & 7530 & 66 & 387 & 357 & 0 & 2 & 1 & 1 & 6 & 6 & 159 & 929 & 858 \\
\hline Georgia & 88500 & 9760 & 6950 & 4200 & 463 & 330 & 22 & 2 & 1 & 72 & 8 & 5 & 10100 & 1110 & 792 \\
\hline Tennessee & 1950 & 2500 & 6510 & 92 & 119 & 309 & 0 & 0 & 1 & 1 & 2 & 5 & 222 & 285 & 741 \\
\hline Indiana & 11800 & 4900 & 6340 & 558 & 233 & 301 & 2 & 1 & 1 & 9 & 4 & 5 & 1340 & 559 & 722 \\
\hline Oregon & 2710 & 1270 & 4890 & 129 & 60 & 232 & 0 & 0 & 1 & 2 & 1 & 4 & 309 & 144 & 557 \\
\hline Missouri & 1730 & 21700 & 4740 & 82 & 1030 & 225 & 0 & 5 & 1 & 1 & 17 & 3 & 197 & 2470 & 540 \\
\hline Alabama & 2760 & 965 & 4670 & 131 & 45 & 221 & 0 & 0 & 1 & 2 & 0 & 3 & 315 & 110 & 532 \\
\hline U.S. Total & 1810000 & 799000 & 1110000 & 85700 & 37900 & 52800 & 453 & 200 & 279 & 1480 & 657 & 915 & 206000 & 91100 & 127000 \\
\hline
\end{tabular}


Table B-8. Yearly Material Requirements (metric tons) for Scenario 2: Decarb

\begin{tabular}{|c|c|c|c|c|c|c|c|c|c|c|c|c|c|c|c|}
\hline \multirow[b]{2}{*}{ State } & \multicolumn{3}{|c|}{ Glass } & \multicolumn{3}{|c|}{ Silicon } & \multicolumn{3}{|c|}{ Silver } & \multicolumn{3}{|c|}{ Copper } & \multicolumn{3}{|c|}{ Aluminum } \\
\hline & 2030 & 2040 & 2050 & 2030 & 2040 & 2050 & 2030 & 2040 & 2050 & 2030 & 2040 & 2050 & 2030 & 2040 & 2050 \\
\hline Pennsylvania & 26600 & 4480 & 278000 & 1260 & 212 & 13200 & 6 & 1 & 69 & 21 & 3 & 229 & 3030 & 510 & 31700 \\
\hline Virginia & 144000 & 8340 & 255000 & 6830 & 396 & 12100 & 36 & 2 & 63 & 118 & 6 & 209 & 16400 & 951 & 29000 \\
\hline Florida & 332000 & 13600 & 131000 & 15700 & 643 & 6200 & 83 & 3 & 32 & 273 & 11 & 107 & 37800 & 1540 & 14900 \\
\hline California & 101000 & 27600 & 80900 & 4810 & 1310 & 3840 & 25 & 6 & 20 & 83 & 22 & 66 & 11600 & 3140 & 9220 \\
\hline Maryland & 98700 & 1370 & 78900 & 4680 & 65 & 3740 & 24 & 0 & 19 & 81 & 1 & 64 & 11200 & 156 & 8990 \\
\hline Georgia & 19100 & 36100 & 75800 & 906 & 1710 & 3600 & 4 & 9 & 19 & 15 & 29 & 62 & 2180 & 4110 & 8640 \\
\hline South Carolina & 109000 & 47700 & 65300 & 5180 & 2260 & 3100 & 27 & 12 & 16 & 89 & 39 & 53 & 12400 & 5440 & 7440 \\
\hline Missouri & 10200 & 4990 & 48300 & 482 & 237 & 2290 & 2 & 1 & 12 & 8 & 4 & 39 & 1160 & 569 & 5510 \\
\hline Ohio & 166000 & 7010 & 45300 & 7870 & 333 & 2150 & 41 & 1 & 11 & 136 & 5 & 37 & 18900 & 799 & 5160 \\
\hline North Carolina & 56500 & 46000 & 41200 & 2680 & 2180 & 1960 & 14 & 11 & 10 & 46 & 37 & 33 & 6440 & 5230 & 4700 \\
\hline Texas & 245000 & 21000 & 27600 & 11600 & 994 & 1310 & 61 & 5 & 6 & 201 & 17 & 22 & 27900 & 2390 & 3140 \\
\hline Colorado & 32900 & 1550 & 11100 & 1560 & 73 & 527 & 8 & 0 & 2 & 27 & 1 & 9 & 3750 & 177 & 1260 \\
\hline West Virginia & 981 & 810 & 9750 & 46 & 38 & 462 & 0 & 0 & 2 & 0 & 0 & 8 & 112 & 92 & 1110 \\
\hline Tennessee & 3420 & 3390 & 7930 & 162 & 161 & 376 & 0 & 0 & 1 & 2 & 2 & 6 & 390 & 386 & 904 \\
\hline Kentucky & 271000 & 32400 & 7830 & 12900 & 1540 & 372 & 68 & 8 & 1 & 223 & 26 & 6 & 30900 & 3700 & 892 \\
\hline Michigan & 34600 & 8920 & 7650 & 1640 & 423 & 363 & 8 & 2 & 1 & 28 & 7 & 6 & 3950 & 1020 & 872 \\
\hline Mississippi & 118000 & 2450 & 7100 & 5600 & 116 & 337 & 29 & 0 & 1 & 97 & 2 & 5 & 13500 & 279 & 809 \\
\hline New Jersey & 11600 & 1890 & 6150 & 551 & 89 & 292 & 2 & 0 & 1 & 9 & 1 & 5 & 1320 & 215 & 700 \\
\hline Indiana & 7460 & 7840 & 6060 & 354 & 372 & 287 & 1 & 1 & 1 & 6 & 6 & 4 & 850 & 894 & 690 \\
\hline Alabama & 4660 & 1650 & 5300 & 221 & 78 & 251 & 1 & 0 & 1 & 3 & 1 & 4 & 531 & 188 & 603 \\
\hline Oklahoma & 11400 & 7840 & 4890 & 541 & 372 & 232 & 2 & 1 & 1 & 9 & 6 & 4 & 1300 & 893 & 557 \\
\hline New York & 89700 & 776 & 3830 & 4260 & 36 & 182 & 22 & 0 & 0 & 73 & 0 & 3 & 10200 & 88 & 436 \\
\hline Kansas & 1990 & 1730 & 3780 & 94 & 82 & 179 & 0 & 0 & 0 & 1 & 1 & 3 & 226 & 197 & 431 \\
\hline Other States & 423000 & 32900 & 40800 & 20100 & 1560 & 1930 & 106 & 8 & 10 & 348 & 27 & 33 & 48200 & 3750 & 4650 \\
\hline U.S. Total & 2320000 & 322000 & 1250000 & 110000 & 15300 & 59300 & 582 & 80 & 313 & 1910 & 265 & 1030 & 264000 & 36700 & 142000 \\
\hline
\end{tabular}


Table B-9. Yearly Material Requirements (metric tons) for Scenario 3: Decarb+E

Yearly Material Requirements (metric tons) for Scenario 3: Decarb+E

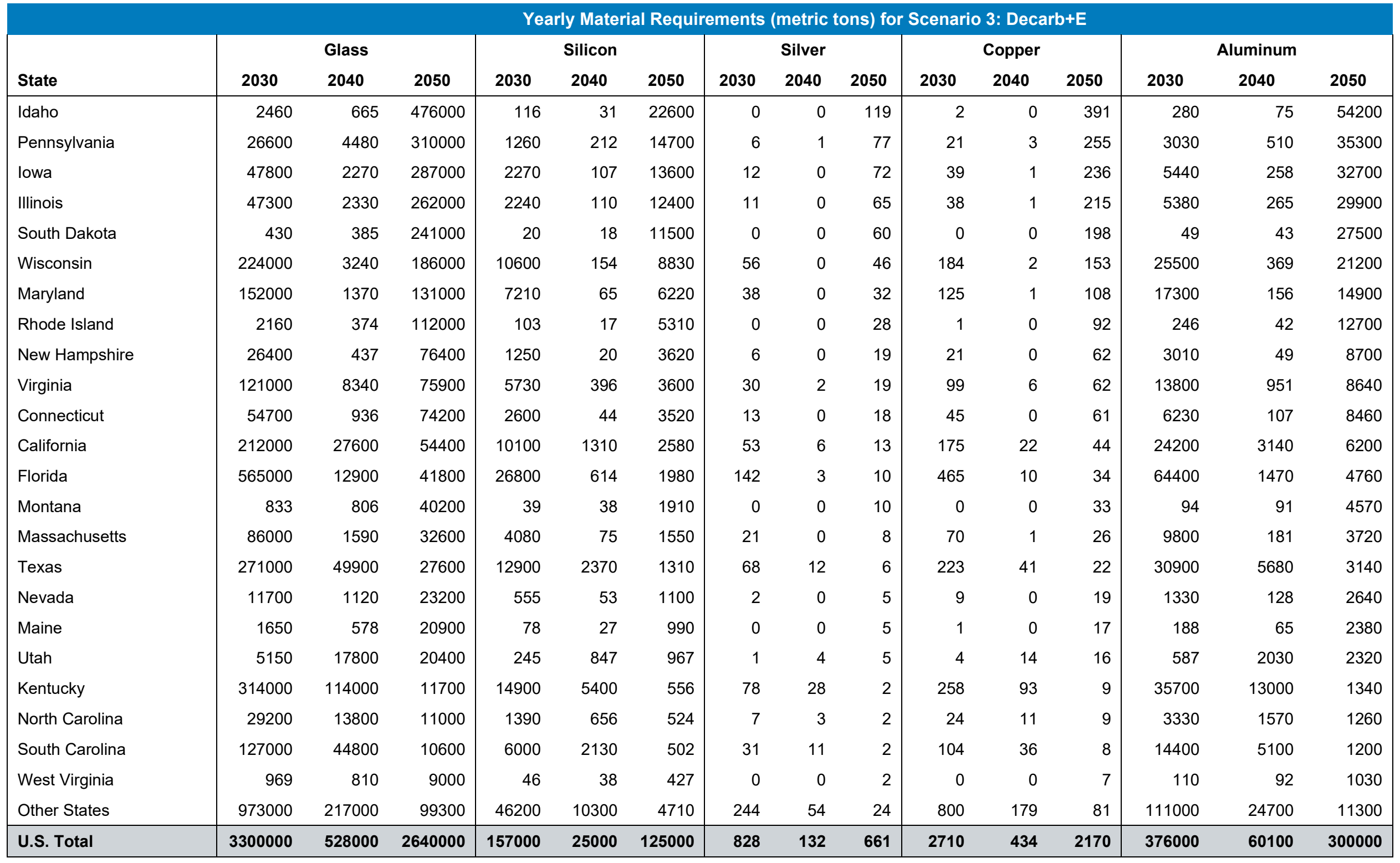


Table B-10. Cumulative Material Requirements (metric tons) for Scenario 1: Reference

\begin{tabular}{|c|c|c|c|c|c|c|c|c|c|c|c|c|c|c|c|}
\hline \multirow[b]{2}{*}{ State } & \multicolumn{3}{|c|}{ Glass } & \multicolumn{3}{|c|}{ Silicon } & \multicolumn{3}{|c|}{ Silver } & \multicolumn{3}{|c|}{ Copper } & \multicolumn{3}{|c|}{ Aluminum } \\
\hline & 2030 & 2040 & 2050 & 2030 & 2040 & 2050 & 2030 & 2040 & 2050 & 2030 & 2040 & 2050 & 2030 & 2040 & 2050 \\
\hline California & 2050000 & 3290000 & 4360000 & 152000 & 211000 & 261000 & 1200 & 1510 & 1780 & 1780 & 2800 & 3680 & 321000 & 462000 & 584000 \\
\hline Texas & 1670000 & 2910000 & 3920000 & 95200 & 154000 & 202000 & 657 & 967 & 1220 & 1620 & 2640 & 3470 & 222000 & 363000 & 479000 \\
\hline Florida & 843000 & 1590000 & 3230000 & 47500 & 82700 & 161000 & 320 & 506 & 919 & 780 & 1390 & 2740 & 110000 & 195000 & 382000 \\
\hline South Carolina & 902000 & 1480000 & 2350000 & 47100 & 74700 & 116000 & 296 & 442 & 661 & 822 & 1300 & 2020 & 112000 & 178000 & 277000 \\
\hline Kentucky & 130000 & 436000 & 1490000 & 6530 & 21100 & 71300 & 38 & 116 & 381 & 116 & 368 & 1240 & 15600 & 50600 & 171000 \\
\hline North Carolina & 343000 & 497000 & 1450000 & 27000 & 34300 & 79400 & 205 & 243 & 482 & 299 & 426 & 1210 & 55000 & 72600 & 181000 \\
\hline New York & 399000 & 761000 & 1290000 & 23800 & 40900 & 66100 & 165 & 256 & 389 & 367 & 664 & 1100 & 54000 & 95200 & 156000 \\
\hline Virginia & 196000 & 400000 & 1210000 & 11800 & 21400 & 59900 & 83 & 135 & 338 & 185 & 352 & 1020 & 26800 & 50000 & 142000 \\
\hline Maryland & 493000 & 508000 & 874000 & 33300 & 34000 & 51400 & 269 & 272 & 364 & 486 & 498 & 798 & 74000 & 75700 & 117000 \\
\hline Arizona & 496000 & 631000 & 860000 & 33000 & 39400 & 50300 & 263 & 297 & 355 & 440 & 551 & 740 & 73800 & 89100 & 115000 \\
\hline Michigan & 357000 & 674000 & 760000 & 18200 & 33200 & 37300 & 110 & 189 & 211 & 323 & 583 & 654 & 43500 & 79600 & 89400 \\
\hline Ohio & 88800 & 218000 & 734000 & 5200 & 11300 & 35800 & 38 & 70 & 200 & 80 & 187 & 611 & 12100 & 26800 & 85500 \\
\hline Georgia & 233000 & 365000 & 699000 & 15100 & 21300 & 37100 & 103 & 135 & 219 & 206 & 314 & 589 & 32600 & 47500 & 85600 \\
\hline Illinois & 421000 & 625000 & 636000 & 22200 & 31900 & 32400 & 144 & 195 & 198 & 403 & 571 & 580 & 53200 & 76500 & 77700 \\
\hline Oklahoma & 194000 & 434000 & 577000 & 9690 & 21000 & 27800 & 57 & 117 & 153 & 174 & 371 & 488 & 23300 & 50500 & 66800 \\
\hline Missouri & 243000 & 305000 & 573000 & 12600 & 15600 & 28300 & 78 & 94 & 161 & 223 & 273 & 493 & 30000 & 37100 & 67600 \\
\hline Wisconsin & 108000 & 275000 & 545000 & 5600 & 13500 & 26300 & 34 & 76 & 145 & 99 & 237 & 459 & 13400 & 32400 & 63200 \\
\hline Nevada & 224000 & 293000 & 484000 & 17100 & 20300 & 29400 & 138 & 155 & 203 & 196 & 252 & 409 & 36000 & 43800 & 65600 \\
\hline Massachusetts & 170000 & 192000 & 465000 & 14600 & 15600 & 28600 & 117 & 123 & 191 & 141 & 159 & 384 & 29100 & 31600 & 62800 \\
\hline Mississippi & 130000 & 154000 & 444000 & 6810 & 7940 & 21700 & 42 & 48 & 121 & 120 & 139 & 378 & 16100 & 18800 & 51900 \\
\hline Indiana & 296000 & 353000 & 416000 & 17000 & 19700 & 22600 & 117 & 132 & 148 & 297 & 344 & 395 & 40000 & 46500 & 53600 \\
\hline lowa & 123000 & 259000 & 401000 & 6400 & 12900 & 19600 & 40 & 74 & 110 & 114 & 226 & 343 & 15300 & 30800 & 46900 \\
\hline Colorado & 150000 & 206000 & 348000 & 10100 & 12700 & 19500 & 79 & 93 & 129 & 133 & 179 & 296 & 22200 & 28600 & 44800 \\
\hline Other States & 1980000 & 2590000 & 3680000 & 124000 & 153000 & 205000 & 918 & 1070 & 1340 & 1850 & 2340 & 3240 & 281000 & 350000 & 474000 \\
\hline U.S. Total & 12200000 & 19400000 & 31800000 & 762000 & 1100000 & 1690000 & 5520 & 7320 & 10400 & 11300 & 17200 & 27300 & 1710000 & 2530000 & 3940000 \\
\hline
\end{tabular}


Table B-11. Cumulative Material Requirements (metric tons) for Scenario 2: Decarb

\begin{tabular}{|c|c|c|c|c|c|c|c|c|c|c|c|c|c|c|c|}
\hline \multirow[b]{3}{*}{ State } & \multicolumn{15}{|c|}{ Cumulative Material Requirements (metric tons) for Scenario 2: Decarb } \\
\hline & \multicolumn{3}{|c|}{ Glass } & \multicolumn{3}{|c|}{ Silicon } & \multicolumn{3}{|c|}{ Silver } & \multicolumn{3}{|c|}{ Copper } & \multicolumn{3}{|c|}{ Aluminum } \\
\hline & 2030 & 2040 & 2050 & 2030 & 2040 & 2050 & 2030 & 2040 & 2050 & 2030 & 2040 & 2050 & 2030 & 2040 & 2050 \\
\hline Florida & 1830000 & 4580000 & 5530000 & 99100 & 229000 & 274000 & 650 & 1340 & 1580 & 1730 & 3980 & 4760 & 234000 & 547000 & 655000 \\
\hline California & 2070000 & 3200000 & 3730000 & 153000 & 207000 & 231000 & 1210 & 1490 & 1620 & 1800 & 2730 & 3160 & 323000 & 452000 & 512000 \\
\hline South Carolina & 1660000 & 2780000 & 3510000 & 87600 & 141000 & 175000 & 564 & 843 & 1030 & 1580 & 2500 & 3100 & 209000 & 337000 & 419000 \\
\hline Kentucky & 623000 & 1670000 & 2280000 & 31300 & 81000 & 110000 & 187 & 450 & 603 & 564 & 1420 & 1930 & 75200 & 194000 & 264000 \\
\hline North Carolina & 410000 & 1710000 & 2230000 & 30300 & 92200 & 117000 & 224 & 551 & 680 & 358 & 1430 & 1850 & 62900 & 211000 & 270000 \\
\hline Virginia & 717000 & 1230000 & 1970000 & 38900 & 63200 & 98500 & 256 & 385 & 571 & 687 & 1110 & 1720 & 92100 & 150000 & 235000 \\
\hline Michigan & 450000 & 870000 & 1330000 & 23300 & 43300 & 65100 & 146 & 252 & 367 & 421 & 767 & 1150 & 55900 & 104000 & 156000 \\
\hline Pennsylvania & 137000 & 199000 & 1230000 & 8080 & 11000 & 59900 & 60 & 76 & 335 & 126 & 177 & 1020 & 18900 & 25900 & 143000 \\
\hline Maryland & 586000 & 884000 & 1190000 & 37600 & 51800 & 66500 & 291 & 366 & 443 & 564 & 810 & 1060 & 84500 & 119000 & 154000 \\
\hline Ohio & 286000 & 804000 & 1150000 & 15200 & 39800 & 56300 & 98 & 229 & 316 & 261 & 687 & 972 & 36100 & 95100 & 135000 \\
\hline Illinois & 850000 & 992000 & 1020000 & 45400 & 52100 & 53400 & 299 & 335 & 341 & 835 & 952 & 973 & 109000 & 125000 & 128000 \\
\hline Wisconsin & 276000 & 638000 & 981000 & 14300 & 31500 & 47700 & 90 & 181 & 267 & 260 & 558 & 840 & 34300 & 75600 & 115000 \\
\hline Georgia & 321000 & 525000 & 961000 & 19900 & 29600 & 50300 & 138 & 189 & 298 & 302 & 469 & 828 & 44400 & 67600 & 117000 \\
\hline Mississippi & 431000 & 860000 & 907000 & 22000 & 42400 & 44600 & 135 & 243 & 255 & 399 & 751 & 790 & 52800 & 102000 & 107000 \\
\hline New York & 396000 & 697000 & 777000 & 23600 & 37900 & 41700 & 164 & 240 & 260 & 365 & 613 & 678 & 53800 & 88000 & 97100 \\
\hline Massachusetts & 226000 & 581000 & 749000 & 17300 & 34100 & 42100 & 133 & 222 & 264 & 190 & 481 & 620 & 35800 & 76200 & 95400 \\
\hline Indiana & 546000 & 642000 & 729000 & 30800 & 35400 & 39500 & 213 & 237 & 259 & 552 & 631 & 703 & 73300 & 84200 & 94100 \\
\hline Nebraska & 605000 & 616000 & 710000 & 31900 & 32400 & 36900 & 207 & 210 & 234 & 594 & 603 & 680 & 76900 & 78200 & 88800 \\
\hline Oklahoma & 358000 & 534000 & 676000 & 19000 & 27300 & 34100 & 124 & 168 & 204 & 352 & 496 & 613 & 45700 & 65700 & 81900 \\
\hline Louisiana & 194000 & 630000 & 666000 & 10200 & 30900 & 32600 & 65 & 175 & 184 & 184 & 542 & 572 & 24400 & 74100 & 78200 \\
\hline Missouri & 191000 & 508000 & 666000 & 10400 & 25500 & 33000 & 68 & 148 & 188 & 185 & 445 & 575 & 24700 & 60800 & 78800 \\
\hline
\end{tabular}


Table B-12. Cumulative Material Requirements (metric tons) for Scenario 3: Decarb+E

\begin{tabular}{|c|c|c|c|c|c|c|c|c|c|c|c|c|c|c|c|}
\hline \multirow[b]{2}{*}{ State } & \multicolumn{3}{|c|}{ Glass } & \multicolumn{3}{|c|}{ Silicon } & \multicolumn{3}{|c|}{ Silver } & \multicolumn{3}{|c|}{ Copper } & \multicolumn{3}{|c|}{ Aluminum } \\
\hline & 2030 & 2040 & 2050 & 2030 & 2040 & 2050 & 2030 & 2040 & 2050 & 2030 & 2040 & 2050 & 2030 & 2040 & 2050 \\
\hline Texas & 2450000 & 6620000 & 7620000 & 134000 & 332000 & 380000 & 891 & 1940 & 2190 & 2330 & 5760 & 6590 & 316000 & 792000 & 906000 \\
\hline Florida & 2410000 & 6080000 & 7410000 & 129000 & 303000 & 366000 & 838 & 1760 & 2090 & 2280 & 5300 & 6390 & 306000 & 724000 & 876000 \\
\hline California & 2520000 & 4140000 & 5030000 & 176000 & 253000 & 295000 & 1360 & 1760 & 1980 & 2230 & 3550 & 4290 & 379000 & 563000 & 665000 \\
\hline South Carolina & 1810000 & 3440000 & 4860000 & 97000 & 175000 & 242000 & 639 & 1050 & 1400 & 1760 & 3100 & 4260 & 232000 & 418000 & 579000 \\
\hline Kentucky & 763000 & 2690000 & 3640000 & 38300 & 130000 & 175000 & 230 & 713 & 952 & 696 & 2280 & 3060 & 92300 & 312000 & 420000 \\
\hline North Carolina & 666000 & 2590000 & 2950000 & 43100 & 134000 & 151000 & 301 & 784 & 874 & 594 & 2170 & 2470 & 93800 & 313000 & 354000 \\
\hline Virginia & 690000 & 1910000 & 2640000 & 36400 & 94200 & 129000 & 232 & 537 & 721 & 636 & 1640 & 2240 & 86200 & 225000 & 309000 \\
\hline Arizona & 795000 & 1440000 & 2100000 & 49100 & 79700 & 111000 & 370 & 531 & 698 & 736 & 1270 & 1810 & 112000 & 186000 & 261000 \\
\hline Maryland & 677000 & 890000 & 2090000 & 42400 & 52500 & 110000 & 321 & 375 & 676 & 646 & 821 & 1810 & 95800 & 120000 & 257000 \\
\hline Tennessee & 340000 & 391000 & 2070000 & 18900 & 21400 & 101000 & 130 & 143 & 563 & 339 & 381 & 1760 & 45100 & 50900 & 242000 \\
\hline Illinois & 1030000 & 1470000 & 2020000 & 54400 & 75500 & 102000 & 356 & 467 & 605 & 1010 & 1370 & 1820 & 131000 & 182000 & 244000 \\
\hline Pennsylvania & 137000 & 1000000 & 1870000 & 8080 & 49000 & 90200 & 60 & 277 & 495 & 126 & 835 & 1550 & 18900 & 117000 & 216000 \\
\hline Ohio & 382000 & 1260000 & 1840000 & 19900 & 61600 & 89200 & 127 & 347 & 493 & 349 & 1070 & 1550 & 47500 & 147000 & 214000 \\
\hline New York & 564000 & 1410000 & 1770000 & 32000 & 72000 & 89300 & 214 & 426 & 517 & 517 & 1210 & 1510 & 73800 & 170000 & 211000 \\
\hline Michigan & 772000 & 1160000 & 1720000 & 39800 & 58400 & 84800 & 249 & 347 & 486 & 724 & 1050 & 1500 & 95500 & 140000 & 203000 \\
\hline Wisconsin & 413000 & 746000 & 1610000 & 20900 & 36800 & 77700 & 127 & 211 & 427 & 377 & 651 & 1360 & 50300 & 88300 & 187000 \\
\hline Mississippi & 316000 & 1230000 & 1380000 & 16200 & 59400 & 66800 & 99 & 328 & 367 & 290 & 1040 & 1170 & 38700 & 143000 & 160000 \\
\hline Georgia & 365000 & 873000 & 1300000 & 21600 & 45700 & 65900 & 140 & 267 & 374 & 322 & 739 & 1090 & 48200 & 106000 & 155000 \\
\hline Alabama & 33500 & 618000 & 1210000 & 2180 & 29900 & 58200 & 15 & 162 & 311 & 31 & 512 & 1000 & 4780 & 71400 & 139000 \\
\hline Idaho & 32800 & 233000 & 1200000 & 2290 & 11800 & 57500 & 16 & 66 & 308 & 30 & 195 & 987 & 4860 & 27600 & 137000 \\
\hline Indiana & 298000 & 396000 & 1160000 & 17000 & 21700 & 57700 & 118 & 143 & 333 & 298 & 379 & 1000 & 40200 & 51400 & 138000 \\
\hline Oklahoma & 423000 & 644000 & 1050000 & 22300 & 32800 & 51800 & 145 & 200 & 301 & 415 & 596 & 926 & 53800 & 78900 & 125000 \\
\hline Louisiana & 373000 & 790000 & 968000 & 18900 & 38700 & 47100 & 114 & 218 & 263 & 338 & 681 & 827 & 45200 & 92700 & 113000 \\
\hline Other States & 3930000 & 7770000 & 11000000 & 235000 & 417000 & 572000 & 1660 & 2620 & 3440 & 3630 & 6780 & 9470 & 536000 & 973000 & 1350000 \\
\hline U.S. Total & 22200000 & 49800000 & 70600000 & 1280000 & 2580000 & 3570000 & 8750 & 15700 & 20900 & 20700 & 43400 & 60500 & 2950000 & 6090000 & 8460000 \\
\hline
\end{tabular}


Table B-13. Yearly EOL Materials by Material, by State (metric tons) for Scenario 1: Reference

\begin{tabular}{|c|c|c|c|c|c|c|c|c|c|c|c|c|c|c|c|}
\hline \multirow[b]{2}{*}{ State } & \multicolumn{3}{|c|}{ Glass } & \multicolumn{3}{|c|}{ Silicon } & \multicolumn{3}{|c|}{ Silver } & \multicolumn{3}{|c|}{ Copper } & \multicolumn{3}{|c|}{ Aluminum } \\
\hline & 2030 & 2040 & 2050 & 2030 & 2040 & 2050 & 2030 & 2040 & 2050 & 2030 & 2040 & 2050 & 2030 & 2040 & 2050 \\
\hline Alabama & 16 & 515 & 1120 & 0.81 & 25.8 & 50.9 & 0.00836 & 0.266 & 0.489 & 0.0125 & 0.413 & 0.991 & 2.78 & 88.2 & 174 \\
\hline Arkansas & 6.57 & 257 & 637 & 0.331 & 12.8 & 29 & 0.00341 & 0.133 & 0.28 & 0.00541 & 0.214 & 0.571 & 1.12 & 43.6 & 98.7 \\
\hline Arizona & 1730 & 23200 & 8430 & 89.9 & 1180 & 374 & 1.86 & 16.6 & 3.52 & 1.17 & 15.6 & 7.29 & 405 & 4600 & 1280 \\
\hline California & 6350 & 158000 & 55800 & 328 & 8010 & 2630 & 6.73 & 104 & 26.4 & 4.33 & 107 & 48 & 1410 & 30300 & 8980 \\
\hline Colorado & 465 & 5060 & 3060 & 24.1 & 257 & 142 & 0.51 & 3.59 & 1.4 & 0.316 & 3.55 & 2.65 & 108 & 992 & 484 \\
\hline Connecticut & 107 & 3320 & 5130 & 5.45 & 165 & 233 & 0.0891 & 1.98 & 2.31 & 0.0772 & 2.49 & 4.71 & 22.1 & 602 & 791 \\
\hline Delaware & 68.8 & 615 & 1960 & 3.58 & 30.9 & 75.5 & 0.0763 & 0.454 & 0.595 & 0.0465 & 0.433 & 1.76 & 16.3 & 122 & 259 \\
\hline Florida & 284 & 6020 & 17800 & 14.5 & 295 & 797 & 0.279 & 3.36 & 7.67 & 0.21 & 5.02 & 16.3 & 60.1 & 1030 & 2700 \\
\hline Georgia & 177 & 5250 & 6030 & 9.03 & 264 & 283 & 0.116 & 2.99 & 2.84 & 0.128 & 3.87 & 5.32 & 33.7 & 947 & 964 \\
\hline lowa & 9.04 & 516 & 833 & 0.459 & 25.9 & 34.3 & 0.00546 & 0.312 & 0.299 & 0.0065 & 0.362 & 0.762 & 1.67 & 95.5 & 119 \\
\hline Idaho & 23.1 & 712 & 1300 & 1.17 & 35.6 & 61.5 & 0.012 & 0.366 & 0.611 & 0.018 & 0.576 & 1.15 & 4.01 & 121 & 208 \\
\hline Illinois & 56.6 & 673 & 5630 & 2.93 & 32.2 & 221 & 0.0614 & 0.423 & 1.82 & 0.0391 & 0.542 & 5.13 & 13.3 & 121 & 760 \\
\hline Indiana & 57 & 2770 & 7740 & 2.92 & 138 & 308 & 0.0437 & 1.69 & 2.6 & 0.0396 & 1.94 & 7.22 & 11.5 & 513 & 1070 \\
\hline Kansas & 8.41 & 712 & 7120 & 0.426 & 33.7 & 275 & 0.00528 & 0.388 & 2.22 & 0.00585 & 0.53 & 6.64 & 1.58 & 124 & 959 \\
\hline Kentucky & 2.84 & 109 & 770 & 0.143 & 5.32 & 30.6 & 0.00149 & 0.0542 & 0.253 & 0.00225 & 0.0893 & 0.691 & 0.491 & 18.2 & 105 \\
\hline Louisiana & 18.3 & 703 & 1030 & 0.94 & 35.2 & 43.1 & 0.0164 & 0.432 & 0.383 & 0.0129 & 0.494 & 0.932 & 3.76 & 130 & 147 \\
\hline Massachusetts & 649 & 19900 & 6130 & 33.4 & 1010 & 302 & 0.576 & 12.8 & 3.11 & 0.446 & 13.5 & 5.15 & 139 & 3790 & 1020 \\
\hline Maryland & 334 & 10400 & 30300 & 16.9 & 504 & 1370 & 0.276 & 5.79 & 13.7 & 0.251 & 8.61 & 28.4 & 68.3 & 1790 & 4650 \\
\hline
\end{tabular}


Yearly EOL Materials by Material, by State (metric tons) for Scenario 1: Reference

\begin{tabular}{|c|c|c|c|c|c|c|c|c|c|c|c|c|c|c|c|}
\hline \multirow[b]{2}{*}{ State } & \multicolumn{3}{|c|}{ Glass } & \multicolumn{3}{|c|}{ Silicon } & \multicolumn{3}{|c|}{ Silver } & \multicolumn{3}{|c|}{ Copper } & \multicolumn{3}{|c|}{ Aluminum } \\
\hline & 2030 & 2040 & 2050 & 2030 & 2040 & 2050 & 2030 & 2040 & 2050 & 2030 & 2040 & 2050 & 2030 & 2040 & 2050 \\
\hline Maine & 14.7 & 470 & 880 & 0.76 & 23.5 & 36.6 & 0.0144 & 0.297 & 0.335 & 0.0101 & 0.326 & 0.807 & 3.22 & 88.3 & 120 \\
\hline Michigan & 11.6 & 603 & 2600 & 0.583 & 29.6 & 106 & 0.00647 & 0.331 & 0.91 & 0.00902 & 0.468 & 2.39 & 2.05 & 105 & 365 \\
\hline Minnesota & 86.5 & 3020 & 4560 & 4.37 & 152 & 222 & 0.0453 & 1.59 & 2.23 & 0.0692 & 2.45 & 3.98 & 14.9 & 518 & 742 \\
\hline Missouri & 43.4 & 2010 & 762 & 2.22 & 102 & 33 & 0.0345 & 1.29 & 0.302 & 0.0296 & 1.34 & 0.657 & 8.93 & 383 & 113 \\
\hline Mississippi & 8.45 & 348 & 810 & 0.421 & 17.2 & 38.7 & 0.00425 & 0.175 & 0.385 & 0.00736 & 0.305 & 0.726 & 1.4 & 57.3 & 120 \\
\hline Montana & 1.59 & 65.2 & 104 & 0.0801 & 3.27 & 4.93 & 0.000845 & 0.0352 & 0.0487 & 0.00129 & 0.0524 & 0.0916 & 0.274 & 11.3 & 16.5 \\
\hline North Carolina & 733 & 22900 & 13500 & 37.6 & 1160 & 651 & 0.587 & 14.1 & 6.6 & 0.518 & 16.1 & 11.6 & 150 & 4260 & 2200 \\
\hline North Dakota & 7.86 & 504 & 90.1 & 0.401 & 25.5 & 4.4 & 0.00503 & 0.32 & 0.0459 & 0.00538 & 0.335 & 0.074 & 1.5 & 95.9 & 15.1 \\
\hline Nebraska & 9.19 & 573 & 1730 & 0.468 & 28.6 & 66.3 & 0.00572 & 0.349 & 0.515 & 0.00642 & 0.394 & 1.56 & 1.73 & 107 & 228 \\
\hline New Hampshire & 7.09 & 261 & 283 & 0.36 & 13.1 & 13.4 & 0.0039 & 0.147 & 0.134 & 0.0053 & 0.194 & 0.247 & 1.27 & 46.7 & 45.5 \\
\hline New Jersey & 1620 & 16000 & 5390 & 84.5 & 814 & 255 & 1.8 & 12 & 2.58 & 1.1 & 10.9 & 4.7 & 385 & 3230 & 869 \\
\hline New Mexico & 390 & 4480 & 1430 & 20.3 & 228 & 68.5 & 0.443 & 3.23 & 0.689 & 0.264 & 3.05 & 1.2 & 91.5 & 887 & 235 \\
\hline Nevada & 783 & 12700 & 7820 & 40.6 & 645 & 365 & 0.819 & 8.47 & 3.65 & 0.536 & 8.89 & 6.85 & 177 & 2440 & 1250 \\
\hline New York & 369 & 7500 & 7980 & 19 & 378 & 353 & 0.354 & 4.78 & 3.31 & 0.257 & 5.37 & 7.08 & 81.3 & 1410 & 1200 \\
\hline Ohio & 127 & 1360 & 1940 & 6.62 & 68.4 & 84.7 & 0.149 & 0.977 & 0.811 & 0.0866 & 0.981 & 1.79 & 30.2 & 266 & 292 \\
\hline Oklahoma & 2.04 & 91.5 & 620 & 0.103 & 4.45 & 24.9 & 0.00106 & 0.0456 & 0.206 & 0.00171 & 0.0775 & 0.558 & 0.346 & 15.1 & 84.9 \\
\hline Oregon & 118 & 1490 & 2990 & 6.09 & 74.9 & 129 & 0.122 & 0.955 & 1.18 & 0.0823 & 1.14 & 2.67 & 26.6 & 277 & 440 \\
\hline Pennsylvania & 292 & 2130 & 2120 & 15.2 & 108 & 91 & 0.334 & 1.7 & 0.842 & 0.197 & 1.49 & 1.93 & 70.1 & 437 & 313 \\
\hline Rhode Island & 8.63 & 442 & 727 & 0.432 & 22 & 33.9 & 0.00478 & 0.249 & 0.339 & 0.00691 & 0.346 & 0.662 & 1.51 & 77.9 & 114 \\
\hline
\end{tabular}


Yearly EOL Materials by Material, by State (metric tons) for Scenario 1: Reference

\begin{tabular}{|c|c|c|c|c|c|c|c|c|c|c|c|c|c|c|c|}
\hline \multirow[b]{2}{*}{ State } & \multicolumn{3}{|c|}{ Glass } & \multicolumn{3}{|c|}{ Silicon } & \multicolumn{3}{|c|}{ Silver } & \multicolumn{3}{|c|}{ Copper } & \multicolumn{3}{|c|}{ Aluminum } \\
\hline & 2030 & 2040 & 2050 & 2030 & 2040 & 2050 & 2030 & 2040 & 2050 & 2030 & 2040 & 2050 & 2030 & 2040 & 2050 \\
\hline South Carolina & 46.7 & 2310 & 8900 & 2.28 & 111 & 404 & 0.0234 & 1.14 & 4 & 0.0411 & 2.09 & 8.27 & 7.67 & 373 & 1370 \\
\hline South Dakota & 7.99 & 507 & 93.5 & 0.407 & 25.7 & 4.56 & 0.0051 & 0.321 & 0.0475 & 0.00547 & 0.337 & 0.0768 & 1.52 & 96.4 & 15.7 \\
\hline Tennessee & 86.7 & 1660 & 3600 & 4.49 & 83.6 & 142 & 0.0879 & 1.1 & 1.15 & 0.0592 & 1.16 & 3.25 & 19.8 & 318 & 486 \\
\hline Texas & 396 & 11300 & 41800 & 20.2 & 554 & 1780 & 0.338 & 6.33 & 16.2 & 0.294 & 9.13 & 38.6 & 81.3 & 1970 & 6080 \\
\hline Utah & 137 & 3730 & 4480 & 6.96 & 188 & 215 & 0.0742 & 1.98 & 2.16 & 0.101 & 2.82 & 3.84 & 24.4 & 657 & 731 \\
\hline Virginia & 44.2 & 1990 & 6840 & 2.19 & 96.3 & 309 & 0.0227 & 1 & 3.04 & 0.037 & 1.72 & 6.33 & 7.44 & 328 & 1050 \\
\hline Vermont & 51.8 & 1380 & 571 & 2.67 & 70 & 27.6 & 0.0457 & 0.883 & 0.28 & 0.0358 & 0.952 & 0.483 & 11.1 & 262 & 94 \\
\hline Washington & 33.5 & 736 & 625 & 1.73 & 37.1 & 29.3 & 0.0312 & 0.466 & 0.291 & 0.0234 & 0.53 & 0.557 & 7.32 & 138 & 99 \\
\hline Wisconsin & 18.6 & 342 & 927 & 0.962 & 17.1 & 37.7 & 0.0186 & 0.218 & 0.321 & 0.013 & 0.253 & 0.838 & 4.19 & 63.7 & 129 \\
\hline West Virginia & 7.92 & 508 & 150 & 0.404 & 25.7 & 6.81 & 0.00506 & 0.322 & 0.0665 & 0.00543 & 0.34 & 0.128 & 1.51 & 96.6 & 23.4 \\
\hline Wyoming & 4.46 & 178 & 330 & 0.223 & 8.88 & 16.3 & 0.00225 & 0.0902 & 0.165 & 0.00388 & 0.155 & 0.291 & 0.74 & 29.5 & 54 \\
\hline U.S. Total & 15800 & 340000 & 285000 & 818 & 17200 & 12800 & 16.1 & 220 & 123 & 10.9 & 239 & 256 & 3520 & 64400 & 43700 \\
\hline
\end{tabular}


Table B-14. Yearly EOL Materials by Material, by State (metric tons) for Scenario 2: Decarb

\begin{tabular}{|c|c|c|c|c|c|c|c|c|c|c|c|c|c|c|c|}
\hline \multirow[b]{2}{*}{ State } & \multicolumn{3}{|c|}{ Glass } & \multicolumn{3}{|c|}{ Silicon } & \multicolumn{3}{|c|}{ Silver } & \multicolumn{3}{|c|}{ Copper } & \multicolumn{3}{|c|}{ Aluminum } \\
\hline & 2030 & 2040 & 2050 & 2030 & 2040 & 2050 & 2030 & 2040 & 2050 & 2030 & 2040 & 2050 & 2030 & 2040 & 2050 \\
\hline Alabama & 16 & 515 & 1130 & 0.81 & 25.8 & 51.2 & 0.00836 & 0.266 & 0.491 & 0.0125 & 0.413 & 0.998 & 2.78 & 88.2 & 175 \\
\hline Arkansas & 6.55 & 257 & 656 & 0.33 & 12.8 & 29.7 & 0.00341 & 0.133 & 0.284 & 0.0054 & 0.213 & 0.588 & 1.12 & 43.5 & 101 \\
\hline Arizona & 1730 & 23400 & 13200 & 89.9 & 1190 & 563 & 1.86 & 16.7 & 5.13 & 1.17 & 15.8 & 11.9 & 405 & 4630 & 1950 \\
\hline California & 6350 & 158000 & 55900 & 328 & 8010 & 2630 & 6.73 & 104 & 26.4 & 4.33 & 107 & 48.1 & 1410 & 30300 & 9000 \\
\hline Colorado & 465 & 5070 & 3710 & 24.2 & 258 & 167 & 0.51 & 3.59 & 1.58 & 0.316 & 3.56 & 3.24 & 108 & 994 & 568 \\
\hline Connecticut & 107 & 3310 & 4910 & 5.45 & 165 & 225 & 0.089 & 1.98 & 2.24 & 0.0771 & 2.48 & 4.51 & 22.1 & 600 & 762 \\
\hline Delaware & 68.8 & 591 & 741 & 3.58 & 30 & 30.3 & 0.0763 & 0.448 & 0.258 & 0.0465 & 0.412 & 0.662 & 16.3 & 119 & 104 \\
\hline Florida & 284 & 6320 & 29300 & 14.5 & 307 & 1240 & 0.279 & 3.45 & 11.2 & 0.211 & 5.31 & 27 & 60.1 & 1080 & 4230 \\
\hline Georgia & 177 & 5300 & 8720 & 9.03 & 266 & 383 & 0.116 & 3.01 & 3.59 & 0.128 & 3.92 & 7.75 & 33.7 & 953 & 1310 \\
\hline lowa & 9.04 & 515 & 786 & 0.459 & 25.8 & 32.6 & 0.00546 & 0.312 & 0.287 & 0.0065 & 0.362 & 0.721 & 1.67 & 95.4 & 113 \\
\hline Idaho & 23.1 & 712 & 1320 & 1.17 & 35.6 & 62.3 & 0.012 & 0.366 & 0.617 & 0.018 & 0.576 & 1.17 & 4.01 & 122 & 211 \\
\hline Illinois & 56.7 & 906 & 15400 & 2.93 & 41.1 & 591 & 0.0614 & 0.493 & 4.7 & 0.0392 & 0.758 & 14.1 & 13.3 & 152 & 2040 \\
\hline Indiana & 57.2 & 2960 & 14300 & 2.92 & 145 & 563 & 0.0437 & 1.75 & 4.68 & 0.0397 & 2.12 & 13.4 & 11.6 & 540 & 1970 \\
\hline Kansas & 8.46 & 766 & 8530 & 0.429 & 35.8 & 331 & 0.0053 & 0.406 & 2.71 & 0.0059 & 0.581 & 8.02 & 1.59 & 132 & 1160 \\
\hline Kentucky & 2.89 & 170 & 2760 & 0.145 & 7.7 & 108 & 0.0015 & 0.0738 & 0.892 & 0.00229 & 0.147 & 2.58 & 0.498 & 26.6 & 378 \\
\hline Louisiana & 18.3 & 730 & 2250 & 0.938 & 36.2 & 89.2 & 0.0164 & 0.44 & 0.744 & 0.0128 & 0.52 & 2.06 & 3.76 & 134 & 308 \\
\hline Massachusetts & 649 & 19900 & 6160 & 33.4 & 1010 & 303 & 0.576 & 12.8 & 3.12 & 0.446 & 13.5 & 5.18 & 139 & 3790 & 1030 \\
\hline Maryland & 331 & 10200 & 29500 & 16.7 & 496 & 1340 & 0.275 & 5.71 & 13.4 & 0.249 & 8.45 & 27.6 & 67.9 & 1760 & 4530 \\
\hline
\end{tabular}


Yearly EOL Materials by Material, by State (metric tons) for Scenario 2: Decarb

\begin{tabular}{|c|c|c|c|c|c|c|c|c|c|c|c|c|c|c|c|}
\hline \multirow[b]{2}{*}{ State } & \multicolumn{3}{|c|}{ Glass } & \multicolumn{3}{|c|}{ Silicon } & \multicolumn{3}{|c|}{ Silver } & \multicolumn{3}{|c|}{ Copper } & \multicolumn{3}{|c|}{ Aluminum } \\
\hline & 2030 & 2040 & 2050 & 2030 & 2040 & 2050 & 2030 & 2040 & 2050 & 2030 & 2040 & 2050 & 2030 & 2040 & 2050 \\
\hline Maine & 14.7 & 459 & 636 & 0.759 & 23 & 26.7 & 0.0144 & 0.293 & 0.246 & 0.0101 & 0.316 & 0.581 & 3.21 & 86.8 & 93.8 \\
\hline Michigan & 11.6 & 637 & 3700 & 0.584 & 31 & 149 & 0.00648 & 0.342 & 1.27 & 0.00904 & 0.5 & 3.45 & 2.05 & 110 & 516 \\
\hline Minnesota & 86.5 & 3020 & 4610 & 4.37 & 152 & 224 & 0.0453 & 1.59 & 2.24 & 0.0692 & 2.45 & 4.03 & 14.9 & 519 & 749 \\
\hline Missouri & 43.4 & 2060 & 3090 & 2.23 & 103 & 120 & 0.0345 & 1.3 & 0.967 & 0.0296 & 1.39 & 2.78 & 8.93 & 390 & 414 \\
\hline Mississippi & 8.45 & 393 & 3230 & 0.422 & 18.9 & 129 & 0.00426 & 0.188 & 1.06 & 0.00737 & 0.346 & 2.91 & 1.4 & 63.1 & 439 \\
\hline Montana & 1.59 & 65.2 & 105 & 0.0801 & 3.27 & 5.01 & 0.000845 & 0.0352 & 0.0492 & 0.00129 & 0.0525 & 0.0933 & 0.274 & 11.3 & 16.8 \\
\hline North Carolina & 733 & 22900 & 13600 & 37.6 & 1160 & 657 & 0.587 & 14.1 & 6.65 & 0.518 & 16.1 & 11.7 & 150 & 4260 & 2220 \\
\hline Nebraska & 9.23 & 735 & 9710 & 0.469 & 34.7 & 365 & 0.00573 & 0.395 & 2.77 & 0.00646 & 0.542 & 8.81 & 1.73 & 128 & 1260 \\
\hline New Hampshire & 7.1 & 261 & 293 & 0.36 & 13.2 & 13.8 & 0.0039 & 0.147 & 0.136 & 0.0053 & 0.194 & 0.255 & 1.27 & 46.8 & 46.7 \\
\hline New Jersey & 1620 & 16000 & 5450 & 84.5 & 814 & 258 & 1.8 & 12 & 2.6 & 1.1 & 10.9 & 4.76 & 385 & 3230 & 878 \\
\hline New Mexico & 390 & 4480 & 1470 & 20.3 & 228 & 70 & 0.443 & 3.23 & 0.7 & 0.264 & 3.05 & 1.24 & 91.5 & 887 & 240 \\
\hline Nevada & 783 & 12800 & 10100 & 40.6 & 647 & 452 & 0.819 & 8.49 & 4.29 & 0.536 & 8.93 & 8.95 & 177 & 2450 & 1550 \\
\hline New York & 369 & 7500 & 8040 & 19 & 378 & 356 & 0.354 & 4.78 & 3.33 & 0.257 & 5.37 & 7.14 & 81.3 & 1410 & 1210 \\
\hline Ohio & 127 & 1410 & 3700 & 6.62 & 70.4 & 153 & 0.149 & 0.993 & 1.36 & 0.0867 & 1.03 & 3.44 & 30.2 & 272 & 530 \\
\hline Oklahoma & 2.1 & 218 & 6130 & 0.105 & 9.26 & 233 & 0.00107 & 0.0831 & 1.81 & 0.00176 & 0.194 & 5.62 & 0.353 & 31.8 & 806 \\
\hline Pennsylvania & 292 & 2130 & 2200 & 15.2 & 108 & 93.9 & 0.334 & 1.7 & 0.865 & 0.197 & 1.49 & 2.01 & 70.1 & 438 & 323 \\
\hline Rhode Island & 8.63 & 443 & 737 & 0.432 & 22 & 34.3 & 0.00479 & 0.249 & 0.342 & 0.00691 & 0.347 & 0.671 & 1.51 & 78 & 116 \\
\hline
\end{tabular}

114 
Yearly EOL Materials by Material, by State (metric tons) for Scenario 2: Decarb

\begin{tabular}{|c|c|c|c|c|c|c|c|c|c|c|c|c|c|c|c|}
\hline \multirow[b]{2}{*}{ State } & \multicolumn{3}{|c|}{ Glass } & \multicolumn{3}{|c|}{ Silicon } & \multicolumn{3}{|c|}{ Silver } & \multicolumn{3}{|c|}{ Copper } & \multicolumn{3}{|c|}{ Aluminum } \\
\hline & 2030 & 2040 & 2050 & 2030 & 2040 & 2050 & 2030 & 2040 & 2050 & 2030 & 2040 & 2050 & 2030 & 2040 & 2050 \\
\hline South Carolina & 46.8 & 2600 & 21800 & 2.29 & 122 & 891 & 0.0234 & 1.22 & 7.72 & 0.0412 & 2.35 & 20.1 & 7.68 & 411 & 3050 \\
\hline South Dakota & 7.99 & 507 & 96.5 & 0.407 & 25.7 & 4.68 & 0.0051 & 0.322 & 0.0484 & 0.00547 & 0.337 & 0.0796 & 1.52 & 96.5 & 16.1 \\
\hline Tennessee & 86.8 & 1800 & 7330 & 4.5 & 88.9 & 290 & 0.088 & 1.15 & 2.41 & 0.0593 & 1.29 & 6.86 & 19.8 & 337 & 1010 \\
\hline Texas & 396 & 11700 & 54900 & 20.2 & 567 & 2280 & 0.338 & 6.43 & 20.2 & 0.295 & 9.44 & 50.7 & 81.4 & 2010 & 7820 \\
\hline Utah & 137 & 3730 & 4490 & 6.96 & 188 & 215 & 0.0742 & 1.98 & 2.16 & 0.101 & 2.82 & 3.84 & 24.4 & 657 & 733 \\
\hline Virginia & 44.2 & 2140 & 14000 & 2.19 & 102 & 579 & 0.0227 & 1.05 & 5.09 & 0.0371 & 1.86 & 12.9 & 7.45 & 348 & 1980 \\
\hline Vermont & 51.8 & 1380 & 578 & 2.67 & 70 & 27.9 & 0.0457 & 0.883 & 0.282 & 0.0358 & 0.952 & 0.49 & 11.1 & 262 & 95 \\
\hline Washington & 33.5 & 743 & 1140 & 1.73 & 37.3 & 48.4 & 0.0312 & 0.468 & 0.433 & 0.0234 & 0.536 & 1.02 & 7.32 & 139 & 165 \\
\hline Wisconsin & 18.6 & 387 & 3220 & 0.962 & 18.8 & 123 & 0.0186 & 0.231 & 0.963 & 0.013 & 0.293 & 2.92 & 4.19 & 69.5 & 424 \\
\hline West Virginia & 7.93 & 567 & 3270 & 0.404 & 27.9 & 123 & 0.00506 & 0.338 & 0.932 & 0.00544 & 0.393 & 2.94 & 1.51 & 104 & 423 \\
\hline Wyoming & 4.46 & 178 & 332 & 0.223 & 8.88 & 16.4 & 0.00225 & 0.0902 & 0.166 & 0.00388 & 0.155 & 0.293 & 0.74 & 29.5 & 54.3 \\
\hline U.S. Total & 15800 & 343000 & 392000 & 818 & 17300 & 16800 & 16.1 & 221 & 155 & 10.9 & 242 & 354 & 3520 & 64800 & 57700 \\
\hline
\end{tabular}


Table B-15. Yearly EOL Materials by Material, by State (metric tons) for Scenario 3: Decarb+E

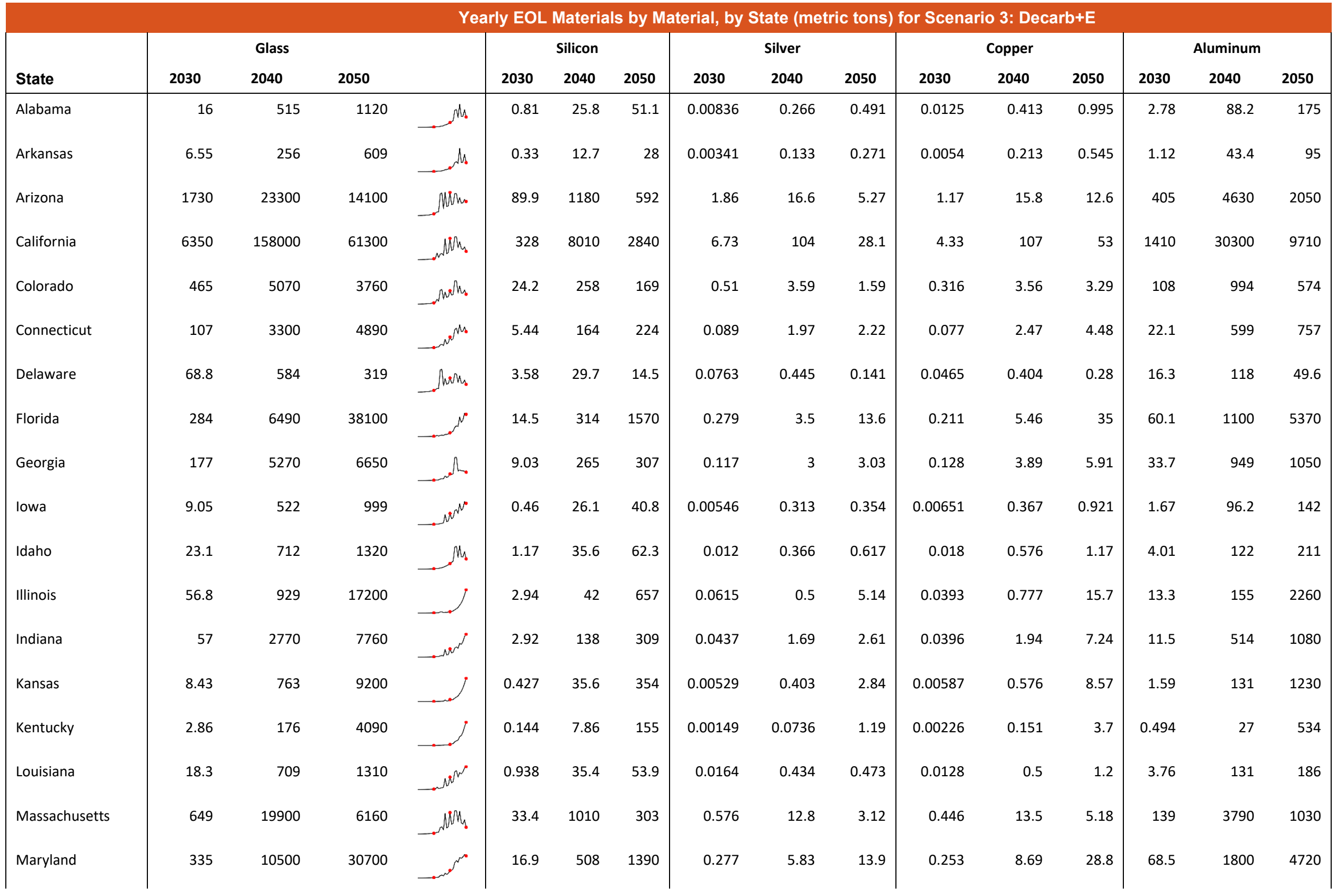


Yearly EOL Materials by Material, by State (metric tons) for Scenario 3: Decarb+E

\begin{tabular}{|c|c|c|c|c|c|c|c|c|c|c|c|c|c|c|c|}
\hline \multirow[b]{2}{*}{ State } & \multicolumn{3}{|c|}{ Glass } & \multicolumn{3}{|c|}{ Silicon } & \multicolumn{3}{|c|}{ Silver } & \multicolumn{3}{|c|}{ Copper } & \multicolumn{3}{|c|}{ Aluminum } \\
\hline & 2030 & 2040 & 2050 & 2030 & 2040 & 2050 & 2030 & 2040 & 2050 & 2030 & 2040 & 2050 & 2030 & 2040 & 2050 \\
\hline Maine & 14.7 & 464 & 750 & 0.759 & 23.2 & 31.3 & 0.0144 & 0.295 & 0.287 & 0.0101 & 0.321 & 0.686 & 3.22 & 87.5 & 110 \\
\hline Michigan & 11.6 & 683 & 5310 & 0.586 & 32.7 & 211 & 0.00649 & 0.357 & 1.77 & 0.00908 & 0.543 & 4.95 & 2.05 & 116 & 733 \\
\hline Minnesota & 86.5 & 3020 & 4580 & 4.37 & 152 & 223 & 0.0453 & 1.59 & 2.24 & 0.0692 & 2.45 & 4.01 & 14.9 & 519 & 746 \\
\hline Missouri & 43.4 & 2000 & 533 & 2.22 & 101 & 24.5 & 0.0345 & 1.29 & 0.239 & 0.0296 & 1.34 & 0.451 & 8.93 & 383 & 83.7 \\
\hline Mississippi & 8.45 & 380 & 2560 & 0.422 & 18.5 & 104 & 0.00425 & 0.184 & 0.87 & 0.00737 & 0.335 & 2.31 & 1.4 & 61.5 & 353 \\
\hline Montana & 1.59 & 65.2 & 105 & 0.0801 & 3.27 & 5.01 & 0.000845 & 0.0352 & 0.0492 & 0.00129 & 0.0525 & 0.0933 & 0.274 & 11.3 & 16.8 \\
\hline North Carolina & 733 & 22900 & 13700 & 37.6 & 1160 & 659 & 0.587 & 14.1 & 6.66 & 0.518 & 16.1 & 11.8 & 150 & 4260 & 2230 \\
\hline North Dakota & 7.86 & 504 & 125 & 0.401 & 25.5 & 5.65 & 0.00503 & 0.32 & 0.0546 & 0.00538 & 0.335 & 0.103 & 1.5 & 95.9 & 19.4 \\
\hline Nebraska & 9.2 & 708 & 8870 & 0.468 & 33.6 & 332 & 0.00572 & 0.386 & 2.49 & 0.00643 & 0.516 & 8 & 1.73 & 124 & 1140 \\
\hline New Hampshire & 7.1 & 261 & 293 & 0.36 & 13.2 & 13.8 & 0.0039 & 0.147 & 0.136 & 0.0053 & 0.194 & 0.255 & 1.27 & 46.8 & 46.7 \\
\hline New Jersey & 1620 & 16000 & 5590 & 84.5 & 815 & 264 & 1.8 & 12 & 2.66 & 1.1 & 10.9 & 4.89 & 385 & 3230 & 899 \\
\hline New Mexico & 390 & 4480 & 1470 & 20.3 & 228 & 69.7 & 0.443 & 3.23 & 0.698 & 0.264 & 3.05 & 1.23 & 91.5 & 887 & 239 \\
\hline Nevada & 783 & 12800 & 8450 & 40.6 & 645 & 388 & 0.819 & 8.48 & 3.82 & 0.536 & 8.9 & 7.41 & 177 & 2440 & 1330 \\
\hline New York & 369 & 7500 & 8070 & 19 & 378 & 357 & 0.354 & 4.78 & 3.33 & 0.257 & 5.37 & 7.16 & 81.3 & 1410 & 1210 \\
\hline Ohio & 127 & 1390 & 2790 & 6.62 & 69.3 & 118 & 0.149 & 0.984 & 1.07 & 0.0867 & 1 & 2.59 & 30.2 & 269 & 406 \\
\hline Oklahoma & 2.09 & 228 & 6890 & 0.104 & 9.62 & 261 & 0.00107 & 0.0855 & 2.01 & 0.00176 & 0.203 & 6.29 & 0.352 & 33 & 900 \\
\hline Oregon & 118 & 1530 & 4110 & 6.09 & 76.3 & 173 & 0.122 & 0.966 & 1.53 & 0.0823 & 1.17 & 3.73 & 26.6 & 281 & 593 \\
\hline Pennsylvania & 292 & 2130 & 2200 & 15.2 & 108 & 94.1 & 0.334 & 1.7 & 0.866 & 0.197 & 1.49 & 2.01 & 70.1 & 438 & 323 \\
\hline Rhode Island & 8.63 & 443 & 737 & 0.432 & 22 & 34.3 & 0.00479 & 0.249 & 0.342 & 0.00691 & 0.347 & 0.671 & 1.51 & 78 & 116 \\
\hline
\end{tabular}

117 
Yearly EOL Materials by Material, by State (metric tons) for Scenario 3: Decarb+E

\begin{tabular}{|c|c|c|c|c|c|c|c|c|c|c|c|c|c|c|c|}
\hline \multirow[b]{2}{*}{ State } & \multicolumn{3}{|c|}{ Glass } & \multicolumn{3}{|c|}{ Silicon } & \multicolumn{3}{|c|}{ Silver } & \multicolumn{3}{|c|}{ Copper } & \multicolumn{3}{|c|}{ Aluminum } \\
\hline & 2030 & 2040 & 2050 & 2030 & 2040 & 2050 & 2030 & 2040 & 2050 & 2030 & 2040 & 2050 & 2030 & 2040 & 2050 \\
\hline South Carolina & 47 & 2890 & 32700 & 2.29 & 133 & 1310 & 0.0235 & 1.31 & 11.1 & 0.0414 & 2.62 & 30.3 & 7.71 & 450 & 4510 \\
\hline South Dakota & 7.99 & 507 & 96.6 & 0.407 & 25.7 & 4.68 & 0.0051 & 0.322 & 0.0485 & 0.00547 & 0.337 & 0.0796 & 1.52 & 96.5 & 16.1 \\
\hline Tennessee & 86.8 & 1790 & 7680 & 4.49 & 88.6 & 301 & 0.088 & 1.14 & 2.46 & 0.0593 & 1.28 & 7.12 & 19.8 & 336 & 1050 \\
\hline Texas & 396 & 11400 & 44400 & 20.2 & 555 & 1870 & 0.338 & 6.34 & 16.9 & 0.294 & 9.16 & 40.9 & 81.3 & 1970 & 6410 \\
\hline Utah & 137 & 3730 & 4500 & 6.96 & 188 & 215 & 0.0742 & 1.98 & 2.16 & 0.101 & 2.82 & 3.85 & 24.4 & 657 & 733 \\
\hline Virginia & 44.2 & 2000 & 7590 & 2.19 & 96.8 & 337 & 0.0227 & 1.01 & 3.25 & 0.037 & 1.73 & 7 & 7.44 & 330 & 1140 \\
\hline Vermont & 51.8 & 1380 & 578 & 2.67 & 70 & 27.9 & 0.0457 & 0.883 & 0.282 & 0.0358 & 0.952 & 0.49 & 11.1 & 262 & 95 \\
\hline Washington & 33.5 & 775 & 2860 & 1.73 & 38.5 & 112 & 0.0312 & 0.477 & 0.908 & 0.0234 & 0.565 & 2.57 & 7.32 & 143 & 385 \\
\hline Wisconsin & 18.6 & 391 & 3260 & 0.962 & 18.9 & 125 & 0.0186 & 0.232 & 0.985 & 0.013 & 0.298 & 2.96 & 4.19 & 70.1 & 431 \\
\hline West Virginia & 7.92 & 509 & 262 & 0.404 & 25.7 & 10.9 & 0.00506 & 0.322 & 0.0954 & 0.00543 & 0.34 & 0.225 & 1.51 & 96.7 & 37.3 \\
\hline Wyoming & 4.46 & 178 & 364 & 0.223 & 8.9 & 17.6 & 0.00225 & 0.0904 & 0.174 & 0.00388 & 0.155 & 0.322 & 0.74 & 29.6 & 58.4 \\
\hline U.S. Total & 15800 & 343000 & 391000 & 818 & 17300 & 16800 & 16.1 & 221 & 154 & 10.9 & 242 & 353 & 3520 & 64800 & 57600 \\
\hline
\end{tabular}


Table B-16. Cumulative EOL Materials by Material, by State (metric tons) for Scenario 1: Reference

Cumulative EOL Materials by Material, by State (metric tons) for Scenario 1: Reference

\begin{tabular}{|c|c|c|c|c|c|c|c|c|c|c|c|c|c|c|c|}
\hline \multirow[b]{2}{*}{ State } & \multicolumn{3}{|c|}{ Glass } & \multicolumn{3}{|c|}{ Silicon } & \multicolumn{3}{|c|}{ Silver } & \multicolumn{3}{|c|}{ Copper } & \multicolumn{3}{|c|}{ Aluminum } \\
\hline & 2030 & 2040 & 2050 & 2030 & 2040 & 2050 & 2030 & 2040 & 2050 & 2030 & 2040 & 2050 & 2030 & 2040 & 2050 \\
\hline Arkansas & 13800 & 462000 & 1620000 & 714 & 23800 & 81600 & 15.9 & 413 & 1060 & 9.31 & 317 & 1200 & 3150 & 97300 & 302000 \\
\hline Arizona & 55.8 & 5070 & 65900 & 2.78 & 247 & 3120 & 0.0291 & 2.57 & 31.5 & 0.0457 & 4.38 & 58.9 & 9.52 & 840 & 10500 \\
\hline California & 562 & 21300 & 188000 & 29 & 1070 & 8980 & 0.635 & 16.8 & 96.6 & 0.4 & 16.9 & 164 & 126 & 4130 & 30800 \\
\hline Colorado & 16.4 & 1330 & 17900 & 0.831 & 66.2 & 809 & 0.00941 & 0.742 & 7.77 & 0.0125 & 1.05 & 15.8 & 2.95 & 234 & 2770 \\
\hline Connecticut & 103 & 5930 & 49700 & 5.32 & 299 & 2200 & 0.085 & 4.11 & 22.3 & 0.0708 & 4.2 & 42.5 & 21.6 & 1150 & 7840 \\
\hline Delaware & 3.87 & 284 & 4950 & 0.196 & 14.1 & 221 & 0.00204 & 0.145 & 2.04 & 0.00303 & 0.23 & 4.28 & 0.675 & 48.1 & 752 \\
\hline Florida & 297 & 7500 & 24300 & 15.5 & 387 & 1180 & 0.361 & 7.88 & 16.6 & 0.201 & 5.21 & 19.7 & 71.4 & 1700 & 4490 \\
\hline Georgia & 683 & 16400 & 37700 & 35.6 & 850 & 1870 & 0.798 & 17.7 & 29.6 & 0.459 & 11.2 & 28.9 & 165 & 3840 & 7520 \\
\hline lowa & 13.1 & 943 & 3860 & 0.67 & 48.1 & 193 & 0.0085 & 0.621 & 2.25 & 0.00892 & 0.644 & 2.85 & 2.51 & 181 & 698 \\
\hline Illinois & 601 & 30700 & 277000 & 30.7 & 1520 & 13000 & 0.562 & 21.2 & 140 & 0.431 & 24.7 & 249 & 130 & 5770 & 45000 \\
\hline Indiana & 158 & 4000 & 15000 & 8.23 & 207 & 686 & 0.18 & 4.14 & 8.88 & 0.106 & 2.73 & 12.1 & 37.9 & 923 & 2610 \\
\hline Kansas & 3730 & 95700 & 210000 & 194 & 4960 & 10700 & 4.25 & 99 & 169 & 2.51 & 64.9 & 154 & 894 & 22100 & 43000 \\
\hline Kentucky & 762 & 26500 & 128000 & 39.5 & 1360 & 6290 & 0.789 & 22.4 & 74.4 & 0.522 & 18.8 & 102 & 173 & 5540 & 22600 \\
\hline Louisiana & 103 & 4060 & 17000 & 5.3 & 209 & 862 & 0.0975 & 3.22 & 10.4 & 0.07 & 2.83 & 12.8 & 22.7 & 836 & 3130 \\
\hline Massachusetts & 10.4 & 662 & 5510 & 0.528 & 33.5 & 275 & 0.00578 & 0.37 & 2.86 & 0.00764 & 0.5 & 4.4 & 1.87 & 118 & 945 \\
\hline Maryland & 1290 & 53500 & 206000 & 66.5 & 2750 & 10500 & 1.23 & 42.4 & 128 & 0.876 & 37 & 155 & 285 & 11000 & 38100 \\
\hline Maine & 199 & 9290 & 62700 & 10.2 & 469 & 3030 & 0.183 & 6.74 & 33.5 & 0.139 & 6.96 & 53 & 43 & 1810 & 10600 \\
\hline Michigan & 11.9 & 1000 & 9560 & 0.599 & 50 & 466 & 0.00678 & 0.562 & 4.82 & 0.00927 & 0.807 & 8.31 & 2.12 & 175 & 1580 \\
\hline Minnesota & 30.6 & 1220 & 7200 & 1.58 & 62.3 & 333 & 0.0325 & 1 & 3.77 & 0.0207 & 0.854 & 5.94 & 6.9 & 251 & 1210 \\
\hline Missouri & 31.9 & 2070 & 21800 & 1.62 & 104 & 1080 & 0.0167 & 1.07 & 11 & 0.0245 & 1.66 & 18 & 5.57 & 356 & 3670 \\
\hline Mississippi & 2.14 & 165 & 1720 & 0.108 & 8.31 & 85.4 & 0.00115 & 0.0888 & 0.868 & 0.00171 & 0.135 & 1.47 & 0.372 & 28.5 & 286 \\
\hline North Dakota & 3900 & 109000 & 264000 & 203 & 5630 & 13300 & 4.33 & 107 & 199 & 2.62 & 73.6 & 191 & 925 & 24600 & 52500 \\
\hline Nebraska & 897 & 23100 & 58800 & 46.7 & 1200 & 3000 & 1.06 & 23.8 & 44.8 & 0.604 & 15.7 & 42.6 & 214 & 5230 & 11700 \\
\hline New Hampshire & 13.3 & 942 & 3670 & 0.677 & 48.1 & 186 & 0.00857 & 0.622 & 2.18 & 0.009 & 0.641 & 2.66 & 2.54 & 181 & 673 \\
\hline
\end{tabular}

119 
Cumulative EOL Materials by Material, by State (metric tons) for Scenario 1: Reference

\begin{tabular}{|c|c|c|c|c|c|c|c|c|c|c|c|c|c|c|c|}
\hline \multirow[b]{2}{*}{ State } & \multicolumn{3}{|c|}{ Glass } & \multicolumn{3}{|c|}{ Silicon } & \multicolumn{3}{|c|}{ Silver } & \multicolumn{3}{|c|}{ Copper } & \multicolumn{3}{|c|}{ Aluminum } \\
\hline & 2030 & 2040 & 2050 & 2030 & 2040 & 2050 & 2030 & 2040 & 2050 & 2030 & 2040 & 2050 & 2030 & 2040 & 2050 \\
\hline New Jersey & 1050 & 27700 & 83800 & 54.6 & 1430 & 4230 & 1.21 & 27.7 & 59.1 & 0.709 & 19.1 & 63.1 & 249 & 6230 & 16100 \\
\hline New Mexico & 13.1 & 932 & 3580 & 0.667 & 47.6 & 181 & 0.00847 & 0.617 & 2.14 & 0.00887 & 0.634 & 2.59 & 2.51 & 180 & 658 \\
\hline Nevada & 14.9 & 1090 & 10200 & 0.759 & 54.9 & 446 & 0.00941 & 0.687 & 4.27 & 0.0103 & 0.761 & 8.52 & 2.82 & 205 & 1560 \\
\hline New York & 117 & 8290 & 86300 & 5.92 & 418 & 4310 & 0.0618 & 4.35 & 43.9 & 0.0924 & 6.74 & 72.4 & 20.3 & 1420 & 14500 \\
\hline Ohio & 14.2 & 1030 & 7850 & 0.721 & 52.3 & 368 & 0.00873 & 0.639 & 3.8 & 0.01 & 0.744 & 6.48 & 2.65 & 192 & 1290 \\
\hline Oklahoma & 39.5 & 1310 & 7830 & 2.05 & 67.1 & 363 & 0.042 & 1.15 & 4.08 & 0.027 & 0.942 & 6.58 & 9.15 & 279 & 1300 \\
\hline Oregon & 730 & 34000 & 340000 & 37.5 & 1700 & 15700 & 0.708 & 24.2 & 162 & 0.522 & 26.7 & 299 & 159 & 6470 & 54300 \\
\hline Pennsylvania & 2.63 & 228 & 4050 & 0.132 & 11.3 & 181 & 0.00137 & 0.116 & 1.68 & 0.00217 & 0.194 & 3.57 & 0.448 & 38 & 611 \\
\hline Rhode Island & 253 & 7450 & 39300 & 13.1 & 383 & 1910 & 0.28 & 6.83 & 22.5 & 0.174 & 5.37 & 32.2 & 59 & 1600 & 6830 \\
\hline South Carolina & 13.6 & 1250 & 29900 & 0.694 & 60.3 & 1200 & 0.00875 & 0.724 & 10.4 & 0.00933 & 0.927 & 27.2 & 2.6 & 224 & 4200 \\
\hline South Dakota & 81.2 & 4300 & 16500 & 4.18 & 220 & 821 & 0.0689 & 3.16 & 9.85 & 0.0549 & 2.93 & 12.3 & 17.2 & 861 & 3000 \\
\hline Tennessee & 8.61 & 679 & 8190 & 0.434 & 34 & 399 & 0.00452 & 0.352 & 4 & 0.007 & 0.567 & 7.08 & 1.48 & 115 & 1340 \\
\hline Texas & 35.2 & 1650 & 10400 & 1.82 & 83.5 & 493 & 0.0359 & 1.23 & 5.41 & 0.0243 & 1.18 & 8.48 & 7.55 & 320 & 1740 \\
\hline Utah & 127 & 3610 & 29800 & 6.59 & 183 & 1270 & 0.143 & 3.45 & 13.4 & 0.0862 & 2.62 & 26.2 & 30.3 & 794 & 4560 \\
\hline Virginia & 10.3 & 931 & 11700 & 0.514 & 46.3 & 575 & 0.00519 & 0.469 & 5.79 & 0.00892 & 0.817 & 10.3 & 1.71 & 154 & 1910 \\
\hline Vermont & 22.1 & 1460 & 16200 & 1.12 & 73.4 & 795 & 0.0116 & 0.758 & 7.99 & 0.0171 & 1.16 & 13.4 & 3.86 & 251 & 2700 \\
\hline Washington & 188 & 6090 & 29300 & 9.74 & 313 & 1350 & 0.199 & 5.5 & 15.8 & 0.127 & 4.22 & 23.9 & 43.7 & 1320 & 4940 \\
\hline Wisconsin & 290 & 14900 & 111000 & 14.8 & 754 & 5500 & 0.207 & 9.23 & 58.5 & 0.206 & 11 & 87.2 & 56.9 & 2760 & 19200 \\
\hline West Virginia & 54.8 & 5840 & 81800 & 2.7 & 282 & 3860 & 0.0277 & 2.89 & 38.9 & 0.0476 & 5.25 & 74.7 & 9.09 & 946 & 13000 \\
\hline Wyoming & 1350 & 61800 & 332000 & 69.6 & 3160 & 16700 & 1.19 & 44.7 & 189 & 0.939 & 44.2 & 259 & 287 & 12200 & 59100 \\
\hline U.S. Total & 33600 & 1130000 & 4860000 & 1740 & 58100 & 240000 & 36.8 & 992 & 2950 & 22.9 & 795 & 3830 & 7710 & 238000 & 873000 \\
\hline
\end{tabular}


Table B-17. Cumulative EOL Materials by Material, by State (metric tons) for Scenario 2: Decarb

Cumulative EOL Materials by Material, by State (metric tons) for Scenario 2: Decarb

\begin{tabular}{|c|c|c|c|c|c|c|c|c|c|c|c|c|c|c|c|}
\hline \multirow[b]{3}{*}{ State } & \multicolumn{15}{|c|}{ Cumulative EOL Materials by Material, by State (metric tons) for Scenario 2: Decarb } \\
\hline & \multicolumn{3}{|c|}{ Glass } & \multicolumn{3}{|c|}{ Silicon } & \multicolumn{3}{|c|}{ Silver } & \multicolumn{3}{|c|}{ Copper } & \multicolumn{3}{|c|}{ Aluminum } \\
\hline & 2030 & 2040 & 2050 & 2030 & 2040 & 2050 & 2030 & 2040 & 2050 & 2030 & 2040 & 2050 & 2030 & 2040 & 2050 \\
\hline Arkansas & 13800 & 462000 & 1620000 & 714 & 23800 & 81600 & 15.9 & 413 & 1060 & 9.31 & 317 & 1200 & 3150 & 97300 & 302000 \\
\hline Arizona & 55.8 & 5070 & 65900 & 2.78 & 247 & 3120 & 0.0291 & 2.57 & 31.5 & 0.0457 & 4.38 & 58.9 & 9.52 & 840 & 10500 \\
\hline California & 562 & 21300 & 188000 & 29 & 1070 & 8980 & 0.635 & 16.8 & 96.6 & 0.4 & 16.9 & 164 & 126 & 4130 & 30800 \\
\hline Colorado & 16.4 & 1330 & 17900 & 0.831 & 66.2 & 809 & 0.00941 & 0.742 & 7.77 & 0.0125 & 1.05 & 15.8 & 2.95 & 234 & 2770 \\
\hline Connecticut & 103 & 5930 & 49700 & 5.32 & 299 & 2200 & 0.085 & 4.11 & 22.3 & 0.0708 & 4.2 & 42.5 & 21.6 & 1150 & 7840 \\
\hline Delaware & 3.87 & 284 & 4950 & 0.196 & 14.1 & 221 & 0.00204 & 0.145 & 2.04 & 0.00303 & 0.23 & 4.28 & 0.675 & 48.1 & 752 \\
\hline Florida & 297 & 7500 & 24300 & 15.5 & 387 & 1180 & 0.361 & 7.88 & 16.6 & 0.201 & 5.21 & 19.7 & 71.4 & 1700 & 4490 \\
\hline Georgia & 683 & 16400 & 37700 & 35.6 & 850 & 1870 & 0.798 & 17.7 & 29.6 & 0.459 & 11.2 & 28.9 & 165 & 3840 & 7520 \\
\hline lowa & 13.1 & 943 & 3860 & 0.67 & 48.1 & 193 & 0.0085 & 0.621 & 2.25 & 0.00892 & 0.644 & 2.85 & 2.51 & 181 & 698 \\
\hline Illinois & 601 & 30700 & 277000 & 30.7 & 1520 & 13000 & 0.562 & 21.2 & 140 & 0.431 & 24.7 & 249 & 130 & 5770 & 45000 \\
\hline Indiana & 158 & 4000 & 15000 & 8.23 & 207 & 686 & 0.18 & 4.14 & 8.88 & 0.106 & 2.73 & 12.1 & 37.9 & 923 & 2610 \\
\hline Kansas & 3730 & 95700 & 210000 & 194 & 4960 & 10700 & 4.25 & 99 & 169 & 2.51 & 64.9 & 154 & 894 & 22100 & 43000 \\
\hline Kentucky & 762 & 26500 & 128000 & 39.5 & 1360 & 6290 & 0.789 & 22.4 & 74.4 & 0.522 & 18.8 & 102 & 173 & 5540 & 22600 \\
\hline Louisiana & 103 & 4060 & 17000 & 5.3 & 209 & 862 & 0.0975 & 3.22 & 10.4 & 0.07 & 2.83 & 12.8 & 22.7 & 836 & 3130 \\
\hline Massachusetts & 10.4 & 662 & 5510 & 0.528 & 33.5 & 275 & 0.00578 & 0.37 & 2.86 & 0.00764 & 0.5 & 4.4 & 1.87 & 118 & 945 \\
\hline Maryland & 1290 & 53500 & 206000 & 66.5 & 2750 & 10500 & 1.23 & 42.4 & 128 & 0.876 & 37 & 155 & 285 & 11000 & 38100 \\
\hline Maine & 199 & 9290 & 62700 & 10.2 & 469 & 3030 & 0.183 & 6.74 & 33.5 & 0.139 & 6.96 & 53 & 43 & 1810 & 10600 \\
\hline Michigan & 11.9 & 1000 & 9560 & 0.599 & 50 & 466 & 0.00678 & 0.562 & 4.82 & 0.00927 & 0.807 & 8.31 & 2.12 & 175 & 1580 \\
\hline Minnesota & 30.6 & 1220 & 7200 & 1.58 & 62.3 & 333 & 0.0325 & 1 & 3.77 & 0.0207 & 0.854 & 5.94 & 6.9 & 251 & 1210 \\
\hline Missouri & 31.9 & 2070 & 21800 & 1.62 & 104 & 1080 & 0.0167 & 1.07 & 11 & 0.0245 & 1.66 & 18 & 5.57 & 356 & 3670 \\
\hline Mississippi & 2.14 & 165 & 1720 & 0.108 & 8.31 & 85.4 & 0.00115 & 0.0888 & 0.868 & 0.00171 & 0.135 & 1.47 & 0.372 & 28.5 & 286 \\
\hline North Dakota & 3900 & 109000 & 264000 & 203 & 5630 & 13300 & 4.33 & 107 & 199 & 2.62 & 73.6 & 191 & 925 & 24600 & 52500 \\
\hline Nebraska & 897 & 23100 & 58800 & 46.7 & 1200 & 3000 & 1.06 & 23.8 & 44.8 & 0.604 & 15.7 & 42.6 & 214 & 5230 & 11700 \\
\hline New Hampshire & 13.3 & 942 & 3670 & 0.677 & 48.1 & 186 & 0.00857 & 0.622 & 2.18 & 0.009 & 0.641 & 2.66 & 2.54 & 181 & 673 \\
\hline
\end{tabular}


Cumulative EOL Materials by Material, by State (metric tons) for Scenario 2: Decarb

\begin{tabular}{|c|c|c|c|c|c|c|c|c|c|c|c|c|c|c|c|}
\hline \multirow[b]{2}{*}{ State } & \multicolumn{3}{|c|}{ Glass } & \multicolumn{3}{|c|}{ Silicon } & \multicolumn{3}{|c|}{ Silver } & \multicolumn{3}{|c|}{ Copper } & \multicolumn{3}{|c|}{ Aluminum } \\
\hline & 2030 & 2040 & 2050 & 2030 & 2040 & 2050 & 2030 & 2040 & 2050 & 2030 & 2040 & 2050 & 2030 & 2040 & 2050 \\
\hline New Jersey & 1050 & 27700 & 83800 & 54.6 & 1430 & 4230 & 1.21 & 27.7 & 59.1 & 0.709 & 19.1 & 63.1 & 249 & 6230 & 16100 \\
\hline New Mexico & 13.1 & 932 & 3580 & 0.667 & 47.6 & 181 & 0.00847 & 0.617 & 2.14 & 0.00887 & 0.634 & 2.59 & 2.51 & 180 & 658 \\
\hline Nevada & 14.9 & 1090 & 10200 & 0.759 & 54.9 & 446 & 0.00941 & 0.687 & 4.27 & 0.0103 & 0.761 & 8.52 & 2.82 & 205 & 1560 \\
\hline New York & 117 & 8290 & 86300 & 5.92 & 418 & 4310 & 0.0618 & 4.35 & 43.9 & 0.0924 & 6.74 & 72.4 & 20.3 & 1420 & 14500 \\
\hline Ohio & 14.2 & 1030 & 7850 & 0.721 & 52.3 & 368 & 0.00873 & 0.639 & 3.8 & 0.01 & 0.744 & 6.48 & 2.65 & 192 & 1290 \\
\hline Oklahoma & 39.5 & 1310 & 7830 & 2.05 & 67.1 & 363 & 0.042 & 1.15 & 4.08 & 0.027 & 0.942 & 6.58 & 9.15 & 279 & 1300 \\
\hline Oregon & 730 & 34000 & 340000 & 37.5 & 1700 & 15700 & 0.708 & 24.2 & 162 & 0.522 & 26.7 & 299 & 159 & 6470 & 54300 \\
\hline Pennsylvania & 2.63 & 228 & 4050 & 0.132 & 11.3 & 181 & 0.00137 & 0.116 & 1.68 & 0.00217 & 0.194 & 3.57 & 0.448 & 38 & 611 \\
\hline Rhode Island & 253 & 7450 & 39300 & 13.1 & 383 & 1910 & 0.28 & 6.83 & 22.5 & 0.174 & 5.37 & 32.2 & 59 & 1600 & 6830 \\
\hline South Carolina & 13.6 & 1250 & 29900 & 0.694 & 60.3 & 1200 & 0.00875 & 0.724 & 10.4 & 0.00933 & 0.927 & 27.2 & 2.6 & 224 & 4200 \\
\hline South Dakota & 81.2 & 4300 & 16500 & 4.18 & 220 & 821 & 0.0689 & 3.16 & 9.85 & 0.0549 & 2.93 & 12.3 & 17.2 & 861 & 3000 \\
\hline Tennessee & 8.61 & 679 & 8190 & 0.434 & 34 & 399 & 0.00452 & 0.352 & 4 & 0.007 & 0.567 & 7.08 & 1.48 & 115 & 1340 \\
\hline Texas & 35.2 & 1650 & 10400 & 1.82 & 83.5 & 493 & 0.0359 & 1.23 & 5.41 & 0.0243 & 1.18 & 8.48 & 7.55 & 320 & 1740 \\
\hline Utah & 127 & 3610 & 29800 & 6.59 & 183 & 1270 & 0.143 & 3.45 & 13.4 & 0.0862 & 2.62 & 26.2 & 30.3 & 794 & 4560 \\
\hline Virginia & 10.3 & 931 & 11700 & 0.514 & 46.3 & 575 & 0.00519 & 0.469 & 5.79 & 0.00892 & 0.817 & 10.3 & 1.71 & 154 & 1910 \\
\hline Vermont & 22.1 & 1460 & 16200 & 1.12 & 73.4 & 795 & 0.0116 & 0.758 & 7.99 & 0.0171 & 1.16 & 13.4 & 3.86 & 251 & 2700 \\
\hline Washington & 188 & 6090 & 29300 & 9.74 & 313 & 1350 & 0.199 & 5.5 & 15.8 & 0.127 & 4.22 & 23.9 & 43.7 & 1320 & 4940 \\
\hline Wisconsin & 290 & 14900 & 111000 & 14.8 & 754 & 5500 & 0.207 & 9.23 & 58.5 & 0.206 & 11 & 87.2 & 56.9 & 2760 & 19200 \\
\hline West Virginia & 54.8 & 5840 & 81800 & 2.7 & 282 & 3860 & 0.0277 & 2.89 & 38.9 & 0.0476 & 5.25 & 74.7 & 9.09 & 946 & 13000 \\
\hline Wyoming & 1350 & 61800 & 332000 & 69.6 & 3160 & 16700 & 1.19 & 44.7 & 189 & 0.939 & 44.2 & 259 & 287 & 12200 & 59100 \\
\hline U.S. Total & 33600 & 1130000 & 4860000 & 1740 & 58100 & 240000 & 36.8 & 992 & 2950 & 22.9 & 795 & 3830 & 7710 & 238000 & 873000 \\
\hline
\end{tabular}


Table B-18. Cumulative EOL Materials by Material, by State (metric tons) for Scenario 3: Decarb+E

Cumulative EOL Materials by Material, by State (metric tons) for Scenario 3: Decarb+E

\begin{tabular}{|c|c|c|c|c|c|c|c|c|c|c|c|c|c|c|c|}
\hline \multirow[b]{2}{*}{ State } & \multicolumn{3}{|c|}{ Glass } & \multicolumn{3}{|c|}{ Silicon } & \multicolumn{3}{|c|}{ Silver } & \multicolumn{3}{|c|}{ Copper } & \multicolumn{3}{|c|}{ Aluminum } \\
\hline & 2030 & 2040 & 2050 & 2030 & 2040 & 2050 & 2030 & 2040 & 2050 & 2030 & 2040 & 2050 & 2030 & 2040 & 2050 \\
\hline Alabama & 67.9 & 2540 & 19500 & 3.52 & 129 & 873 & 0.0682 & 2.06 & 9.1 & 0.0467 & 1.82 & 16.4 & 15.4 & 523 & 3090 \\
\hline Arkansas & 13800 & 463000 & 1640000 & 714 & 23800 & 82400 & 15.9 & 413 & 1070 & 9.31 & 318 & 1220 & 3150 & 97300 & 305000 \\
\hline Arizona & 55.8 & 5080 & 68300 & 2.78 & 248 & 3210 & 0.0291 & 2.57 & 32.2 & 0.0457 & 4.39 & 61.1 & 9.52 & 841 & 10900 \\
\hline California & 562 & 22000 & 260000 & 29 & 1100 & 11700 & 0.635 & 17 & 118 & 0.4 & 17.4 & 231 & 126 & 4220 & 40400 \\
\hline Colorado & 16.5 & 1450 & 28000 & 0.832 & 70.7 & 1200 & 0.00942 & 0.779 & 11 & 0.0125 & 1.16 & 25.3 & 2.95 & 249 & 4140 \\
\hline Connecticut & 103 & 5930 & 49800 & 5.32 & 299 & 2210 & 0.085 & 4.11 & 22.4 & 0.0708 & 4.2 & 42.6 & 21.6 & 1150 & 7850 \\
\hline Delaware & 3.88 & 369 & 16400 & 0.196 & 17.3 & 650 & 0.00205 & 0.169 & 5.3 & 0.00303 & 0.309 & 14.7 & 0.676 & 59.3 & 2230 \\
\hline Florida & 297 & 7540 & 27500 & 15.5 & 388 & 1300 & 0.361 & 7.89 & 17.6 & 0.201 & 5.24 & 22.7 & 71.4 & 1710 & 4910 \\
\hline Georgia & 683 & 16400 & 38000 & 35.6 & 850 & 1880 & 0.798 & 17.7 & 29.7 & 0.459 & 11.2 & 29.1 & 165 & 3840 & 7550 \\
\hline lowa & 13.1 & 943 & 4150 & 0.67 & 48.1 & 204 & 0.0085 & 0.622 & 2.32 & 0.00892 & 0.644 & 3.1 & 2.51 & 181 & 734 \\
\hline Illinois & 602 & 30900 & 280000 & 30.8 & 1530 & 13200 & 0.562 & 21.3 & 141 & 0.432 & 24.8 & 252 & 131 & 5800 & 45500 \\
\hline Indiana & 158 & 3970 & 9430 & 8.23 & 206 & 476 & 0.18 & 4.13 & 7.32 & 0.106 & 2.7 & 6.99 & 37.9 & 918 & 1890 \\
\hline Kansas & 3730 & 95800 & 212000 & 194 & 4970 & 10800 & 4.25 & 99 & 170 & 2.51 & 65 & 155 & 894 & 22100 & 43200 \\
\hline Kentucky & 762 & 26500 & 128000 & 39.5 & 1360 & 6300 & 0.789 & 22.4 & 74.5 & 0.522 & 18.8 & 102 & 173 & 5540 & 22700 \\
\hline Louisiana & 103 & 4060 & 17100 & 5.3 & 209 & 863 & 0.0975 & 3.22 & 10.4 & 0.07 & 2.83 & 12.9 & 22.7 & 836 & 3130 \\
\hline Massachusetts & 10.4 & 663 & 5540 & 0.528 & 33.5 & 276 & 0.00578 & 0.371 & 2.87 & 0.00765 & 0.5 & 4.43 & 1.87 & 118 & 949 \\
\hline Maryland & 1290 & 53500 & 206000 & 66.6 & 2750 & 10500 & 1.23 & 42.4 & 128 & 0.876 & 37 & 155 & 285 & 11000 & 38100 \\
\hline Maine & 198 & 9250 & 61500 & 10.2 & 467 & 2980 & 0.183 & 6.72 & 33 & 0.139 & 6.92 & 51.9 & 43 & 1810 & 10400 \\
\hline Michigan & 11.9 & 1000 & 9600 & 0.599 & 50 & 468 & 0.00679 & 0.563 & 4.84 & 0.00927 & 0.807 & 8.34 & 2.12 & 175 & 1580 \\
\hline Minnesota & 30.6 & 1210 & 6650 & 1.58 & 61.9 & 310 & 0.0325 & 1 & 3.57 & 0.0207 & 0.845 & 5.44 & 6.9 & 249 & 1130 \\
\hline Missouri & 31.9 & 2070 & 21900 & 1.62 & 104 & 1080 & 0.0167 & 1.07 & 11 & 0.0245 & 1.66 & 18.1 & 5.57 & 356 & 3680 \\
\hline Mississippi & 2.13 & 165 & 1730 & 0.108 & 8.31 & 85.6 & 0.00115 & 0.0888 & 0.87 & 0.00171 & 0.135 & 1.48 & 0.371 & 28.5 & 287 \\
\hline North Dakota & 3900 & 109000 & 285000 & 203 & 5640 & 14100 & 4.33 & 107 & 205 & 2.62 & 73.8 & 211 & 925 & 24600 & 55400 \\
\hline Nebraska & 897 & 23100 & 58900 & 46.7 & 1200 & 3000 & 1.06 & 23.8 & 44.8 & 0.604 & 15.7 & 42.7 & 214 & 5230 & 11700 \\
\hline New Hampshire & 13.3 & 942 & 3680 & 0.677 & 48.1 & 186 & 0.00857 & 0.622 & 2.19 & 0.009 & 0.641 & 2.67 & 2.54 & 182 & 675 \\
\hline
\end{tabular}


Cumulative EOL Materials by Material, by State (metric tons) for Scenario 3: Decarb+E

\begin{tabular}{|c|c|c|c|c|c|c|c|c|c|c|c|c|c|c|c|}
\hline \multirow[b]{2}{*}{ State } & \multicolumn{3}{|c|}{ Glass } & \multicolumn{3}{|c|}{ Silicon } & \multicolumn{3}{|c|}{ Silver } & \multicolumn{3}{|c|}{ Copper } & \multicolumn{3}{|c|}{ Aluminum } \\
\hline & 2030 & 2040 & 2050 & 2030 & 2040 & 2050 & 2030 & 2040 & 2050 & 2030 & 2040 & 2050 & 2030 & 2040 & 2050 \\
\hline New Jersey & 1050 & 27700 & 86300 & 54.6 & 1430 & 4320 & 1.21 & 27.7 & 59.8 & 0.709 & 19.1 & 65.3 & 249 & 6230 & 16400 \\
\hline New Mexico & 13.1 & 932 & 3660 & 0.667 & 47.7 & 184 & 0.00847 & 0.617 & 2.16 & 0.00887 & 0.634 & 2.67 & 2.51 & 180 & 668 \\
\hline Nevada & 14.9 & 1250 & 34700 & 0.759 & 61 & 1360 & 0.00941 & 0.733 & 11.1 & 0.0103 & 0.908 & 30.6 & 2.82 & 225 & 4690 \\
\hline New York & 117 & 8290 & 86400 & 5.92 & 418 & 4320 & 0.0618 & 4.35 & 43.9 & 0.0924 & 6.74 & 72.5 & 20.3 & 1420 & 14500 \\
\hline Ohio & 14.2 & 1040 & 8510 & 0.721 & 52.6 & 394 & 0.00874 & 0.642 & 4.02 & 0.01 & 0.752 & 7.11 & 2.65 & 193 & 1380 \\
\hline Oklahoma & 39.5 & 1370 & 15900 & 2.05 & 69.5 & 668 & 0.042 & 1.17 & 6.4 & 0.027 & 1 & 14 & 9.15 & 287 & 2350 \\
\hline Oregon & 730 & 34100 & 349000 & 37.5 & 1700 & 16100 & 0.708 & 24.2 & 165 & 0.522 & 26.7 & 307 & 159 & 6470 & 55400 \\
\hline Pennsylvania & 2.64 & 405 & 26100 & 0.133 & 18 & 1010 & 0.00138 & 0.168 & 8.05 & 0.00218 & 0.356 & 23.7 & 0.45 & 61.3 & 3480 \\
\hline Rhode Island & 253 & 7500 & 43500 & 13.1 & 385 & 2070 & 0.28 & 6.84 & 23.8 & 0.174 & 5.41 & 36.2 & 59 & 1610 & 7410 \\
\hline South Carolina & 13.6 & 1320 & 37300 & 0.695 & 62.9 & 1480 & 0.00875 & 0.745 & 12.6 & 0.00934 & 0.991 & 34.1 & 2.6 & 233 & 5190 \\
\hline South Dakota & 81.2 & 4300 & 15800 & 4.18 & 220 & 793 & 0.0689 & 3.16 & 9.64 & 0.0549 & 2.93 & 11.6 & 17.2 & 860 & 2900 \\
\hline Tennessee & 8.6 & 676 & 8080 & 0.434 & 33.8 & 395 & 0.00451 & 0.351 & 3.96 & 0.00699 & 0.564 & 6.97 & 1.48 & 115 & 1330 \\
\hline Texas & 35.2 & 1650 & 11400 & 1.81 & 83.7 & 530 & 0.0359 & 1.23 & 5.72 & 0.0242 & 1.18 & 9.41 & 7.55 & 321 & 1880 \\
\hline Utah & 127 & 3950 & 70500 & 6.6 & 196 & 2810 & 0.143 & 3.56 & 25.2 & 0.0863 & 2.93 & 63.5 & 30.3 & 839 & 9870 \\
\hline Virginia & 10.3 & 971 & 17700 & 0.514 & 47.7 & 798 & 0.00519 & 0.48 & 7.45 & 0.00892 & 0.853 & 15.7 & 1.71 & 159 & 2670 \\
\hline Vermont & 22.1 & 1460 & 16200 & 1.12 & 73.4 & 796 & 0.0116 & 0.758 & 8 & 0.0171 & 1.16 & 13.5 & 3.86 & 251 & 2700 \\
\hline Washington & 188 & 6270 & 44800 & 9.74 & 320 & 1950 & 0.199 & 5.56 & 20.8 & 0.127 & 4.39 & 38.6 & 43.7 & 1350 & 7060 \\
\hline Wisconsin & 290 & 14900 & 113000 & 14.8 & 755 & 5590 & 0.207 & 9.23 & 59.2 & 0.206 & 11 & 89.3 & 56.9 & 2770 & 19500 \\
\hline West Virginia & 54.9 & 6620 & 167000 & 2.7 & 312 & 7120 & 0.0278 & 3.13 & 64.4 & 0.0477 & 5.98 & 154 & 9.1 & 1050 & 24300 \\
\hline Wyoming & 1350 & 61800 & 333000 & 69.6 & 3160 & 16700 & 1.19 & 44.7 & 189 & 0.939 & 44.2 & 259 & 287 & 12200 & 59200 \\
\hline U.S. Total & 33600 & 1140000 & 5240000 & 1740 & 58200 & 254000 & 36.8 & 993 & 3060 & 22.9 & 798 & 4180 & 7710 & 239000 & 923000 \\
\hline
\end{tabular}




\section{Appendix C. Order-of-Magnitude Estimates of Air- Quality Benefits of the Solar Futures Study Scenarios}

Detailed in this appendix is the methodology for the order-of-magnitude estimation of the airquality benefits of the Solar Futures Study scenarios. Included within each section is discussion of uncertainty in the inputs.

\section{Emissions from the Power Sector}

Power-sector emissions of $\mathrm{SO}_{2}$ and $\mathrm{NO}_{\mathrm{x}}$ are determined within the power-sector modeling itself. Direct emissions of PM from the power sector are not included. Direct PM benefits due to limiting total power-sector emissions are commonly considered small compared to $\mathrm{NO}_{\mathrm{x}}$ and $\mathrm{SO}_{2}$ benefits (due to relatively low emission rates of direct PM from power plants). For example, EPA estimated that the direct PM benefits of the Clean Power Plan were less than $10 \%$ of total benefits. ${ }^{190}$ Total annual power-sector emissions are reported for the contiguous United States every 2 years, and results are interpolated for the off years (Figure C-1). Power-sector emissions are reduced to zero by 2050 but decline quickly through 2030. This means cumulative monetized health benefits are sensitive to the timing of the decline; delayed emission reductions would reduce the total benefits. The benefits are most sensitive to the counterfactual scenario (the Reference scenario). In the Reference scenario, emissions are roughly halved by 2050 . This Reference emissions decline represents less decline than was observed over the last 15 years.
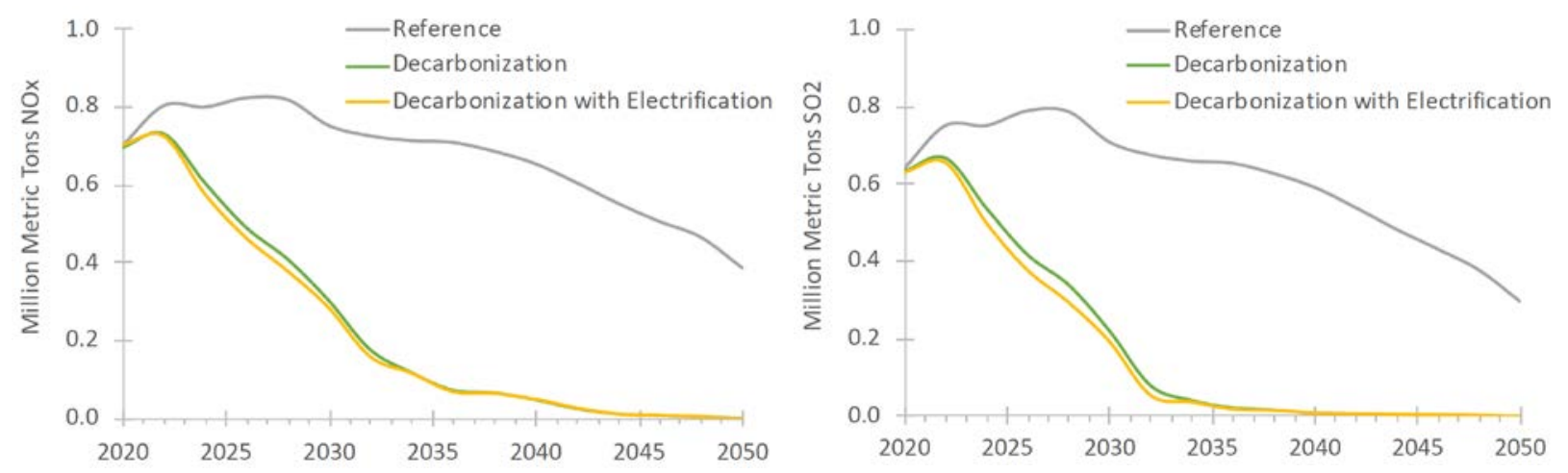

Figure $\mathrm{C}-1$. Total $\mathrm{NO}_{x}$ and $\mathrm{SO}_{2}$ emissions from the power sector

\section{Emissions from Vehicles}

Vehicle emissions are not directly calculated within the scenario modeling. However, energy use by sector and fuel type are calculated within the scenario modeling. We use total diesel and gasoline energy from the transportation sector from each scenario to estimate total fuel use. We then develop fleet-average emission factors to convert fuel use to total emissions, and finally we multiply the total emissions by marginal damage factors (or benefit-per-ton factors) to calculate total damages by scenario.

Vehicle fuel use: We make a simplifying assumption about vehicle types. We model all gasoline vehicles as light-duty vehicles, and we model all diesel vehicles as heavy-duty trucks. This simplification is justified because, in the 2020 Reference scenario, light-duty gasoline vehicles 
accounted for $94 \%$ of total gasoline use. Similarly, heavy-duty diesel trucks accounted for $59 \%$ of total diesel use, and medium-duty diesel trucks accounted for another $16 \%$. Because mediumduty diesel trucks are subject to the same emission regulations as heavy-duty diesel trucks, the distinction between the two vehicle types is not impactful for our analysis, and the simplification of heavy-duty diesel vehicles representing all diesel fuel use is justified.

To find total fuel use, we convert quads of energy to kilograms of fuel using the conversion factors shown in Table C-1. In 2019, the United States used 1.4E+11 gallons of gasoline, ${ }^{308}$ which is similar to the implied 2020 use under the Reference scenario of $1.54 \mathrm{E}+11$ gallons. Modeled transportation-sector diesel use is also similar to actual 2020 use. Total vehicle fuel use by scenario and fuel type is shown in Figure C-2, which illustrates that the Decarb+E scenario assumes significant electrification of light-duty vehicles but less electrification of heavy-duty diesel vehicles. Because heavy-duty diesel vehicles have much higher emission rates per kilogram of fuel used, this scenario will only produce moderate air-quality benefits relative to the total sector air-quality damages. The electrification of vehicles is also weighted toward the final decade of the study period. This delay realistically represents the slow pace of vehicle stock turnover, though it would be conceivable to develop electrification programs that target the oldest and highest-emitting vehicles for replacement in the near term. A program following this replacement strategy would have much larger air-quality benefits, but it would likely be more expensive and challenging to implement.

Table C-1. Conversion Factors Used to Estimate Kilograms of Fuel Use from Quads of Energy

1 quad $=1 \mathrm{E}+15$ British thermal units $(\mathrm{Btu})$

1 gallon gasoline $=120,286 \mathrm{Btu}$

1 gallon diesel $=137,381 \mathrm{Btu}$

1 gallon gasoline $=2.86$ kilograms $(\mathrm{kg})$

1 gallon diesel $=3.13 \mathrm{~kg}$

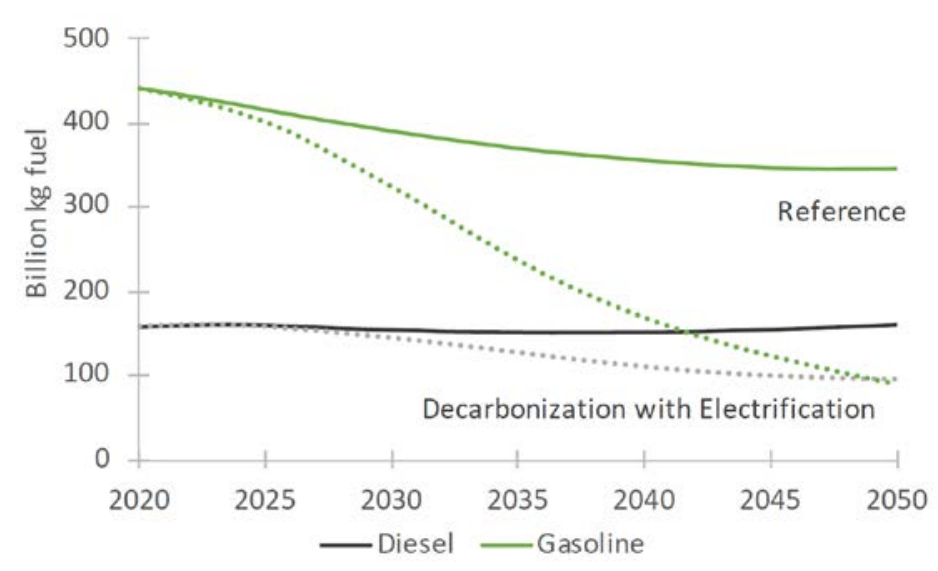

Figure C-2. Total vehicle fuel use by scenario

Vehicle emission rates: To find total pollutant emissions by vehicles, we develop emission rates to convert fuel burned into emissions. For vehicles, we are interested in emissions of $\mathrm{NO}_{\mathrm{x}}$ and $\mathrm{PM}$. We do not include $\mathrm{SO}_{2}$ emissions from the vehicle sector, because sulfur has been largely 
removed from gasoline and diesel fuels. Of PM, we are interested in $\mathrm{PM}_{2.5}$. As mentioned in the main text, emission rates from vehicles have declined rapidly in recent years and are expected to decline further in the years to come. Our emissions rates must reflect this expected decline, or risk substantially overestimating the benefits of electrification. It is theoretically possible that vehicle emission regulations could be reversed in the future, in which case our estimate will underestimate the benefits of electrification.

We base our emission rates on EPA's MOVES model, ${ }^{192}$ run under default conditions (this includes existing emission regulations for new vehicles). The impact of existing regulations is to dramatically reduce total fleet-level emissions as the vehicle stock turns over. To understand how the emission factors implied by EPA MOVES relate to recent trends in emission factors, we examine historical observations of vehicle emissions in real-world settings. Measured fleetaverage emissions are shown in Figure C-3 and Table C-2. Our forward-looking emission rates (Figure $\mathrm{C}-4$ ) begin at roughly the level of the most recent measured emission rates shown in Figure C-3 and Table C-2. This rough match provides some confidence that the forecast emission rates are realistic, at least given current information.

Despite the rough match between current modeled and observed fleet-emission rates, there is some uncertainty about how emission factors will evolve in the future. Most importantly, regulations could change to be more or less strict. "Replacement" programs could be initiated, which would target on-road, high-emitting vehicles for replacement, rather than waiting for the vehicles to be retired at the end of their life. Also, there is uncertainty related to the performance of emission-control equipment over the lifetime of a vehicle. Technological improvements aside from electrification could also improve pollutant emissions.

We do not consider other pollutants, such as $\mathrm{SO}_{2}$ and volatile organic compound (VOC) emissions. These pollutants also contribute to air-quality and health impacts, but sulfur has largely been removed from vehicle fuel, and vehicle VOC impacts are highly variable and challenging to quantify. Finally, our estimates of PM emissions only include tailpipe emissions, but not brake wear, tire wear, or dust. The simplest assumption is that these other sources of PM emissions will not change due to vehicle electrification. However, this is not necessarily true. The use of regenerative breaking from electric vehicles could substantially reduce brake wear emissions. In addition, the increased weight of electric vehicles could increase tire wear.
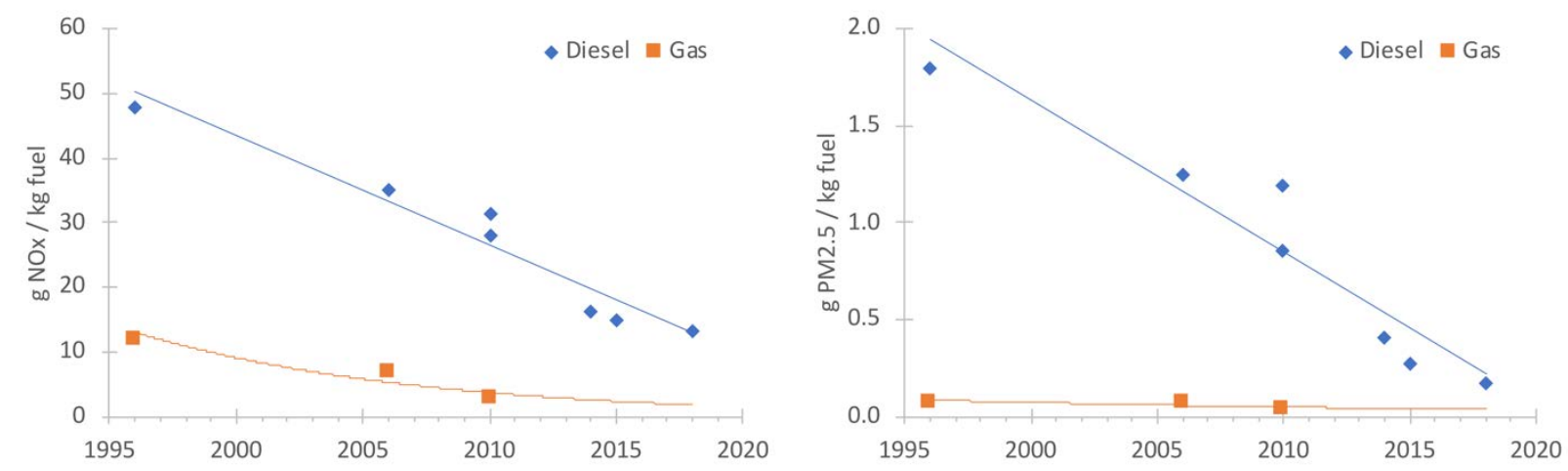

Figure C-3. Fleet-average $\mathrm{NO}_{\mathrm{x}}$ and $\mathrm{PM}_{2.5}$ emission rates of light-duty cars and heavy-duty diesel trucks, based on observed emissions ${ }^{194-197}$

See notes about these emission factors associated with Table C-2. 

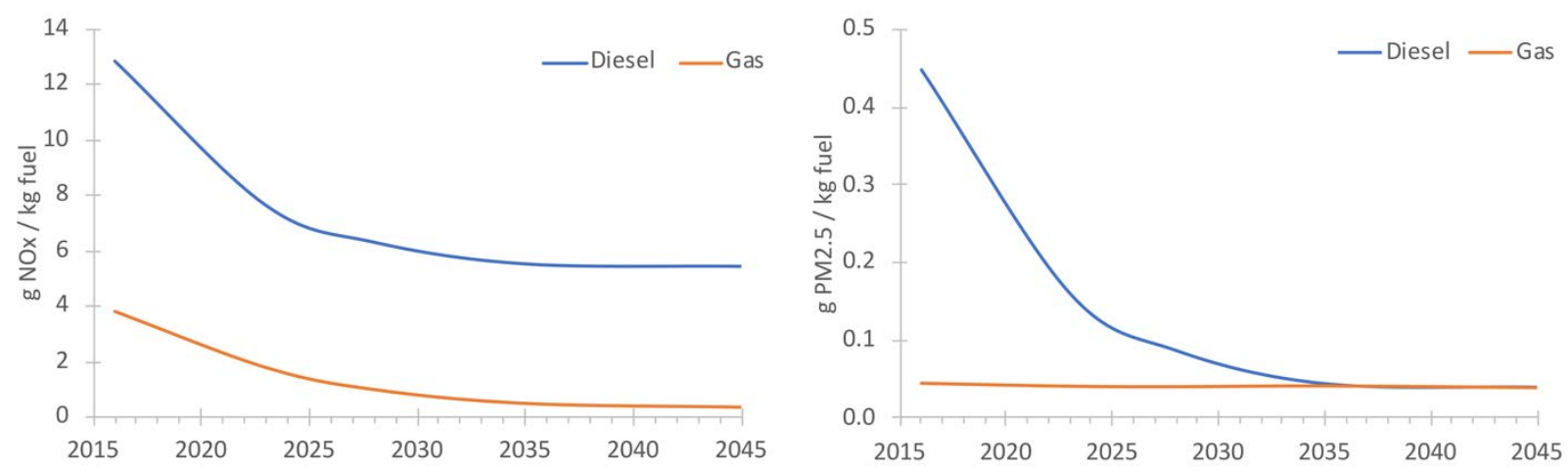

Figure C-4. Future vehicle $\mathrm{NO}_{\mathrm{x}}$ and $\mathrm{PM}_{2.5}$ emission rates based on EPA MOVES model

Table C-2. Summary of Observed Fleet-Average Emission (g/kg fuel) Factors from the Literature

\begin{tabular}{|c|c|c|c|c|c|c|c|c|c|}
\hline Pollutant & Location & Reference $^{194-197}$ & Fuel Type & 1996 & 2006 & 2010 & 2014 & 2015 & 2018 \\
\hline NOx & National & $\begin{array}{l}\text { Dallmann \& Harley } \\
(2010)^{194}\end{array}$ & Gas & 12 & 7 & & & & \\
\hline NOx & California & McDonald et al (2012) ${ }^{195}$ & Gas & & & 3 & & & \\
\hline NOx & National & $\begin{array}{l}\text { Dallmann \& Harley } \\
(2010)^{194}\end{array}$ & Diesel & 48 & 35 & & & & \\
\hline NOx & California & McDonald et al (2012) ${ }^{195}$ & Diesel & & & 28 & & & \\
\hline NOx & California & Preble et al $(2019)^{197}$ & Diesel & & & 31.3 & 16.3 & 15 & 13.2 \\
\hline $\mathrm{PM}_{2.5}$ & National & $\begin{array}{l}\text { Dallmann \& Harley } \\
(2010)^{194}\end{array}$ & Gas & 0.078 & 0.075 & & & & \\
\hline $\mathrm{PM}_{2.5}$ & California & McDonald et al (2015) ${ }^{196}$ & Gas & & & 0.04 & & & \\
\hline $\mathrm{PM}_{2.5}$ & National & $\begin{array}{l}\text { Dallmann \& Harley } \\
(2010)^{194}\end{array}$ & Diesel & 1.8 & 1.25 & & & & \\
\hline $\mathrm{PM}_{2.5}$ & California & McDonald et al (2015) ${ }^{196}$ & Diesel & & & 1.2 & & & \\
\hline $\mathrm{BC}$ & California & Preble et al (2019) & Diesel & & & 0.86 & 0.41 & 0.28 & 0.18 \\
\hline
\end{tabular}

$\mathrm{BC}$ stands for 'black carbon,' which is a subset of total $\mathrm{PM}_{2.5}$ emissions. BC emission rates will be representative, but a bit lower than total $\mathrm{PM}_{2.5}$ emissions. There are likely some differences between California and national vehicle fleets, as California has its own vehicle emissions regulations, in addition to federal regulations. Still, the California values provide insight into the overall trajectory of vehicle emissions.

To determine fuel input-normalized future emission rates from EPA MOVES, we first convert $\mathrm{CO}_{2}$ emissions to fuel mass and then normalize total $\mathrm{NO}_{\mathrm{x}}$ and $\mathrm{PM}_{2.5}$ emissions by fuel. The key conversion factors here are 8.9 and $10.2 \mathrm{~kg} \mathrm{CO}_{2}$ per gallon of gasoline and diesel respectively. Total $\mathrm{CO}_{2}, \mathrm{NO}_{\mathrm{x}}$, and $\mathrm{PM}_{2.5}$ emissions are reported in Chapter 6 of EPA (2021). ${ }^{192}$ Emissions were interpolated between years and extrapolated through to 2050 (from 2045).

To demonstrate the calculations described above, we present an example of the process here. EPA MOVES reports that diesel vehicles will emit 0.52 billion metric tons of $\mathrm{CO}_{2}$ in 2028 . This implies that $1.6 \mathrm{E}+11 \mathrm{~kg}$ of diesel fuel would be burned $\left(10.2 \mathrm{~kg} \mathrm{CO}_{2}\right.$ per gallon of diesel is used to convert the $\mathrm{CO}_{2}$ emissions to volume of fuel, which is subsequently converted to $\mathrm{kg}$ of fuel). EPA MOVES also reports that 1.01 million tons of $\mathrm{NO}_{\mathrm{x}}$ will be emitted by diesel vehicles in 2028. This implies a fleet-average emission factor of $6.3 \mathrm{~g} \mathrm{NO}_{\mathrm{x}}$ per $\mathrm{kg}$ diesel fuel in 2028. In this 
manner, emissions were calculated across the study period. Emission rates were interpolated between years without EPA MOVES data.

Though these emission rates are simply based on the MOVES model, the rates are consistent with the measured emissions of on-road vehicles (Figure C-3, Figure C-4, Table C-2). This consistency provides an independent validation of the MOVES model, and of other simplifications we have made. Of course, this validation only applies to the near-term prediction of emission rates, but it still adds confidence that at least our emission rates match general expectations and observations in the near term.

Total vehicle emissions: Total vehicle emissions are simply the product of each year's fuel use and emission factors. Figure C-5 shows total emissions from the vehicle sector. This figure also shows the split of total emissions by diesel and gasoline vehicles for the Reference scenario. From these plots, two aspects are clear. First, diesel vehicles represent the bulk of $\mathrm{NO}_{\mathrm{x}}$ emissions, and the bulk of near-term $\mathrm{PM}_{2.5}$ emissions. This implies that, because the Decarb $+\mathrm{E}$ scenario focuses on light-duty vehicles, it does not address the substantial emissions from heavyduty vehicles. Second, Reference scenario emissions between 2021 and 2030 account for roughly half of the total emissions during the study period (for both $\mathrm{NO}_{\mathrm{x}}$ and $\mathrm{PM}_{2.5}$ ). In other words, vehicle emissions over the next decade are equal to the vehicle emissions of the following two decades (2031-2050). However, most of the emission savings from the Decarb+E scenario occur after 2030. Because Reference scenario vehicle emissions are weighted toward the near term (before 2030), Decarb+E scenario emission reductions do not ramp up until after 2030, and a time-based discount rate is applied to the value of the emission benefits, the ratio of the avoided vehicle health damages to total Reference scenario vehicle health damages $(0.18)$ is smaller than the ratio of avoided vehicle fuel-use to total Reference scenario fuel use (0.29). To summarize, two aspects limit the effectiveness of the Decarb+E scenario for reducing air-quality and health damages: 1) emission reductions depend on fleet turnover rather than replacement, delaying impact until after 2030, and 2) electrification is focused on the light-duty sector, despite diesel vehicles contributing a majority of the total emissions. Expanding the vehicle electrification scenario to maximize benefits by including replacement of high emitters, early action, and increased focus on heavy-duty diesel would be more expensive than the current Decarb $+\mathrm{E}$ scenario. It is outside the scope of this analysis to estimate whether the benefits of that expansion would outweigh added costs. 

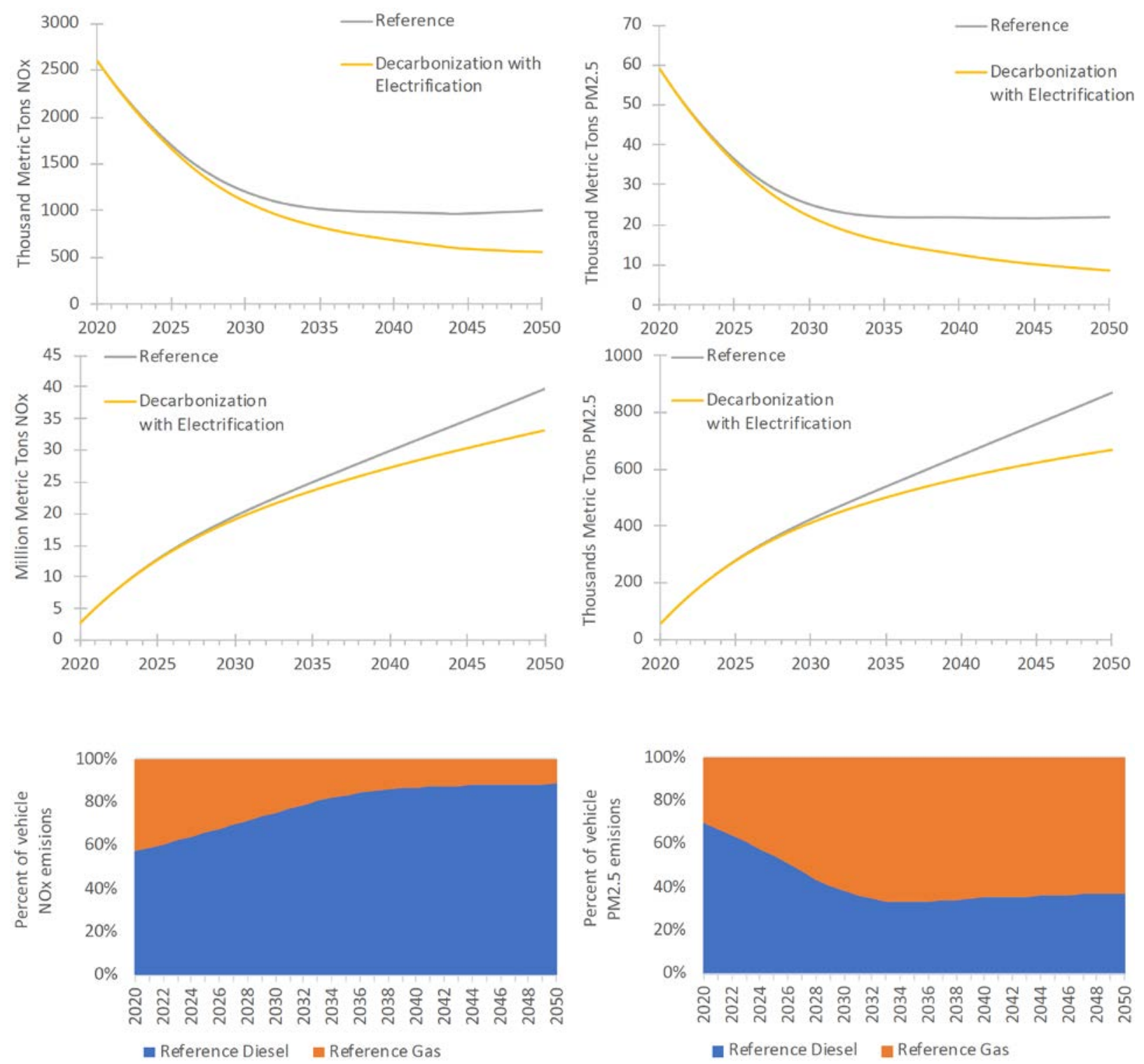

Figure C-5. Total annual (top) and cumulative (middle) $\mathrm{NO}_{\mathrm{x}}$ and $\mathrm{PM}_{2.5}$ emissions from vehicles and (bottom) split of emissions by diesel or gasoline vehicles within the Reference scenario

\section{Benefit-per-Ton Estimates}

We use literature-based estimates of the benefits per ton of avoided emissions. The same marginal factors are used to describe the benefit of avoiding a ton of emissions or the damage of releasing a ton of emissions (the "marginal damage" factor).

Power-sector benefit-per-ton estimates: Benefit-per-ton estimates for the power sector and transportation sector are based on different studies, because a study that presented benefit-perton estimates for both sectors and included forward-looking estimates was not available. Therefore, we use separate, but state-of-the-science, studies for each sector that include forwardlooking estimates. The negative consequence of this choice is that the studies monetize moderately different sets of benefits from pollutant emissions. For example, the power-sector estimates include small benefits from reduced ozone exposure due to $\mathrm{NO}_{\mathrm{x}}$ emission reductions. 
The vehicle-sector estimates do not include this damage pathway. From an order of magnitude perspective, these differences are inconsequential, because total monetary benefits are dominated by the reduced incidence of death due to reduced exposure to PM. We compare both powersector and vehicle-sector Reference scenario 2020 damages to independent literature estimates to confirm that our estimates are roughly similar to independent analyses.

Power-sector benefit-per-ton estimates are derived from the EPA's Regulatory Impact Analysis of the Clean Power Plan. ${ }^{190}$ Specifically, we use the low-end, national, $3 \%$ discount rate, benefitper-ton estimates from Tables 4A-3 through 4A-5 and Tables 4A-9 through 4A-11 in that source. $\mathrm{NO}_{\mathrm{x}}$ emission reductions can reduce human exposure to both ozone and $\mathrm{PM}\left(\mathrm{NO}_{\mathrm{x}}\right.$ can be a precursor to both ozone and $\mathrm{PM}$ ). The $\mathrm{NO}_{\mathrm{x}}$ ozone and PM benefits are calculated separately and then combined. To calculate $\mathrm{NO}_{\mathrm{x}}$ ozone benefits, annual $\mathrm{NO}_{\mathrm{x}}$ emissions are multiplied by $5 / 12$ (to account for the fact that ozone benefits accrue only during warmer months, or "ozone season") prior to their multiplication with the $\mathrm{NO}_{\mathrm{x}}$-ozone benefit-per-ton numbers. Further details on these benefit estimates can be found in the EPA regulatory document. ${ }^{190}$

Benefit-per-ton estimates for each pollutant are provided for 2020, 2025, and 2030. To find benefits during other years, we interpolate and extrapolate in a linear manner. Power-sector benefit-per-ton estimates are shown in Figure C-6.

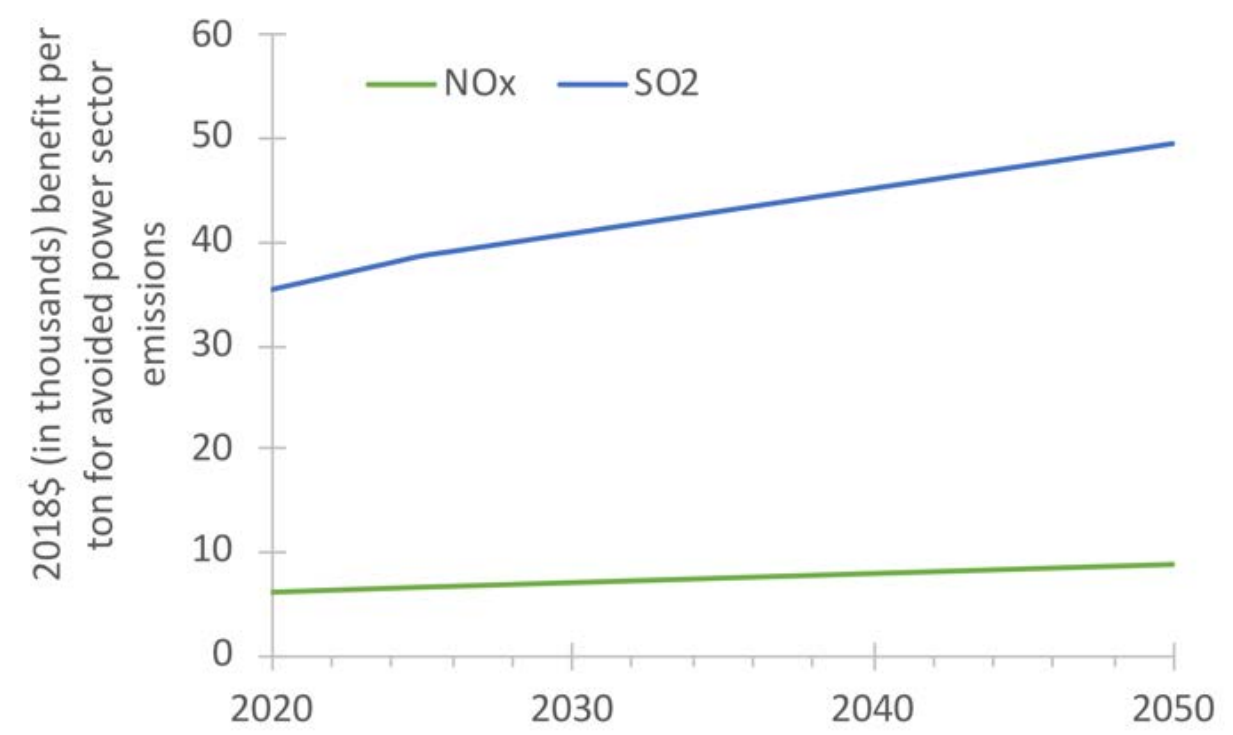

Figure C-6. Power-sector benefits per metric ton of avoided emissions

The Reference scenario air-quality and health damages from the power sector in 2020 are equal to $\$ 27$ billion, roughly equal to independent literature estimates using alternate methods, specifically after accounting for the use of the lower (rather than centralized) marginal damage estimate. ${ }^{193}$ This "sanity check," and a similar check in the vehicle sector, are based on total damages (emissions $\times$ marginal damage) rather than checking the total emissions and the damage factors independently. However, this check still provides some confidence that the results are consistent with existing literature; it is unlikely that large, but perfectly countervailing, errors are present in our analysis. 
Important uncertainties are associated with these benefit-per-ton estimates, beyond the obvious uncertainty associated with any future predictions. These uncertainties are presented in great detail in EPA (2015). ${ }^{190}$ We briefly summarize the most important areas of uncertainty here. First, there are two primary epidemiological study lines that quantify the mortality risk of population exposure to $\mathrm{PM}_{2.5}$. Our benefit numbers represent the study with the lower risk assessment (i.e., Krewski et al., ${ }^{309}$ not Lepuele et al. ${ }^{310}$ ). However, each of these studies is equally valid, and there is an approximate factor of two between these studies. In other words, the total benefits would be doubled if we chose the higher risk estimate. It is common to find an average value between the two estimates, but because we are presenting order-of-magnitude estimates, this is not necessary. A second issue is that we are not calculating the benefits of directly emitted PM from the power sector. Accounting for direct PM power-sector emissions may increase total benefits of decarbonization by approximately $20 \%$. Finally, the air-quality modeling, including both atmospheric chemistry and transport, is uncertain, and different models produce a variety of outcomes. Comparison across models, however, indicates that - when assessing national, sector-wide benefits - total benefit estimates are more sensitive to the epidemiological uncertainties than the air-quality modeling uncertainties. ${ }^{311}$

Vehicle-sector benefit-per-ton estimates: Vehicle-sector benefit-per-ton estimates are derived from Wolfe et al., ${ }^{198}$ which provides national estimates of damages by sector for 2025 . Specifically, we use the national values for the "heavy-duty diesel" sector and "light-duty gas cars and motorcycles" sector presented in that study's Table 2 as the closest matches to our sectors. These values also depend on the exposure-risk relationships developed by Krewski et al. ${ }^{309} \mathrm{We}$ add an escalator of $1 \%$ per year to account for population and income growth. This escalator roughly mirrors the effective escalator found for power-sector benefit-per-ton estimates within the EPA regulatory document. ${ }^{190}$ The final results are not particularly sensitive to the exact value of this escalator (e.g., total benefits from the Decarb+E scenario increase by about $30 \%$ if the escalator is tripled to 3\%). Benefit-per-ton values are shown in Figure C-7.

The Reference scenario air-quality and health damages from the vehicle sector in 2020 are equal to roughly $\$ 50$ billion. We would like to compare this estimate to an independent estimate from the literature. However, while estimates of vehicle-sector damages exist for historical years, we were unable to find current independent estimates of total monetary damages from the on-road sector. This makes it challenging to compare our damage estimates to literature values, because vehicle emission rates have declined dramatically over the past two decades (Figure C-3). Davidson et al. ${ }^{312}$ estimate that emissions from the on-road sector caused about 10,000 deaths in 2011 and will cause 5,500 deaths in 2025. If we use a standard valuation of 9.7 million $2018 \$$ per death, this equates to about $\$ 100$ billion in 2011 and $\$ 50$ billion in 2025 (the $\$ 9.7$ million value is based on the reduced risk of mortality, a topic discussed below and in the main text, with the exact value matching that of Heo et al. ${ }^{313}$ but inflated to $2018 \$$ ). Linearly interpolating between 2011 and 2025 gives a value of $\$ 70$ billion for 2020 . Though $\$ 70$ billion is larger than our $\$ 50$ billion estimate, we would not expect a perfect match due to methodological differences. These estimates match on an order-of-magnitude basis. Note that, to make the comparison on an "apples-to-apples" basis, we isolated mortalities caused by PM exposure within the Davidson et al. ${ }^{312}$ analysis, excluding ozone benefits. 


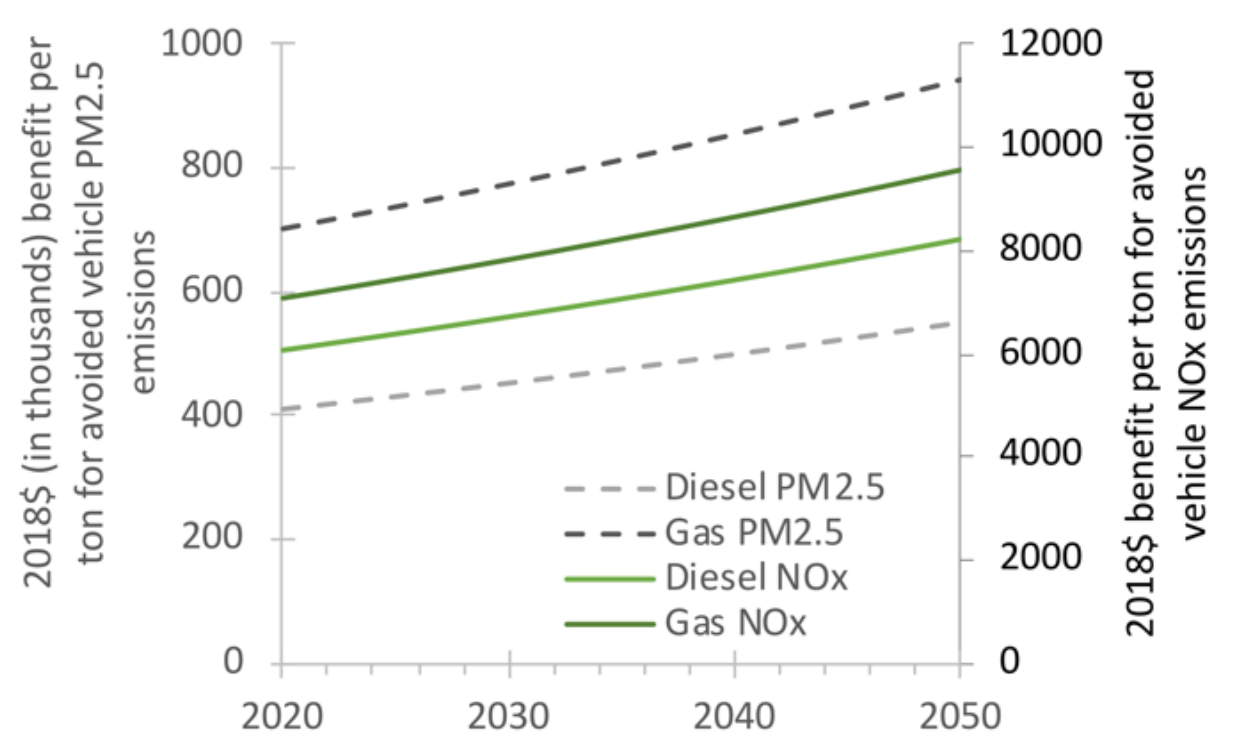

Figure C-7. Vehicle-sector benefit per metric ton of avoided emissions

$\mathrm{PM}_{2.5}$ benefits are shown in the left axis and $\mathrm{NO}_{\mathrm{x}}$ benefits on the right axis. The $\mathrm{PM}_{2.5}$ values are listed in thousands of dollars (i.e., on a per-ton basis, they are an order of magnitude larger than the $\mathrm{NO}_{\mathrm{x}}$ values).

These benefit-per-ton estimates are slightly sensitive to the choice of vehicle type. For example, the benefit per ton for "light-duty gas cars and motorcycles" is about $20 \%$ larger than that for light-duty gas trucks. Of course, the use of national rather than regional values adds some uncertainty. However, as in the power sector, the largest source of uncertainty is related to epidemiolocal relationships and the air-quality transport and chemistry modeling.

Finally, there is uncertainty about how to value premature death. As described in the main text, we use the value of reduced risk of mortality across the population to drive this valuation, often called the "value of statistical life." Further discussion of this topic can be found in EPA (2015). ${ }^{190}$

\section{Summary of Total Benefit Estimates}

We have now summarized how we estimate emissions and marginal damage rates. The product of these two quantities yields total damage (or total benefits), which are then time-discounted with a rate of $5 \%$. Figure C-8 shows discounted total damages by sector, pollutant, and scenario. Benefits of the Decarb and Decarb $+\mathrm{E}$ scenario can be seen as the difference from the Reference scenario. It is clear from this figure that reducing power-sector $\mathrm{SO}_{2}$ emissions provides the majority of the benefits. Near-term reduction of vehicle-sector emissions, $\mathrm{NO}_{\mathrm{x}}$ and especially $\mathrm{PM}_{2.5}$, have the potential to provide substantial additional benefit. However, this would require a different - and potentially more costly — scenario of vehicle replacement, focused on diesel trucks, rather than a scenario based on natural fleet turnover. 

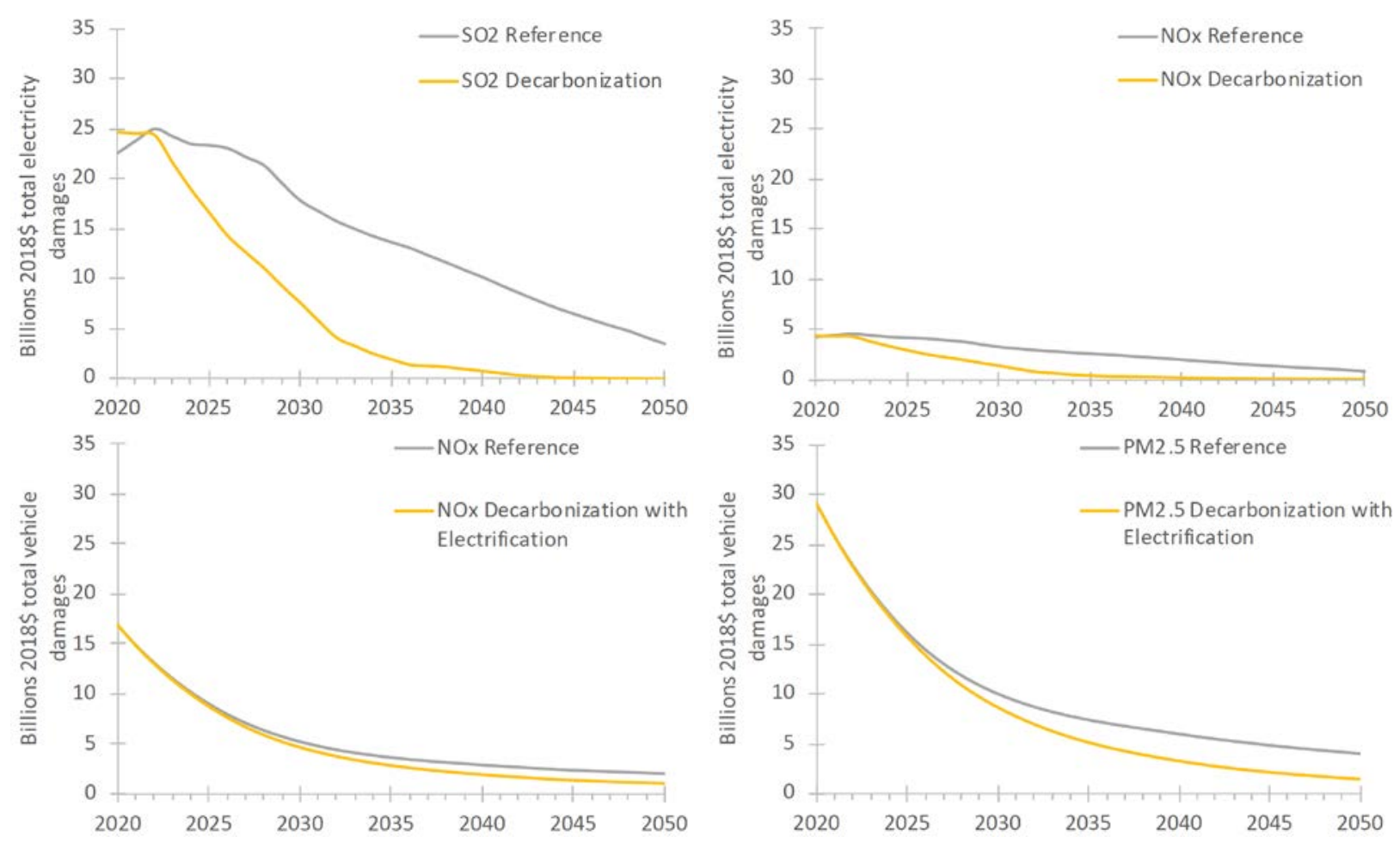

Figure C-8. Discounted annual damages by sector, pollutant, and scenario

The top row shows power-sector damages, and the bottom row shows vehicle-sector damages.

\section{Summary of Key Caveats}

Though we list several important caveats below, we believe that none of these uncertainties (aside from the scenario design itself) would change our findings from an order-of-magnitude perspective. Many, but not all, of these uncertainties imply that our benefit estimates are on the lower end of the range of defensible benefit estimates. We discuss most of these uncertainties above and in the main text.

The most uncertain aspect of our benefit estimates is the future scenarios themselves. Changing regulations, technology, fuel prices, economic conditions, and so forth could render these scenarios irrelevant. Our estimate is especially sensitive to the timing of emission reductions, both for the power sector and the vehicle sector, because both sectors face emission reductions even in the Reference scenario. In general, however, predictions are not so much statements of what will happen, but rather tools for decision making given the best information that is currently available. With that thought, we next discuss important caveats and uncertainties that remain after the scenarios themselves are accepted.

One of the most important uncertainties relates to the epidemiological representation of the health risk of exposure to PM. As described earlier, there are two seminal studies in this field, and we use the study with the lower estimates of risk. The difference between the studies is roughly a factor of two. We use the same main epidemiological study for the vehicle and power sectors. If we used a central value between these two studies, our damage and benefit estimates would increase by roughly $50 \%$. 
There is also uncertainty as to the value of reduced mortality risk, or "value of statistical life," which translates the estimates of avoided mortalities into monetary value. A similar value is used across all the studies we cite, which is close to $\$ 10$ million per avoided death. This value has been used as a "standard" value across many studies over many years. However, this value is fundamentally challenging to quantify and thus represents an important source of uncertainty.

For both sectors, we use national-average benefit-per-ton estimates. There are differences in impact between emissions in different locations, and our analysis does not account for these differences. However, because the analysis is national in scope, the national-average emissions benefit estimates are appropriate.

For both sectors, we analyze only a subset of pollutants and damage pathways. The pollutant sets and damage pathways are not consistent between sectors; we focus on the most important pollutants within each sector and exclude pollutants with minor impacts. These exclusions are likely to be at the level of $10 \%$ to $20 \%$; for example, Davidson et al. ${ }^{312}$ found ozone damages accounted for about $20 \%$ of premature mortalities due to mobile source emissions in 2025 , and EPA found that benefits from reducing directly emitted $\mathrm{PM}_{2.5}$ were less than $8 \%$ of the total monetized benefits of the Clean Power Plan. ${ }^{190}$ Our analysis excludes both ozone damages from vehicles and directly emitted PM from the power sector.

Regarding scope, we do not monetize benefits across all sectors of the economy. Instead, we focus only on the sectors that saw the most change in the scenarios: the power and vehicle sectors.

For the vehicle sector, we assume all gasoline is used in light-duty vehicles and all diesel is used by heavy-duty trucks. This simplification obscures the fact that different vehicle types have different emission rates and are used in different locations. Given that the majority of fuel use falls into the two selected vehicle type categories, and given the relatively narrow spread of emission factors between vehicle types (e.g., light-duty diesel emission rates are within about $20 \%$ of heavy-duty diesel emission rates), shown by Wolfe et al., ${ }^{198}$ we do not believe this uncertainty is critical. However, vehicle emission rates in general may change in the future, especially in response to regulations.

An uncertainty regarding vehicle electrification is the question of which vehicles will be switched to electric. Currently, we assume fleet-average emission rates do not vary by scenario. This assumption could lead to an underestimate or overestimate of vehicle air-quality benefits. Benefits would be underestimated if policies, or cost-benefit calculations by vehicle owners, lead vehicle owners to replace older trucks and cars substantially earlier than they would have without an electric vehicle option. Benefits would be overestimated if switching to electric vehicles occurred only at the end of the expected useful life of gasoline or diesel vehicles. In this latter case, electric vehicles would only replace the purchase of a new (and already relatively clean) vehicle, implying that the fleet average emission factors from the Reference scenario overestimate the emission savings from the switch to electric. However, in the Decarb+E scenario, the results are unlikely to be particularly sensitive to the assumptions of which vehicles will be replaced by electric vehicles, because most fuel reduction occurs after 2030, when fleetaverage emission rates are largely stable. That is, fleet-average rates have already declined so 
that there is less difference between newer and older vehicle emission rates, and the vintages of vehicles replaced by electric vehicles will be less influential on overall emission benefits.

Finally, there is important uncertainty involved with the air-quality modeling. Many different models have been developed to estimate the benefits of emissions reductions, and there are important differences between these models. However, prior comparisons of these estimates show that the range between different models is generally smaller, or of the same magnitude as, the range between the epidemiological studies themselves. ${ }^{311}$

This discussion summarizes the most important uncertainties and sensitivities related to our benefit estimates. It also summarizes the issues that must be addressed to refine these estimates to be more precise than the current order-of-magnitude assessment. 


\section{Appendix D. CSP Tower Systems: Material Requirements and Retirements}

by Scenario

Table D-1. Material Requirements for CSP Tower Systems (from Whitaker et al. ${ }^{26}$ )

\begin{tabular}{|c|c|c|c|c|c|c|c|}
\hline Material Name & $\begin{array}{l}\text { Site } \\
\text { Improvement } \\
\text { (metric tons) }\end{array}$ & $\begin{array}{l}\text { Receiver } \\
\text { System } \\
\text { (metric } \\
\text { tons) }\end{array}$ & $\begin{array}{l}\text { Collector } \\
\text { System } \\
\text { (metric } \\
\text { tons) }\end{array}$ & $\begin{array}{l}\text { TES System } \\
\text { (metric } \\
\text { tons) }\end{array}$ & $\begin{array}{l}\text { SG1 } \\
\text { System } \\
\text { (metric } \\
\text { tons) }\end{array}$ & $\begin{array}{l}\text { EPG1 } \\
\text { System } \\
\text { (metric } \\
\text { tons) }\end{array}$ & $\begin{array}{l}\text { Total } \\
\text { (metric } \\
\text { tons) }\end{array}$ \\
\hline Concrete & $6.24 \mathrm{E}+02$ & $5.30 \mathrm{E}+04$ & $7.16 \mathrm{E}+04$ & $2.88 \mathrm{E}+03$ & $1.01 \mathrm{E}+04$ & $1.22 \mathrm{E}+04$ & $1.50 E+05$ \\
\hline Aggregate & $7.47 \mathrm{E}+04$ & 0 & 0 & 0 & 0 & $4.48 \mathrm{E}+02$ & $7.51 E+04$ \\
\hline Carbon steel & $9.91 \mathrm{E}+01$ & $3.28 \mathrm{E}+03$ & $2.78 \mathrm{E}+04$ & $5.25 \mathrm{E}+02$ & $2.90 \mathrm{E}+03$ & $5.18 \mathrm{E}+03$ & $3.98 \mathrm{E}+04$ \\
\hline Sodium nitrate & 0 & 0 & 0 & $1.05 E+04$ & 0 & 0 & $1.05 E+04$ \\
\hline Solar glass & 0 & 0 & $1.00 \mathrm{E}+04$ & 0 & 0 & 0 & $1.00 E+04$ \\
\hline Asphalt & $9.22 \mathrm{E}+03$ & 0 & 0 & 0 & 0 & 0 & $9.22 \mathrm{E}+03$ \\
\hline Potassium nitrate & 0 & 0 & 0 & $6.97 \mathrm{E}+03$ & 0 & 0 & $6.97 E+03$ \\
\hline Rip rap & $5.80 \mathrm{E}+03$ & 0 & 0 & 0 & 0 & 0 & $5.80 \mathrm{E}+03$ \\
\hline Stainless steel & 0 & $2.11 \mathrm{E}+02$ & 0 & $4.52 \mathrm{E}+02$ & $1.43 \mathrm{E}+02$ & $3.41 \mathrm{E}+01$ & $8.40 E+02$ \\
\hline Brick & 0 & 0 & 0 & $7.38 \mathrm{E}+02$ & 0 & 0 & $7.38 \mathrm{E}+02$ \\
\hline High-density polyethylene & $3.50 \mathrm{E}+02$ & $1.05 E+00$ & 0 & 4.94E-01 & 8.83E-01 & $5.02 \mathrm{E}+01$ & $4.03 E+02$ \\
\hline Copper & $1.13 \mathrm{E}+00$ & $4.18 \mathrm{E}+01$ & 0 & $9.99 \mathrm{E}+00$ & $6.83 E+01$ & $1.84 \mathrm{E}+02$ & $3.05 E+02$ \\
\hline Aluminum & 2.39E-02 & $6.12 \mathrm{E}+00$ & 0 & $1.66 \mathrm{E}+01$ & $7.30 \mathrm{E}+00$ & $2.57 \mathrm{E}+02$ & $2.87 E+02$ \\
\hline Mineral wool & 0 & $6.68 \mathrm{E}+01$ & 0 & $1.47 \mathrm{E}+02$ & 0 & $1.29 \mathrm{E}+00$ & $2.15 E+02$ \\
\hline Foam glass & 0 & 0 & 0 & $1.51 \mathrm{E}+02$ & 0 & 0 & $1.51 \mathrm{E}+02$ \\
\hline Calcium silicate & 0 & $5.93 \mathrm{E}+01$ & 0 & 0 & $2.58 \mathrm{E}+01$ & $4.67 \mathrm{E}+01$ & $1.32 \mathrm{E}+02$ \\
\hline Transformer oil & 0 & 0 & 0 & 0 & 0 & $5.53 \mathrm{E}+01$ & $5.53 E+01$ \\
\hline Polypropylene & $4.90 \mathrm{E}+01$ & $2.85 \mathrm{E}-02$ & 0 & 0 & $2.20 \mathrm{E}-02$ & $2.58 \mathrm{E}-01$ & $4.93 E+01$ \\
\hline
\end{tabular}




\begin{tabular}{|c|c|c|c|c|c|c|c|}
\hline Material Name & $\begin{array}{l}\text { Site } \\
\text { Improvement } \\
\text { (metric tons) }\end{array}$ & $\begin{array}{l}\text { Receiver } \\
\text { System } \\
\text { (metric } \\
\text { tons) }\end{array}$ & $\begin{array}{l}\text { Collector } \\
\text { System } \\
\text { (metric } \\
\text { tons) }\end{array}$ & $\begin{array}{l}\text { TES System } \\
\text { (metric } \\
\text { tons) }\end{array}$ & $\begin{array}{l}\text { SG1 } \\
\text { System } \\
\text { (metric } \\
\text { tons) }\end{array}$ & $\begin{array}{l}\text { EPG1 } \\
\text { System } \\
\text { (metric } \\
\text { tons) }\end{array}$ & $\begin{array}{l}\text { Total } \\
\text { (metric } \\
\text { tons) }\end{array}$ \\
\hline Polyvinyl chloride & 0 & $1.25 \mathrm{E}+01$ & 0 & $2.09 \mathrm{E}+00$ & $9.78 \mathrm{E}+00$ & $2.23 E+01$ & $4.66 \mathrm{E}+01$ \\
\hline Zinc & $8.52 E+00$ & $1.20 \mathrm{E}+01$ & 0 & 3.50E-01 & $1.03 E+01$ & $8.42 \mathrm{E}+00$ & $3.97 \mathrm{E}+01$ \\
\hline Fiber glass & 0 & 2.08E-02 & 0 & 0 & 1.60E-02 & $3.84 \mathrm{E}+01$ & $3.84 \mathrm{E}+01$ \\
\hline Fiber board & 0 & 0 & 0 & $3.33 \mathrm{E}+01$ & 0 & 0 & $3.33 E+01$ \\
\hline Lubricating oil & 0 & 0 & 0 & 0 & 0 & $2.66 \mathrm{E}+01$ & $2.66 \mathrm{E}+01$ \\
\hline Propylene glycol & 0 & 0 & 0 & 0 & 0 & $1.17 \mathrm{E}+01$ & 1.17E+01 \\
\hline Rubber & 0 & 7.12E-01 & 0 & 0 & $4.23 E+00$ & $3.41 \mathrm{E}+00$ & $8.35 E+00$ \\
\hline Epoxy resin & 0 & 6.99E-01 & 0 & $1.00 \mathrm{E}-01$ & $6.72 \mathrm{E}-01$ & $4.67 \mathrm{E}+00$ & $6.14 \mathrm{E}+00$ \\
\hline Nickel alloys & 0 & $3.86 \mathrm{E}+00$ & 0 & $5.81 \mathrm{E}-01$ & $1.28 \mathrm{E}+00$ & $1.31 \mathrm{E}-02$ & $5.73 E+00$ \\
\hline
\end{tabular}

${ }^{1} \mathrm{SG}$ is steam generation system; EPG is the electric power generation system. 
Table D-2. CSP Retirements by Scenario (from ReEDS)

\begin{tabular}{|l|l|l|l|}
\hline Scenario & Year & State & $\begin{array}{l}\text { Retired } \\
\text { Capacity (GW) }\end{array}$ \\
\hline Decarb & 2044 & Arizona & 0.1477 \\
\hline Decarb & 2046 & Nevada & 0.055 \\
\hline Decarb & 2040 & California & 0.2015 \\
\hline Decarb & 2040 & Nevada & 0.03425 \\
\hline Decarb & 2040 & Arizona & 0.00125 \\
\hline Decarb & 2040 & California & 0.00175 \\
\hline Decarb & 2042 & Arizona & 0.0025 \\
\hline Decarb & 2042 & New & 0.0005 \\
\hline Mecarb & 2042 & Colorado & 0.015 \\
\hline Decarb & 2042 & California & 0.015024 \\
\hline Decarb & 2044 & California & 0.4646 \\
\hline Decarb & 2044 & California & 0.00315 \\
\hline Decarb & 2044 & Utah & 0.00075 \\
\hline Decarb & 2044 & Arizona & 0.001 \\
\hline Decarb+E & 2044 & Arizona & 0.1477 \\
\hline Decarb+E & 2046 & Nevada & 0.055 \\
\hline Decarb+E & 2040 & California & 0.2015 \\
\hline Decarb+E & 2040 & Nevada & 0.03425 \\
\hline Decarb+E & 2040 & Arizona & 0.00125 \\
\hline Decarb+E & 2040 & California & 0.00175 \\
\hline Decarb+E & 2042 & Arizona & 0.0025 \\
\hline Decarb+E & 2042 & New & 0.0005 \\
& & Mexico & \\
\hline
\end{tabular}




\begin{tabular}{|c|c|c|c|}
\hline Scenario & Year & State & $\begin{array}{l}\text { Retired } \\
\text { Capacity (GW) }\end{array}$ \\
\hline Decarb+E & 2042 & Colorado & 0.015 \\
\hline Decarb+E & 2042 & California & 0.015024 \\
\hline Decarb+E & 2044 & California & 0.4646 \\
\hline Decarb+E & 2044 & California & 0.00315 \\
\hline Decarb+E & 2044 & Utah & 0.00075 \\
\hline Decarb+E & 2044 & Arizona & 0.001 \\
\hline Reference & 2044 & Arizona & 0.1477 \\
\hline Reference & 2046 & Nevada & 0.055 \\
\hline Reference & 2040 & California & 0.2015 \\
\hline Reference & 2040 & Nevada & 0.03425 \\
\hline Reference & 2040 & Arizona & 0.00125 \\
\hline Reference & 2040 & California & 0.00175 \\
\hline Reference & 2042 & Arizona & 0.0025 \\
\hline Reference & 2042 & $\begin{array}{l}\text { New } \\
\text { Mexico }\end{array}$ & 0.0005 \\
\hline Reference & 2042 & Colorado & 0.015 \\
\hline Reference & 2042 & California & 0.015024 \\
\hline Reference & 2044 & California & 0.4646 \\
\hline Reference & 2044 & California & 0.00315 \\
\hline Reference & 2044 & Utah & 0.00075 \\
\hline Reference & 2044 & Arizona & 0.001 \\
\hline
\end{tabular}

